Florida International University

FIU Digital Commons

FIU Electronic Theses and Dissertations

University Graduate School

$11-13-2020$

\title{
Numerical Modeling and Conjugate Heat Transfer Analysis of Single U-Tube Vertical Borehole Heat Exchangers
}

Talha Khan

Florida International University, tkhan019@fiu.edu

Follow this and additional works at: https://digitalcommons.fiu.edu/etd

Part of the Energy Systems Commons, Heat Transfer, Combustion Commons, Manufacturing Commons, and the Other Mechanical Engineering Commons

\section{Recommended Citation}

Khan, Talha, "Numerical Modeling and Conjugate Heat Transfer Analysis of Single U-Tube Vertical Borehole Heat Exchangers" (2020). FIU Electronic Theses and Dissertations. 4550.

https://digitalcommons.fiu.edu/etd/4550

This work is brought to you for free and open access by the University Graduate School at FIU Digital Commons. It has been accepted for inclusion in FIU Electronic Theses and Dissertations by an authorized administrator of FIU Digital Commons. For more information, please contact dcc@fiu.edu. 


\section{FLORIDA INTERNATIONAL UNIVERSITY}

Miami, Florida

\section{NUMERICAL MODELING AND CONJUGATE HEAT TRANSFER ANALYSIS OF SINGLE U-TUBE VERTICAL BOREHOLE HEAT EXCHANGERS}

A thesis submitted in partial fulfillment of

the requirements for the degree of

MASTER OF SCIENCE

in

MECHANICAL ENGINEERING

by

Talha Khan

2020 
To: Dean John L. Volakis

College of Engineering and Computing

This thesis, written by Talha Khan and entitled Numerical Modeling and Conjugate Heat Transfer Analysis of Single U-Tube Vertical Borehole Heat Exchangers, having been approved in respect to style and intellectual content, is referred to you for judgement.

We have read this thesis and recommend that it be approved.

$\begin{array}{r}\hline \text { Yiding Cao } \\ \hline \text { Lu Zhang } \\ \hline\end{array}$

Cheng-Xian (Charlie) Lin, Major Professor

Date of Defense: November 13, 2020

The thesis of Talha Khan is approved

Dean John L. Volakis

College of Engineering and Computing

Andres G. Gil

Vice-President for Research and Economic Development

And Dean of University Graduate School 


\section{DEDICATION}

This study is wholeheartedly dedicated to my beloved parents, Nuruddin Khan and Salma Khan, whose moral and financial support and sacrifices, great and small, made it possible for me to complete this dissertation.

This study is also dedicated to my sisters, Farah Khan Zahir and Sana Khan for indulging their precious time in morally supporting me throughout. 


\section{ACKNOWLEDGMENTS}

I would like to express my deepest gratitude to major supervisor, Dr. Cheng-Xian Lin, for his inspiring guidance and encouragement throughout my work and for invaluable influence he has made in my academic life, without whose help this dissertation work would not have been completed. His consistent encouragement and word of appreciation were a source of inspiration for me.

I am also indebted to my co-supervisors, Dr. Yiding Cao and Dr. Lu Zhang for giving me this opportunity and for their help and support in my work. I am also thankful to Professor George Dulikravich and Professor Ibrahim Nur Tansel for their help and guidance in building my academic career.

I am also thankful to my colleague in the Sustainable Energy and Thermal Transport System Lab, Pratik Mahyawanshi for his constant advice in completing this project and also for the time spent in the lab to guide me. I would also like to thank my colleagues in the Computational Fluids and Energy Sciences Lab, Beichao Hu, Saja-Al-Rifai, Kiflom Tesfarmariam and Anirban Saha for their constant help and support. My colleagues have inspired me throughout this duration of study and with whom I have established a friendship that I will cherish throughout my life. Special thanks to my friends, Sharif Ahmed Sarkar, Didarul Alam Rahat, Dishon Edward, Niyati Panchal, Priya Tripathi, Namrata Agarwal, Asim Nabi, Suprabha Das, Pranav Gangwani, Guilherme Daldegan, Tawhid Rahman, Rakshit Prabhakar, Abhijeet Chodankar, Aditya Tiwari, Dr. Majid Almas, Santanu Mandal and all my friends at FIU. 
I am grateful to my parents for their endless love, support and complete understanding during my stay in FIU and their support during down times. Special thanks to my father and my sisters for providing their inputs and feedback in the project.

My loving thanks to the Florida International University community for helping me blend into the new environment and providing me the opportunity to gel with the best researchers and students. 


\begin{abstract}
OF THE THESIS
NUMERICAL MODELING AND CONJUGATE HEAT TRANSFER ANALYSIS OF SINGLE U-TUBE VERTICAL BOREHOLE HEAT EXCHANGERS
\end{abstract}

by

Talha Khan

Florida International University, 2020

Miami, Florida

Professor Cheng-Xian (Charlie) Lin, Major Professor

The primary purpose of this thesis was to develop a design for improving the efficiency of the vertical type single u-tube borehole heat exchanger. A through literature review of the various existing analytical and numerical models of the borehole heat exchanger (BHEs) was performed and numerical modeling of the BHE was conducted to solve the conjugate heat transfer problem in the BHE in 3D using ANSYS Fluent 2019R1.A comparison between the results obtained using various mesh sizes, types, different turbulence models showed the independence of the parameters on the numerical simulation results.

From the numerical simulation it was evident that the outlet temperature of the fluid was dependent upon the residence time of the fluid inside the pipe. Keeping this in mind, a design change incorporating the addition of trapezoidal finned casing between the grout and the domain has been proposed to enhance the efficiency of the BHE. On performing numerical simulations, it was seen that the addition of fins improved the heat transfer characteristics of the BHE, thus proving the hypothesis to be true. 


\section{TABLE OF CONTENTS}

CHAPTER

PAGE NUMBER

CHAPTER I. INTRODUCTION

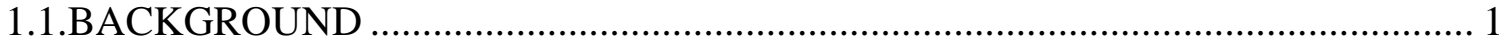

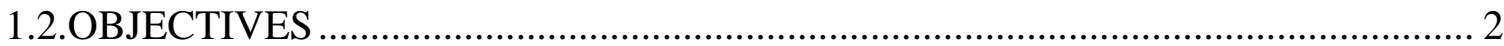

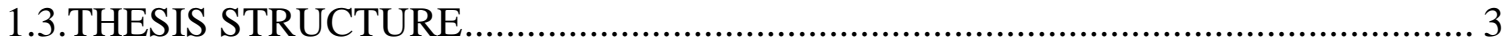

CHAPTER 2 LITERATURE REVIEW OF HEAT PUMPS AND THE BOREHOLE

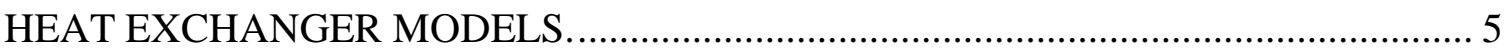

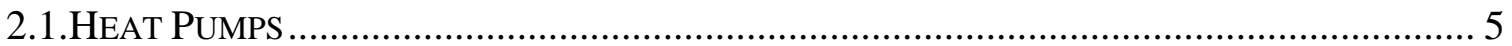

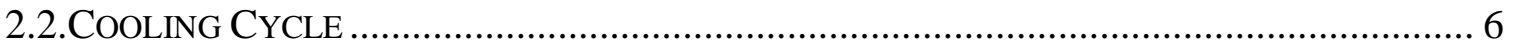

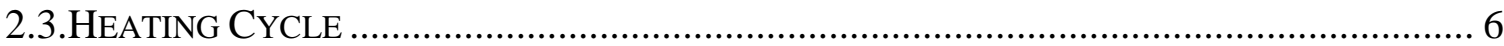

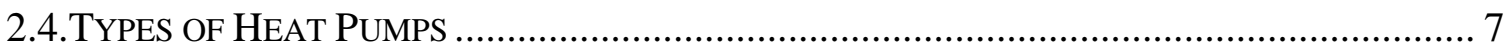

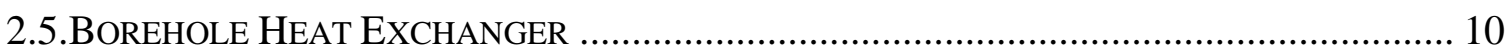

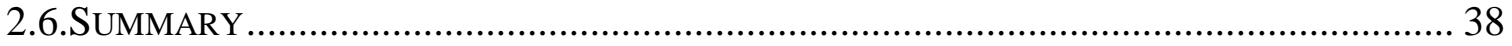

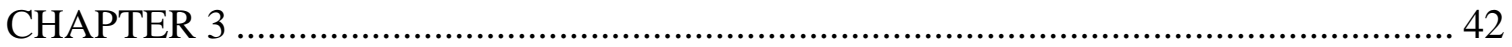

DEVELOPMENT OF THE THREE-DIMENSIONAL MODEL AND ITS

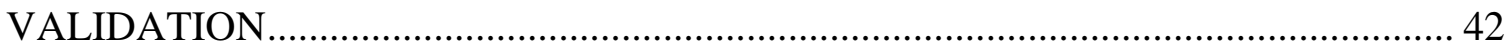

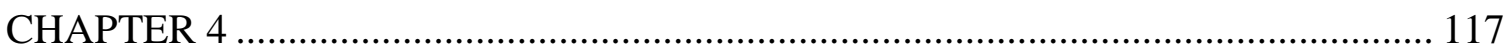

DESIGN MODIFICATION TO THE BHE TO IMPROVE HEAT TRANSFER ......... 117

CHAPTER 5 CONCLUSION AND FUTURE SCOPE OF WORK........................... 136

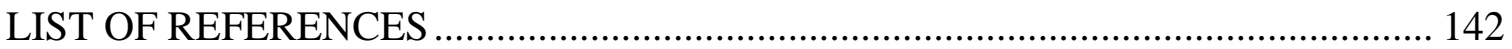




\section{LIST OF TABLES}

TABLE

PAGE NUMBER

Table 1:Equation fit coefficients given by Paul for 4 different configurations ------------- 23

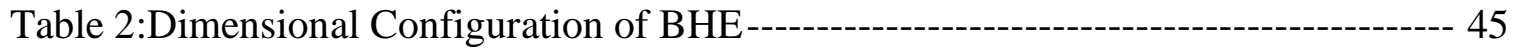

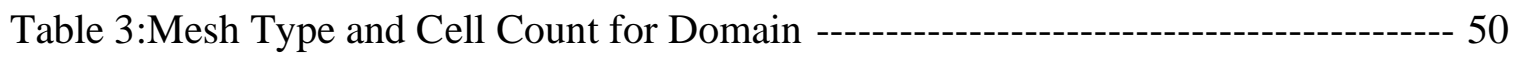

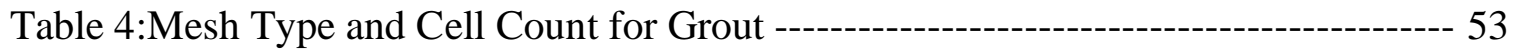

Table 5:Mesh Type and Cell Count for Pipe---------------------------------------------------- 55

Table 6:Mesh Type and Cell Count for Fluid -------------------------------------------------- 59

Table 7: Mesh Type and Size of various components of BHE ------------------------ 60

Table 8:Materials and Thermal Properties of various components for validation with He, M., 2012---------------- 62

Table 9:Materials and Thermal Properties of various components for validation with

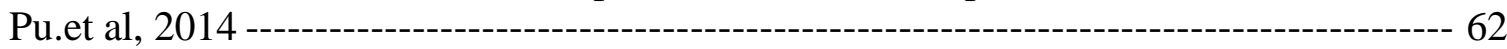

Table 10: Inlet Velocity and its corresponding Reynolds Number from He, M., 2012 -- 63

Table 11: Table Summarizing Grid Independence Study ------------------------------------ 78

Table 12:Table Summarizing Mesh Independence Study ------------------------------------ 82

Table 13:Summary of results obtained from numerical simulation in ANSYS Fluent-- 108

Table 14:Comparison between experimental result and CFD result for $308.47 \mathrm{~K}$ inlet temperature ---------------------------------------------------------------------------------------- 109

Table 15:Comparison between experimental result and CFD result for $278.21 \mathrm{~K}$ inlet temperature ------------------------------------------------------------------------------------------ 109

Table 16: Table summarizing the different mesh types and mesh sizes used for Grid

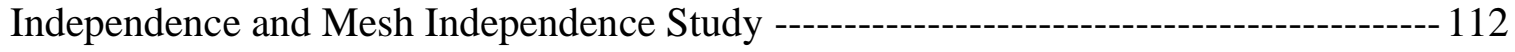

Table 17: BHE component dimension table with fins --------------------------------------- 121

Table 18: Table for mesh sizes of different components ------------------------------------ 126

Table 19:Table for material properties ----------------------------------------------------------- 129 
Table 20:Comparison of results with and without fins -------------------------------------- 130

Table 21: Price of Material used in Installation of BHE ----------------------------------- 132 


\section{LIST OF FIGURES}

FIGURE

PAGE NUMBER

Figure 1:Heat Pump Schematic depicting cooling and heating cycles (Vandenberg, 2002)

Figure 2: Operating Cycles of Air Source Heat Pumps (Source:

https://www.tnmagazine.org/benefits-air-source-heat-pumps/) 8

Figure 3: Temperature Profile of the Earth(Source:

http://geothermalenergyproduction.blogspot.com/p/how-energy-is-produced.html) ........ 9

Figure 4: Operating Cycles of Ground Source Heat Pumps (Source: Jeon et.al, 2018) ... 10

Figure 5:Three types of commonly used configurations of BHE. from left to right, single u-tube, double u-tube and concentric tubes (Source: M He 2012) ......................... 11

Figure 6:Equivalent Diameter of BHE with Single U-Tube ...................................... 21

Figure 7:Shank Spacing Model by Paul................................................................... 22

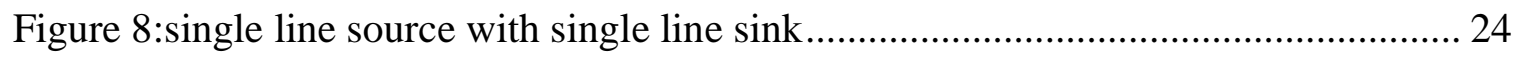

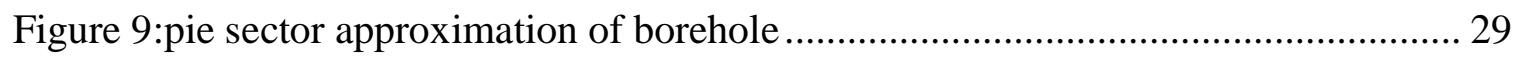

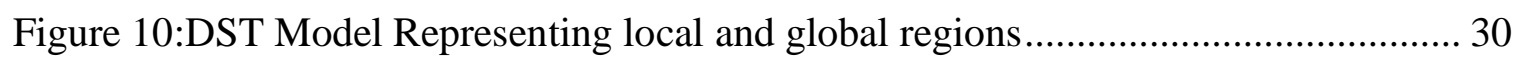

Figure 11:Layered differentiation of BHE in radial direction .................................. 31

Figure 12:Layered differentiation of BHE in vertical direction ................................ 34

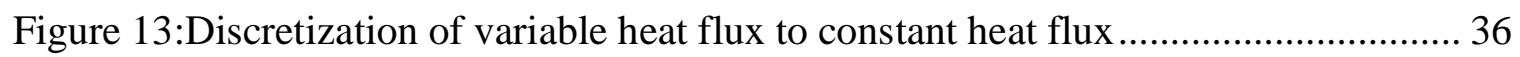

Figure 14:Heat Transfer process with electrical analogy in ground .............................. 37

Figure 15:Bore hole resistance for single u-tube, double u-tube and coaxial u-tube ....... 38

Figure 16: Schematic Diagram of Single U-Tube Vertical BHE ................................ 44

Figure 17:Geometry of the entire structure with the direction of flow indicated ............ 46

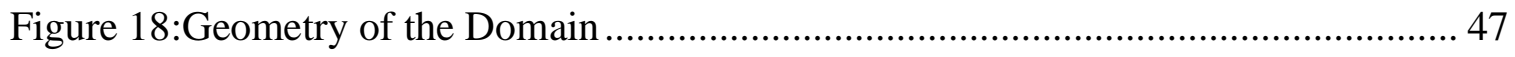

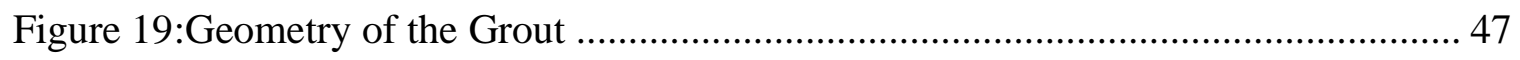




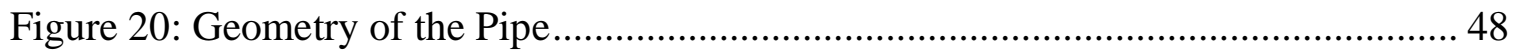

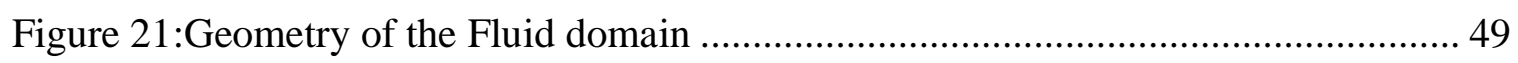

Figure 22:Hexahedral Mesh for Domain .................................................................. 51

Figure 23:Polyhedral Mesh of Domain.................................................................... 52

Figure 24:Hexahedral Mesh for Grout..................................................................... 53

Figure 25:Polyhedral Mesh of Grout ........................................................................ 54

Figure 26:Hexahedral Mesh for Pipe ……………………......................................... 56

Figure 27:Polyhedral Mesh of Pipe for coarse and medium refinement .......................... 57

Figure 28:Polyhedral mesh of Pipe for fine refinement test case ..................................... 57

Figure 29:Hexahedral Mesh for Fluid without Inflation Layer ........................................ 59

Figure 30:Polyhedral Mesh of Fluid with medium refinement with prism layers on

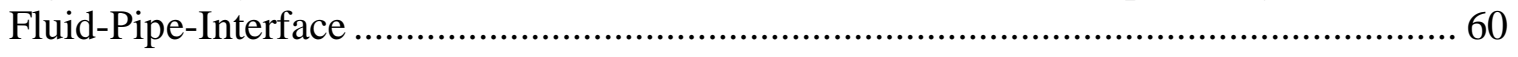

Figure 31:Polyhedral Mesh of Fluid for fine refinement test case with prism layers on

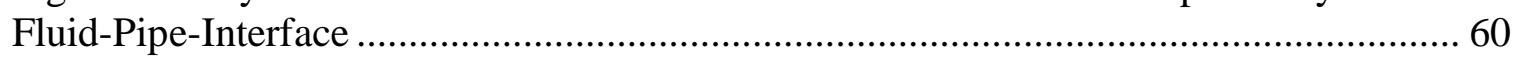

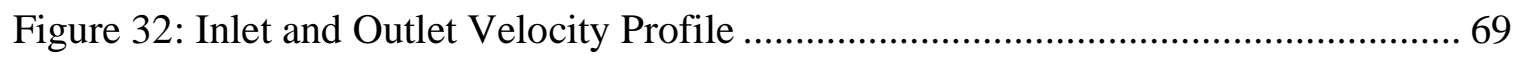

Figure 33: Turbulent Kinetic Energy Contour at U-Bend ............................................ 70

Figure 34: Heat Flux Contour at U- Bend ................................................................... 70

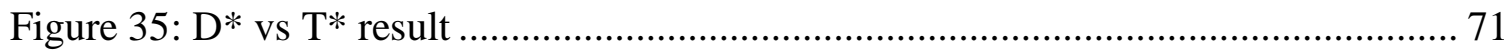

Figure 36:Inlet and Outlet Temperature Contour …………………………………..... 72

Figure 37: Turbulent Kinetic Energy Contour at U-bend .............................................. 73

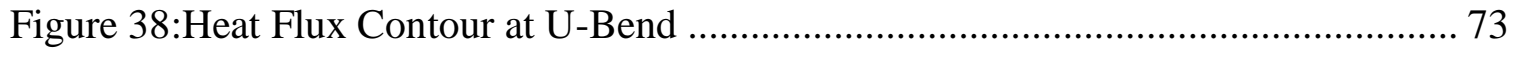

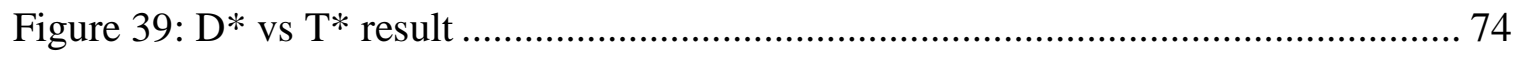

Figure 40 : Inlet and Outlet Temperature Contour ………………………………..... 75

Figure 41: Turbulent Kinetic Energy Contour at U-Bend ............................................... 76

Figure 42: Heat Flux Contour at U- Bend ................................................................. 76 


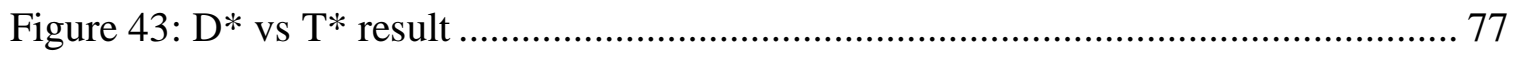

Figure 44 : Inlet and Outlet Temperature Contour ………………………………..... 79

Figure 45: Turbulent Kinetic Energy Contour at U-Bend ............................................. 80

Figure 46: Heat Flux Contour at U- Bend ............................................................... 80

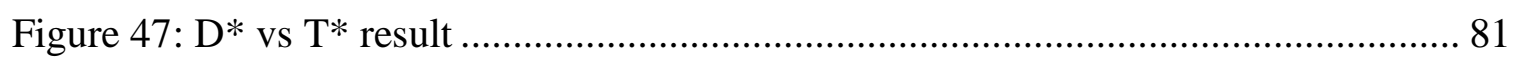

Figure 48: Inlet and Outlet Temperature Contour ........................................................ 82

Figure 49: Turbulent Kinetic Energy Contour at U-Bend .............................................. 83

Figure 50: Heat Flux Contour at U- Bend ............................................................... 83

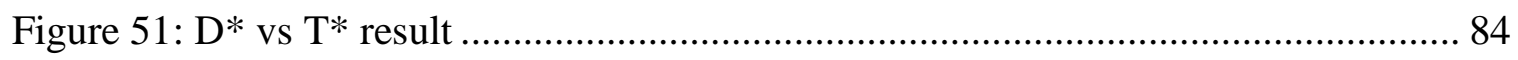

Figure 52: Inlet and Outlet Temperature Contour ..................................................... 85

Figure 53 : Turbulent Kinetic Energy Contour at U-Bend ........................................... 85

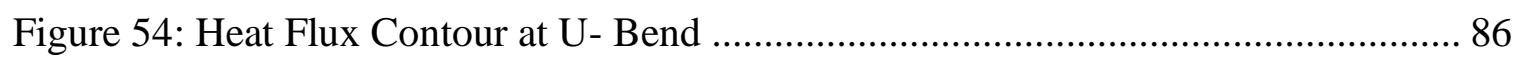

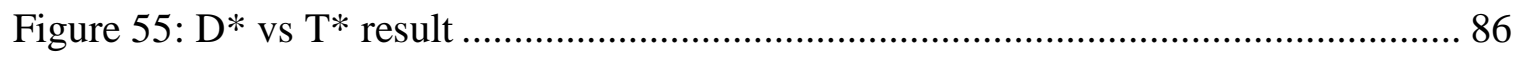

Figure 56: Inlet and Outlet Temperature Contour ......................................................... 87

Figure 57: Turbulent Kinetic Energy Contour at U-Bend and at Inlet and Outlet

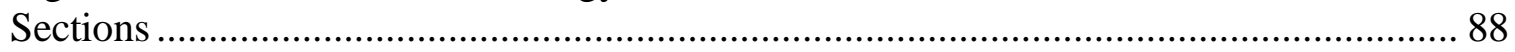

Figure 58: Heat Flux Contour at U-Bend and at Inlet and Outlet Sections at Fluid-Pipe-

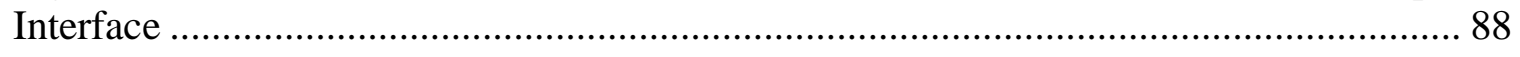

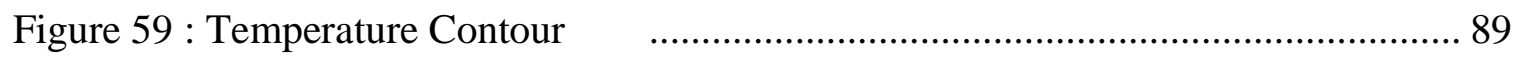

Figure 60 : Heat Flux Contour at Grout-Domain Interface ………………………........ 89

Figure 61 : Dotted Curve represents data from He, M., 2012 and Continuous line represents results obtained from CFD simulation in Fluent ............................................ 90

Figure 62: Inlet and Outlet Temperature Contour ......................................................... 91

Figure 63 : Turbulent Kinetic Energy Contour at U-Bend and at Inlet and Outlet Sections 
Figure 64: Heat Flux Contour at U-Bend and at Inlet and Outlet Sections in the fluid-

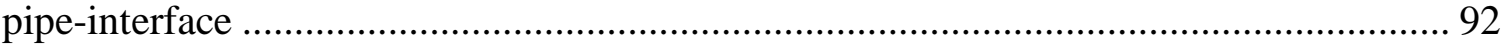

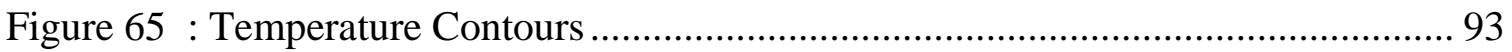

Figure 66 : Heat Flux Contour at Grout-Domain Interface .......................................... 93

Figure 67 : Dotted Curve represents data from He, M., 2012 and Continuous line represents results obtained from CFD simulation in Fluent .......................................... 94

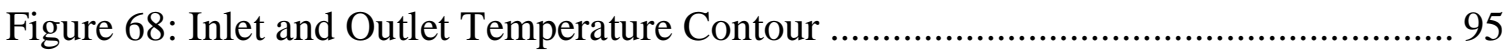

Figure 69 : Turbulent Kinetic Energy Contour at U-Bend and at Inlet and Outlet Sections

Figure 70 : Heat Flux Contour at U-Bend and at Inlet and Outlet Sections at Fluid-PipeInterface

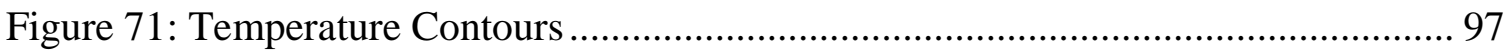

Figure 72 : Heat Flux Contour at Grout-Domain Interface ....................................... 97

Figure 73: Dotted Curve represents data from He, M., 2012 and Continuous line represents results obtained from CFD simulation in Fluent ........................................ 98

Figure 74 : Inlet and Outlet Temperature Contour .................................................. 99

Figure 75 : Turbulent Kinetic Energy Contour at U-Bend and at Inlet and Outlet Sections

Figure 76: Heat Flux Contour at U-Bend and at Inlet and Outlet Sections at Fluid-Pipe-

Interface 100

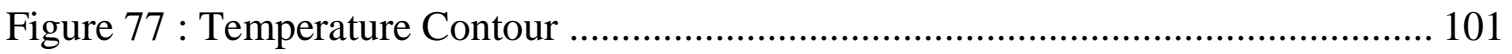

Figure 78 : Heat Flux Contour at Grout-Domain Interface ....................................... 101

Figure 79 :Dotted Curve represents data from He, M., 2012 and Continuous line represents results obtained from CFD simulation in Fluent 102

Figure 80 : Inlet and Outlet Temperature Contour

Figure 81 : Turbulent Kinetic Energy Contour at U-Bend and at Inlet and Outlet Sections

Figure 82: Heat Flux Contour at U-Bend and at Inlet and Outlet Sections at Fluid-PipeInterface 
Figure 83 : Temperature Contours .................................................................... 105

Figure 84: Heat Flux Contour at Grout-Domain Interface ........................................... 105

Figure 85 : Dotted Curve represents data from He, M., 2012. and Continuous line represents results obtained from CFD simulation in Fluent ........................................... 106

Figure 86: Correlation between Average Surface Heat Transfer Co-efficient and Heat Flux with Reynolds Number .................................................................................... 108

Figure 87: Different types of fin design used in cooling of various heated components 120 Figure 88: Schematic Diagram of Modified Heat Exchanger ....................................... 122

Figure 89: Geometry of Modified Domain ................................................................. 123

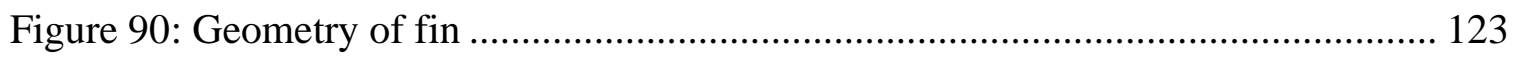

Figure 91:Geometry of Modified Grout ………………………………………….... 124

Figure 92: Geometry of Pipe

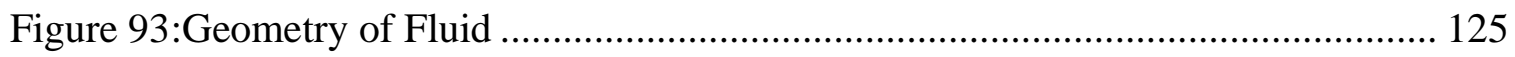

Figure 94:Discretized Geometry ………………………….................................. 126

Figure 95:Discretized Modified Domain ………………........................................... 127

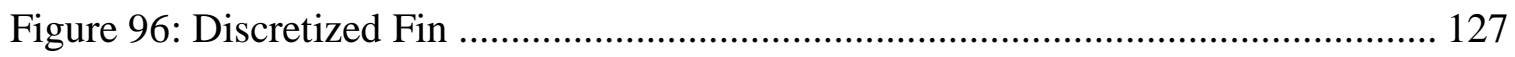

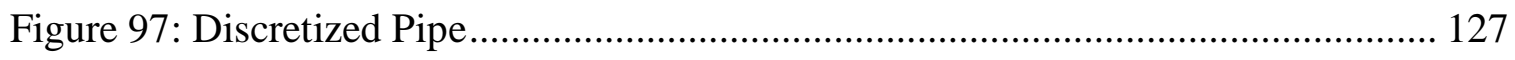

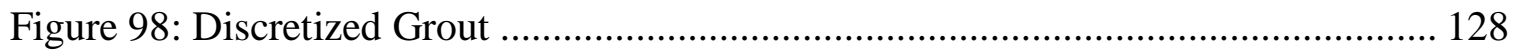

Figure 99: Discretized Fluid Domain ................................................................... 128

Figure 100: Correlation between Average Surface Heat Transfer Co-efficient and Heat Flux with Reynolds Number ...................................................................................... 130 


\section{NOMENCLATURE USED}

$\alpha$

D

F

f

g

$\mathrm{H}$

h

$\mathrm{J}_{0}$

$\mathrm{J}_{1}$

$\mathrm{k}$ thermal diffusivity $\left(\mathrm{m}^{2} / \mathrm{s}\right)$

equation fit coefficient

(dimensionless)

viscosity $(\mathrm{kg} / \mathrm{m} . \mathrm{s})$

time (dimensionless)

phase (radians)

density $\left(\mathrm{kg} / \mathrm{m}^{3}\right)$

amplitude

volume thermal capacity $(\mathrm{J} /(\mathrm{m} 3 . \mathrm{K})$

specific heat capacity (J/kg.K)

coefficient of performance (dimensionless)

diameter (m)

diffusion heat flux $\left(\mathrm{W} / \mathrm{m}^{2}\right)$

frequency $(\mathrm{Hz})$

g-function

depth (m)

convective heat transfer coefficient $\left(\mathrm{W} / \mathrm{m}^{2} \mathrm{~K}\right)$

Bessel function of first kind of zeroth order

Bessel function of first kind of first order

thermal conductivity (W/m.K) 
$\mathrm{L}$

LA

$\mathrm{m}$

$\mathrm{Nu}$

$\mathrm{P}$

Q

$\operatorname{Pr}$

q

$\mathrm{R}$

$\operatorname{Re}$

r

S

$\mathrm{T}$

$\mathrm{t}$

$\mathrm{v}, \mathrm{V}$

Y0

Y1 distance $(\mathrm{m})$

tank volume $\left(\mathrm{m}^{3}\right)$

mass flow rate $(\mathrm{kg} / \mathrm{s})$

Nusselt number

(dimensionless)

period (radians)

heat transfer rate $(\mathrm{W} / \mathrm{m})$

Prandtl number

(Dimensionless)

Heat flux (W/m2)

thermal resistance $(\mathrm{m} . \mathrm{K} / \mathrm{W})$

Reynolds number

(dimensionless)

radius (m)

surface area $\left(\mathrm{m}^{2}\right)$

temperature $\left({ }^{\circ} \mathrm{C}\right)$

time (s)

fluid velocity $(\mathrm{m} / \mathrm{s})$, volume

flow rate $\left(\mathrm{m}^{3} / \mathrm{s}\right)$

Bessel function of second kind of zeroth order

Bessel function of second kind of first order 


\section{CHAPTER I. INTRODUCTION}

\subsection{BACKGROUND}

With the Global Energy requirement increasing every day, there has been a considerable rise in interest towards the utilization of renewable sources of energy to fulfill these needs. The extent of the availability of fossil-based energy is now questionable. Also, the utilization of these conventional sources of energy has a considerable effect on the environment, as it tends to generate harmful emissions, namely the oxides of carbon, nitrogen and suspended particulate matter. The Climate Change Act of 2008, Pielke (2009) has said that UK should target to reduce the emission of carbon dioxide and other greenhouse gases by $80 \%$ by the year 2050 in UK relative to the 1990 baseline.

Keeping in mind the current scenario, there has been a rise in interest in developing sustainable technological methods for tapping the renewable and non-conventional sources of energy. The idea is to develop feasible technologies for practically tapping these sources of energy to its maximum tapping potential.

Methods to utilize various renewable sources of energy, such as solar panels, heat pumps, wind turbines, etc. are being explored. Keeping this in mind, Geothermal Energy has become one of the sources of providing low grade energy for local energy requirements. As such, the potential of geothermal energy is tapped using heat pump systems, as they operate in low grade energy requirements.

Ground Source Heat Pump Systems (GSHP) are being proposed as the most sustainable and popular type of direct-use geothermal energy to provide heating, and cooling applications (Lund and Boyd, 2016) due to their high coefficient of performance (COP). 
The GSHP system uses the ground as the source or sink to either absorb heat or to dissipate it, as per the requirement. The GSHP system involves the application of a ground heat exchanger called the Borehole Heat Exchanger (BHE). A borehole typically consists of a U-tube pipe, which is backfilled with grout.

The main objective of using the ground is due to the reason that ground temperature tends to be more stable as compared to that of air used for air heat pump systems. Also, with their potential of reducing the carbon dioxide emissions, the GSHP systems are receiving increasing interest. The idea of this study is to employ the use of the physical law that states that heat transfers from a warmer body to another with lower temperature for effective energy utilization.

\subsection{OBJECTIVES}

The primary objective of the current research is to review the existing models for BHEs, which shows that various models of the BHEs have been developed to simplify the analysis of the heat exchanger, and to study the heat transfer in and around the BHEs. The various assumptions that have been made in the different models are to simplify the computational effort in the simulation of the models.

The second major objective of this study is to develop a fully discretized three-dimensional numerical model for the BHE in order to study the heat transfer characteristics in three dimensions. 
Thirdly, the final objective of this study is to identify the various methods through which the heat transfer across the BHE can be enhanced as per the requirements and its applications.

\subsection{THESIS STRUCTURE}

The thesis is structured according to the objectives of study and presented in five chapters. This chapter introduces the background and the objectives of this study.

Chapter 2 introduces us to heat pumps, its working cycles and the different types of heat pumps that are predominantly employed for various applications. This chapter also provides a thorough literature review of the various BHE model developments. The various pros and cons of these models and the limit of their applications have also been discussed in this chapter.

Chapter 3 presents the original methodology developed for discretizing the threedimensional numerical model of the BHE. This chapter subsequently discusses simple steady state three dimensional simulations performed for studying the various heat transfer characteristics of the BHE. The simulation results are used to validate the experimental data and numerical results compiled from two different sources. This chapter also compares the effect of the variation of size of the grid, the type of the mesh used, the turbulence model employed and the effect of gravity on the numerical solution.

Chapter 4 of this thesis discusses the interpretations of the simulation results obtained in chapter 3 and provides methods and discussions of improving the heat transfer characteristics of BHE. This takes into account the transit time of flow, Reynolds Number variation and thermal properties of the various components of the BHE and suggests design changes along with simulation results to back the proposal. This chapter also covers a brief 
cost analysis of installing a vertical type single u-tube BHE. This chapter also studies the limitations of the current three-dimensional models and the improvements suggested in the previous chapter.

Chapter 5 presents a summary of the main findings of this study, and future scope of work in this topic. 


\section{CHAPTER 2 LITERATURE REVIEW OF HEAT PUMPS AND THE BOREHOLE}

\section{HEAT EXCHANGER MODELS.}

\subsection{HeAt PuMPS}

A heat pump is categorized as a device or machine that extracts heat from a lower temperature source and supplies it to a heat sink at a higher temperature. Thus, such a device can be used for heating in the winter or cooling in the summer. Such equipment is more efficient than electric heating in mild and moderate climates. Contrary to gas or oilbased boilers, heat pumps produce heat at lower temperatures for consistent periods of time.

There are a variety of components in the Heat Pump: evaporator, compressor, condenser, expansion valves, and reverse valves. The working principles and heat pump elements of both the heating and cooling processes are presented in Figure 1 (Cengel and Boles, 1994).
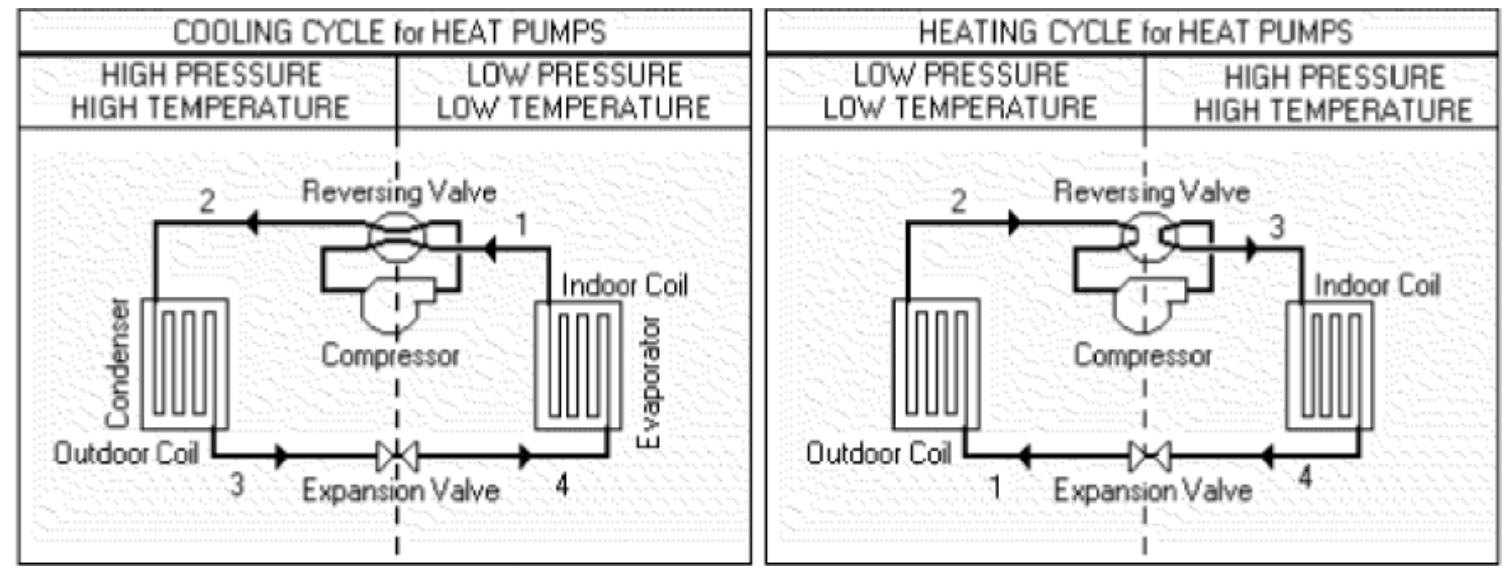

Figure 1:Heat Pump Schematic depicting cooling and heating cycles (Vandenberg, 2002) 


\subsection{CoOling CyCle}

- The refrigerant after absorbing heat from the air in the building (heat source) through the evaporator / cooling coil, where it is at low temperature and pressure, the refrigerant vapor reaches the compressor. Work is done on the refrigerant while compressing and increasing the pressure in the compressor.

- The refrigerant exits the compressor as hot vapor under very high pressure, which then reaches the condenser (heat sink). The condenser loop condenses the vapor to liquid.

- The refrigerant then exits the condenser as a warm liquid. The expansion valve controls the flow from the condenser in such a way so that it only allows liquid refrigerant to pass through.

- As the refrigerant expands after exiting the expansion valve it becomes a cold liquid. The liquid evaporates as it moves through the cooling coil (located in the indoor air unit). The coolant then absorbs indoor heat from the air that blows over the surface of the coil and thus cools the building. A refrigerant now becomes cool vapor and the loop begins.

\subsection{HeATING CYCLE}

- As a cool liquid, the refrigerant enters the outdoor coil.

- The cold liquid absorbs heat from its surroundings (from air or geothermal source) and exits as a cool vapour. And the cool vapour enters the compressor. 
- As an extremely hot vapour, which is much hotter than the internal air, the refrigerant exits the compressor. To pass the heat into the building, a fan blows over the hot coils.

- As a warm liquid, the refrigerant exits the indoor coil and then enters the expansion valve to cool the liquid.

Two types of heat pumps exist. The air source heat pump (ASHP), which transfers heat between indoor and outdoor air, is the most common form of heat pump. Since the late 1940s, ground source heat pumps (GSHPs) have been used that use the constant temperature of the ground as the medium for heat exchange instead of outside air temperature (Ruqun Wu, 2009).

\subsection{TYPES OF HEAT PUMPS}

\subsubsection{Air Source Heat Pumps}

Air Source Heat Pumps are the most common types of heat pumps and are used to extract energy from external air, where heat is removed from indoor air and rejected to the outdoor air in the cooling cycle, whereas the vice versa cycle takes place in the heating cycle as shown in Figure 2. Conventional HVAC systems operate using the ASHP system. Compared to GSHPs, ASHPs have a smaller land footprint. 


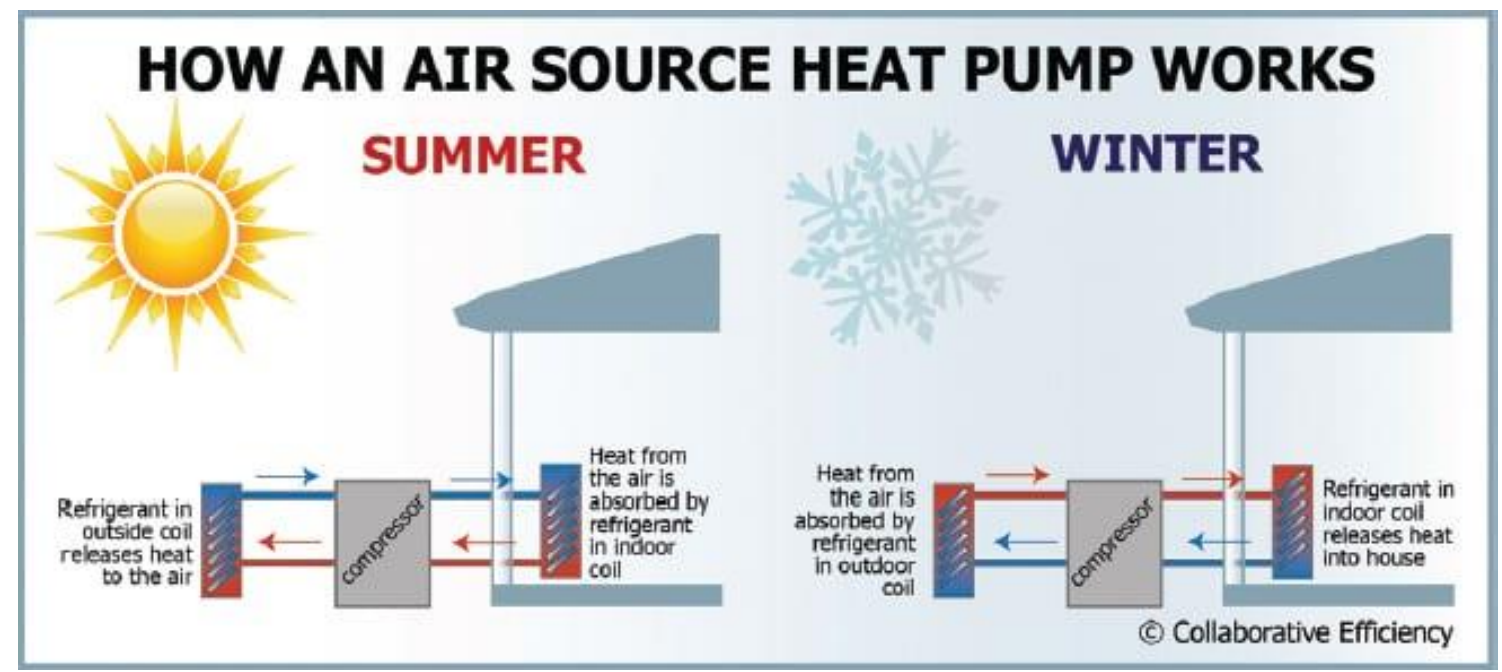

Figure 2: Operating Cycles of Air Source Heat Pumps (Source: https://www.tnmagazine.org/benefits-air-source-heat-pumps/)

\subsubsection{Ground Source Heat Pumps}

Highly effective, renewable energy technologies for heating and cooling purposes are ground-source or geothermal heat pumps. This technology based on the principle that the Earth's temperature is comparatively stable in depth, warmer than winter air and cooler than summer air. During the winter, a geothermal heat pump can transfer the heat stored in the Earth's surface into a building, and during the summer, it can transfer heat out of the house as shown in Figure 4. For the successful application of geothermal heat pumps, special geological conditions, such as hot springs, are not needed.

The Earth, partly from its formation (30-50 percent) and partly from the radioactive decay within it (50-70 percent), retains a lot of thermal energy. Within the inner core, temperatures are in the range of about $4,800-7,700^{\circ} \mathrm{C}$ as shown in Figure 3 . In all, $99 \%$ of the Planet is hotter than $1,000^{\circ} \mathrm{C}$ and the remainder is even hotter than $100^{\circ} \mathrm{C}$, which recommends the use of this energy (Robin, 1999). 


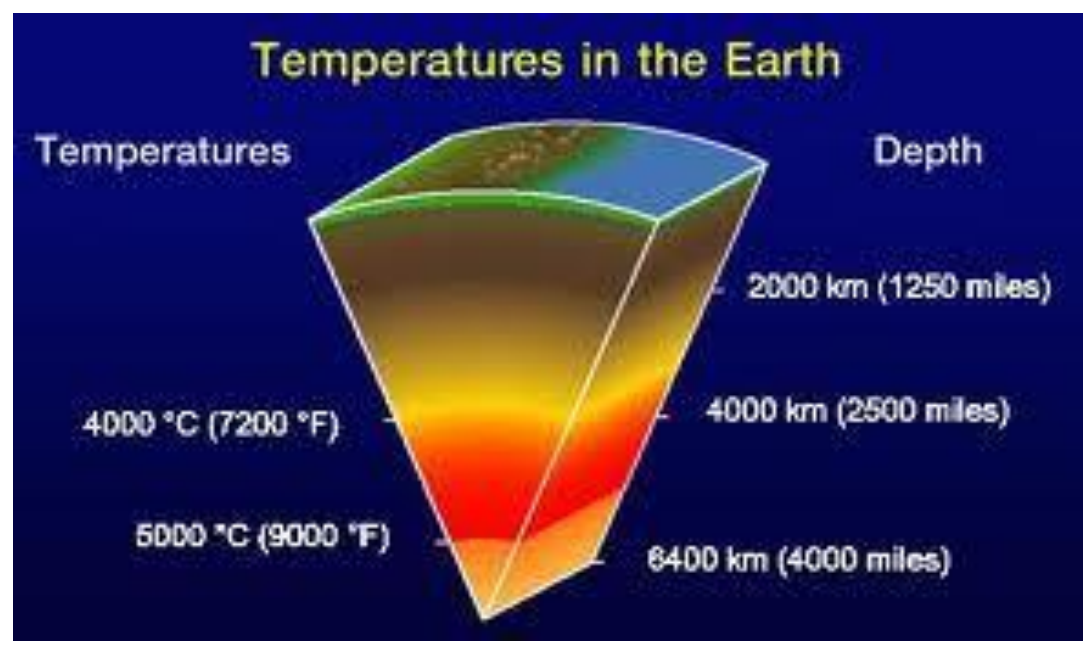

Figure 3: Temperature Profile of the Earth(Source:

http://geothermalenergyproduction.blogspot.com/p/how-energy-is-produced.html)

In the last 10 years, in around 33 countries, including the UK, GSHPs have gained more popularity and have seen an annual increase of 10 percent. There is no complete data, but the number of plants installed is estimated to have recently reached 1,700,000 worldwide (Lund, 2007).

Geothermal energy can generally be divided into one of the following three categories (as defined by ASHRAE, (2003):

- High-temperature $\left(>150^{\circ} \mathrm{C}\right)$ output of electric power.

- Intermediate- and low-temperature $\left(<150^{\circ} \mathrm{C}\right)$ applications for direct-use.

- General GSHP applications $\left(<32^{\circ} \mathrm{C}\right)$.

Both GSHP types consist of the following components (beginning from the inside to the outside):

- Interior distribution system for heating and cooling.

- A pump for heat. 
- The earth connection(coils)-Ground Source Heat Exchanger/Borehole Heat Exchanger.

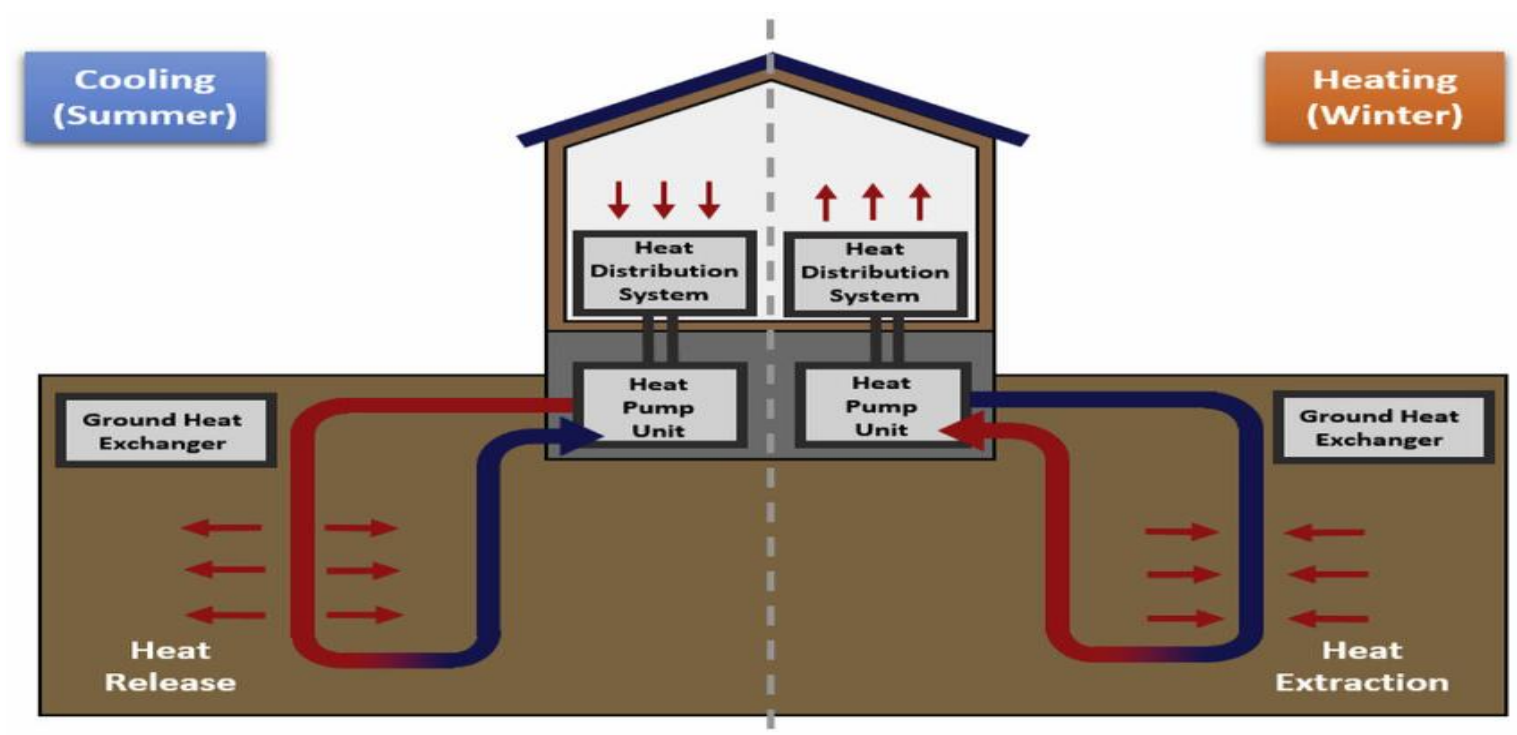

Figure 4: Operating Cycles of Ground Source Heat Pumps (Source: Jeon et.al, 2018)

\subsection{BOREHOLE HEAT EXCHANGER}

Two types of ground heat exchanger are known viz. open looped and closed looped type.

The ground water is directly used by an open loop system to serve as the working fluid entering the heat pumps. Owing to their ability to contaminate the ground water table, these devices are not used. On the other side, since it utilizes a pipe system to circulate the operating fluid externally pumped into the system, closed loop systems are more predominantly used. Now, it is possible to provide a closed loop system of two forms, vertical and horizontal. A vertical closed loop system was considered in this thesis. A literature review of the different models of the Borehole heat exchanger and the drawbacks and their applications is also presented in this chapter. 
The most popular type of ground heat exchanger used in GSHP systems is the Borehole Heat exchanger. There are three types of widely used vertical BHEs, as described earlier: single U-tube, double U-tube and concentric tubes. Figure 2 shows the diagram of these three types.
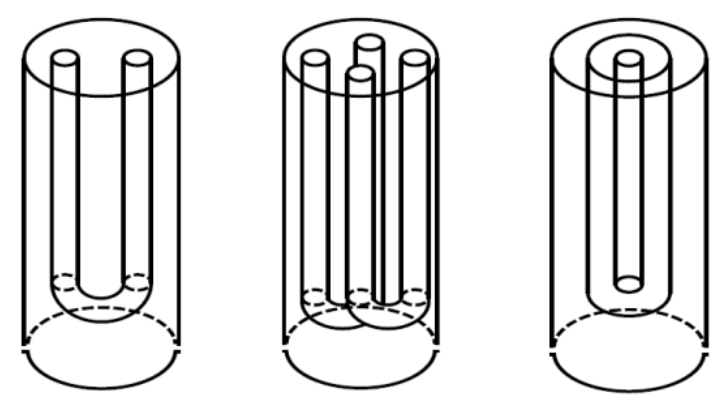

Figure 5:Three types of commonly used configurations of BHE. from left to right, single u-tube, double u-tube and concentric tubes (Source: M He 2012)

In general, the tubes are made up of high-density polyethylene pipes with heat-fused joints, which provide the characteristics and strength of effective heat transfer. In general, the fluid is water, often combined with anti-freezing solutions, which serves as the conduit for heat to and from the ground to be rejected or removed. The gap is backfilled with grout, which also helps to pass heat and provide the pipe loop with support.

Typically, a BHE is $150 \mathrm{~mm}$ in diameter and $100 \mathrm{~m}$ in length. The transportation time of the fluid that passes through the tubes usually ranges from one minute and a half to 25 minutes approximately (M He 2012). It can be predicted that this would cause delays in temperature responses. The soil is usually stratified along the borehole depth and it is typical to have different layers of geological material along the borehole depth (clay, sandstone, gravel, etc.). The undisturbed profile of ground temperature along the borehole depth is not standardized. The temperature of the ground below 10 metres deep is often 
considered constant, but a geothermal gradient of $0.01-0.03 \mathrm{~K} / \mathrm{m}$ provides a more detailed definition of the distribution of the ground temperature (M He 2012). The heat transfer method of a BHE for a grouted BHE consists of three components: convection heat transfer between the fluid and the inner pipe wall; heat transfer of conduction through the pipes and grout, and conduction heat transfer through the ground (and advection if there is ground water flow).

Different analytical and computational models have been developed and improved over the years and used to measure heat exchanged between the borehole and the domain of heat exchange with the purposes to:

- Determine the dimensions of the BHE.

- Predict BHE thermal performance.

Depending upon the approach used for model development, models of BHEs can be divided into four categories:

- analytical models

- steady state borehole models

- response factor models

- discretized models

This chapter reviews models of BHEs according to the four categories.

\subsubsection{Analytical Models}

The 3D transient conjugate heat transfer problem involving a complex geometry and boundary conditions of the BHEs, does not have analytical solution. A number of simplifying assumptions were made in order to develop analytical models for BHEs. The 
simplest one involves viewing the entire borehole as an infinitely long line source and disregarding the borehole's thermal properties, such as the fluid, pipe, and grout thermal mass. The line source theory proposed by Kelvin (1882) can be extended to establish the so-called 'line source model' by making these assumptions. The solution of the cylinder source (Carslaw and Jaeger, 1947) is similar but makes the assumption that it is possible to consider the two legs of the U-tube as a single pipe co-axial with the borehole. This method also ignores the thermal mass of the fluid, tubing, and grout.

\subsubsection{Line Source Model}

The primary assumption in the model of the line source is to view the entire borehole as an infinitely long line source and to ignore the borehole's thermal properties, such as the fluid's thermal mass, tubing, and backfilling materials. Lord Kelvin (1882) implemented the earliest use of this method in order to assess thermal efficiency via ground heat exchanger tubing. Therefore, "Kelvin 's line source theory" is also called this model.

Assuming a uniform initial temperature and a constant heat flux per unit depth at zero radius, the relation given by Ingersoll (1954) for the temperature at any time at any radius can be written as:

$$
\begin{array}{r}
T-T_{0}=\frac{Q}{2 \pi k} \int_{x}^{\infty} \frac{e^{-\beta^{2}}}{\beta} d \beta \equiv \frac{Q}{2 \pi k} I(X) \\
\beta=\frac{r}{\sqrt[2]{\alpha\left(t-t^{r}\right)}}
\end{array}
$$




$$
X=\frac{r}{\sqrt[2]{\alpha t}}
$$

where,

$T=$ temperature of the ground at radius $r\left({ }^{\circ} \mathrm{C}\right)$,

$T_{0}=$ initial temperature of the ground $\left({ }^{\circ} \mathrm{C}\right)$,

$Q=$ heat flux per unit length of borehole $(\mathrm{W} / \mathrm{m})$,

$r=$ radius from the line source $(\mathrm{m})$,

$k=$ thermal conductivity of the ground (W/mK),

$\alpha=$ thermal diffusivity of the ground ( $\mathrm{m} 2 / \mathrm{s})$,

$t=$ time since the start of the operation $(\mathrm{s})$.

The following approximation can be used to find values of the integral term:-

$$
I(X)=2.303 \log _{10} \frac{1}{X}+\frac{X^{2}}{2}+\frac{X^{2}}{8}-0.2886
$$

Carslaw and Jaeger (1947) utilized the exponential integral $\mathrm{E}_{1}$ to approximate the solution of the line source model and derived the most commonly used equation to estimate the thermal conductivity of the ground during in situ thermal response tests. This line source equation is given as:

$$
T-T_{0}=\frac{Q}{4 \pi k} \int_{r^{2} / 4 \alpha t}^{\infty} \frac{e^{-u}}{u} d u \equiv \frac{Q}{4 \pi k} E_{1}\left(\frac{r^{2}}{4 \alpha t}\right)
$$


The exponential integral $E_{1}$ can be estimated by:

$$
E_{1}\left(\frac{r^{2}}{4 \alpha t}\right)=-\gamma-\ln \left(\frac{r^{2}}{4 \alpha t}\right)-\sum_{n=1}^{\infty}(-1)^{n} \frac{\left(\frac{r^{2}}{4 \alpha t}\right)^{n}}{n n !} \cong \ln \left(\frac{4 \alpha t}{r^{2}}\right)-\gamma
$$

where $\gamma$ is Euler's constant, which is equal to $(0.5772 \ldots)$. The natural logarithm approximation of the exponential integral $\mathrm{E}_{1}$ in equation (2.4) gives errors less than $10 \%$ for the time criterion $t_{c} \geq 5 r^{2} 2 / \alpha$.

Then the temperature at the borehole wall $(r=r b)$ at time $t$ can then be expressed as:

$$
T_{b}=\frac{r^{2}}{4 \alpha t}\left[\ln \left(\frac{4 \alpha t}{r_{b}^{2}}\right)-\gamma\right]+T_{0}
$$

with, $t_{c} \geq 5 r^{2} 2 / \alpha \quad$ which typically has the range between 3 to 10 hours.

Assuming the heat transfer within the borehole is in a steady-state, at any time, the relationship between the mean temperature of the fluid and the temperature of the borehole can be determined using a thermal borehole resistance so that:

$$
T_{f}=T_{b}+Q \cdot R_{b}
$$




$$
=\frac{Q}{4 \pi k} \ln (t)+Q\left\{R_{b}+\right.
$$

$$
\left.\frac{1}{4 \pi k}\left[\ln \left(\frac{4 \alpha}{r^{2}}\right)-\gamma\right]\right\}+T_{0}
$$

where $T_{f}$ is the mean fluid temperature, $T_{b}$ is the borehole temperature $R_{b}$ is the borehole thermal resistance. For a given constant heat flux, the fluid temperature varies linearly with the natural $\log$ of time and the last two terms of equation 2.6 are constant with respect to time.

The geometry of the borehole, along with the thermal capabilities of the fluid, pipes and grout material inside the borehole, is inevitably ignored. Furthermore, the model is not appropriate for applications with limited time scales in which the dynamic response inside

the borehole should be taken into account. In addition, the borehole is regarded as infinitely long, such that the borehole's heat flow is still radial and normal to the borehole.

Despite its limitations, because of its simplicity and efficiency in terms of computation, the line source model has been widely used in the study of in situ thermal response test results.

\subsubsection{Cylinder Source Theory}

Assuming that the two pipes are a single infinitely long pipe, which are coaxial with the borehole having infinite length, the cylinder source solution (Carslaw and Jaeger, 1947) can also be utilized to calculate the distribution of temperature of the infinite ground having 
an initial temperature in the domain of the borehole at any given time. With the further assumption of a constant heat flux along the borehole, the governing equation for the heat transfer problem in one dimension can be written as:

$$
\frac{\partial^{2} \theta}{\partial r^{2}}+\frac{1}{r} \frac{\partial \theta}{\partial r}-\frac{1}{\alpha} \frac{\partial \theta}{\partial r}=0 \quad r_{0}<r<\infty
$$

while the boundary and initial condition can be written as:

$$
\begin{array}{cc}
-2 \pi \cdot r_{0} \cdot k \frac{\partial \theta}{\partial r}=Q & r=r_{0} \cdot t>0 \\
\frac{\partial \theta}{\partial r}=0 & r=0 \\
\theta=0 & t=0, r>r_{0}
\end{array}
$$

where $\theta=T-T_{0}$, is the difference between the temperature of the ground measured at radial distance $r$ from the cylinder source at time $t$ and the initial temperature $\left({ }^{\circ} \mathrm{C}\right)$.

Using Laplace transform and the inverse Laplace transform, the solution can be expressed as: 


$$
\theta(r, t)=\frac{2 Q}{\pi k} \int\left(1-e^{-\alpha u^{2} t}\right) \frac{J_{0}(u, r) Y_{1}(u \alpha)-Y_{0}(u r) J_{1}(u \alpha)}{u^{2}\left[J_{1}^{2}(u \alpha)+Y_{1}^{2}(u \alpha)\right]} d u
$$

where $J_{0}, J_{l}, Y_{0}, Y_{l}$ are the zero and the first order Bessel functions.

The cylindrical source approach was developed by Kavanaugh (1985) and was later tested by using experimental data from two test sites (Kavanaugh, 1992). Since the cylinder source solution considers the two pipes as one, it ignores the short circuit heat transfer within the borehole arising due to the temperature difference between these two pipes. Kavanaugh suggested two methods to correct this effect due to short circuit and the details of this correction can be found in Yavuzturk's thesis (Yavuzturk, 1999).

Similar to the line source model, the cylinder source solution also assumes that the borehole is infinitely long with a homogenous ground along its depth. The geometry, the thermal properties of the materials of the BHE and fluid transport were ignored. The heat transfers between the fluid and the borehole temperatures was described using a thermal resistance. The steady state thermal resistance of borehole by superposition can be calculated using this model. Detail methods of calculation can be found in Young (2004).

\subsubsection{Steady State Models}

Steady-state borehole models are developed mainly for estimation of borehole thermal resistance through the use of analytical models. The steady-state borehole models make the primary assumption that there is a steady state heat transfer in the borehole. The heat flux of the borehole and the temperature difference between the fluid and the borehole wall is a ratio with a constant value. Thermal resistance can therefore, be employed to define the 
relationship between the heat flux, the temperature difference of the fluid, and the borehole wall which is as follows (He, 2012):

$$
R_{b}=\frac{T_{f}-T_{b}}{Q}
$$

where,

$\mathrm{R}_{\mathrm{b}}=$ borehole thermal resistance $(\mathrm{Km} / \mathrm{W})$,

$\mathrm{Q}=$ heat flux per unit length of the borehole $(\mathrm{W} / \mathrm{m})$,

$\mathrm{T}_{\mathrm{f}}=$ average temperature of the fluid $\left({ }^{\circ} \mathrm{C}\right)$,

$\mathrm{T}_{\mathrm{b}}=$ average temperature of the borehole wall $\left({ }^{\circ} \mathrm{C}\right)$.

The borehole thermal resistance consists of the convective resistance of the fluid, the conductive resistance of the pipes, and the conductive resistance of the grout. The relationship of the borehole's thermal resistance and the thermal resistance of the fluid, pipe and grout can be presented as:

$$
R_{b}=\frac{R_{f}-R_{p}}{2}+R_{g}
$$

where $R_{f}$ is the convective resistance of the fluid within one pipe, $R_{p}$ is the conductive resistance of one pipe, and $\mathrm{R}_{\mathrm{g}}$ is the conductive resistance of the grout. The conductive resistance of the fluid within one pipe can be estimated by (Incorpera et al., 2007): 


$$
R_{p}=\frac{\ln \left(\frac{r_{2}}{r_{1}}\right)}{2 \pi k_{p}}
$$

where,

$r_{2}=$ outside diameter of the pipe $(\mathrm{m})$,

$k_{p}=$ conductivity of the pipe $(\mathrm{W} / \mathrm{mK})$.

A number of steady state borehole models have been developed to address this and are discussed below.

\subsubsection{Equivalent Diameter Model}

A simple way of calculating the borehole thermal resistance in one-dimensional steadystate conditions is illustrated by the equivalent diameter model which was developed by Gu and O'Neal (1998). Gu and O'Neal (1998) assumed that the thermal influences of one pipe concentric with a borehole can be used to represent the thermal influences of the two arms of a U-tube for deriving an expression to calculate the equivalent diameter of a concentric pipe (Figure 3). 

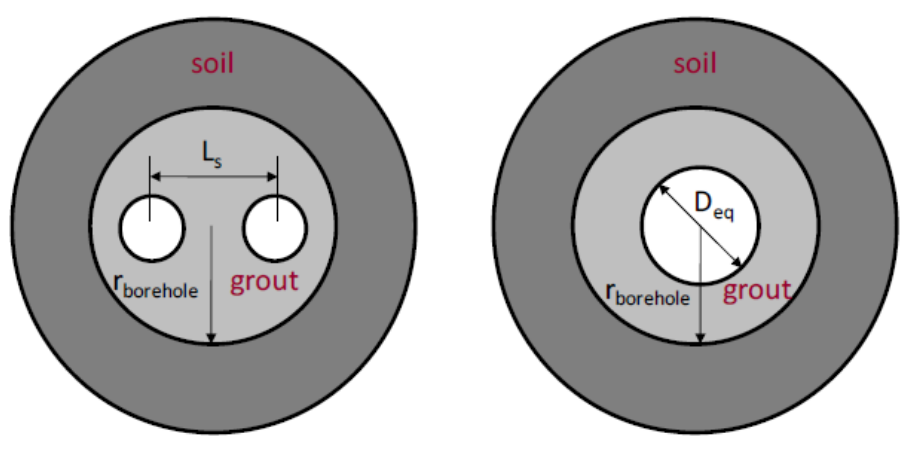

Figure 6:Equivalent Diameter of BHE with Single U-Tube

$$
D_{e q}=\sqrt{2 D_{p}} \cdot L_{s} \quad D_{p} \leq L_{s} \leq r_{\text {borehole }}
$$

where,

$D_{e q}=$ equivalent diameter of the pipe (m),

$D_{p}=$ diameter of the pipe, and $L_{s}$ is the centre to centre distance between the two legs of the U-tube.

In this case, the resistance of the grout, can be calculated by utilizing the general equation for radial heat conduction through a cylinder (Incropera et al., 2007).

$$
R_{g}=\frac{\ln \left(\frac{D_{b}}{D_{e q}}\right)}{2 \pi k_{g}}
$$


where,

$D_{b}=$ diameter of the borehole (m),

$k_{g}=$ thermal conductivity of the grout $(\mathrm{W} / \mathrm{mK})$.

\subsubsection{Paul's Model}

This model was developed to calculate the thermal resistance of grout by using the purported 'shape factor correlations', which were derived using experimental data from a test apparatus and simulation results from a two dimensional finite element model (Paul, 1996).

Four different configurations classified according to the shank spacing $S_{1}$ and $S_{2}$ were taken into account in Paul's Model (Figure 7).

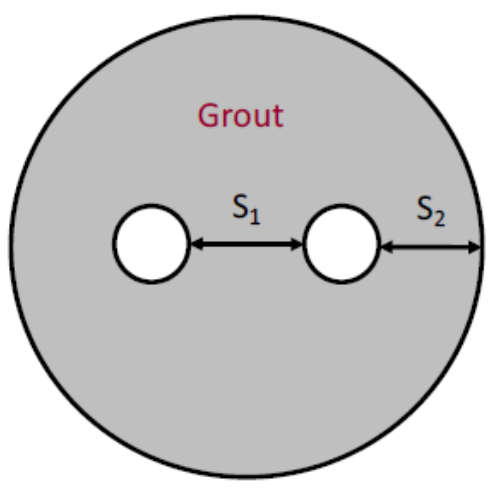

\section{Spacing Condition:}

$\begin{array}{lc}\text { Case A: } & S_{1}=0 \\ \text { Case B: } & S_{1}=0.3124 \mathrm{~cm} \\ \text { Case C: } & S_{1}=S_{2} \\ \text { Case D: } & S_{2}=0.300 \mathrm{~cm}\end{array}$

Figure 7:Shank Spacing Model by Paul

By adding the shape factor, the grout thermal resistance can be expressed as:

$$
R_{g}=\frac{1}{k_{g} \cdot S}
$$


where $S$ is the dimensionless shape factor defined as:

$$
S=\beta_{0} \cdot\left(\frac{D_{b}}{D_{p}}\right)^{\beta_{1}}
$$

where,

$\beta_{0}$ and $\beta_{1}=$ dimensionless equation fit coefficients

$D_{p}=$ outer diameter of the pipe.

Equation fit coefficients given by Paul for 4 different configurations in Table 2.1

Table 1:Equation fit coefficients given by Paul for 4 different configurations

\begin{tabular}{|l|l|l|l|l|}
\hline & Case A & Case B & Case C & Case D \\
\hline $\boldsymbol{\beta}_{0}$ & 14.45087 & 20.10038 & 17.44268 & 21.90587 \\
\hline $\boldsymbol{\beta}_{1}$ & -0.8176 & -0.94467 & -0.60515 & -0.3796 \\
\hline $\boldsymbol{R}$ & 0.997096 & 0.992558 & 0.999673 & 0.969875 \\
\hline
\end{tabular}

where,

$R=$ accuracy of the equation fit with reference to the experimental data or numerical model. An $R$ value of 1 indicates a perfect fit.

\subsubsection{Multipole Method}

An analytical solution for $\mathrm{R}_{\mathrm{b}}$ based on line source theory was introduced by the Multipole method developed, by Bennet et al. (1987). It assumes that transfer of heat is through conduction and heat flux from each pipe source is constant. A modified version of the 
Fortran 77 source code given in Bennet et al. (1987) was used to find the Multipole resistance. This method represents the pipes in the circular borehole using a series of line heat sources and sinks. It simulates each pipe by representing the pipe with a line source or line sin and subsequently for each line source/link there is atleast one-line source/sink at a mirror point called the zero order multipole as shown in Figure 8. Addition of more line sources/sinks leads to higher ordered multipoles.

In this method, the borehole resistance is obtained by establishing a temperature at the Utube wall and then determining a heat flux and a temperature profile around the circumference of the borehole wall as shown in Figure 8. An average of 180 points along the circumference of the borehole wall was taken to calculate the temperature at the borehole. Averaging 180 points, versus an average of 360 points, gave a difference in temperature less than $0.00001^{\circ} \mathrm{C}$ (Bennet and Claesson, 1987; He, 2012).

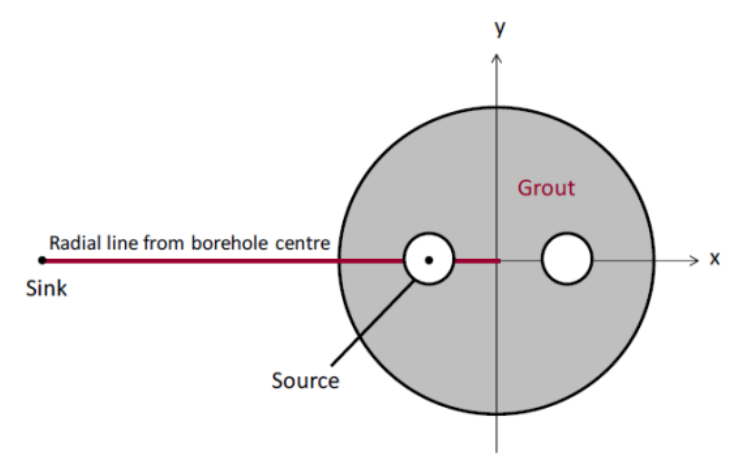

Figure 8:single line source with single line sink

The borehole resistance can be derived by setting a specific temperature for each pipe in the multipole method to estimate the heat flux of each pipe and the average temperature. The expression is as below: 


$$
\begin{aligned}
& \qquad R_{b}=\frac{1}{4 \pi k_{g}}\left[\ln \left(\frac{\lambda_{1} \lambda_{2}^{1+4 \sigma}}{2\left(\lambda_{2}^{4}\right)^{\sigma}}\right)-\frac{\lambda_{3}^{2}\left(1-\left(4 \sigma /\left(\lambda_{2}^{4}-1\right)\right)\right)^{2}}{1+\lambda_{3}^{2}\left(1+\left(16 \sigma /\left(\lambda_{2}^{2}-\frac{1}{\lambda_{2}^{2}}\right)^{2}\right)\right)}\right] \\
& \lambda_{1}=\frac{r_{b}}{r_{n}}, \lambda_{2}=\frac{r_{b}}{0.5 s}, \lambda_{1}=\frac{r_{b}}{s}=\frac{\lambda_{2}}{2 \lambda_{1}}, \sigma=\frac{K_{g}-K_{s}}{K_{g}+K_{s}} \\
& \text { Where }, \mathrm{R}_{\mathrm{b}} \text { is the borehole resistance }(\mathrm{K} . \mathrm{m} / \mathrm{W}), \mathrm{s} \text { is the shank spacing, which defines the } \\
& \text { centre-to centre distance between the two legs of the } \mathrm{U} \text {-tube }, \mathrm{R}_{\mathrm{b}} \text { is the borehole radius (m), } \\
& \mathrm{r}_{\mathrm{p}} \text { is the pipe radius (m), } \mathrm{kg} \text { is the grout thermal conductivity (W/K.m) }
\end{aligned}
$$

\subsubsection{Response Factor Models}

Although analytical models are less suited to design and simulation tasks in cases where time varying heat transfer rates and the influence of surrounding boreholes over long timescales are required to be taken into account although they require less computing effort than numerical approaches and they are suitable for use in the analysis of in-situ thermal response test data. As a result, Response factor models, have been developed to address these issues.

Pre-defined response functions are used to describe the relationship of temperature changes and heat fluxes of BHE fields/arrays in the Response factor models . Hybrid approaches combining the use of analytical and numerical methods are generally adopted for deriving a response functions for pre-defined configurations of BHEs. These models have proved to be highly efficient and have been implemented in both design and simulation software. 


\subsubsection{Long Time Step g-Function Model}

The long time step g-function model was developed by Eskilson (1987) for modelling the BHEs for thermal storage applications. The g-function is a normalized step-response function that describes the relationship between the average borehole temperature and a step in the extraction/rejection for a defined configuration of BHEs. A combination of analytical and numerical techniques is used for its calculation. The two-step process included the following:

- A two-dimensional (radial-axial) finite difference model for a single BHE was constructed for determining its temperature response to a unit step heat pulse.

- The superposition technique was the applied for determining the temperature response to the unit step heat pulse for a pre-defined configuration of multiple BHEs using the temperature distribution of a single borehole obtained in the first step. These temperature responses are then normalized to the so called gfunction.

The g-function is generally defined by discrete set of values that are interpolated in the simulation.

The constant heat extraction rate $\mathrm{Q}(\mathrm{W} / \mathrm{m})$ and constant far-field ground temperature $T_{s}$, the borehole temperature $T_{b}(t)$ can be written as:

$$
T_{b}(t)=T_{s}-Q \cdot R_{q}
$$


where,

$R_{q}=$ time-dependent thermal resistance for a unit heat extraction step, and is written as:

$$
R_{q}=\frac{1}{2 \pi k} \cdot g\left(\frac{t}{t_{s}}, \frac{r_{b}}{H}\right)
$$

where,

$\mathrm{g}\left(\mathrm{t} / \mathrm{t}_{\mathrm{s}}, \mathrm{rb} / \mathrm{H}\right)$ denotes the dimensionless step-response function, called the g-function,

$t_{\mathrm{ss}}=$ steady-state timescale which is determined by the dimensionless time $t / t_{\text {ss }}$ and the ratio of borehole radius $\mathrm{r}_{\mathrm{b}}$ and depth $\mathrm{H}$.

$$
\mathrm{t}_{\mathrm{s}}=\frac{\mathrm{H}^{2}}{9 \alpha}
$$

where, $\alpha=$ ground thermal diffusivity $\left(\mathrm{m}^{2} / \mathrm{s}\right)$.

Rearranging Equation (2.18) and (2.19), the g-function can be expressed as:

$$
g\left(\frac{t}{t_{s}}, \frac{r_{b}}{H}\right)=\frac{2 \pi k \cdot\left(T_{b}(t)-T_{s}\right)}{Q}
$$


In this approach, the complex geometry of a borehole is simplified as a cylinder with a finite length and diameter. The borehole wall temperature is represented by a single temperature. This approach excludes the thermal conductivities and capacities of all the different materials inside a borehole, including fluid, pipes and grout. The solution of the equation is therefore, only valid for time greater than a few hours $\left(t>5 r_{b}^{2} / \alpha\right)$. As a result, this g-function is known as a long time step g-function.

\subsubsection{Short time step g-function Model}

The long-time step g-function model developed by Eskilson (1987) provides an effective solution to simulate borehole fields with defined configurations over long timescales, which range from one month to several years. However, since this method simplifies the borehole geometry and excludes the thermal properties of all the components inside the borehole, it is not suitable for simulation of BHEs on shorter timescales (e.g. hourly), which is an essential requirement for system simulation tasks. In order to expand the application

of the long-time step g-function model, Yavuzturk (1999) developed a two-dimensional numerical model on a polar grid to compute the so-named 'short time step g-function'.

Only half of the borehole was simulated due to its symmetrical geometry. The thermal properties of the materials inside the borehole were modelled, such as the resistance of the pipe and grout due to conduction and the convection resistance due to the flow of the fluid inside the pipes.

The pipe was approximated by cells in a pie-sector instead of explicit modelling. The fluid inside the pipes was also not explicitly modelled so that the heat transfer from the fluid was 
treated by a heat flux boundary condition at the pipe wall. Figure 9 shows the discretization of the borehole geometry on a polar grid .

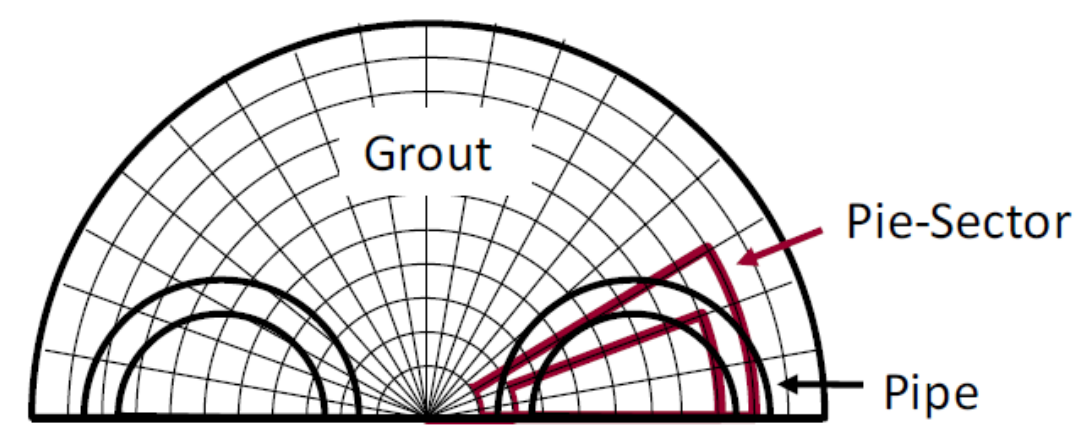

Figure 9:pie sector approximation of borehole

\subsubsection{DST Model}

Hellström (1991) developed the duct storage (DST) model for ground heat storage systems. For multiple BHEs, the model splits the overall ground volume into two regions: the local area and the global area. The storage volume allocated to each specific borehole is the local area. In the local area, there is a heat transfer mechanism between the heat carrier fluid and the borehole wall, which is expressed by the resistance of the borehole. Additionally, the BHEs interact around each borehole with the surrounding ground. The global area is concerned with the issue of heat conduction between the bulk of the volume of storage (the amount of the volume of storage allocated to each borehole) and the surrounding soil. A diagram of the partition of the local and global regions in the DST model is seen in Figure 10. 


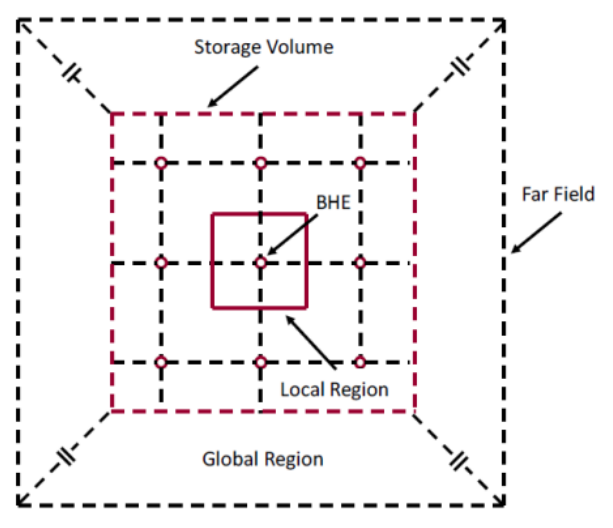

Figure 10:DST Model Representing local and global regions

The heat transfer method of the local area is simplified as a one-dimensional heat transfer problem and a one-dimensional radial mesh has been designed to simulate the transient heat transfer process for brief periods of time. By using the finite difference principle, the variation in temperature at some point in the surrounding region due to the temporary heat transfer mechanism can be measured. To model this steady-flux process for a BHE with different borehole configurations, analytical solutions can be applied, e.g. a single U-tube, double U-tube, concentric tubes, over longer timescales, when the heat flow within the local region reaches a steady-state. There is no heat flux across the boundary of the local area, and the temperature at the border is calculated by superimposing the difference in temperature due to the two adjacent BHEs that share the boundary.

\subsubsection{Discretized Three-Dimensional Numerical Models}

Discrete 3D computational simulation will offer a complete explanation of borehole geometry, recording the dynamic 3D transient heat transfer of BHEs and fluid transportation effects in complete. 


\subsubsection{Vertical BHE Erdwärmesonden (EWS) Model}

In order to simulate the BHE's short time phase transient behaviour, Wetter and Huber (1997) developed the vertical BHE EWS model for BHE with double U-tubes and implemented it in TRNSYS (Type 451). By solving the one-dimensional heat transfer equation in the radial direction using the Crank-Nicholson algorithm, the model was built.The equation can be expressed as follows:

$$
\frac{\partial^{2} T}{\partial r^{2}}+\frac{\partial T}{\partial r}-\frac{1}{\alpha} \frac{\partial T}{\partial t}=0
$$

To solve this equation, the BHE is divided into different layers with variable distances in radial direction (Figure 11).

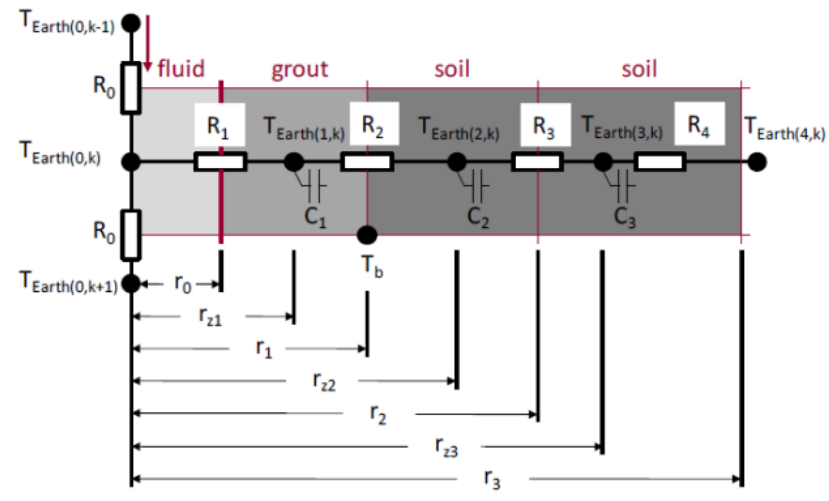

Figure 11:Layered differentiation of BHE in radial direction

$\mathrm{r}_{0}=\mathrm{D}_{\text {in }} / 2=$ inner radius of the pipes

$\mathrm{r}_{1}=\mathrm{D}_{\mathrm{b}} / 2=$ radius of the borehole 


$$
j \geq 2: \quad r_{j}=r_{j-1}+\left(r_{m}-r_{1}\right) \frac{1-f}{1-f^{m-1}} f^{j-2}
$$

where $r_{m}$ is the maximum radius of the simulation area, and $f$ is the grid factor which is defined as:

$$
f=\frac{r_{j+1}-r_{j}}{r_{j}-r_{j-1}}
$$

Applying the Crank-Nicholson scheme for discretization in time, Equation (2.24) can be re-written implicitly:

$$
\begin{gathered}
T_{n+1, j}-\frac{d t}{2} \frac{L_{j}}{C_{j}}\left(T_{n+1, j}-T_{n+1, j}\right)-\frac{d t}{2} \frac{L_{j+1}}{C_{j}}\left(T_{n+1, j+1}-T_{n+1, j}\right) \\
=T_{n . j}+\frac{d t}{2} \frac{L_{j}}{C_{j}}\left(T_{n, j-1}-T_{n, j}\right) \\
+\frac{d t}{2} \frac{L_{j+1}}{C_{j}}\left(T_{n, j+1}-T_{n, j}\right)
\end{gathered}
$$

where 
$\mathrm{n}=$ time coordinate and

$\mathrm{j}=$ radial coordinate.

$\mathrm{C}=$ capacity which is described below:

$$
\begin{gathered}
C_{1}=c_{p, \text { grout }} \rho_{\text {grout }} \pi\left(r_{1}^{2}-4 r_{0}^{2}\right) d l \\
C_{2}=c_{p, \text { soil }} \rho_{\text {soil }} \pi\left(r_{2}^{2}-r_{1}^{2}\right) d l \\
C_{3}=c_{p, \text { soil }} \rho_{\text {soil }} \pi\left(r_{3}^{2}-r_{2}^{2}\right) d l
\end{gathered}
$$

$\mathrm{L}$ is the conductance, which is the reciprocal of a thermal resistance:

$$
L=\frac{1}{R}=\frac{Q}{\Delta T}
$$

And the thermal resistance of the grout and the ground are:

$$
\begin{gathered}
R_{1}=\frac{1}{4} \frac{1}{2 \pi d l}\left(\frac{1}{\alpha r_{0}}+\frac{1}{k_{\text {grout }}} \ln \frac{r_{1}-r_{z 1}}{r_{0}}\right) \\
R_{2}=\frac{1}{2 \pi d l}\left(\frac{1}{k_{\text {grout }}} \ln \frac{r_{1}}{r_{z 1}}+\frac{1}{k_{\text {soil }}} \ln \frac{r_{z 2}}{r_{1}}\right) \\
R_{3}=\frac{1}{2 \pi d l} \frac{1}{k_{\text {soil }}} \ln \frac{r_{z 3}}{r_{z 2}} \\
R_{4}=\frac{1}{2 \pi d l} \frac{1}{k_{\text {soil }}} \ln \frac{r_{3}}{r_{z 3}}
\end{gathered}
$$


In the vertical direction, the BHE is divided into layers with equal distance (Figure 12)

$$
d l=\frac{\text { borehole length }}{\text { DimAxi }}
$$

From the energy balance upwards and downwards in each vertical sheet, the fluid temperature is determined. The fluid temperature is then used as the limiting condition for simulating the thermal transition from the fluid to the ground in the extreme direction stated above.

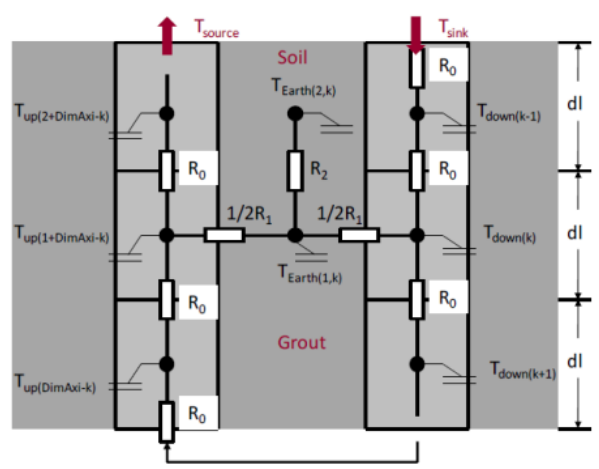

Figure 12:Layered differentiation of BHE in vertical direction

The energy balance for each element gives:

$$
\begin{aligned}
T_{\text {down }(k, n)}= & T_{\text {down }(k, n-1)}+\left(T_{\text {down }(k-1, n)}-T_{\text {down }(k, n-1)}\right) \frac{L_{0} d t}{m c_{p}} \\
& +T_{\text {earth }(k, n-1,1)}-T_{\text {down }(k, n-1)} \frac{L_{1} d t}{2 m c_{p}}
\end{aligned}
$$

And 


$$
\begin{gathered}
T_{u p(k, n)}=T_{u p(k, n-1)}+\left(T_{u p(k-1, n)}-T_{u p(k, n-1)}\right) \frac{L_{0} d t}{m c_{p}} \\
+T_{\text {earth }(1+\text { DimAxi-k,n-1,1) }}-T_{u p(k, n-1)} \frac{L_{1} d t}{2 m c_{p}}
\end{gathered}
$$

With boundary condition

$$
\begin{gathered}
T_{\text {down }(0, n)}=T_{\text {sink }} \\
T_{u p(0, n)}=T_{\text {down(DimAxi,n })} \\
T_{\text {source }}=T_{u p(\operatorname{DimAxi}, n)}
\end{gathered}
$$

Where $\mathrm{L}_{0}$ is defined as:

$$
L_{0}=c_{p, f} \dot{m}=2 \pi r_{0}^{2} v \rho_{f} c_{p, f}
$$

By solving these equations in direction of the flow, the temperature of the fluid can be calculated.

The temperature profile at the exterior limits can be calculated by the use of the analytical source line solution with the pre-defined boundary for the simulation area, i.e. at a range of 2 meters across the borehole, beginning at different times by superimposing constant heat flux. (Ignersoll et al., 1954). The discretization process as seen in Figure 13. 


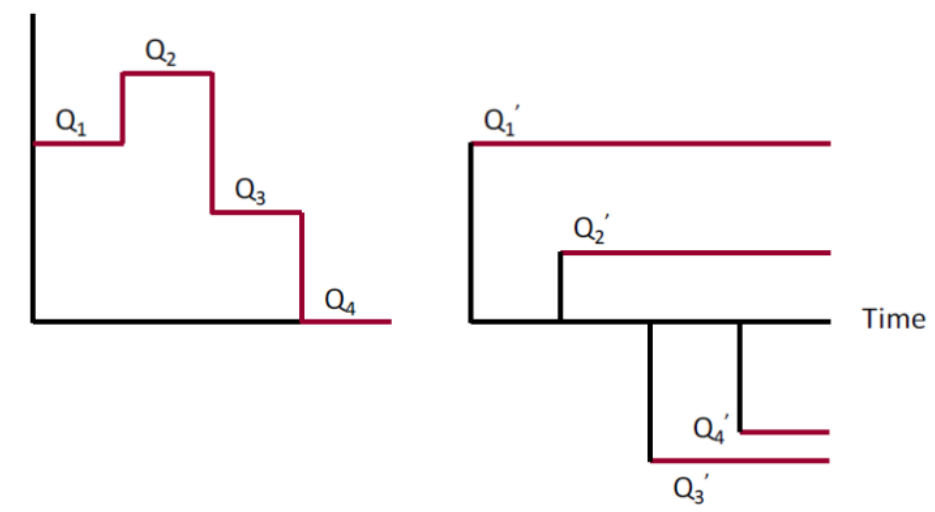

Figure 13:Discretization of variable heat flux to constant heat flux

The EWS model can only simulate a single BHE. The end effect is neglected. The grout is regarded as one element.

\subsubsection{Capacity Resistance Model}

De Carli et al. (2001) developed the Capacity Resistance Model (CaRM) to simulate thermal activity of BHEs by the adoption of an electrical parallel method with lumped capacity and thermal resistance.

The BHE 's surrounding ground is broken up by a number of radial ringed (n) regions and vertically by a number of (m) slices. The heat transfer from the floor is only expected to happen radially, because there is no vertical distribution of heat between layers. There is also a one-dimensional heat conduction problem in each layer for the heat transfer of the soil. 


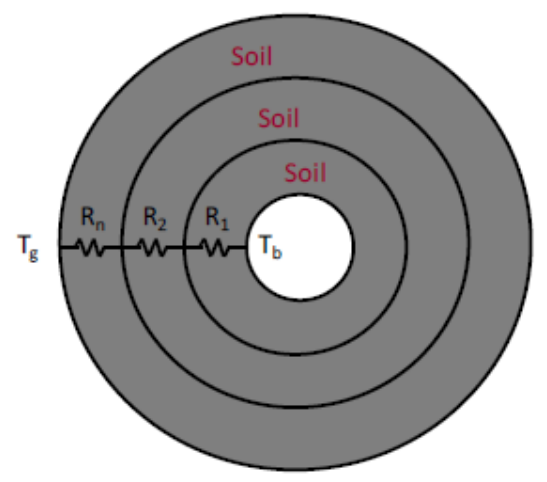

Figure 14:Heat Transfer process with electrical analogy in ground

For each slice, the heat conduction equation can be written as:

$$
\frac{T_{t, k, j-1}-T_{t, k, j}}{R_{k, j-1}}+\frac{T_{t, k, j+1}-T_{t, k, j}}{R_{k, j}}=\mathrm{C}_{\mathrm{k}, \mathrm{j}} \cdot \frac{T_{t, k, j}-T_{t-1, k, j}}{\Delta \tau}
$$

with the boundary condition: $T_{t, k, n}=T_{g}$; where $R_{k, j}$ is the thermal resistance between two adjacent annular regions, which can be calculated:

$$
R_{k, j}=\frac{1}{2 \pi L . k} \ln \frac{\sqrt{\left(r_{k, j}^{2}-r_{k, j-1}^{2}\right) / 2}}{\left(r_{k, j-1}^{2}-r_{k, j-2}^{2}\right) / 2}
$$

and $\mathrm{C}_{\mathrm{k}, \mathrm{j}}$ is the thermal capacity, which is calculated as :

$$
C_{k, j}=\rho c_{p} \cdot \pi \cdot\left(r_{k, j}^{2}-r_{k, j-1}^{2}\right) \cdot \Delta z_{k}
$$


where $r$ is radius. The subscript $k$ indicates the vertical orientation of the slice number, $j$ denotes the radial ring area number and $t$ shows the ring area number time step.

Various arrangements of borehole pipes, such as single $\mathrm{U}$ tube, dual $\mathrm{U}$ tubes and coaxial pipes can be simulated. The thermal resistance between pipe and pipe and between pipe and borehole wall (Figure 15) explains heat equations between fluid and the boiling wall. In the CaRM model the thermal resistors of BHE of various configurations can be interpreted, but from another Finite Element model it must be measured.
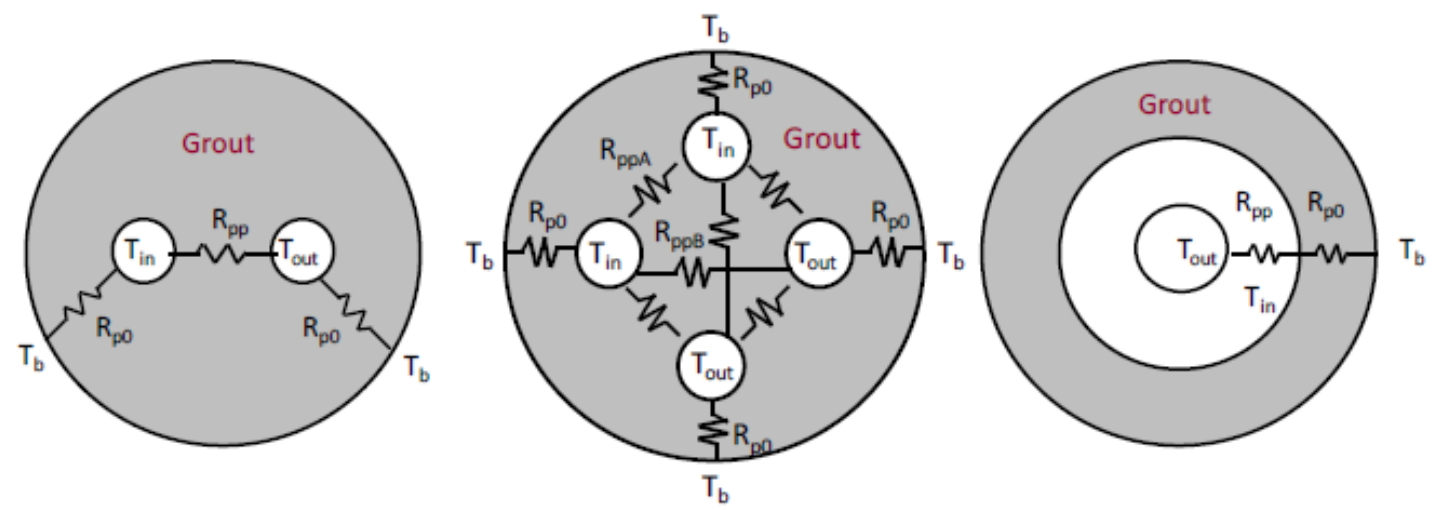

Figure 15:Bore hole resistance for single u-tube, double u-tube and coaxial u-tube

\subsection{SUMMARY}

This chapter briefly introduced heat pumps and described their working cycles, i.e. cooling cycle and heating cycle. Different types of heat pumps, viz., air source heat pumps and ground source heat pumps were also discussed. This chapter also provided an overall review of the existing BHE models. Four different categories of BHE models were discussed, viz., analytical models, steady state borehole models, response factor models and discretized numerical models. 
By making a number of various simplifying assumptions, analytical models have been developed and have been applied to both the design of BHEs and the analysis of in situ test results. Ignoring the geometry and thermal ability of the components in the borehole is one of the most common assumptions. Therefore, analytical models are not appropriate for short timescale applications where the heat transfer mechanism can be controlled by the transient heat transfer inside the borehole. The other common assumption is that the borehole should be assumed to be infinitely deep. As a consequence, the heat transfer below the BHEs cannot be taken into account. This theory also makes analytical models unsuited for multi-annual simulations.

While analytical solutions require less computational effort, they are less suitable for tasks of design and simulation where time-varying heat transfer rates and the effect of nearby boreholes on long time scales are to be taken into account. There was no precise representation of heat transfer inside a borehole, but instead a thermal resistance was used to describe the relationship between the temperatures of the fluid and the borehole wall. The fluid, pipes and grout thermal mass were ignored.

Two-dimensional discrete models provide detailed representation of the geometry of the borehole and allow accurate consideration of the thermal properties of the pipes and grout. However, as fluid temperature variance with depth cannot be directly simulated, assumptions have to be made regarding the fluid temperatures in the two pipes and the boundary conditions associated with them.

Several three-dimensional discretized models have been developed to provide a more general and more accurate heat transfer around BHEs. for example, the CaRM Model and 
the EWS Model was developed using de-coupling and coupling. Although using a threedimensional discrete model to simulate the heat transfer of the surrounding ground is simple and straightforward, some simplifications have been made for the heat transfer inside the borehole so that a one-dimensional model can be used.

Several advantages of a three-dimensional model for BHEs can be found, including: -

- transport of fluid can be represented;

- heat transfer and temperature characteristics along the borehole depth can be modelled;

- varied boundary conditions can be used to numerically simulate the model

In this study, a fully-discretized 3D model for BHEs has been developed for the following reasons:

- To study the heat transfer characteristics of the BHE in 3D with the least computational power and effort.

- To simplify the discretization process for the 3D BHE model. The current CFD techniques, employ the use of tetrahedral mesh or cut-cell mesh for discretization process of the geometry, which increase the cell count as the computational power required.

- To reduce the cell count for discretizing the geometry by using polyhedral mesh and hexahedral mesh.

- To study the effect of grid size on the result of the numerical simulation.

- To study the effect of mesh type on the numerical simulation. 
- To study the effect of various turbulence models on the solution.

- Variation of inlet velocity on the outlet temperature of the solution.

- To reduce the dependence on CFD for designing a BHE.

- Discuss the various methodologies through which the heat transfer rate can be enhanced. 


\section{CHAPTER 3 \\ DEVELOPMENT OF THE THREE-DIMENSIONAL MODEL AND ITS VALIDATION}

The project aims to solve the conjugate heat transfer problem in the borehole heat exchanger. For this purpose, a 3D model of the single U-tube vertical borehole heat exchanger having non-conformal mesh has been created using a finite volume solver based meshing technique with a semi-implicit solver being used for simulation of the system. This chapter focuses on the development of a 3D model of a vertical single U-tube borehole heat exchanger and the process of discretization used for each component of the BHE and the subsequent validation of the numerical simulation. This chapter also discusses the various heat transfer characteristics in and around the BHE, and on successful simulation

of the system in the finite volume-based solver. The simulation of the $3 \mathrm{D}$ model tends to ignore the assumptions made in various models described in the literature review of the borehole heat exchanger models. The 3D model tends to be more accurate as it considers, the flow of the fluid inside the pipe with various circulating velocities of the fluid. The motive of solving the problem using the three-dimensional model was because of the following reasons: -

- 3D models tend to give more realistic and accurate approach towards solving the problem.

- The 2D models does not consider the flow of the fluid inside the pipe, and as such are only valid for validating the analytical solutions.

- $3 \mathrm{D}$ models consider the entire geometry of the system for simulating the numerical results, and as such the heat transfer characteristics of the domain, grout, pipe and the fluid are attained. 
The 3D model is validated with both the experimental data and numerical simulation results in this chapter. Also, the thermal resistances are compared to the analytical solutions. The $3 \mathrm{D}$ model is validated with the steady state $3 \mathrm{D}$ simulation results from the $3 \mathrm{D}$ study performed by He, M., 2012 and with the experimental results from Pu.et al ,2014.

\subsection{Development of 3D Model}

Since the geometry of the 3D model is highly complex, because of the large dimensions, there is no analytical solution that considers the entire geometry of the heat exchanger along with the boundary conditions, as a result of which, the available analytical solutions require less computational power and effort. Analytical models like the line source theory and cylinder source theory, ignore the geometry of the BHE along with the thermal properties of the fluid, pipe, grout and the domain as well, therefore, these models are not suitable for transient simulations where, detailed temperature and other variations of the heat exchanger are needed. Also, since the line source theory considers the heat transfer characteristics in the radial direction, the heat transfer characteristics along the length of the BHE are not ascertained.

In order to simulate the $3 \mathrm{D}$ model of the single U-tube vertical BHE and the surrounding domain, the determination of the geometry and the boundary conditions for running the simulation is the most important step. Then in the next stage, the discretization of the geometry using a suitable software and then to subsequently perform the numerical simulation. Finally, the simulation results are validated with the said references earlier. 

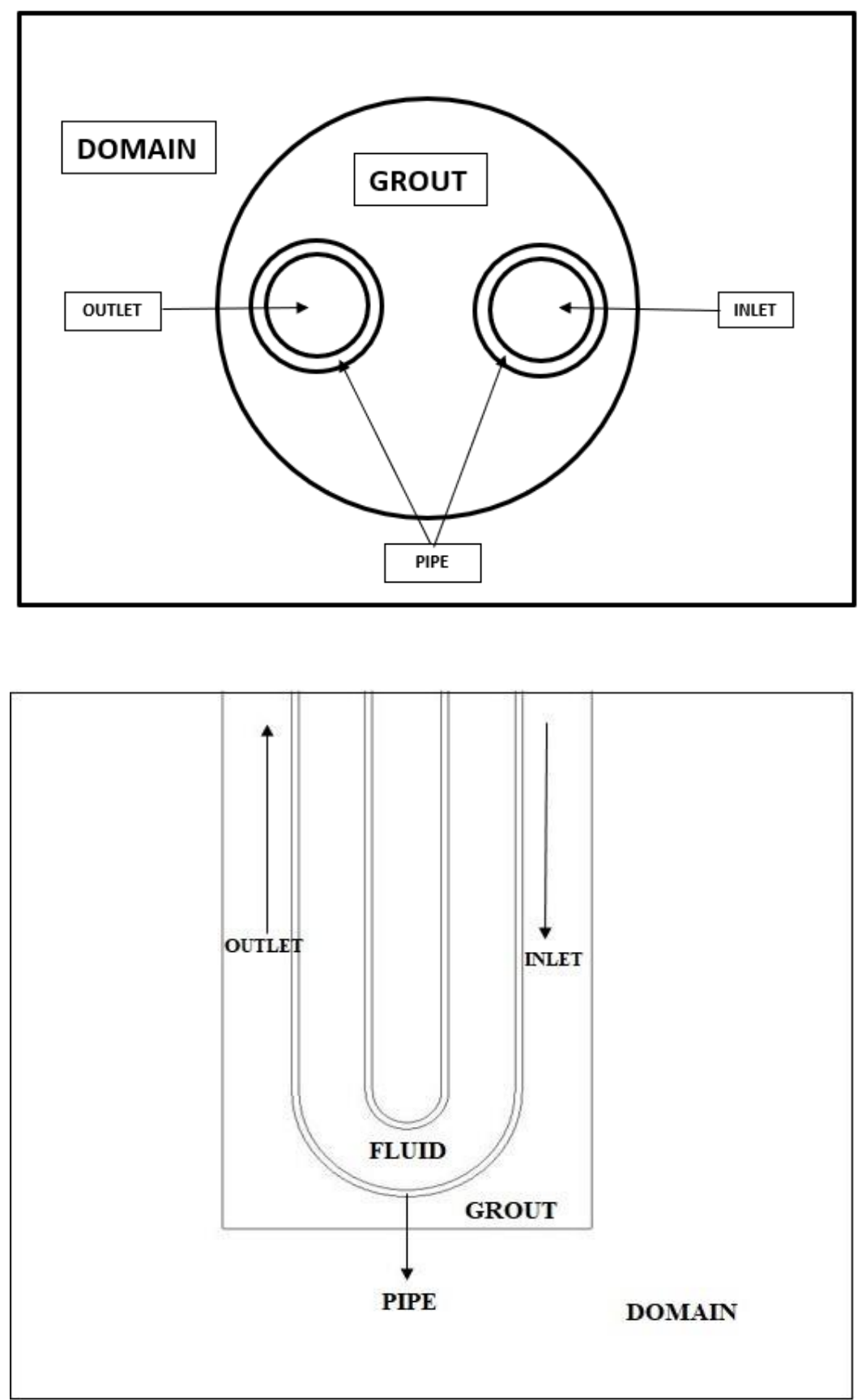

Figure 16: Schematic Diagram of Single U-Tube Vertical BHE 


\subsubsection{Development of 3D Geometry}

The 3D geometry of the Borehole Heat Exchanger along with the simulation domain was created using ANSYS SpaceClaim Design Modeler 2019 R1, which is an embedded CAD software within ANSYS.

Due to the symmetrical geometry of the heat exchanger only half of the BHE is modeled. This has been done to significantly reduce the computational power required to simulate the BHE. Figures $16 \& 17$ shows the fully assembled BHE along with the simulation domain, whereas Figures 18-21 shows the geometry all the components of the BHE. Table 2 shows the dimensions of the various components of the BHE.

Table 2:Dimensional Configuration of BHE

\begin{tabular}{|l|c|c|}
\hline \multicolumn{1}{|c|}{ Part } & Dimension & Unit \\
\hline Diameter of Fluid Section & 27.4 & $\mathrm{~mm}$ \\
\hline $\begin{array}{l}\text { Length of Fluid Straight } \\
\text { Section }\end{array}$ & 99.938 & $\mathrm{~m}$ \\
\hline Pipe Inner Diameter & 27.4 & $\mathrm{~mm}$ \\
\hline Pipe Outer Diameter & 33.4 & $\mathrm{~mm}$ \\
\hline Shank Spacing & 34.53 & $\mathrm{~mm}$ \\
\hline Diameter of Grout & 152.4 & $\mathrm{~mm}$ \\
\hline Length of Borehole & 100 & $\mathrm{~m}$ \\
\hline $\begin{array}{l}\text { Length of Simulation } \\
\text { Domain }\end{array}$ & 120 & $\mathrm{~m}$ \\
\hline $\begin{array}{l}\text { Cross-sectional Dimension } \\
\text { of Domain }\end{array}$ & $2 \times 4$ & $\mathrm{~m}$ \\
\hline
\end{tabular}

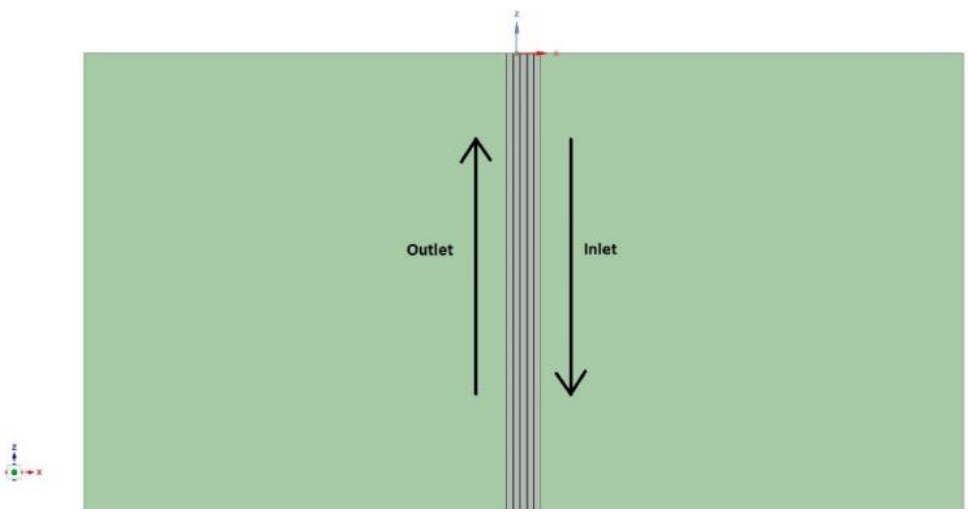




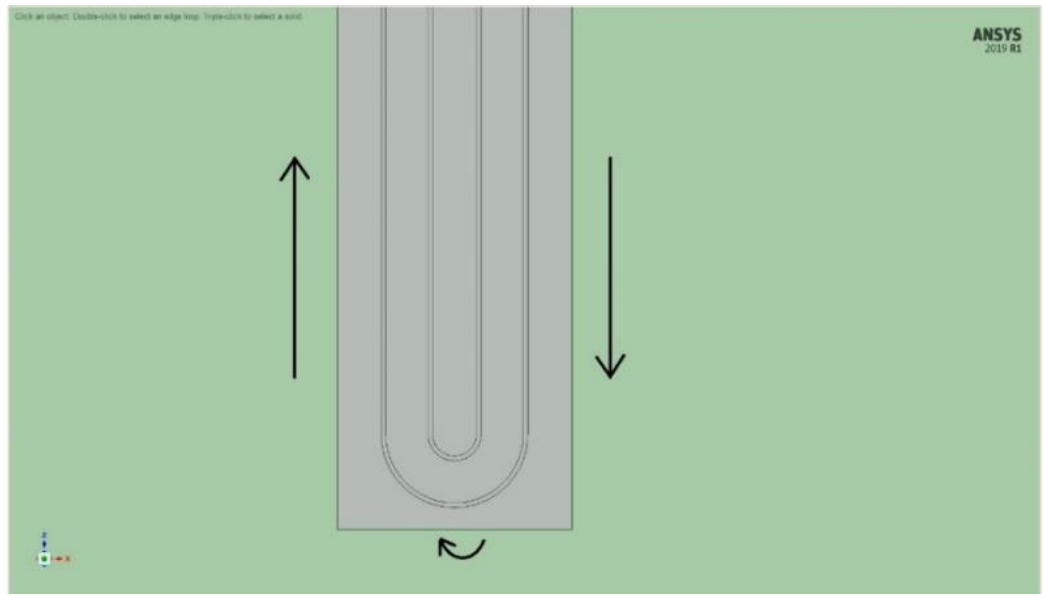

Figure 17:Geometry of the entire structure with the direction of flow indicated

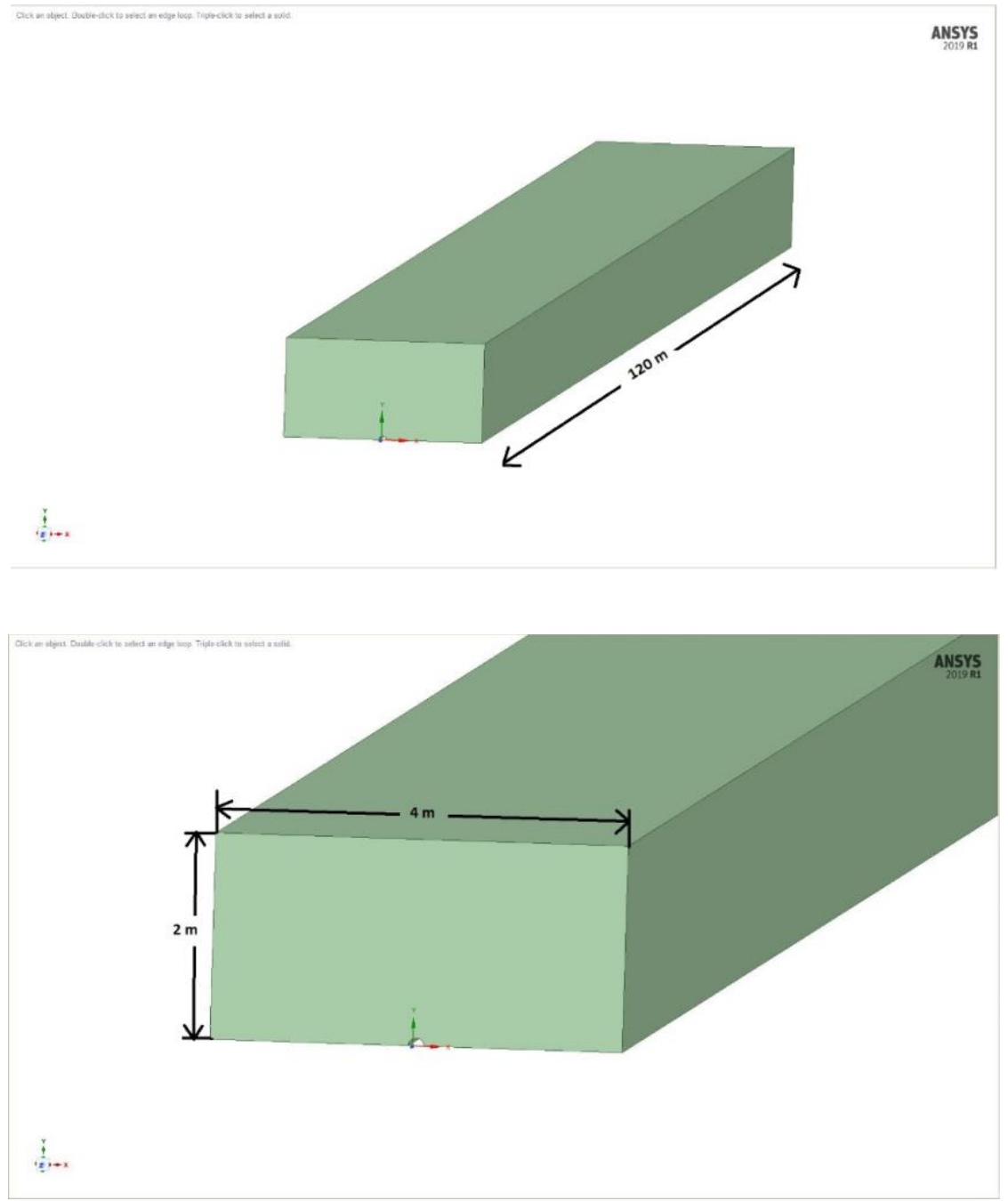




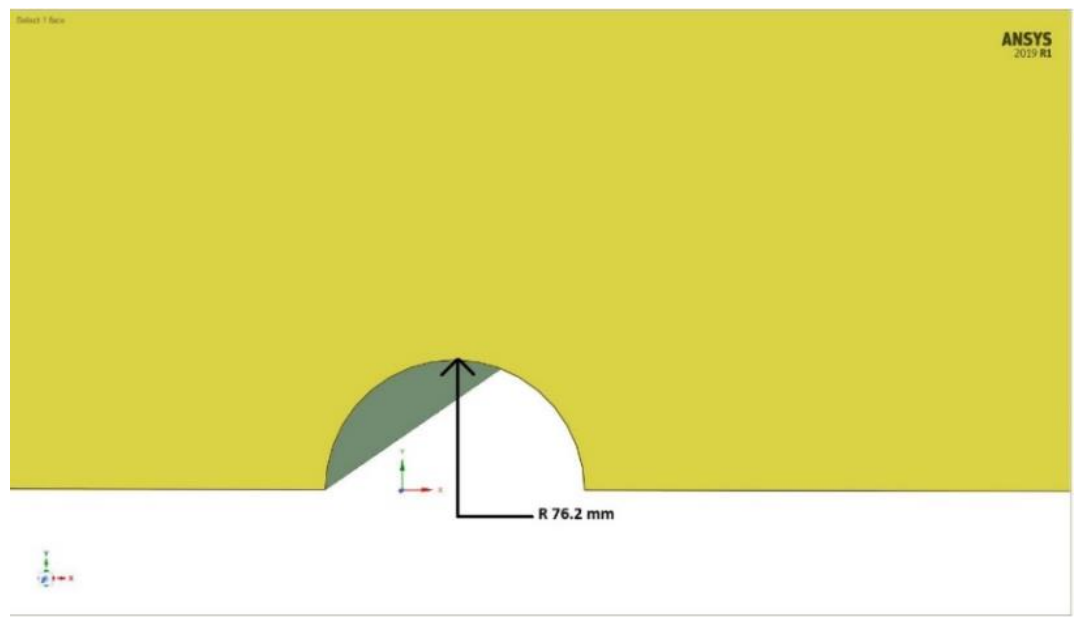

Figure 18:Geometry of the Domain

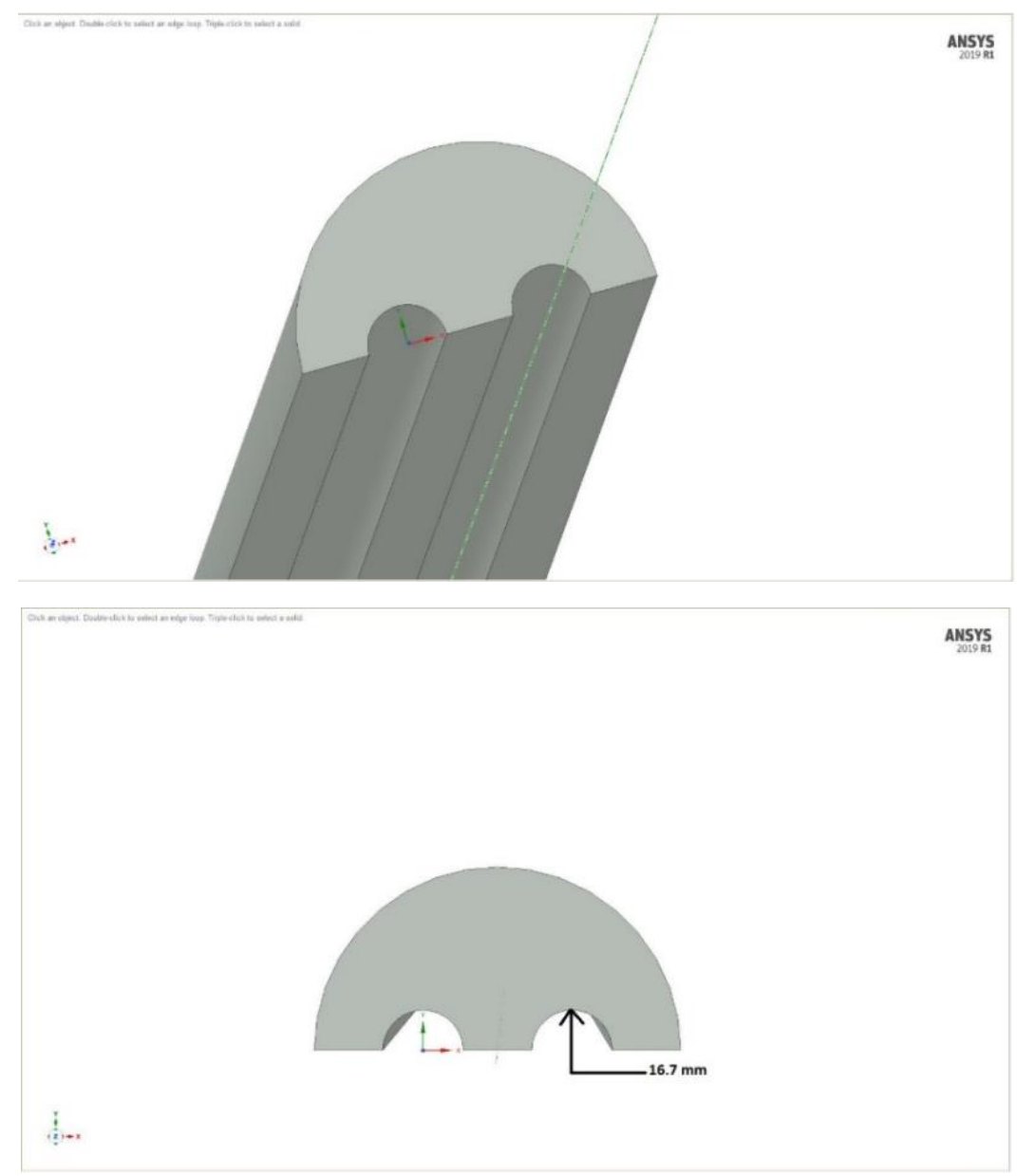

Figure 19:Geometry of the Grout 


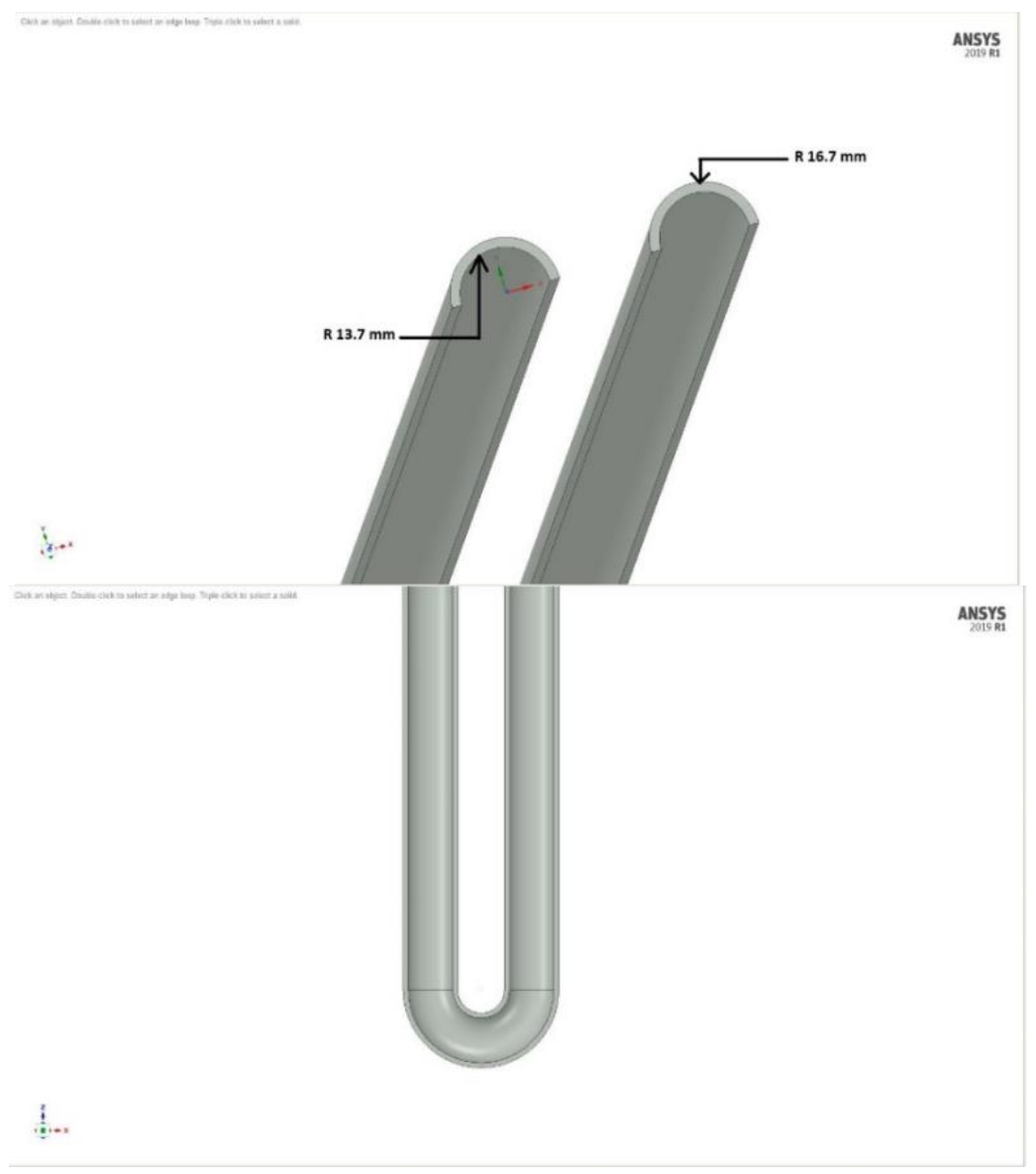

Figure 20: Geometry of the Pipe

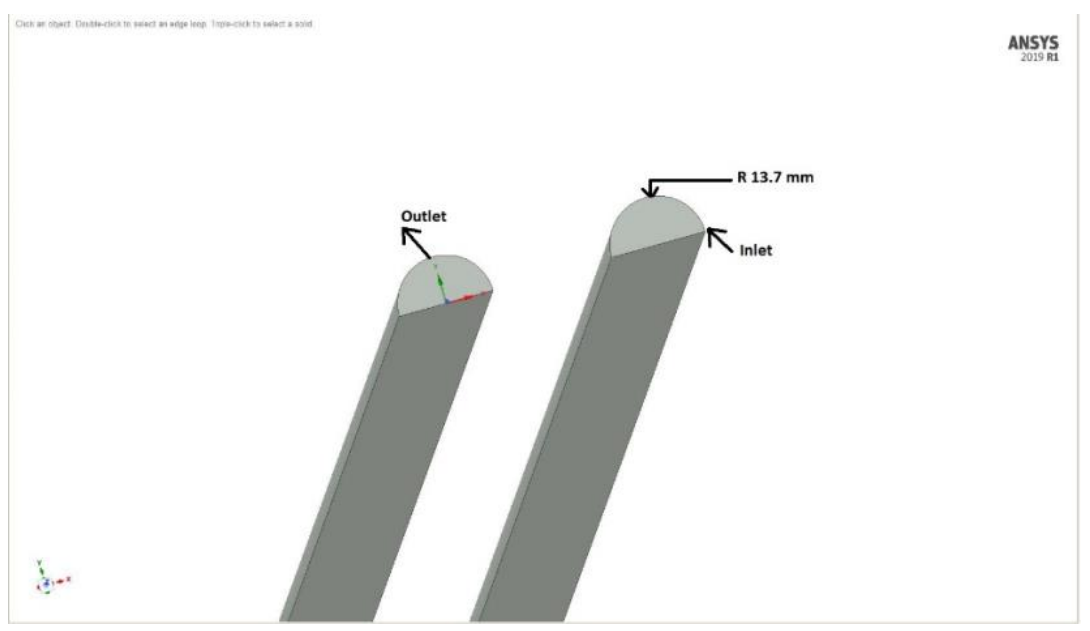




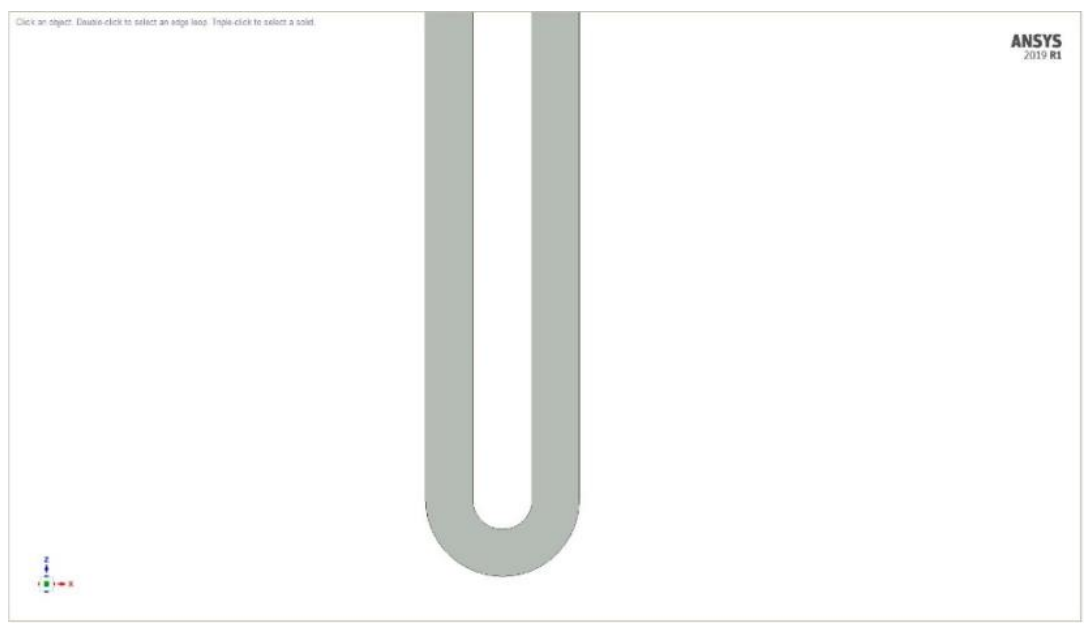

Figure 21:Geometry of the Fluid domain

\subsubsection{Discretizing of 3D Geometry}

The 3D geometry created for the simulation was divided into a number of cells. Two types of mesh with four different mesh sizes was used to create the mesh of the geometry of the BHE and the domain. ANSYS Fluent Mesher was used to create unstructured polyhedral mesh of three different mesh sizes and ANSYS Workbench Mesher was used to create the structured coarse hexahedral mesh. Both the mesh types were non-conformal since the geometry is complex in terms of edges and curves present.

The ideology used in mesh generation was that, lesser number of cells were used along the length of the borehole and a greater number of cells were used to discretize the geometry in the radial direction while creating the hexahedral mesh. This method was adopted because the heat transfer is more predominant in the radial direction than in the longitudinal section. Whereas, in the generation of the unstructured polyhedral mesh, the ideology adopted was to reduce the cell count of the mesh while keeping the number of nodes intact as it is known that ANSYS Fluent is a cell-based solver. So, the lesser the number of cells, the lesser is the computational power required for the numerical solution. 


\subsubsection{Discretizing of Domain}

The hexahedral mesh of the domain was created using ANSYS Workbench Mesher 2019 R1. The hexahedral mesh was coarse, wherein the number of cells across the domain and also along the length was kept at minimum. For discretizing the domain, 10 cells were used to divide the width of the domain, whereas 10000 cells were used to divide the domain along the length of the domain. As such each cell across the width of the domain measured $0.4 \mathrm{~mm}$ while each cell along the length of the domain measured $12 \mathrm{~mm}$.

The polyhedral mesh for the domain that was created using ANSYS Fluent Mesher, was used for all the three different polyhedral mesh sizes. The minimum local and global size that was used for meshing were fixed at 12 cells, whereas the maximum local and global size of the cells were fixed at 3000 cells. The growth rate was kept at default size of 1.2. Furthermore, the number of cells per gap for capturing the proximity was set to default size of 3 . The size of the poly mesh of the domain was kept same for all poly mesh test cases. Figures 22 shows the hex mesh of the domain while Figure 23 shows the poly mesh of the domain.

Table 3:Mesh Type and Cell Count for Domain

\begin{tabular}{|l|l|l|l|l|l|}
\hline $\begin{array}{l}\text { Component } \\
\text { Name }\end{array}$ & $\begin{array}{l}\text { Hexahedral } \\
\text { Mesh }\end{array}$ & $\begin{array}{l}\text { Polyhedral } \\
\text { Mesh with } \\
\text { coarse } \\
\text { refinement }\end{array}$ & $\begin{array}{l}\text { Polyhedral } \\
\text { Mesh } \\
\text { medium } \\
\text { Refinement }\end{array}$ & $\begin{array}{l}\text { Polyhedral } \\
\text { Mesh fine } \\
\text { Refinement }\end{array}$ & $\begin{array}{l}\text { Prism } \\
\text { cells }\end{array}$ \\
\hline Domain & 0.22 million & $\begin{array}{l}0.485 \\
\text { million }\end{array}$ & 0.485 million & 0.485 million & No \\
\hline
\end{tabular}




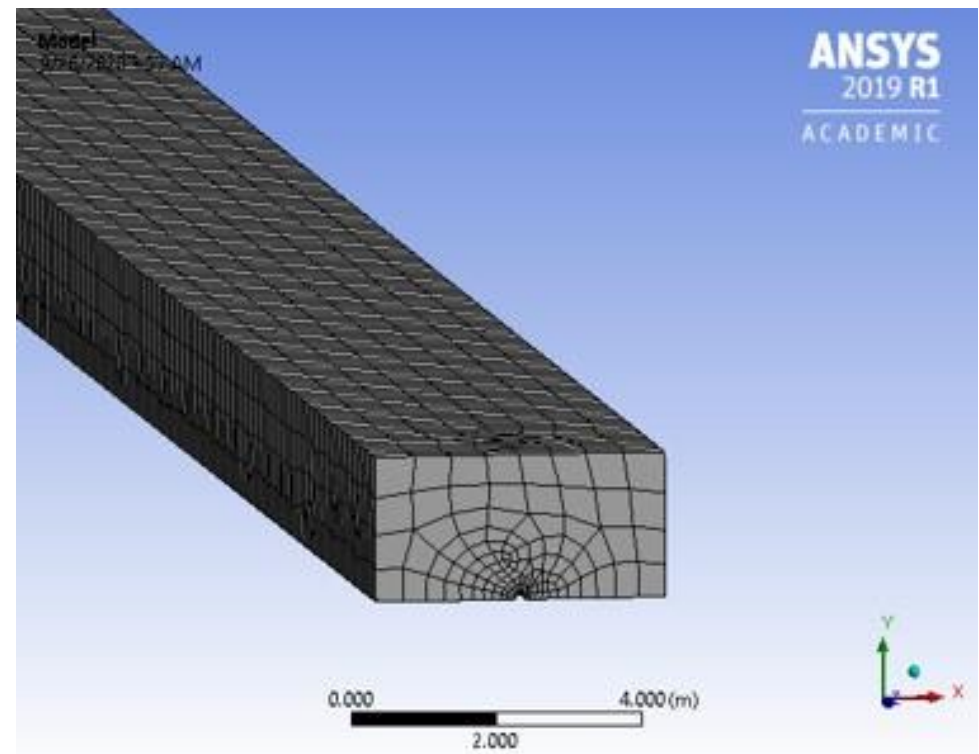

Figure 22:Hexahedral Mesh for Domain
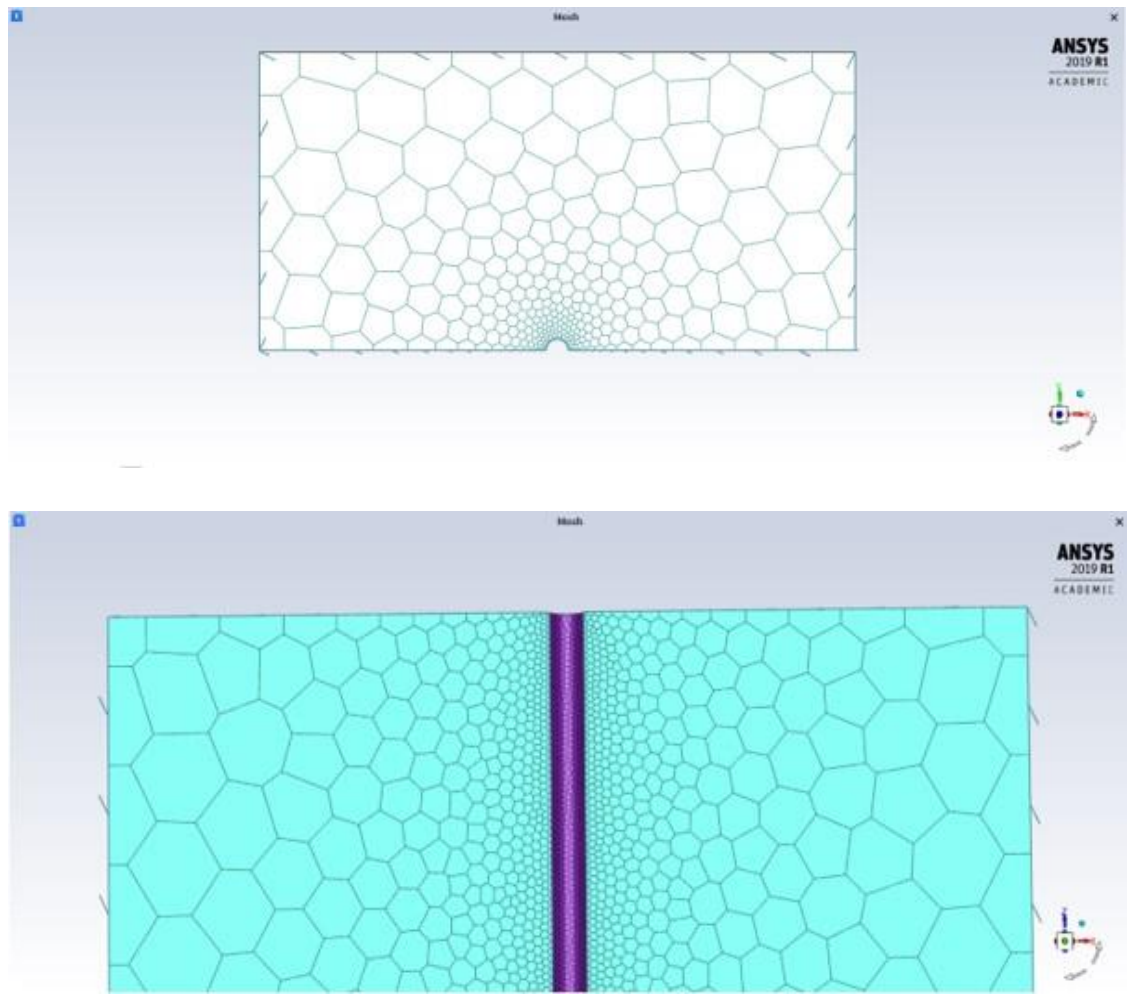


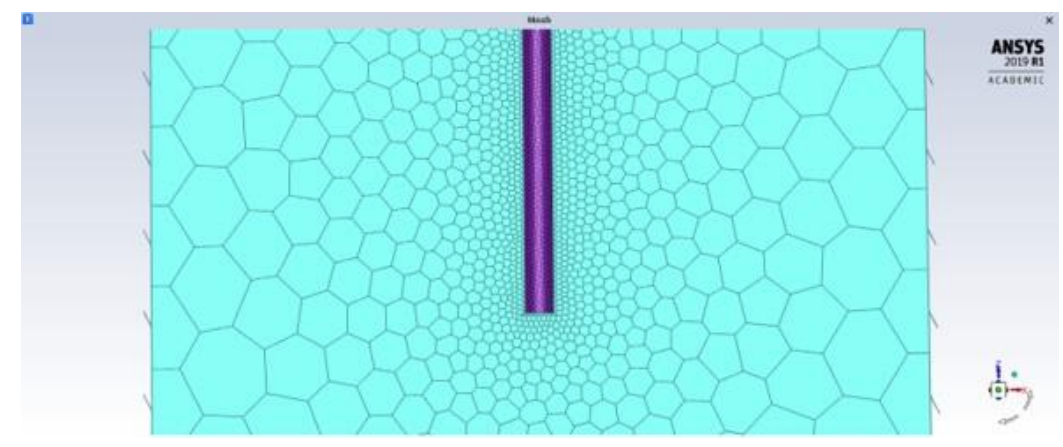

Figure 23:Polyhedral Mesh of Domain

\subsubsection{Discretizing of Grout}

Like the hexahedral mesh of the domain, the hexahedral mesh of the grout was created using ANSYS Workbench Mesher 2019 R1. The hex mesh of the grout was coarse and the cell count in the radial direction and as well as the longitudinal direction was kept at a minimum number. The default meshing parameters of the grout was set to default, whereas the proximity and curvature were both used in the discretizing process. All curved edges of the grout were divided into 10 cells each, whereas the number of cells along the length of the grout was divided into 10000 cells.

Again, like the polyhedral mesh of the domain, the polyhedral mesh of the grout created was used for all the three polyhedral mesh sizes in the grid independence study. In the poly mesh, the global and local cell size that was used was 7.5, while the maximum local and global cell size used was 100, whereas the growth rate was kept at 1.2. The number of cells per gap used to capture the proximity was 10 cells while the cells per gap used to capture the curvature was set at 3 . The size of the poly mesh of the grout was kept the same for all the poly mesh test cases. Table 4 shows the mesh sizes for different mesh types for the grout. Figure 24 shows the hex mesh whereas Figure 25 shows the poly mesh of the grout. 
Table 4:Mesh Type and Cell Count for Grout

\begin{tabular}{|l|l|l|l|l|l|}
\hline $\begin{array}{l}\text { Component } \\
\text { Name }\end{array}$ & $\begin{array}{l}\text { Hexahedral } \\
\text { Mesh }\end{array}$ & $\begin{array}{l}\text { Polyhedral } \\
\text { Mesh } \\
\text { coarse } \\
\text { Refinement }\end{array}$ & $\begin{array}{l}\text { Polyhedral } \\
\text { Mesh } \\
\text { medium } \\
\text { Refinement }\end{array}$ & $\begin{array}{l}\text { Polyhedral } \\
\text { Mesh fine } \\
\text { Refinement }\end{array}$ & $\begin{array}{l}\text { Prism } \\
\text { cells }\end{array}$ \\
\hline Grout & 1.01 million & 1.57 million & 1.57 million & 1.57 million & No \\
\hline
\end{tabular}
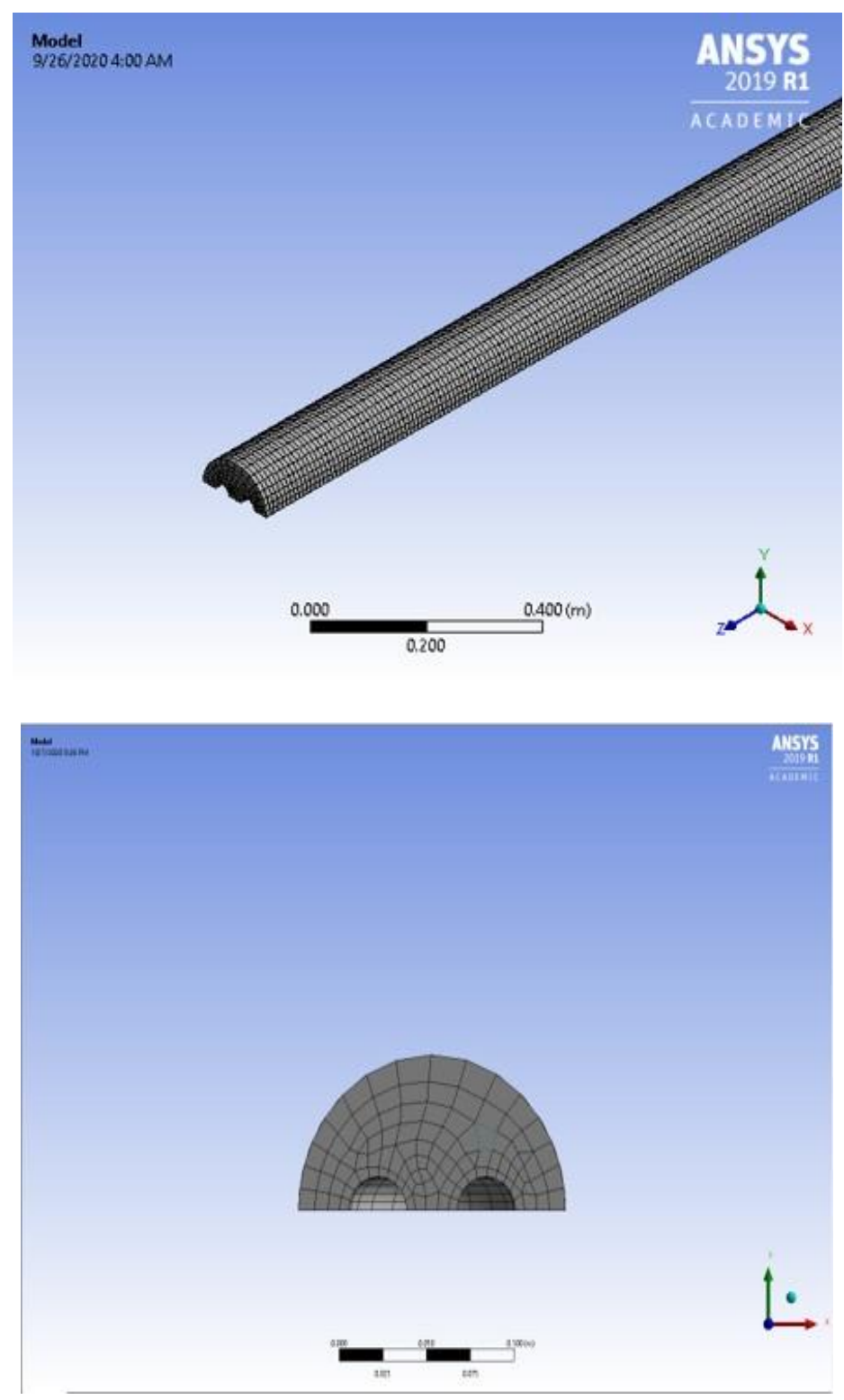

Figure 24:Hexahedral Mesh for Grout 

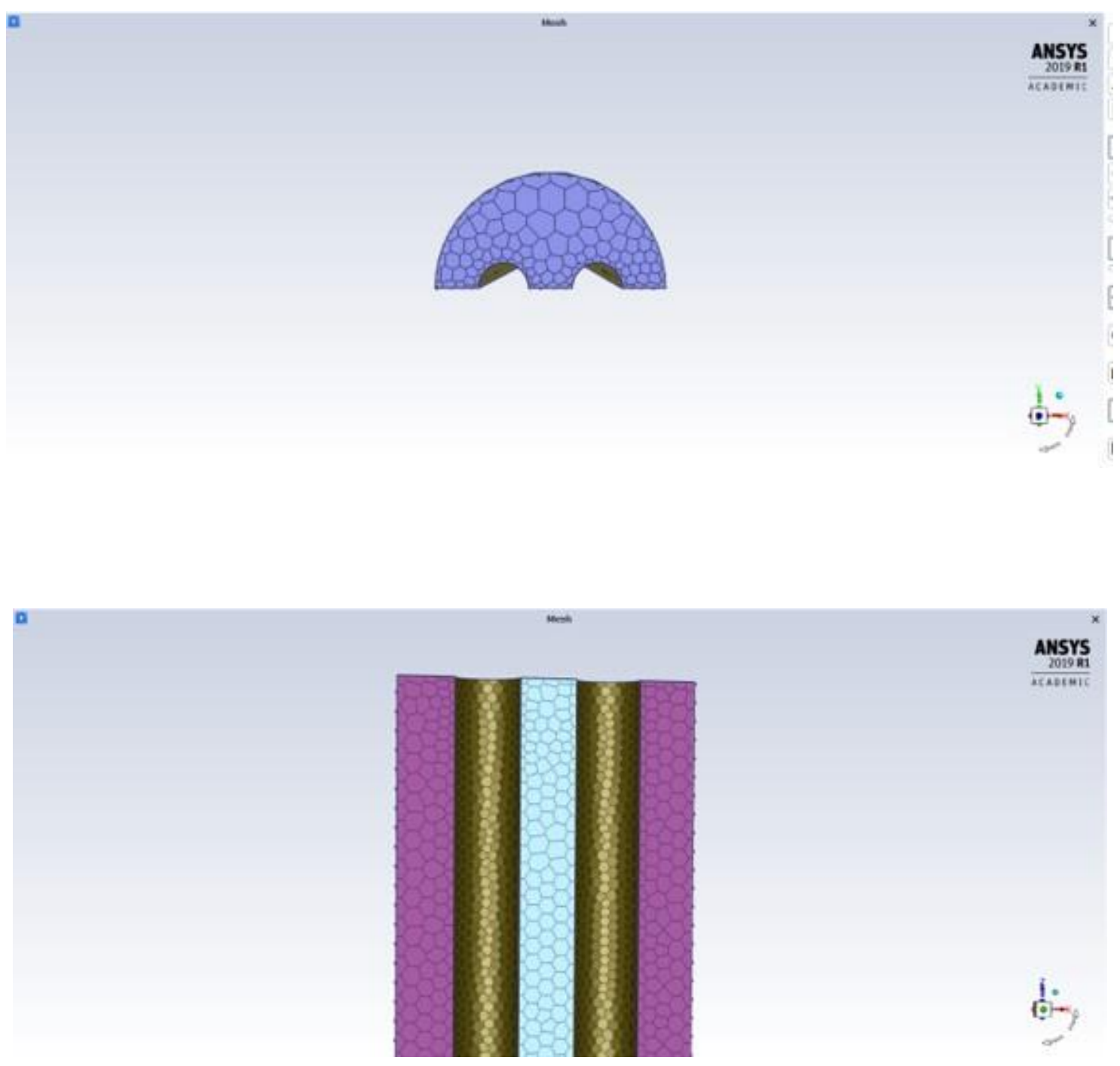

Figure 25:Polyhedral Mesh of Grout

\subsubsection{Discretizing of Pipe}

The hexahedral mesh of the pipe was created using ANSYS Workbench 2019R1 mesher.

The curved edges of the pipe were discretized by 15 cells, whereas the thickness of the pipe was discretized by 3 cells. The length of the pipe was divided by 10000 cells. All other setting in the meshing mode was set to default with only proximity and curvature being captured along with the smoothing being set to high. 
The polyhedral mesh of the pipe that was used for the coarse and medium refined test case was created using ANSYS Fluent Mesher 2019R1. The minimum local and global cell size was kept at 5.5 while the maximum local and global cell size was fixed at 100 . The growth rate of the cells was kept at 1.2 while the cells per gap to capture the proximity was set 3 .

Subsequently, the mesh of the pipe created for the finely refine test case was created using refined mesh controls, where the minimum local and global cell size were set to 2.5, whereas the maximum local and global cell size were set to 100 . The other size controls were set to default. However, the number of cells to capture the proximity on the object faces and edges was set to 12 cells per gap. The mesh size for the coarse and medium refined poly mesh for the pipe was kept the same keeping up with the computational standards for discretizing the pipe in fluid-pipe flow as minimum. Figure 26 shows the hex mesh of the pipe, while Figure 27 shows the poly mesh for coarse and medium refined poly mesh and Figure 28 shows the finely refined poly mesh for the pipe.

Table 5 shows the number of cells for the Pipe generated and the mesh type that was employed.

Table 5:Mesh Type and Cell Count for Pipe

\begin{tabular}{|l|l|l|l|l|l|}
\hline $\begin{array}{l}\text { Component } \\
\text { Name }\end{array}$ & $\begin{array}{l}\text { Hexahedral } \\
\text { Mesh }\end{array}$ & $\begin{array}{l}\text { Polyhedral } \\
\text { Mesh with } \\
\text { coarse } \\
\text { Refinement }\end{array}$ & $\begin{array}{l}\text { Polyhedral } \\
\text { Mesh } \\
\text { medium } \\
\text { Refinement }\end{array}$ & $\begin{array}{l}\text { Polyhedral } \\
\text { Mesh fine } \\
\text { Refinement }\end{array}$ & $\begin{array}{l}\text { Prism } \\
\text { cells }\end{array}$ \\
\hline Pipe & 1.31 million & 0.95 million & 0.95 million & 4.5 million & No \\
\hline
\end{tabular}



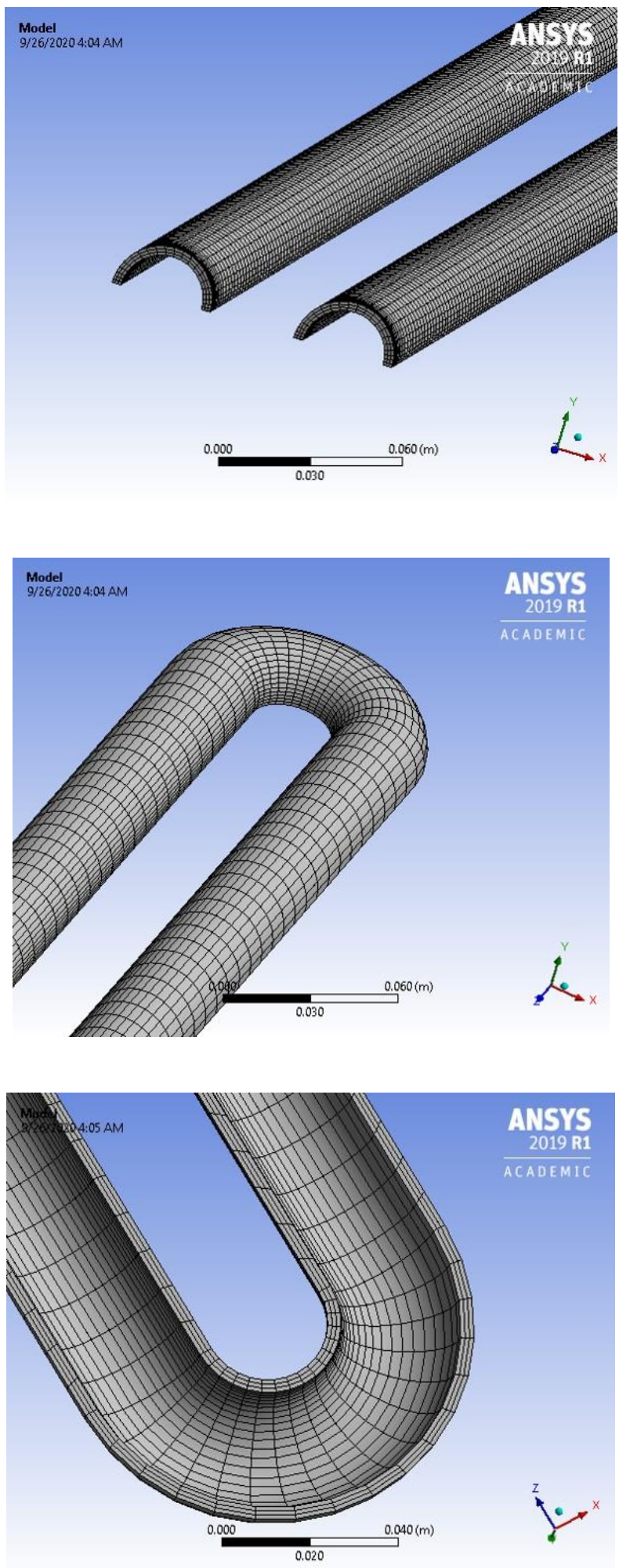

Figure 26:Hexahedral Mesh for Pipe 

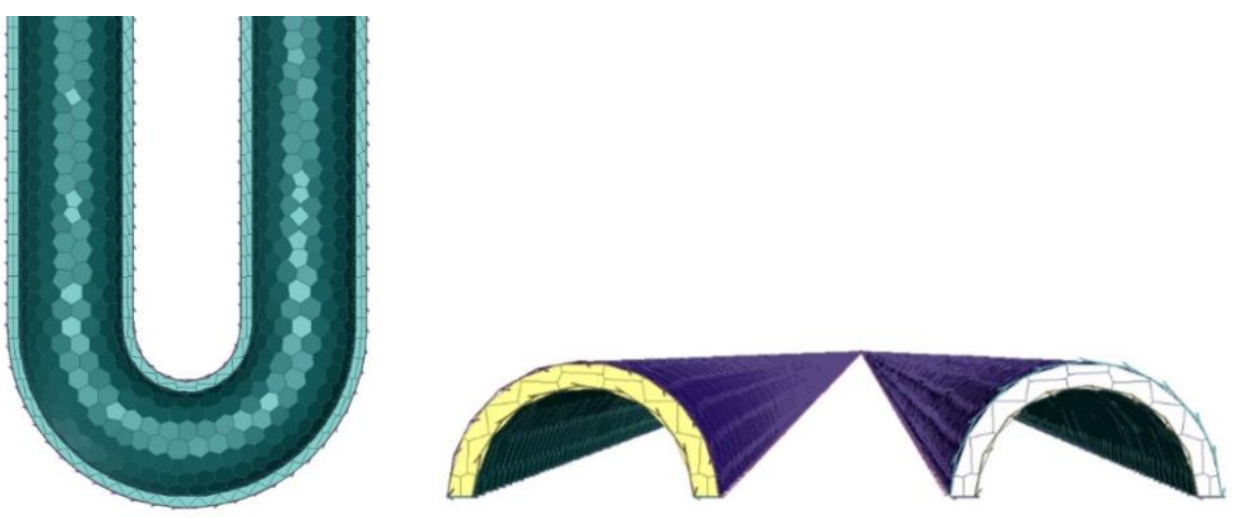

Figure 27:Polyhedral Mesh of Pipe for coarse and medium refinement
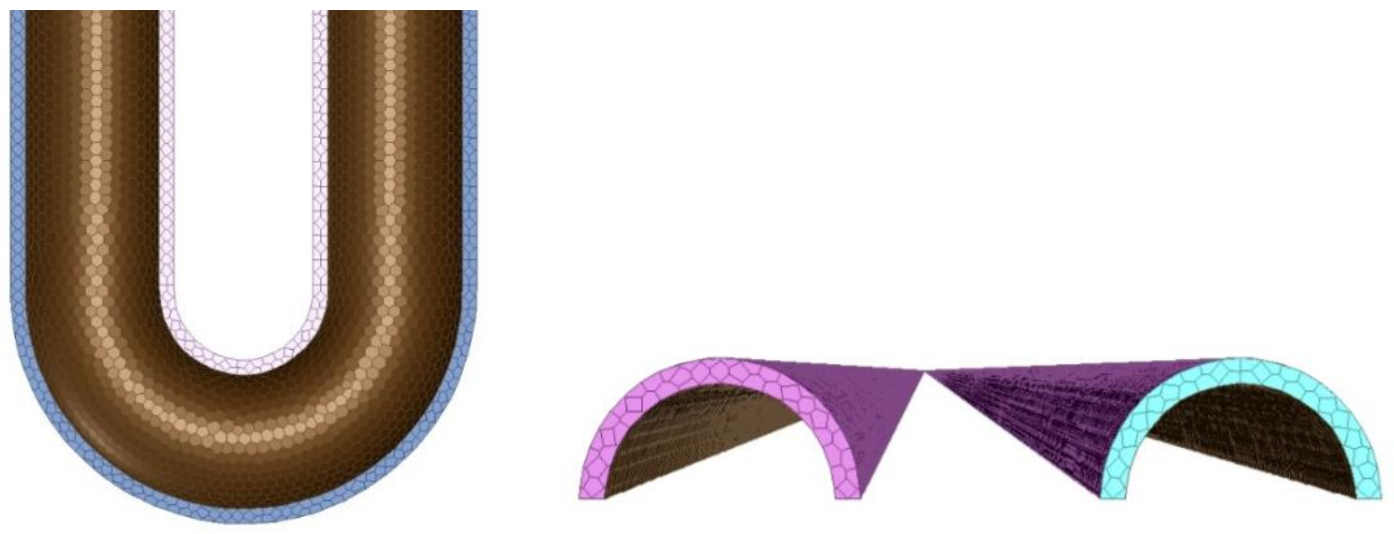

Figure 28:Polyhedral mesh of Pipe for fine refinement test case

\subsubsection{Discretizing of Fluid}

The hexahedral mesh of the fluid was created using the same software, as the other components. The hexahedral mesh of the fluid section was created without any boundary layer, i.e. any inflation/prism layer being grown on the fluid-pipe-interface. The hex mesh created for the fluid section had all the curved surfaces divided by 15 cells whereas the length was discretized using 10000 cells. 
The polyhedral mesh of the fluid that was created for the coarse refined test case had the minimum local and global cell size fixed at 2.5 while the maximum local and global cell size were fixed to 150 , with the cell growth rate kept at 1.2. In this case, the cell size per gap was fixed to 3 cells to capture the proximity and curvature of the object faces and edges. Here, there are no prism layers applied to reduce the cell count of the fluid domain. The polyhedral mesh of the fluid created for the medium refined test case had the minimum local and global cell size fixed to 2.5 while the maximum local and global cell size was fixed to 100 . Here the cell size per gap was set to 10 cells to capture the proximity and curvature of the object faces and edges. The growth rate and the normal angle of growth was set to default numbers of 1.2 and 18 degrees respectively. The number of prism layers was set to 3 , while the height of the first layer was set to $1.71875 \mathrm{~mm}$, being grown on the fluid-pipe-interface of the fluid domain.

Furthermore, the polyhedral mesh of the fluid section that was used for the testing of the finely refined test case was created with minimum local and global cell sizes of 2.5 with the maximum being set to 100 . The cells per gap used to capture the proximity and curvature of the faces and edges was set to 15 cells per gap. Again, the growth rate of the cells and normal angle was set to default numbers. The prism layer was created in the fluidpipe-interface of the fluid zone to capture the boundary layer was also set to 4 layers with the first layer being set to $1.71875 \mathrm{~mm}$.

It is seen that grid size of the fluid domain has been varied in most cases as compared to the grid size of the other components, this is because the governing equations are applied and solved on the fluid section, whereas the other solid bodies are mostly used for conjugate heat transfer, i.e. act as transfer of data from one domain to another. 
Table 6 shows the number of cells for the Fluid generated and the mesh type that was employed.

Table 6:Mesh Type and Cell Count for Fluid

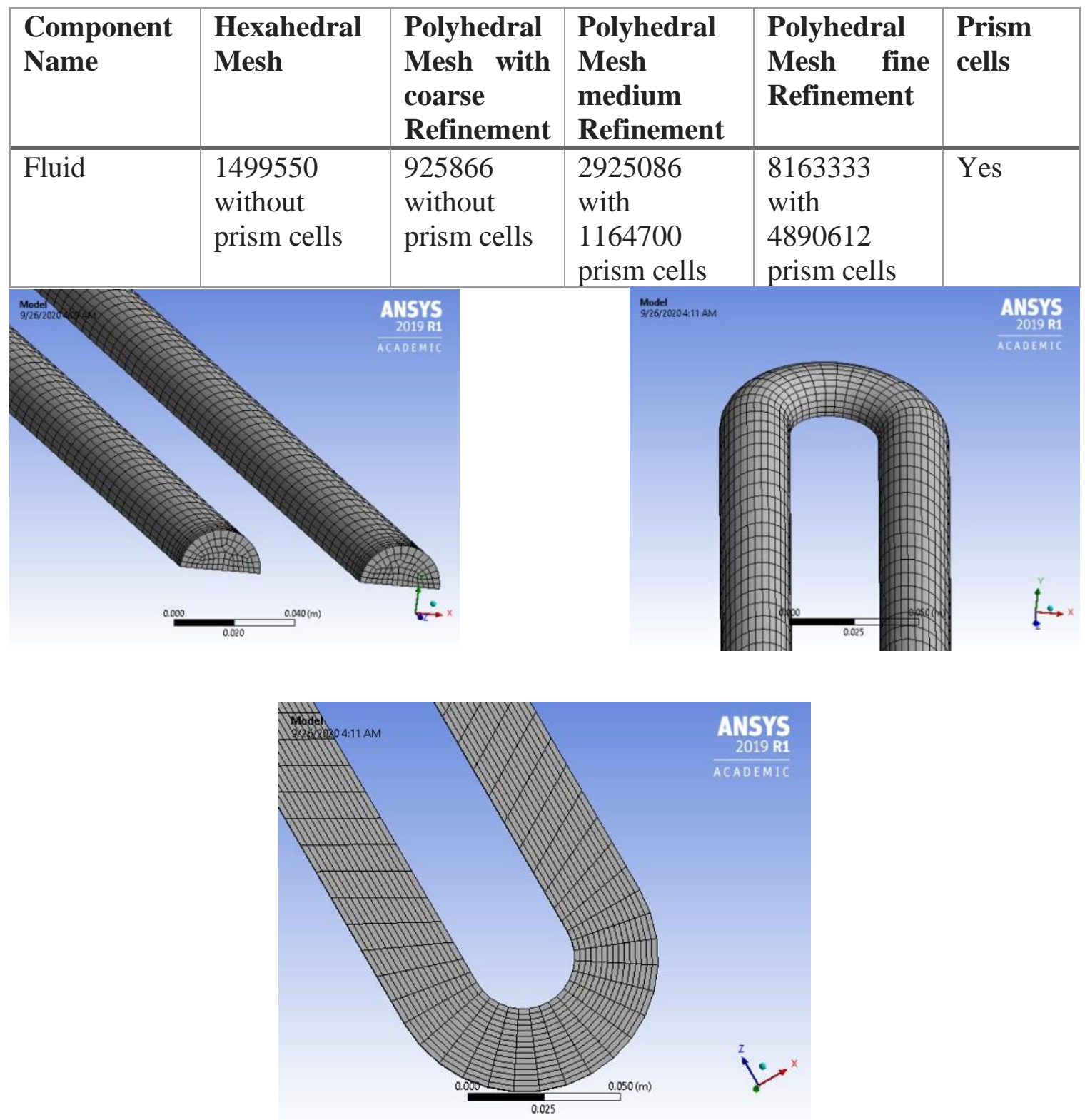

Figure 29:Hexahedral Mesh for Fluid without Inflation Layer 

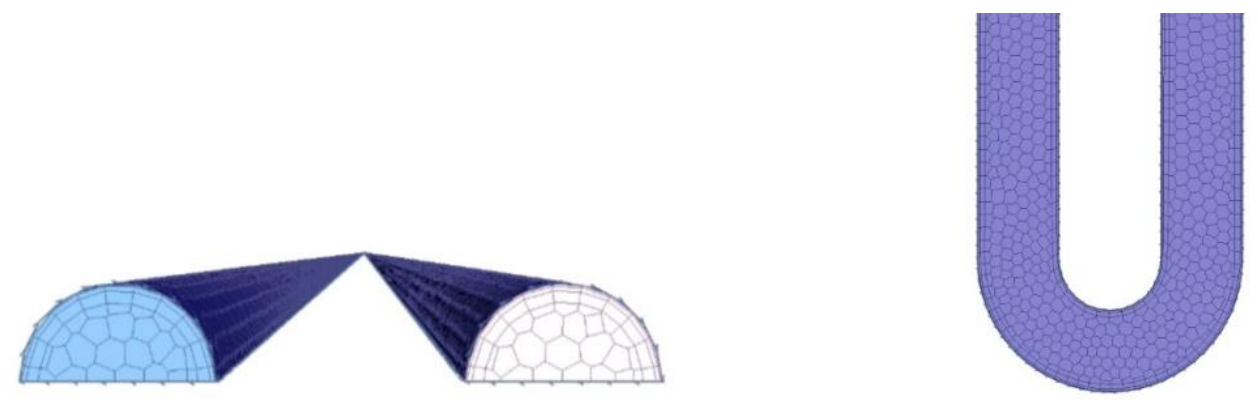

Figure 30:Polyhedral Mesh of Fluid with medium refinement with prism layers on FluidPipe-Interface
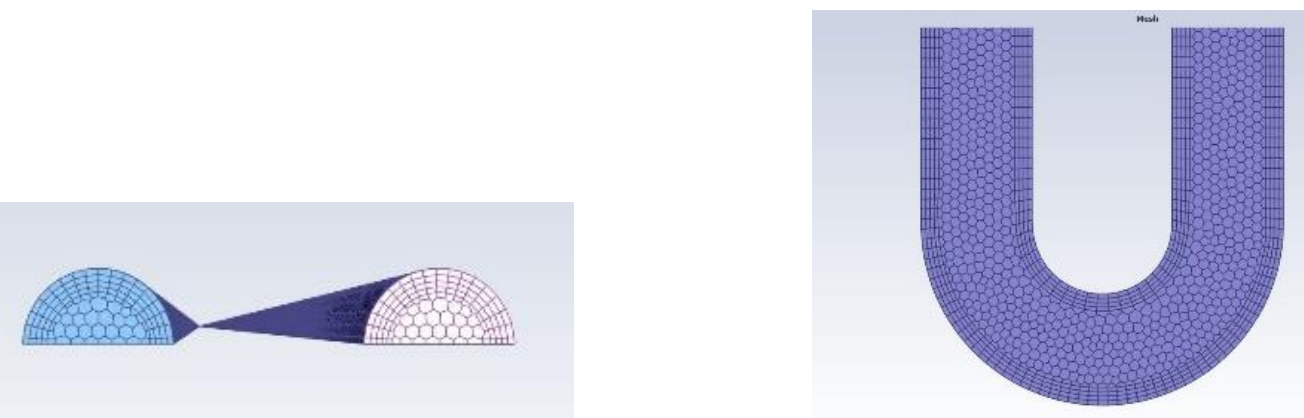

Figure 31:Polyhedral Mesh of Fluid for fine refinement test case with prism layers on Fluid-Pipe-Interface

Table 7: Mesh Type and Size of various components of BHE

\begin{tabular}{|c|c|c|c|c|c|}
\hline Mesh Type & $\begin{array}{l}\text { Component } \\
\text { Name }\end{array}$ & $\begin{array}{l}\text { Number of } \\
\text { Cells (in } \\
\text { millions) }\end{array}$ & $\begin{array}{l}\text { Cells } \\
\text { across gap }\end{array}$ & $\begin{array}{l}\text { Prism cells } \\
\text { in millions }\end{array}$ & $\begin{array}{l}\text { Number of } \\
\text { Prism } \\
\text { layers }\end{array}$ \\
\hline \multirow{4}{*}{$\begin{array}{l}\text { Hexahedral- } \\
4.0 \text { million } \\
\text { cells }\end{array}$} & Domain & 0.22 & 3 & - & - \\
\hline & Grout & 1.01 & 4 & - & - \\
\hline & Pipe & 1.31 & 5 & - & - \\
\hline & Fluid & 1.49 & 10 & - & - \\
\hline \multirow{4}{*}{$\begin{array}{l}\text { Polyhedral- } \\
3.92 \text { million } \\
\text { cells }\end{array}$} & Domain & 0.485 & 3 & - & - \\
\hline & Grout & 1.57 & 10 & - & - \\
\hline & Pipe & 0.95 & 3 & - & - \\
\hline & Fluid & 0.92 & 3 & - & - \\
\hline \multirow{4}{*}{$\begin{array}{l}\text { Polyhedral- } \\
5.9 \text { million } \\
\text { cells }\end{array}$} & Domain & 0.485 & 3 & - & - \\
\hline & Grout & 1.57 & 10 & - & - \\
\hline & Pipe & 0.95 & 3 & - & - \\
\hline & Fluid & 2.92 & 10 & 1.16 & 3 \\
\hline
\end{tabular}




\begin{tabular}{|l|l|l|l|l|l|}
\hline \multirow{2}{*}{$\begin{array}{l}\text { Polyhedral- } \\
\mathbf{1 4 . 5} \text { million } \\
\text { cells }\end{array}$} & Domain & 0.485 & 3 & - & - \\
\cline { 2 - 6 } & Grout & 1.57 & 10 & - & - \\
\cline { 2 - 6 } & Pipe & 4.58 & 12 & - & - \\
\cline { 2 - 6 } & Fluid & 8.16 & 15 & 4.89 & 4 \\
\hline
\end{tabular}

\subsection{Assumptions and Boundary Conditions for the simulation of 3D Model}

The assumptions that have been made to perform the numerical simulation are as follows:

- The temperature of the ground is assumed to be constant, i.e. the undisturbed ground temperature.

- The material properties of the various components of the BHE are homogenous and independent of variation of temperature.

- Steady State simulations have been performed in 3D as the variation in temperature inside the BHE takes a lot time to reflect.

The various boundary conditions based on the assumptions made have been applied to the geometry for simulation for validation with He, M., 2012: -

- The undisturbed ground temperature applied to the simulation domain was $283.15 \mathrm{~K}$.

- The inlet temperature of the fluid is taken to $293.15 \mathrm{~K}$. This is because the BHE is simulated to be operating in cooling mode, i.e. the outlet temperature of the water is assumed is lower than that of the inlet temperature.

The steady state simulation with two test cases were run to validate the experimental results from Pu.et al ,2014; the boundary conditions for each case have been mentioned below: -

- Inlet Temperature- $308.47 \mathrm{~K}$ and $278.21 \mathrm{~K}$ 
- Undisturbed Ground Temperature- 292.25K

- Inlet volume flow rates- $1.173 \mathrm{~kg} / \mathrm{h}$ or $0.552 \mathrm{~m} / \mathrm{s}$ for $308.47 \mathrm{~K}$ and $1.144 \mathrm{~kg} / \mathrm{h}$ or $0.53861 \mathrm{~m} / \mathrm{s}$ for $278.21 \mathrm{~K}$.

\subsection{Material and Thermal Properties of various components of BHE}

The various materials assumed for the components of BHE and their thermal properties are shown in Table 8 for numerical validation with He, M., 2012: -

Table 8:Materials and Thermal Properties of various components for validation with He, M., 2012

\begin{tabular}{|c|c|c|c|c|}
\hline $\begin{array}{c}\text { Component } \\
\text { Name }\end{array}$ & Material & $\begin{array}{c}\text { Density in } \\
\mathbf{k g} / \mathbf{m}^{\mathbf{3}}\end{array}$ & $\begin{array}{c}\text { Specific Heat } \\
\text { Capacity in } \\
\text { J/kgK }\end{array}$ & $\begin{array}{c}\text { Thermal } \\
\text { Conductivity in } \\
\text { W/K.m }\end{array}$ \\
\hline Domain & $\begin{array}{c}\text { Saturated } \\
\text { Sand }\end{array}$ & 1613 & 1549.9 & 2.5 \\
\hline Grout & $\begin{array}{c}30 \% \\
\text { Bentonite } \\
\text { and Sand }\end{array}$ & 1158 & 3443 & 0.75 \\
\hline Pipe & $\begin{array}{c}\text { High Density } \\
\text { Polyethylene }\end{array}$ & 944 & 1900 & 0.39 \\
\hline Fluid & \begin{tabular}{c} 
Water \\
\hline
\end{tabular} & 998.2 & 4182 & 0.6 \\
\hline
\end{tabular}

The various materials assumed for the components of BHE and their thermal properties are shown in Table 9 for validation with experimental results from $\mathrm{Pu}$.et al ,2014: -

Table 9:Materials and Thermal Properties of various components for validation with Pu.et al, 2014

\begin{tabular}{|c|c|c|c|c|}
\hline $\begin{array}{c}\text { Component } \\
\text { Name }\end{array}$ & Material & $\begin{array}{c}\text { Density in } \\
\mathbf{k g} / \mathbf{m}^{\mathbf{3}}\end{array}$ & $\begin{array}{c}\text { Specific Heat } \\
\text { Capacity in } \\
\mathbf{J} / \mathbf{k g K}\end{array}$ & $\begin{array}{c}\text { Thermal } \\
\text { Conductivity in } \\
\text { W/K.m }\end{array}$ \\
\hline Domain & Coarse Sand & 1540 & 1800 & 2.0 \\
\hline Grout & $\begin{array}{c}\text { Cement, } \\
\text { Bentonite } \\
\text { and Sand }\end{array}$ & 1869 & 1880 & 2.0 \\
\hline Pipe & $\begin{array}{c}\text { High Density } \\
\text { Polyethylene }\end{array}$ & 950 & 2300 & 0.44 \\
\hline Fluid & Water & 998.2 & 4182 & 0.6 \\
\hline
\end{tabular}




\subsection{Inlet Velocity of Fluid inside the Pipe and its corresponding Reynolds Number}

The simulation has been performed for five different inlet velocities of the fluid inside the pipe and their Corresponding Reynolds Number has been tabulated in Table 3.7: -

Table 10: Inlet Velocity and its corresponding Reynolds Number from He, M., 2012

\begin{tabular}{|c|c|}
\hline Inlet Fluid Velocity & Reynolds Number \\
\hline $1.0 \mathrm{~m} / \mathrm{s}$ & 25400 \\
\hline $0.8 \mathrm{~m} / \mathrm{s}$ & 20320 \\
\hline $0.6 \mathrm{~m} / \mathrm{s}$ & 15240 \\
\hline $0.4 \mathrm{~m} / \mathrm{s}$ & 10160 \\
\hline $0.2 \mathrm{~m} / \mathrm{s}$ & 5080 \\
\hline
\end{tabular}

\subsection{Case Set-up in ANSYS Fluent 2019R1}

The numerical simulation of the BHE was done in ANSYS Fluent 2019R1, with double precision 3D steady state solver condition. As mentioned earlier since the geometry is symmetrical as such only half of the geometry is discretized and used in the Fluent solver for the numerical simulation. For validation of numerical simulation data with He, M., 2012, five different inlet fluid velocities were tested whereas for validation with experimental data with Pu.et al 2014 two different inlet velocities were tested with the stated boundary conditions in section 3.2 of the paper.

\subsubsection{Viscous Models Used}

The governing equations of fluid flow represent mathematical statements of the conservation laws of physics that are the Navier-Stokes Equations:

- The mass of a fluid is conserved. 
- The rate of change of momentum equals the sum of the forces on a fluid particle (Newton's second law).

- The rate of change of energy is equal to the sum of the rate of heat addition to and the rate of work done on a fluid particle (first law of thermodynamics).

The governing equation that is applied to the problem and solved in Fluent is the NavierStokes Equation, however, since it turbulence has been modeled in this conjugate heat transfer problem, the Reynolds Averaged Navier-Stokes Equation is solved in steady state

which is $U_{j} \frac{\partial U j}{\partial x x_{j}}=-\frac{1}{\rho} \frac{\partial P}{\partial x_{i}}+\frac{\partial}{\partial x_{j}}\left(\frac{\mu}{\rho} \frac{\partial U_{i}}{\partial x_{j}}\right)+\frac{\partial\left(\overline{\left.-u_{u} u u_{j}^{\prime}\right)}\right.}{\partial x_{j}}$

Where, $\frac{\partial \overline{\left(-\hat{u}_{l} u u_{j}\right)}}{\partial x_{j}}$ is called the closure problem which is solved using Eddy viscosity $2-$ equation models, called the $\mathrm{k}-\varepsilon$ model.

Where k equation is $U_{j} \frac{\partial k}{\partial x_{j}}=\frac{\mu_{t}}{\rho} S^{2}-\epsilon+\frac{\partial}{\partial x_{j}}\left[\frac{1}{\rho}\left(\mu+\frac{\mu_{t}}{\sigma_{k}}\right) \frac{\partial k}{\partial x_{j}}\right]$

and $\varepsilon$ is $U_{j} \frac{\partial \epsilon}{\partial x_{j}}=\frac{\epsilon}{k}\left(C_{1 \epsilon} \frac{\mu_{t}}{\rho} S^{2}-C_{2 \epsilon} \epsilon\right)+\frac{\partial}{\partial x_{j}}\left[\frac{1}{\rho}\left(\mu+\frac{\mu_{t}}{\sigma_{\epsilon}}\right) \frac{\partial \epsilon}{\partial x_{j}}\right]$

eddy viscosity is obtained as : ${ }^{\mu_{t}}=\rho C_{\mu} \frac{k^{2}}{\epsilon}$

There are 5 free constants $\sigma_{k}, \sigma_{\mathrm{y}}, \mathrm{C}_{1 \epsilon}, \mathrm{C}_{2 \epsilon}, \mathrm{C}_{3 \epsilon}$

which are,

$\sigma_{\mathrm{k}}=1.0, \sigma_{\mathrm{y}}=1.3$

$\mathrm{C}_{1 \epsilon}=1.44, \mathrm{C}_{2 \epsilon}=1.92$ and $\mathrm{C}_{3 \epsilon}=0.09$ 
Fluent has a built in variety of viscous models that can be used for numerically simulating the flows and capture the turbulent fluctuation, along with laminar and inviscid models. The turbulence models available in Fluent are based on the Reynolds averaged NavierStokes equations (RANS). As such to compute the RANS equations, various turbulence models have been developed to predict and calculate the Reynolds stresses. The selection of the turbulence model depends upon the type of flow characteristics that need to be solved. However, k- $\varepsilon$ models are the most widely used models for validation. The k- $\varepsilon$ model is based on the assumption that there is a relation between the viscous stresses and the Reynolds stresses on the flow. The k- $\varepsilon$ model focusses on the factors affecting the turbulent kinetic energy of the flow.

Now it is known that turbulent flows are affected due to the presence of walls, as perturbation present on the walls are the source of vorticity and turbulence generation in the flow of the fluid. Usually three layers are said to be dividing the flow region the wall, wherein the innermost layer, called the viscous sublayer, the flow is largely laminar. In the next immediate layer, the flow is mostly transitional in nature and in the outer most layer, the flow is fully turbulent in nature, and is called the turbulent layer. The standard wall function used in Fluent is developed by Launder and Spalding (1983) has two model equations, one for $\mathrm{k}$ and the other for $\varepsilon$, where the $\mathrm{k}$ and $\varepsilon$ are used to define the turbulent kinetic energy and rate of turbulence dissipation respectively of the large-scale turbulence models. On the other hand, if the mesh near the wall is fine, and is able to capture the viscous sublayer, then Enhanced Wall Treatment is used. The only drawback of this near wall treatment function is that it requires a very fine mesh with boundary layer near the 
wall, to resolve the viscous sublayer, which increases the number of cells used in the mesh and subsequently requires a greater computational effort.

For the numerical simulation of the BHE, the k- $\varepsilon$ model was tested with following different conditions mentioned below: -

- The first case was numerically simulated and studied with $0.8 \mathrm{~m} / \mathrm{s}$ inlet velocity using Standard k- $\varepsilon$ model with Standard Wall Function selected for the Near Wall Treatment method with the three different sizes of polyhedral mesh.

- The second case was numerically simulated and studied with $0.8 \mathrm{~m} / \mathrm{s}$ inlet velocity using Standard k- $\varepsilon$ model with Standard Wall Function selected for the Near Wall Treatment method with the hex mesh and the coarse poly mesh.

- The third case that was numerically simulated and studied with $0.8 \mathrm{~m} / \mathrm{s}$ inlet velocity using Standard k- $\varepsilon$ model with Standard Wall Function selected for the Near Wall Treatment method and Enhanced Wall treatment k- $\varepsilon$ model using the hex mesh.

- The fourth case that was numerically simulated and studied was using Standard k$\varepsilon$ model with Standard Wall Function selected for the Near Wall Treatment method using the hex mesh with $0.8 \mathrm{~m} / \mathrm{s}$ inlet velocity along with the gravity effect being considered.

- Five different inlet velocities were numerically simulated using Standard k- $\varepsilon$ model with Standard Wall Function selected for the Near Wall Treatment method using the hex mesh for validation with He, M., 2012.

- Finally, two different inlet velocities were numerically simulated using Standard k$\varepsilon$ model with Standard Wall Function selected for the Near Wall Treatment method using the hex mesh for validation with Pu.et al ,2014. 


\subsubsection{Setup of Interface Zones}

The interfaces between the bodies have been coupled to enable two way transfer of data from one entity of the BHE to another, with suitable cell zone material properties being assigned to each part.

\subsubsection{Solution Methods employed}

The pressure-velocity coupling was achieved using the SIMPLE scheme. Since the problem that has been addressed in this study is fairly simple without much complications, as such SIMPLE scheme is employed where the pressure velocity coupling determines the convergence of the solution.

\subsubsection{Initialization of the solution}

The solution has been initialized to calculate all results from the inlet of the fluid, which sets all initial flow values for variables from the inlet and initialize the solution using these values.

\subsection{Results Obtained and Its Validation}

Due to the complexity of the problem, the $3 \mathrm{D}$ conjugate heat transfer problem in $\mathrm{BHE}$ cannot be solved using analytical means. The transport of the fluid, which occurs in the third dimension, poses a challenge in applying the analytical solution to the BHE in 3D.

For validation of data obtained from the numerical simulation the parameters under the study have been normalized to make them dimensionless. The two parameters that have been normalized are depth $\left(\mathrm{D}^{*}\right)$ which is defined as the ratio of the depth of the fluid and the total depth of the borehole. The second dimensionless parameter is temperature $\left(\mathrm{T}^{*}\right)$ 
which is defined as the ratio of temperature difference between the fluid and initial temperature to the difference between the inlet and initial temperature of the simulation.

$$
\mathrm{D}^{*}=\mathrm{D} / \mathrm{D}_{\text {total }}=(-1) * \mathrm{z} / 100
$$

And

$$
\mathrm{T}^{*}=\left(\mathrm{T}-\mathrm{T}_{\text {initial }}\right) /\left(\mathrm{T}_{\text {inlet }}-\mathrm{T}_{\text {initial }}\right)=(\mathrm{T}-283.15) /(293.15-283.15)(\text { Also defined as }
$$

\section{effectiveness of heat exchanger)}

Static temperature monitors were set-up at the outlet of the pipe to check the convergence of the simulation.

The results have been validated with the simulation results from He, M., 2012. The results have been compared with the help of plots $\mathrm{D}^{*}$ vs $\mathrm{T}^{*}$.

The second validation has been done with experimental data from Pu.et al ,2014. Two sets of data have been validated for this purpose with different inlet temperatures and velocities. The outlet temperature obtained from steady state simulations have been compared along with the calculated effectiveness from the experimental data and the effectiveness obtained from the numerical simulation. 


\subsubsection{Results}

- Results 3.6.1.1., 3.6.1.2., and 3.6.1.3. are being used to perform the grid independence study.

- Results 3.6.1.1. and 3.6.1.4. are being used to perform the mesh independence study.

- Results 3.6.1.4. and 3.6.1.5. are being used to study the independence of the turbulence model.

- Results 3.6.1.4. and 3.6.1.6. are being used to study the effect of gravity on the numerical simulation results.

\subsubsection{Results of $0.8 \mathrm{~m} / \mathrm{s}$ Inlet velocity with Standard Wall Treatment and Standard k- $\varepsilon$ Model with Coarse Polyhedral Mesh}

Here the inlet velocity of the fluid was taken as $0.8 \mathrm{~m} / \mathrm{s}$, with inlet temperatures to be $293.15 \mathrm{~K}$ and far field temperature to be $283.15 \mathrm{~K}$ with Standard Wall Treatment and Standard k- $\varepsilon$ Model using the coarse polyhedral mesh.
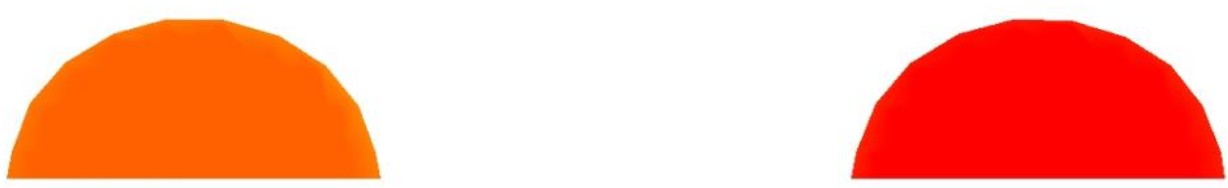

Figure 32: Inlet and Outlet Velocity Profile 


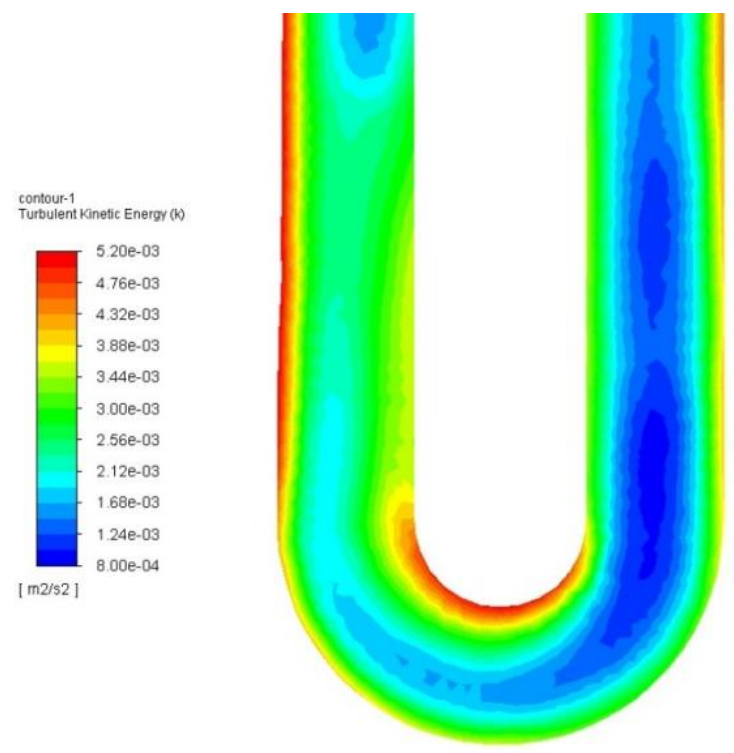

Figure 33: Turbulent Kinetic Energy Contour at U-Bend

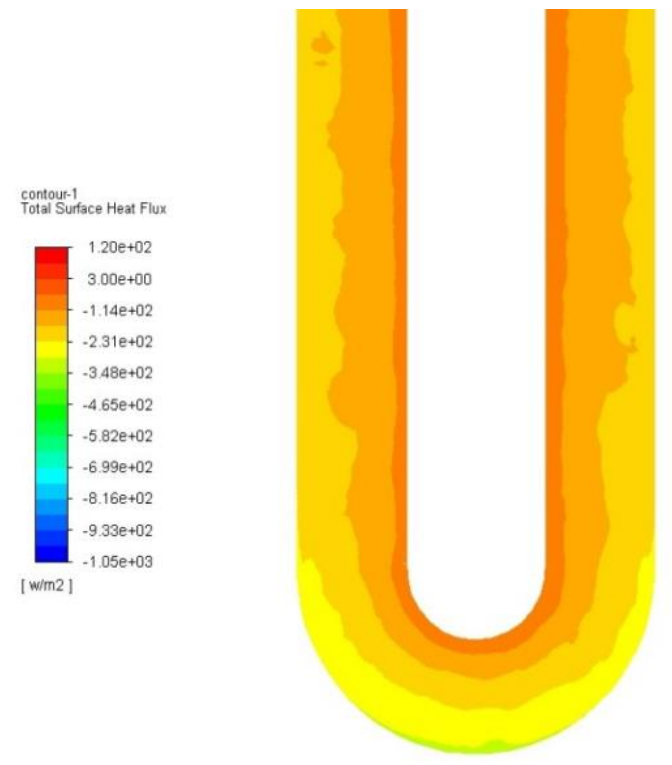

Figure 34: Heat Flux Contour at U- Bend 


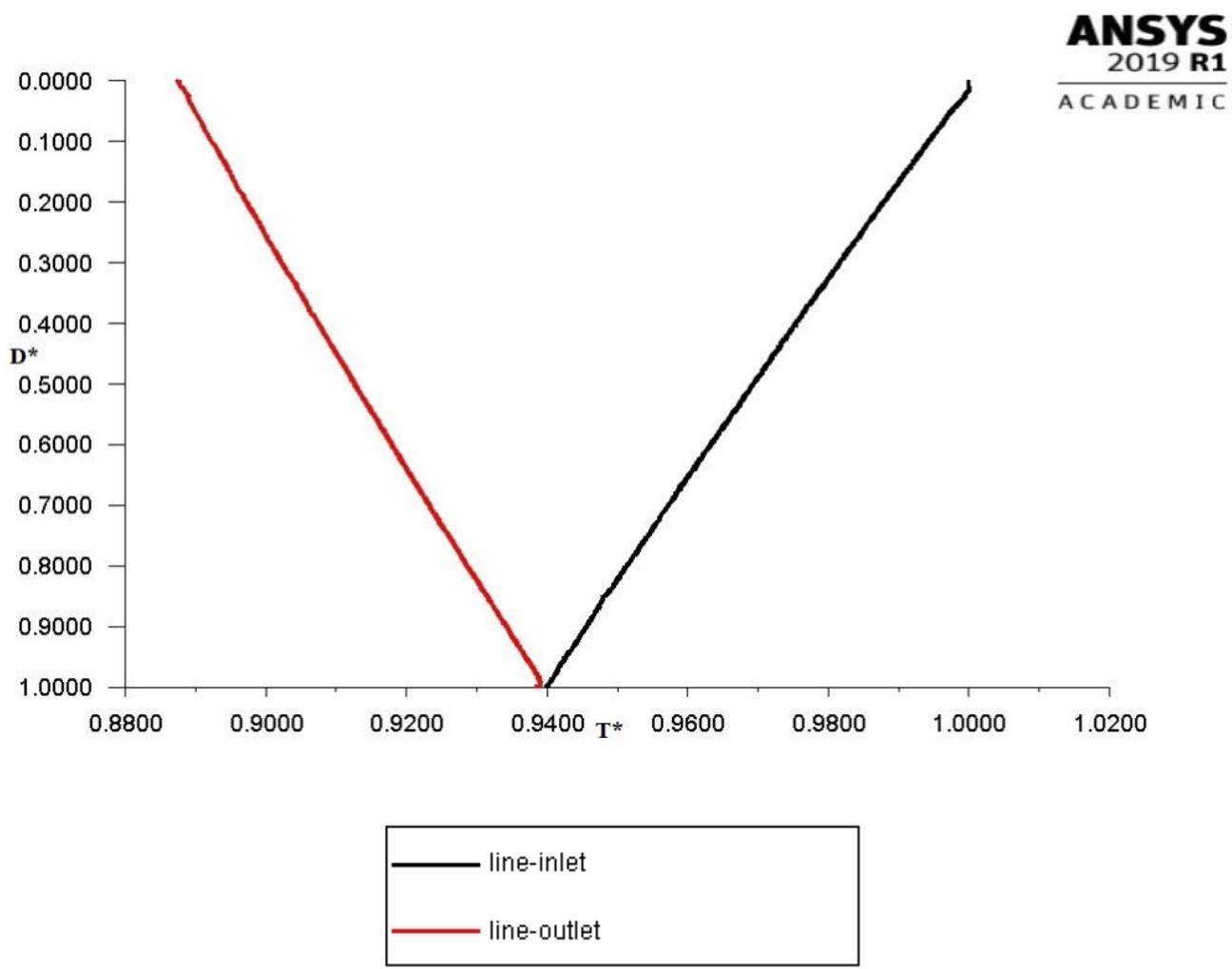

Figure 35: D*vs $T^{*}$ result

Figure 32 shows the inlet and outlet temperature profiles for the given test case whereas, Figure 33 shows the turbulent kinetic energy contour at the u-bend of the pipe, showing that the $\mathrm{u}$ - bend tends to generate minor eddies due to change in direction of pipe flow. Figure 34 depicts that surface heat flux contours at the $\mathrm{u}$ - bend of the pipe. While figure 35 shows the curve between non- dimensional depth $\left(\mathrm{D}^{*}\right)$ and non-dimensional temperature $\left(\mathrm{T}^{*}\right)$. It has been observed that generation of minor eddies at the $\mathrm{u}$-bend has increased the rate of heat transfer at that section. 
3.6.1.2. Results of $0.8 \mathrm{~m} / \mathrm{s}$ Inlet velocity with Standard Wall Treatment and Standard k- $\varepsilon$ Model with Medium Refined Polyhedral Mesh

Here the inlet velocity of the fluid was taken as $0.8 \mathrm{~m} / \mathrm{s}$, with inlet temperatures to be 293.15K and far field temperature to be $283.15 \mathrm{~K}$ with Standard Wall Treatment and Standard k- $\varepsilon$ Model medium refined polyhedral mesh.
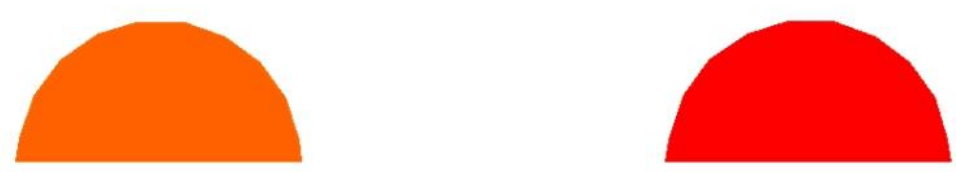

Figure 36:Inlet and Outlet Temperature Contour 

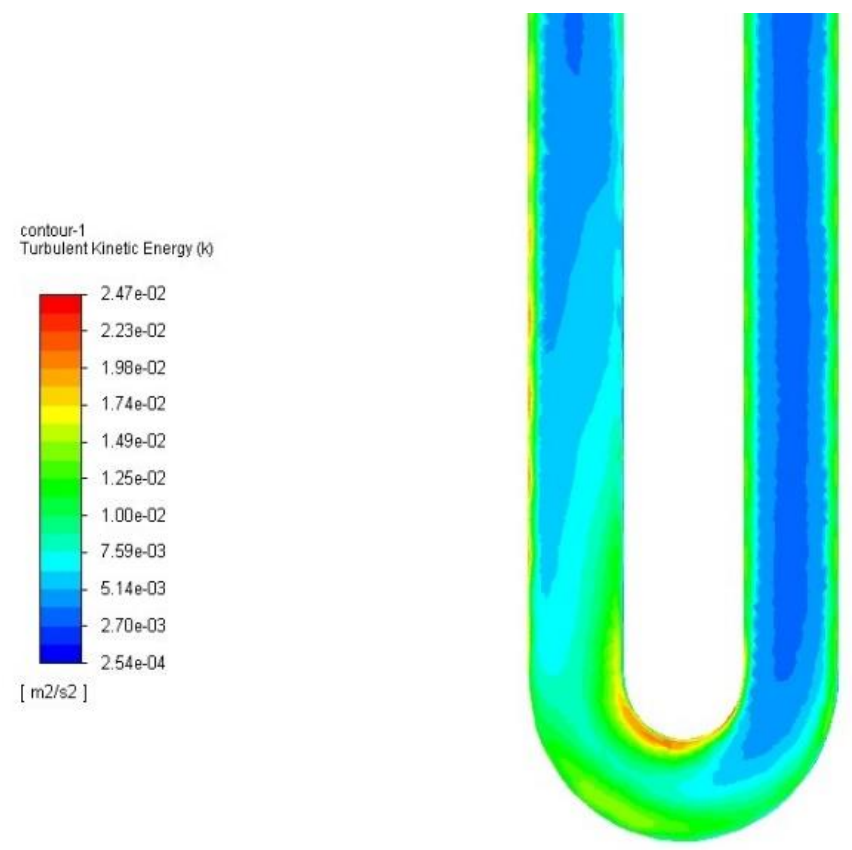

Figure 37: Turbulent Kinetic Energy Contour at U-bend

contour-1

Total Surface Heat Flux
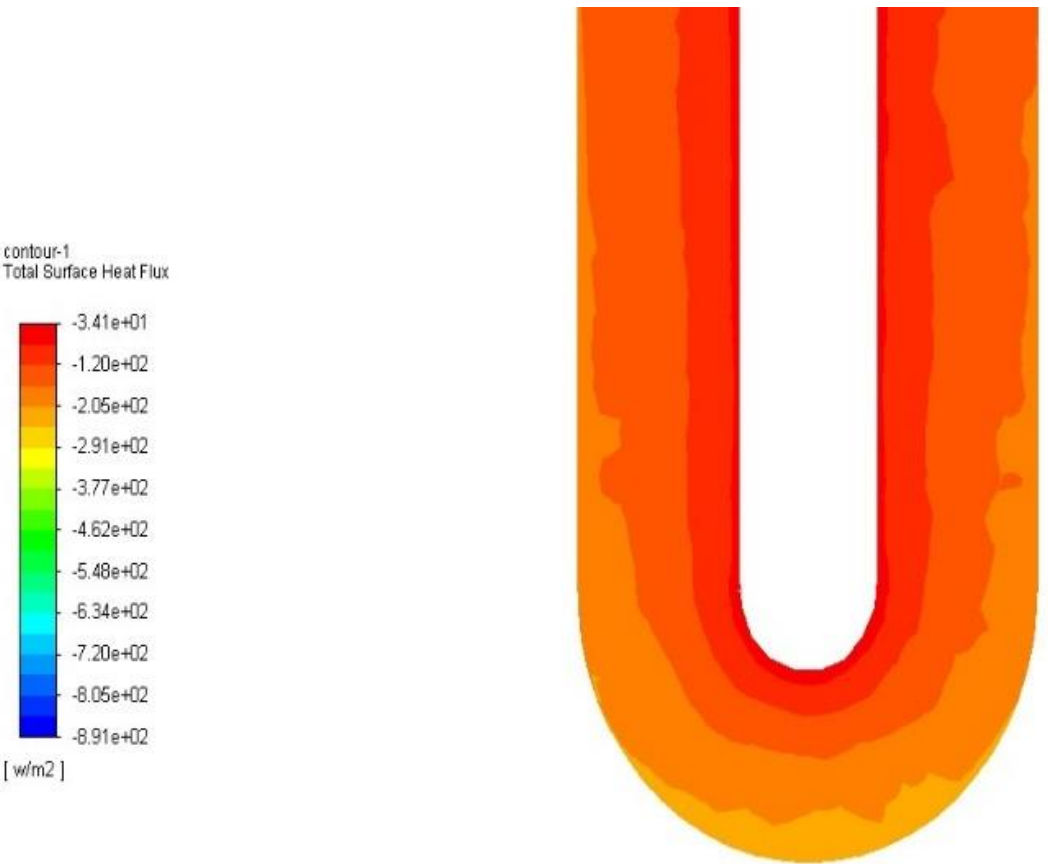

Figure 38:Heat Flux Contour at U-Bend 


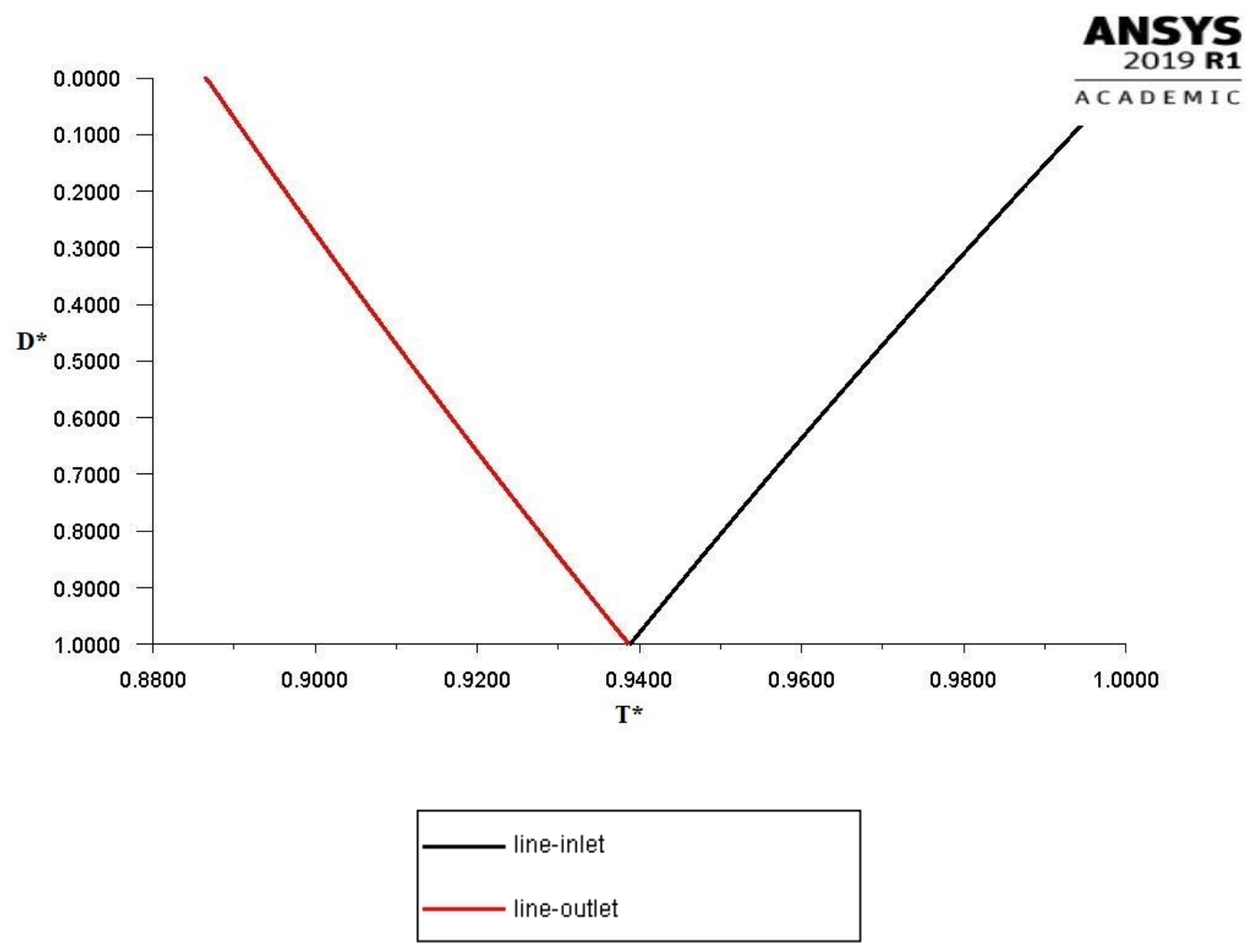

Figure 39: D* vs T* result

Figure 36 shows the inlet and outlet temperature profiles for the given test case while, Figure 37 shows the turbulent kinetic energy contour at the u-bend of the pipe, showing that the $\mathrm{u}$ - bend generates minor eddies due to change in direction of pipe flow and the geometry of the pipe . Figure 38 depicts that surface heat flux contours at the u- bend of the pipe. While figure 39 shows the curve between non- dimensional depth and nondimensional temperature. It has been observed here as well that generation of minor eddies at the u-bend has increased the rate of heat transfer. Also, it has been seen here in Figure 39 that the $\mathrm{D}^{*}$ and $\mathrm{T}^{*}$ curve is similar to the coarse poly mesh $\mathrm{D}^{*}$ vs $\mathrm{T}^{*}$ curve in Figure 35. 


\subsubsection{Results of $0.8 \mathrm{~m} / \mathrm{s}$ Inlet velocity with Standard Wall Treatment and Standard k- $\varepsilon$ Model with Finely Refined Polyhedral Mesh}

Here the inlet velocity of the fluid was taken as $0.8 \mathrm{~m} / \mathrm{s}$, with inlet temperatures to be 293.15K and far field temperature to be $283.15 \mathrm{~K}$ with Standard Wall Treatment and Standard k- $\varepsilon$ Model using the finely refined polyhedral mesh.

$$
\begin{aligned}
& \text { contour-1 } \\
& \text { Static Temperature } \\
& \qquad \begin{array}{l}
2.93 \mathrm{e}+02 \\
2.92 \mathrm{e}+02 \\
2.91 \mathrm{e}+02 \\
2.90 \mathrm{e}+02 \\
2.89 \mathrm{e}+02 \\
2.88 \mathrm{e}+02 \\
2.87 \mathrm{e}+02 \\
2.86 \mathrm{e}+02 \\
2.85 \mathrm{e}+02 \\
2.84 \mathrm{e}+02 \\
2.83 \mathrm{e}+02
\end{array}
\end{aligned}
$$

[k]
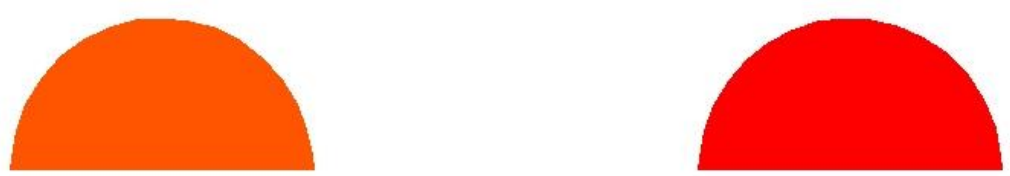

Figure 40 : Inlet and Outlet Temperature Contour 

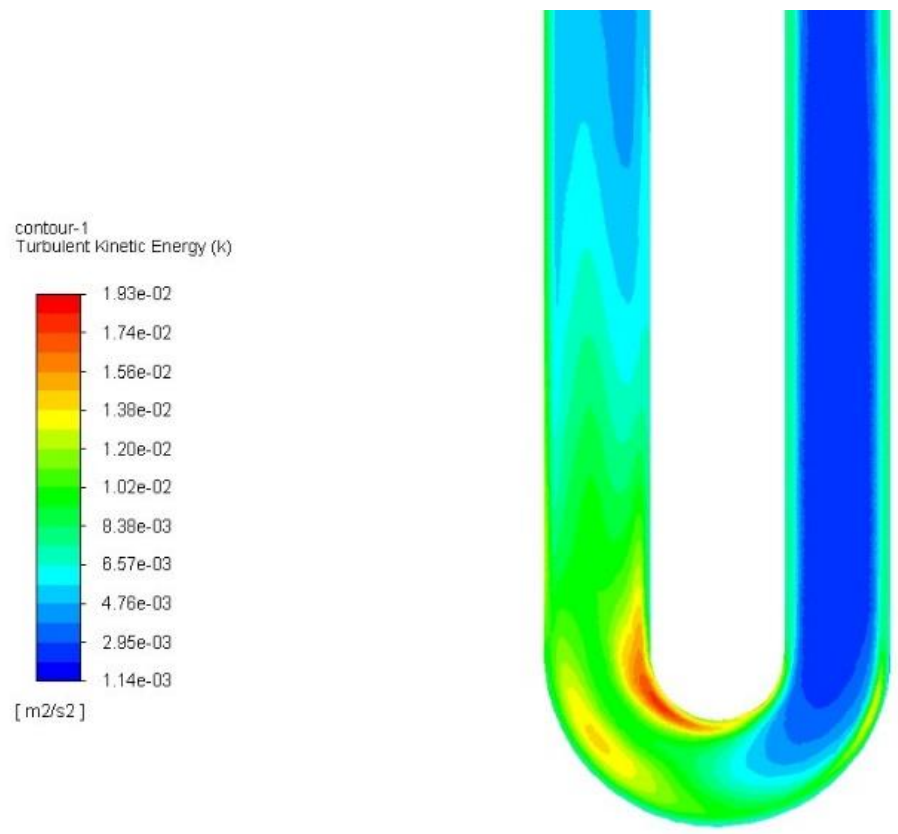

Figure 41: Turbulent Kinetic Energy Contour at U-Bend

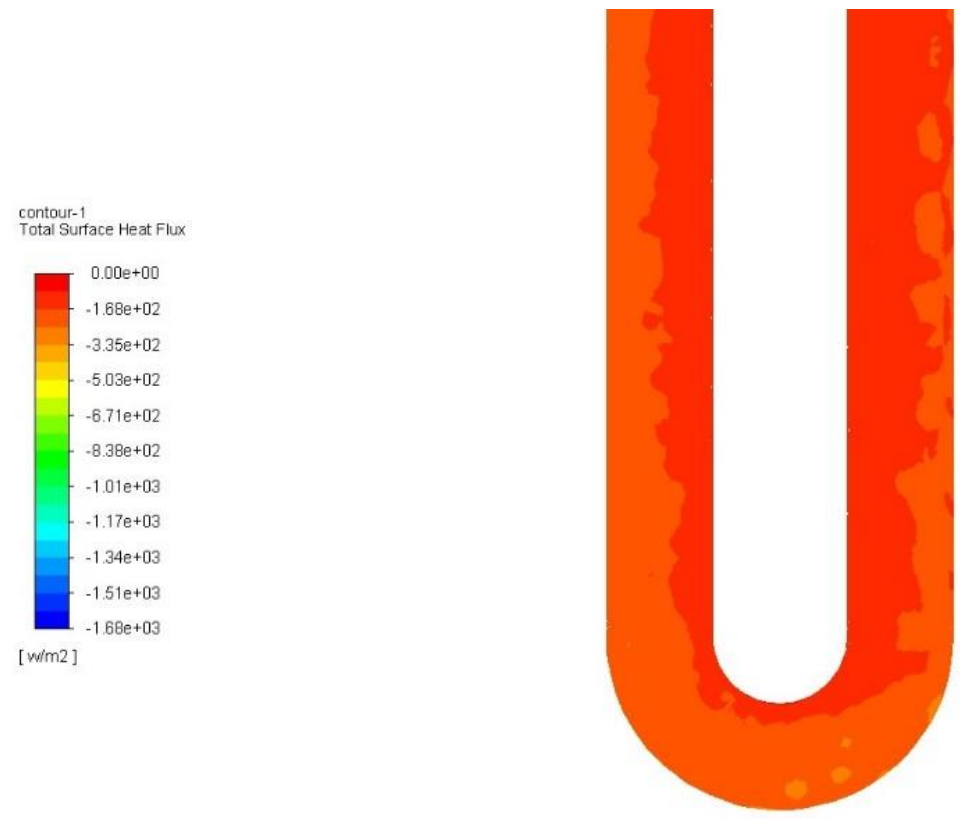

Figure 42: Heat Flux Contour at U- Bend 


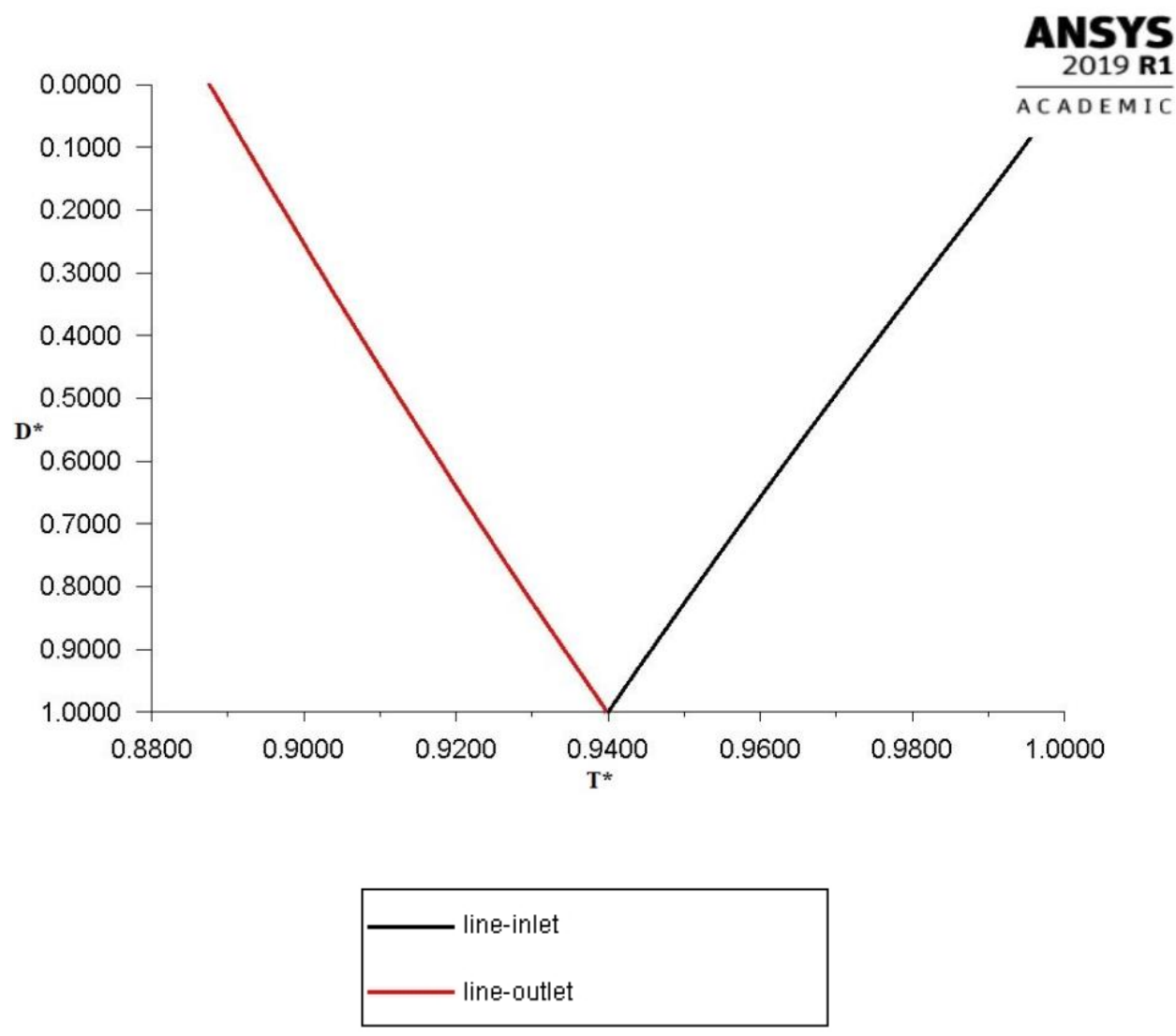

Figure 43: D* vs T* result

Figure 40 shows the inlet and outlet temperature profiles for the given test case while, Figure 41 shows the turbulent kinetic energy contour at the u-bend of the pipe, showing that the $\mathrm{u}$ - bend generates minor eddies due to change in direction of fluid in the pipe. Figure 42 depicts that surface heat flux contours at the $u$ - bend of the pipe. While figure 43 shows the curve between non- dimensional depth and non-dimensional temperature. It has been observed here as well that generation of minor eddies at the u-bend has increased the rate of heat transfer as in earlier test cases. Also, it has been seen here in Figure 43 that the $\mathrm{D}^{*}$ and $\mathrm{T}^{*}$ curve is similar to the coarse poly mesh $\mathrm{D}^{*}$ vs $\mathrm{T}^{*}$ curve in Figure 35 and medium refined poly mesh $D^{*}$ vs $T^{*}$ curve as shown in Figure 39. 
On comparing the non-dimensional depth $\left(\mathrm{D}^{*}\right)$ vs non-dimensional temperature $\left(\mathrm{T}^{*}\right)$ curves for coarse polyhedral mesh from Figure 35, medium refined polyhedral mesh from Figure 39 and finely refined polyhedral mesh from Figure 43 and also comparing the outlet temperatures from Table 11, we see that the grid size of the mesh had minor effect upon the accuracy of the solution. Also from Figure 43 we see that the finely refined polyhedral mesh predicted the non-dimensional temperature closer to 0.94 at non-dimensional depth of 1.0, whereas from Figures 35 and 39, we see that the non-dimensional temperature at non-dimensional depth 1.0 were less accurate as compared to the result from finely refined poly mesh.

Table 11: Table Summarizing Grid Independence Study

\begin{tabular}{|c|c|c|c|c|c|c|}
\hline Mesh Type & $\begin{array}{l}\text { Component } \\
\text { Name }\end{array}$ & $\begin{array}{l}\text { Number } \\
\text { of Cells } \\
\text { (in } \\
\text { millions) }\end{array}$ & $\begin{array}{l}\text { Cells } \\
\text { across } \\
\text { gap }\end{array}$ & $\begin{array}{l}\text { Prism } \\
\text { cells in } \\
\text { millions }\end{array}$ & $\begin{array}{l}\text { Number } \\
\text { of Prism } \\
\text { layers }\end{array}$ & $\begin{array}{l}\text { Outlet } \\
\text { Temperature } \\
\text { in K }\end{array}$ \\
\hline \multirow{4}{*}{$\begin{array}{l}\text { Polyhedral- } \\
3.92 \text { million } \\
\text { cells }\end{array}$} & Domain & 0.485 & 3 & - & - & \multirow[t]{4}{*}{$291.563 \mathrm{~K}$} \\
\hline & Grout & 1.57 & 10 & - & - & \\
\hline & Pipe & 0.95 & 3 & - & - & \\
\hline & Fluid & 0.92 & 3 & - & - & \\
\hline \multirow{4}{*}{$\begin{array}{l}\text { Polyhedral- } \\
5.9 \text { million } \\
\text { cells }\end{array}$} & Domain & 0.485 & 3 & - & - & \multirow[t]{4}{*}{$291.843 \mathrm{~K}$} \\
\hline & Grout & 1.57 & 10 & - & - & \\
\hline & Pipe & 0.95 & 3 & - & - & \\
\hline & Fluid & 2.92 & 10 & 1.16 & 3 & \\
\hline \multirow{4}{*}{$\begin{array}{l}\text { Polyhedral- } \\
14.5 \text { million } \\
\text { cells }\end{array}$} & Domain & 0.485 & 3 & - & - & \multirow[t]{4}{*}{$291.840 \mathrm{~K}$} \\
\hline & Grout & 1.57 & 10 & - & - & \\
\hline & Pipe & 4.58 & 12 & - & - & \\
\hline & Fluid & 8.16 & 15 & 4.89 & 4 & \\
\hline
\end{tabular}




\subsubsection{Results of $0.8 \mathrm{~m} / \mathrm{s}$ Inlet velocity with Standard Wall Treatment and Standard k- $\varepsilon$ Model with Hex Mesh}

Here the inlet velocity of the fluid was taken as $0.8 \mathrm{~m} / \mathrm{s}$, with inlet temperatures to be 293.15K and far field temperature to be $283.15 \mathrm{~K}$ with Standard Wall Treatment and Standard k- $\varepsilon$ Model using the hexahedral mesh.

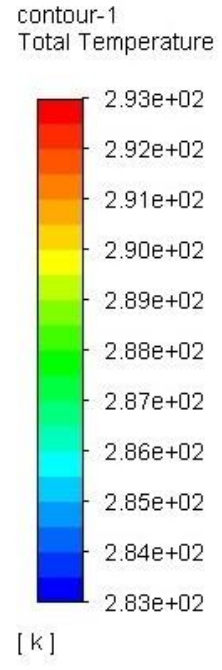

$[\mathrm{k}]$
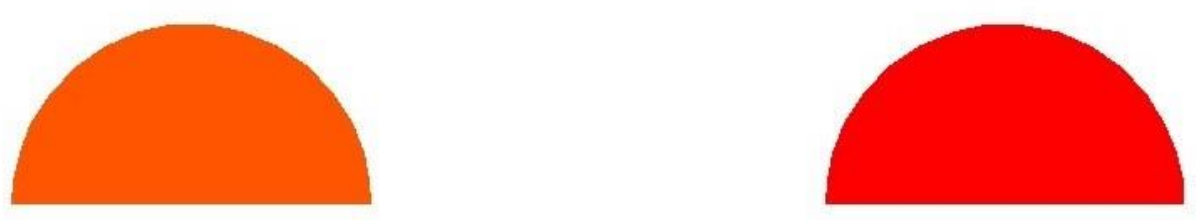

Figure 44 : Inlet and Outlet Temperature Contour 


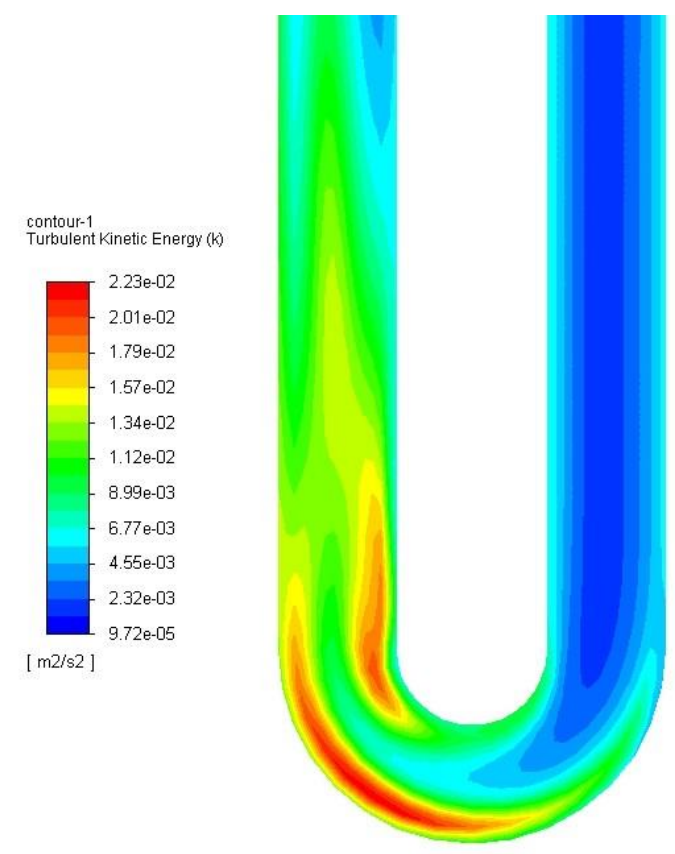

Figure 45: Turbulent Kinetic Energy Contour at U-Bend

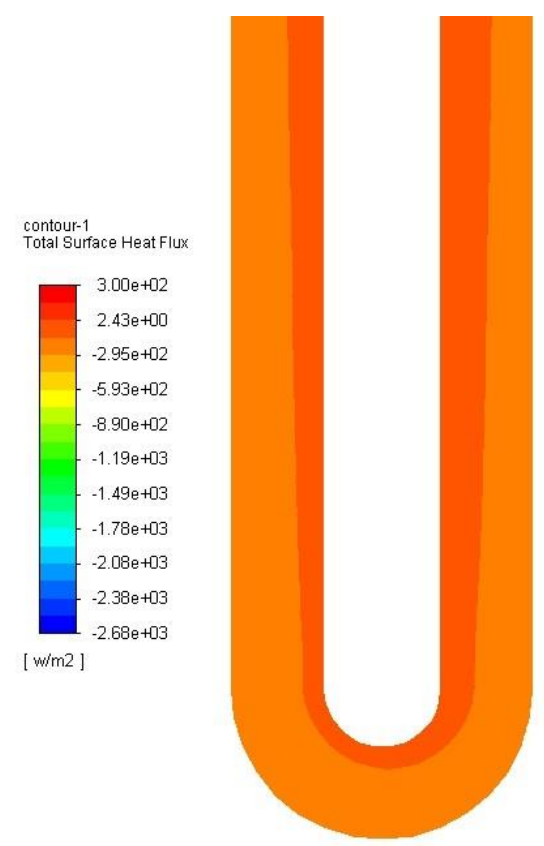

Figure 46: Heat Flux Contour at U- Bend 


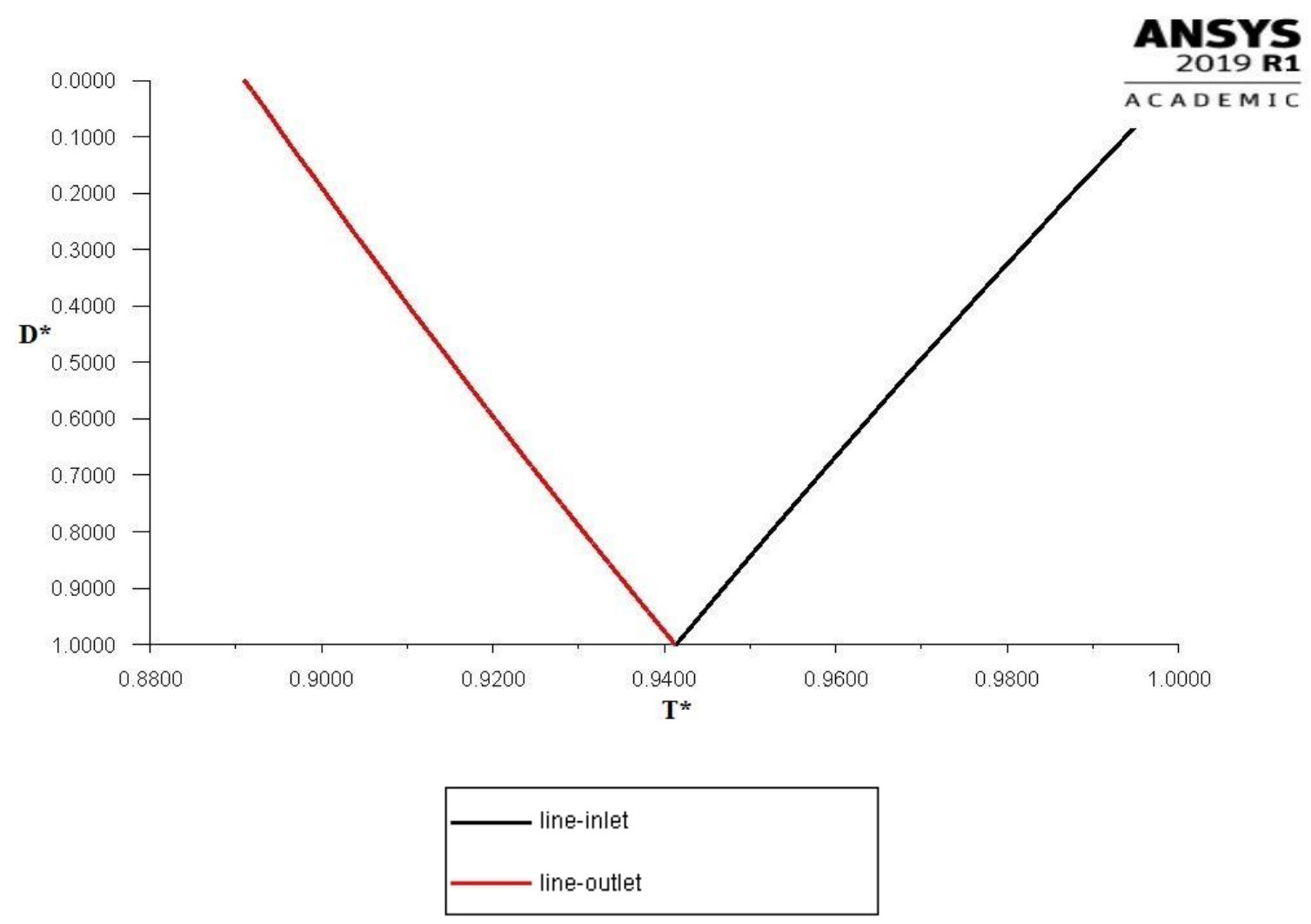

Figure 47: $D^{*}$ vs $T^{*}$ result

Figure 44 shows the temperature contour of the hex mesh test case, while Figure 45 depicts turbulent kinetic energy contours at the $\mathrm{u}$ - bend and Figure 46 shows the total surface heat flux. Figure 47 is the curve between the non-dimensional depth(D*) and non-dimensional temperature $\left(\mathrm{T}^{*}\right)$ for the given test case.

On comparing the non-dimensional depth $\left(\mathrm{D}^{*}\right)$ vs non-dimensional temperature $\left(\mathrm{T}^{*}\right)$ curves for coarse polyhedral mesh from Figure 35 and hexahedral mesh from Figure 47, we see that they are in close agreement with each other, in terms of the $\mathrm{T}^{*}$ at $\mathrm{D}^{*}$ equals 1. Also, comparing the outlet temperatures from Table 12, it can be observed that the outlet temperatures from the two different mesh types was close to each other and hence, we can 
conclude that the result from the numerical simulation was independent of the type of mesh used.

Table 12:Table Summarizing Mesh Independence Study

\begin{tabular}{|c|c|c|c|c|c|c|}
\hline Mesh Type & $\begin{array}{l}\text { Component } \\
\text { Name }\end{array}$ & $\begin{array}{l}\text { Number } \\
\text { of Cells } \\
\text { (in } \\
\text { millions) }\end{array}$ & $\begin{array}{l}\text { Cells } \\
\text { across } \\
\text { gap }\end{array}$ & $\begin{array}{l}\text { Prism } \\
\text { cells in } \\
\text { millions }\end{array}$ & $\begin{array}{l}\text { Number } \\
\text { of Prism } \\
\text { layers }\end{array}$ & $\begin{array}{l}\text { Outlet } \\
\text { Temperature } \\
\text { in } K\end{array}$ \\
\hline \multirow{4}{*}{$\begin{array}{l}\text { Hexahedral- } \\
4.0 \text { million } \\
\text { cells }\end{array}$} & Domain & 0.22 & 3 & - & - & \multirow[t]{4}{*}{$291.05 \mathrm{~K}$} \\
\hline & Grout & 1.01 & 4 & - & - & \\
\hline & Pipe & 1.31 & 5 & - & - & \\
\hline & Fluid & 1.49 & 10 & - & - & \\
\hline \multirow{4}{*}{$\begin{array}{l}\text { Polyhedral- } \\
3.92 \text { million } \\
\text { cells }\end{array}$} & Domain & 0.485 & 3 & - & - & \multirow[t]{4}{*}{$291.56 \mathrm{~K}$} \\
\hline & Grout & 1.57 & 10 & - & - & \\
\hline & Pipe & 0.95 & 3 & - & - & \\
\hline & Fluid & 0.92 & 3 & - & - & \\
\hline
\end{tabular}

3.6.1.5. Results of $0.8 \mathrm{~m} / \mathrm{s}$ Inlet velocity with Enhanced Wall Treatment and Realizable k- $\varepsilon$ Model with Hex Mesh

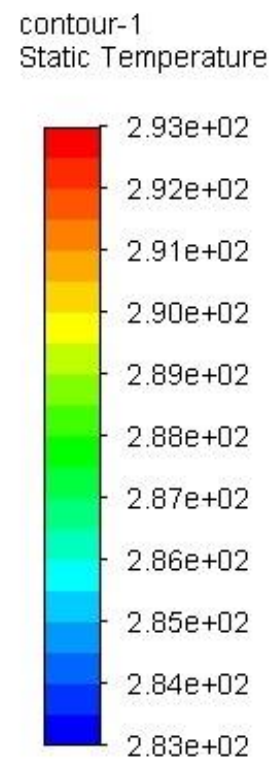

[k]
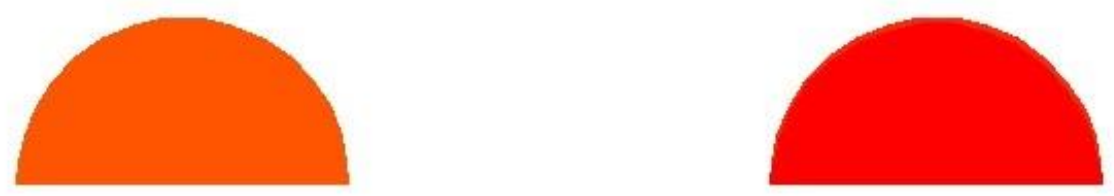

Figure 48: Inlet and Outlet Temperature Contour 
Contour-1 1 Turbulent Kinetic Energy ( $(k)$
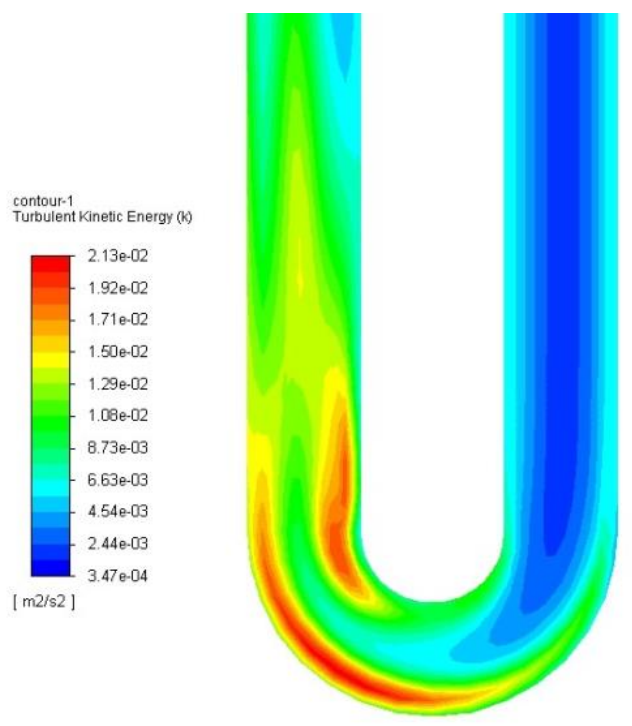

Figure 49: Turbulent Kinetic Energy Contour at U-Bend

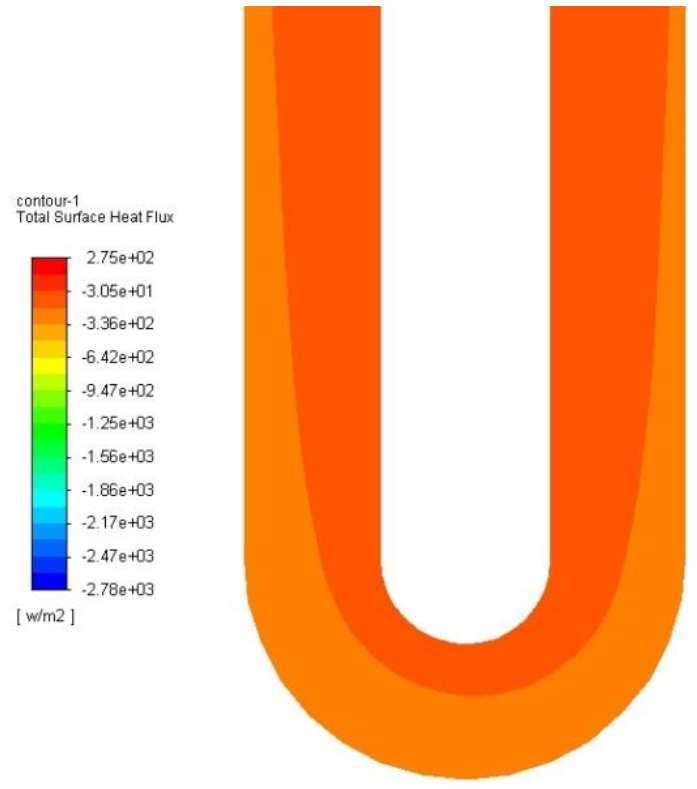

Figure 50: Heat Flux Contour at U- Bend 


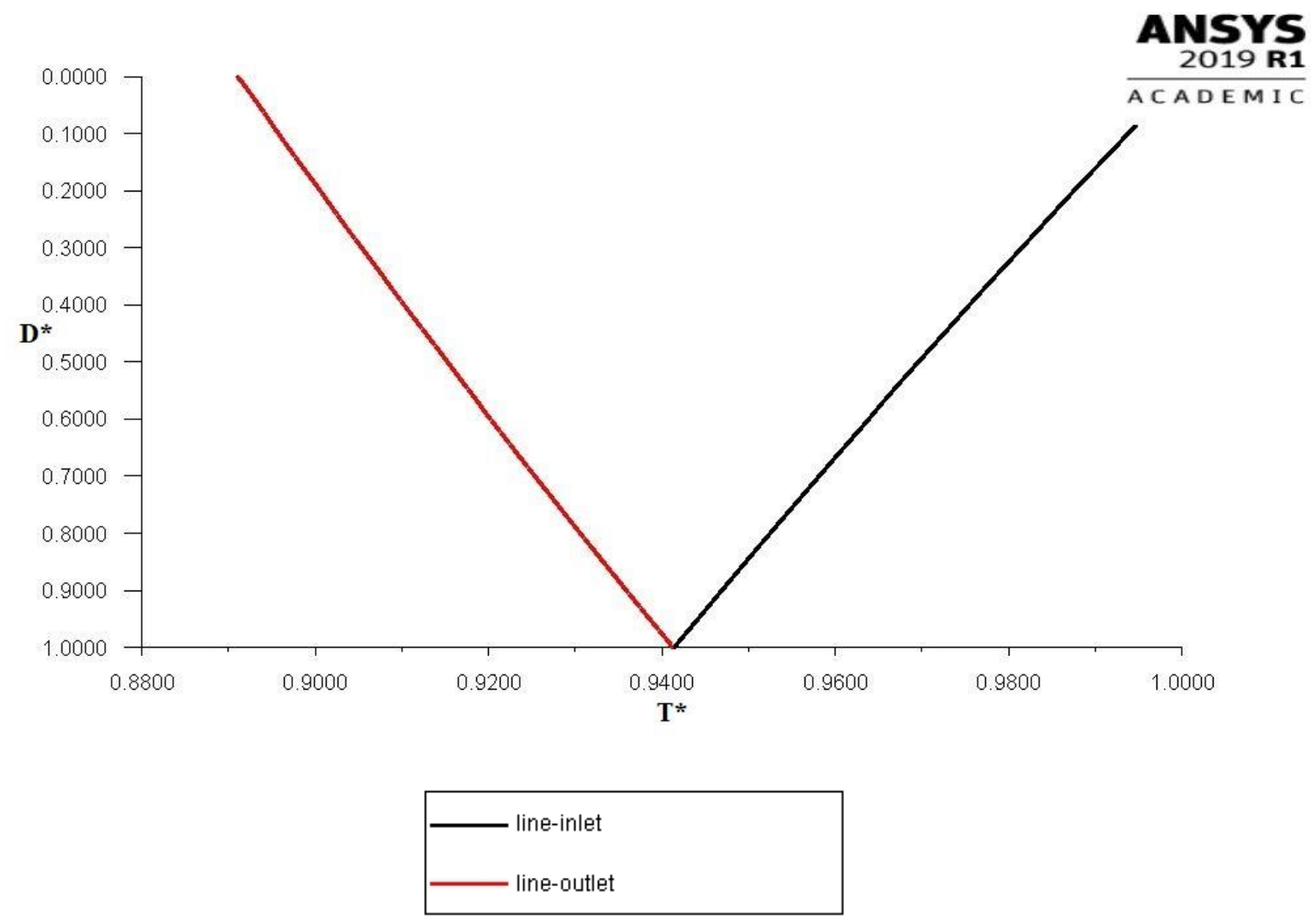

Figure 51: D* vs T* result

Figure 48 shows the inlet and outlet temperature contour for the given test case, whereas Figure 49 shows the turbulent kinetic energy contour at the u-bend of the pipe, and as seen in the earlier test cases, at the u-bend of the pipe, there is generation of eddies due to the flow becoming turbulent and subsequently from Figure 50 it is seen that the rate of heat transfer has also increased at the u-section. Figure 51 shows the non-dimensional temperature $\left(\mathrm{T}^{*}\right)$ at various non-dimensional( $\left.\mathrm{D}^{*}\right)$ depth of the borehole.

On comparing the $\mathrm{D}^{*}$ vs $\mathrm{T}^{*}$ curves from Figure 51 and Figure 47, we see that both the curves have similar trends for $\mathrm{T}^{*}$ at $\mathrm{D}^{*}$ equals 1 , and as such it can be concluded that the type of turbulence model used had no effect upon the outcome of the numerical simulation. 
3.6.1.6. Results of $0.8 \mathrm{~m} / \mathrm{s}$ Inlet velocity with Standard Wall Treatment and Standard k- $\varepsilon$ Model with Hex Mesh and Gravity

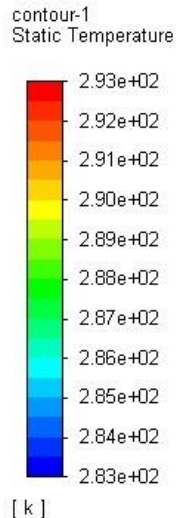

$[\mathrm{k}]$
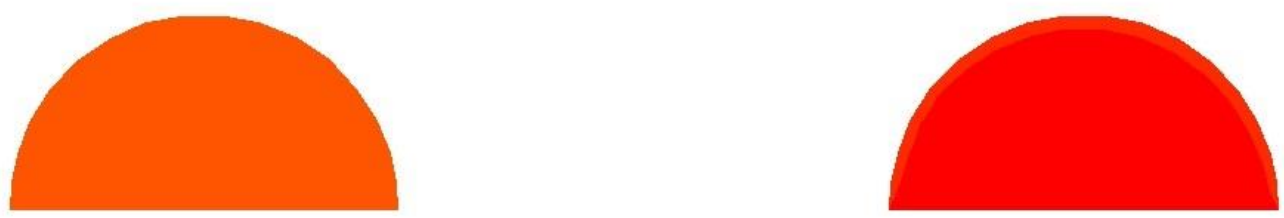

Figure 52: Inlet and Outlet Temperature Contour
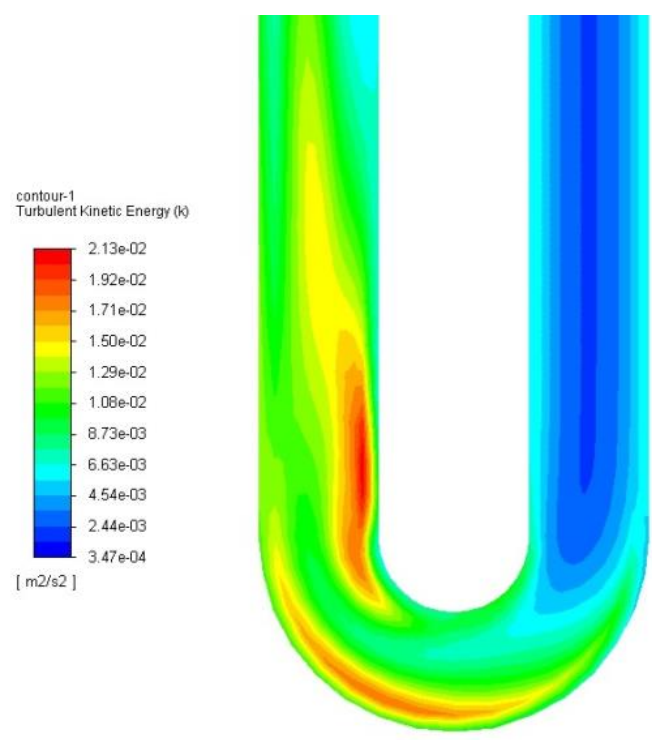

Figure 53 : Turbulent Kinetic Energy Contour at U-Bend 


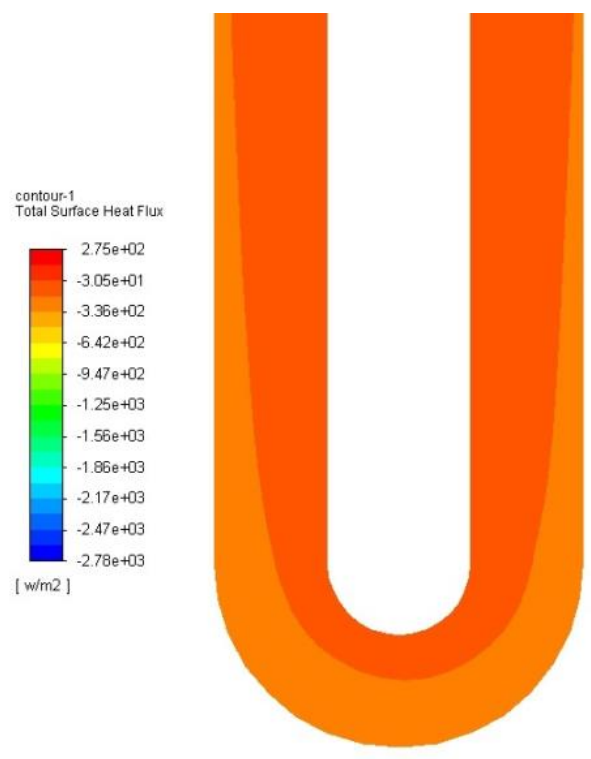

Figure 54: Heat Flux Contour at U- Bend

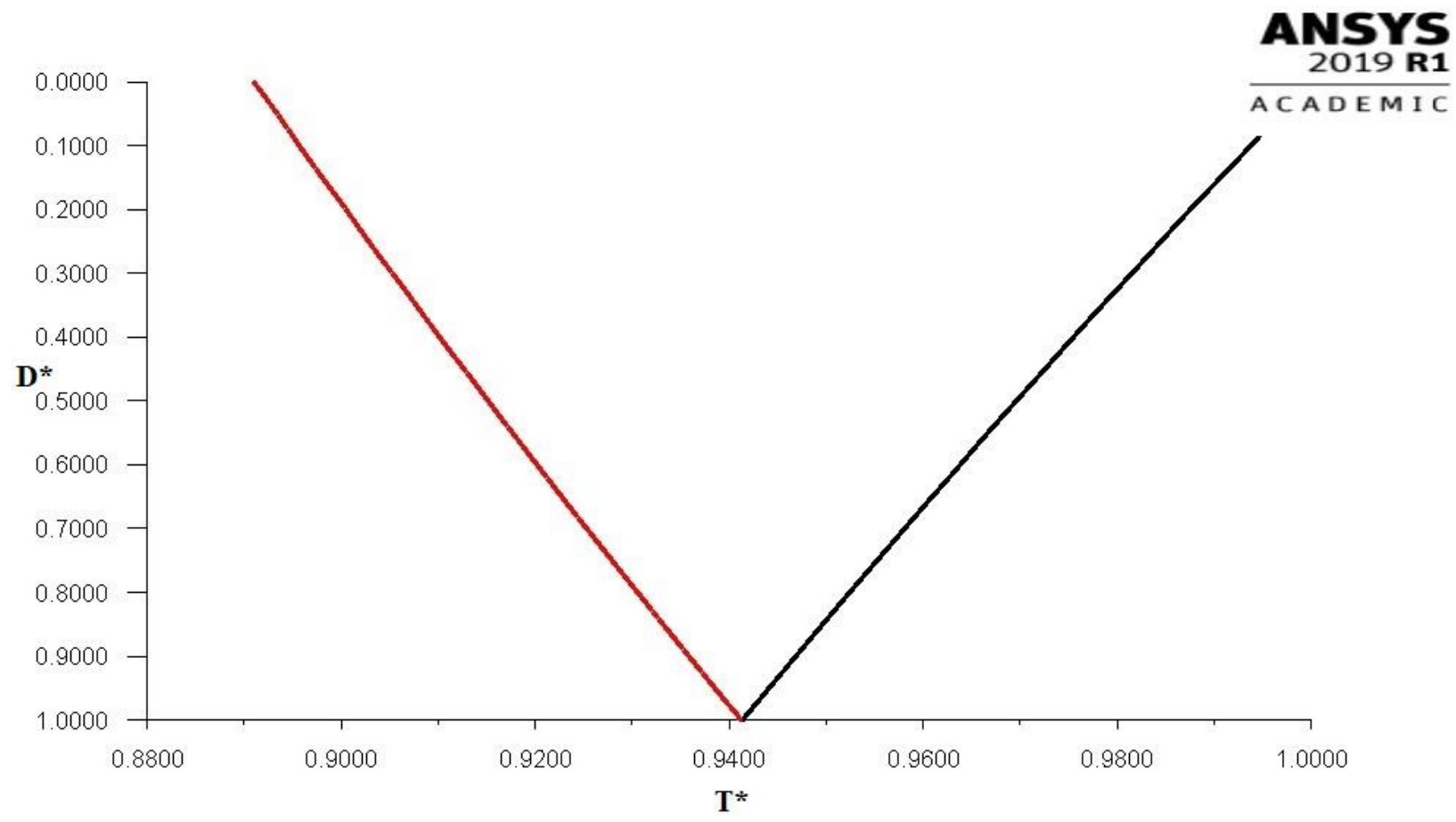

Figure 55: $\mathrm{D}^{*}$ vs $\mathrm{T}^{*}$ result 
Figure 52 shows the inlet and outlet temperature contour of the given test case with gravity being considered. Whereas, Figure 53 depicts the turbulence kinetic energy of the flow at the u-bend and Figure 54 shows the surface heat flux. Figure 55 shows, the nondimensional depth, $\mathrm{D}^{*}$ vs non-dimensional temperature, $\mathrm{T}^{*}$.

On comparing Figure 55 and Figure 47, we see that, the $\mathrm{D}^{*}$ vs $\mathrm{T}^{*}$ curve are the same and henceforth it can be concluded that the gravity has no effect upon the outcome of the numerical simulation and as such the hypothesis of gravity not having any effect on a pressure driven flow has been proved to hold true.

\subsubsection{Validation of Results}

\subsubsection{Validation of Results with He, M., 2012}

\subsection{Results of $0.2 \mathrm{~m} / \mathrm{s}$ Inlet velocity with Standard Wall Treatment and Standard k- $\varepsilon$ Model with Hex Mesh}
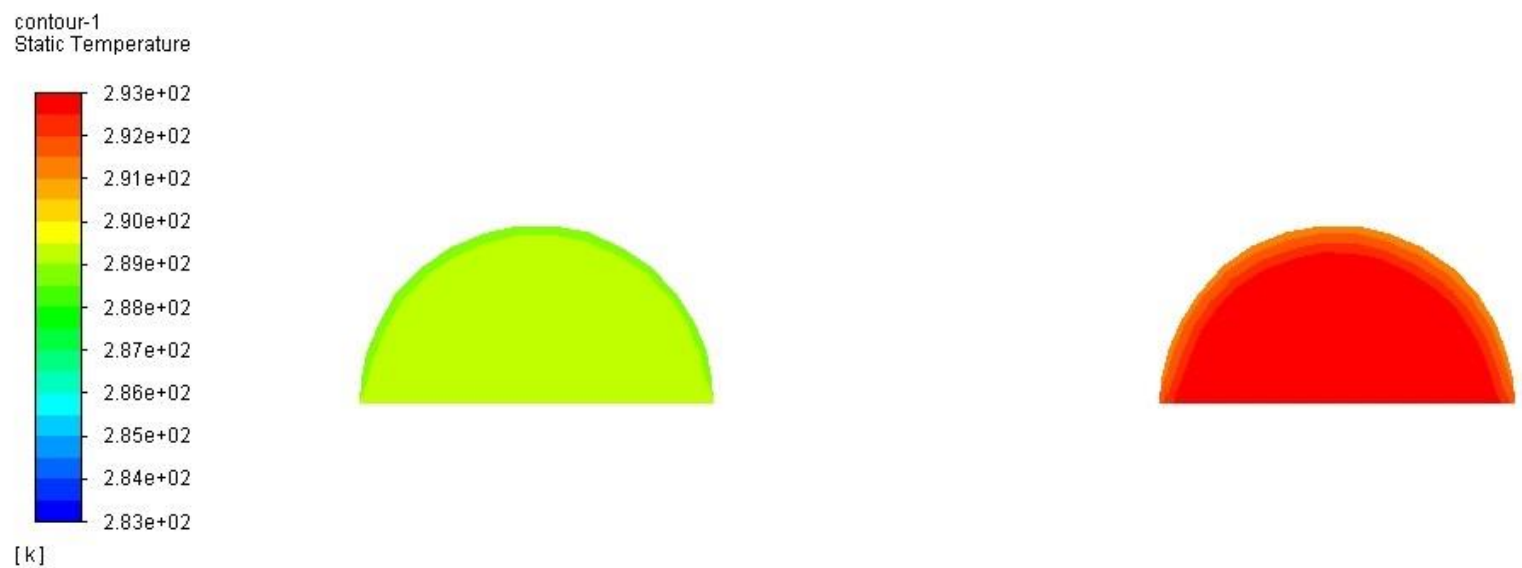

Figure 56: Inlet and Outlet Temperature Contour 


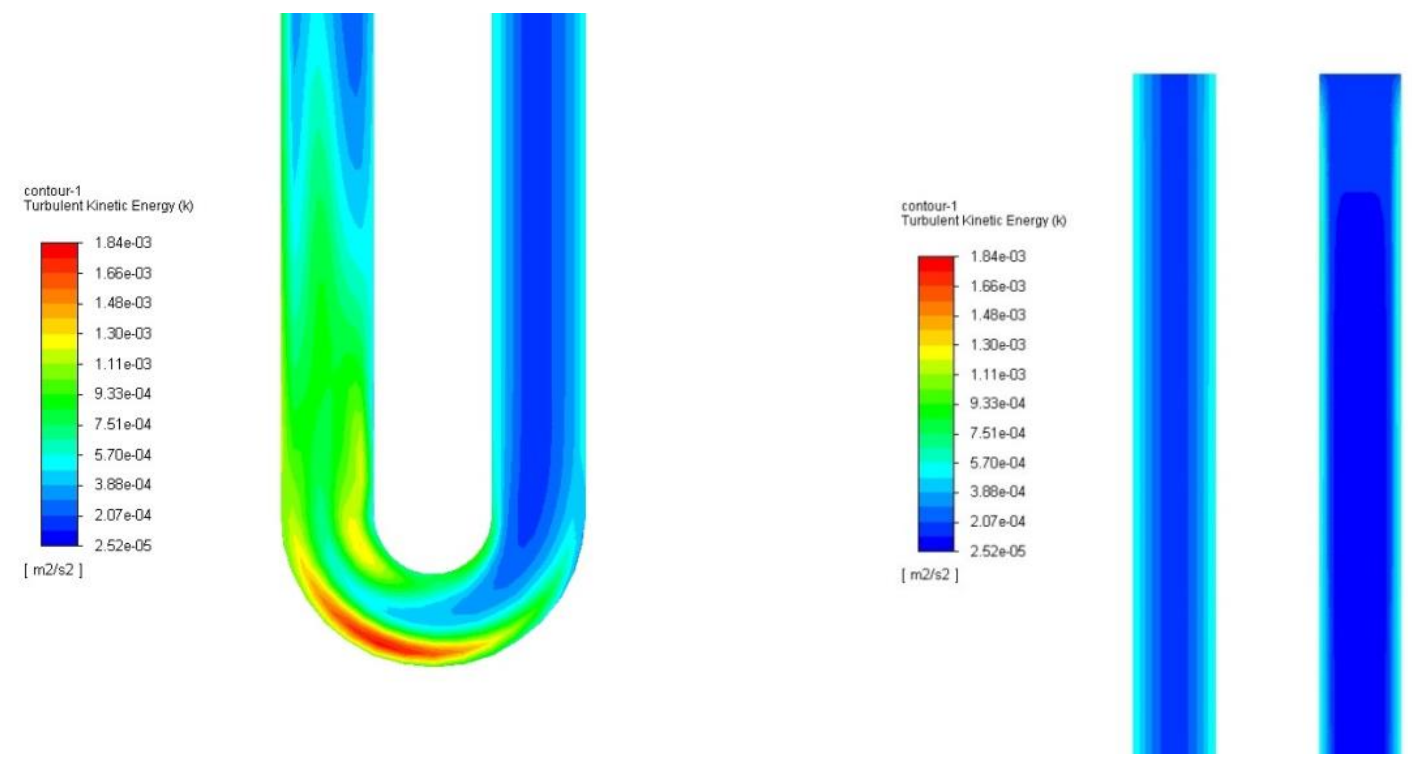

Figure 57: Turbulent Kinetic Energy Contour at U-Bend and at Inlet and Outlet Sections
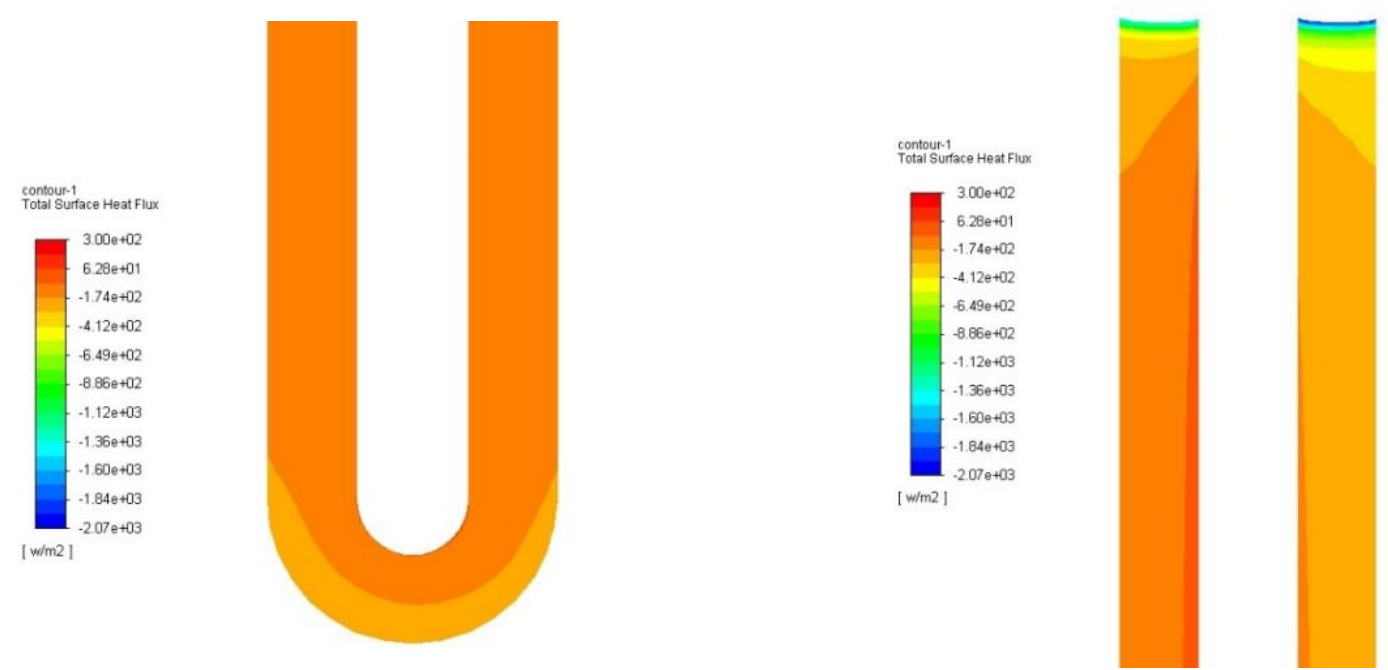

Figure 58: Heat Flux Contour at U-Bend and at Inlet and Outlet Sections at Fluid-PipeInterface 

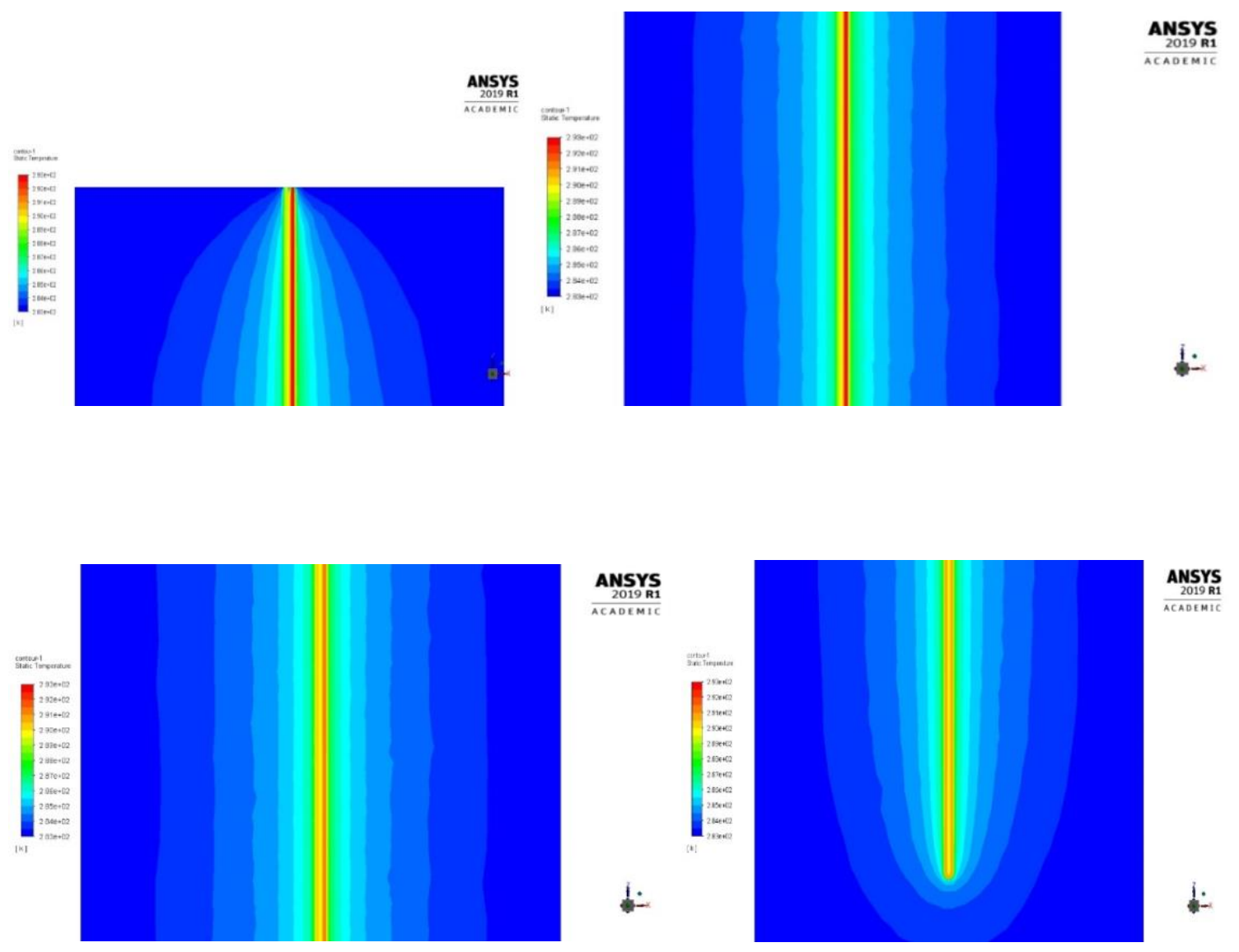

\section{ANSYS}

ACADEMIC

.

i.

Figure 59 : Temperature Contour

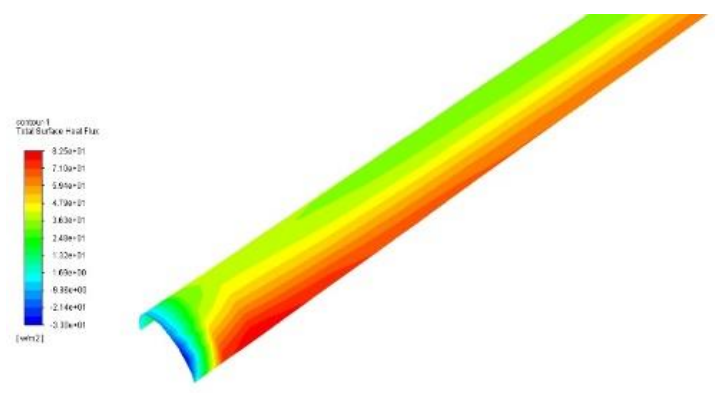

ANSYS

$\frac{2019 \text { R1 }}{\text { ACADEMIC }}$

d

Figure 60 : Heat Flux Contour at Grout-Domain Interface 


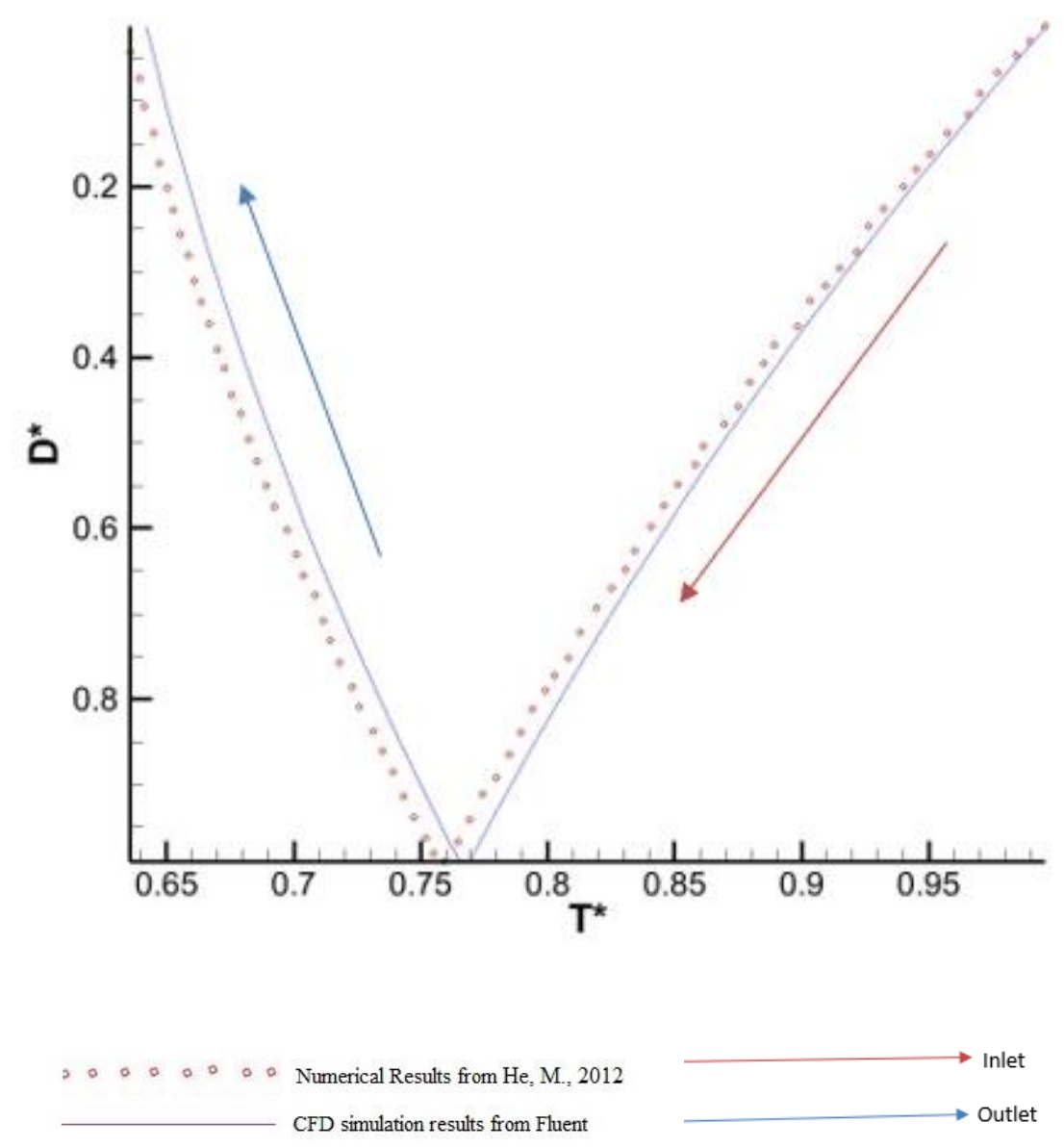

Figure 61 : Dotted Curve represents data from He, M., 2012 and Continuous line represents results obtained from CFD simulation in Fluent

Figure 56 shows the inlet and outlet temperature contours which shows that the outlet temperature achieved for this particular inlet fluid velocity was found to be 289 . 56K.Figure 57 shows the turbulent kinetic energy contour at the straight path and the ubend section. It is evident from the contour that at the inlet there is minor turbulence due to the pressure driven flow and at the u-bend section which leads to the generation of minor eddies. Also, the surface heat flux contours at the fluid-pipe interface depicted in Figure 58 shows the heat transfer rate is higher wherever there is turbulence. Figure 59 shows the temperature distribution contour plotted at the symmetrical plane and Figure 60 shows the 
heat flux contour at the grout-domain interface. Finally, Figure 61 shows the curve between non-dimensional depth $\left(\mathrm{D}^{*}\right)$ and non-dimensional temperature $\left(\mathrm{T}^{*}\right)$, where the dotted line represents the data from, He, M., 2012 and the continuous line represents the numerical simulation results from ANSYS Fluent 2019R1. It is seen from this figure that both the results are in agreement at the inlet sections whereas they deviate as the flow proceeds towards the outlet via the u-bend section.

\subsection{Results of $0.4 \mathrm{~m} / \mathrm{s}$ Inlet velocity with Standard Wall Treatment and Standard k- $\varepsilon$ Model}

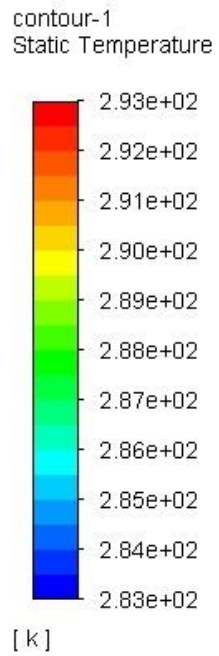

[k]
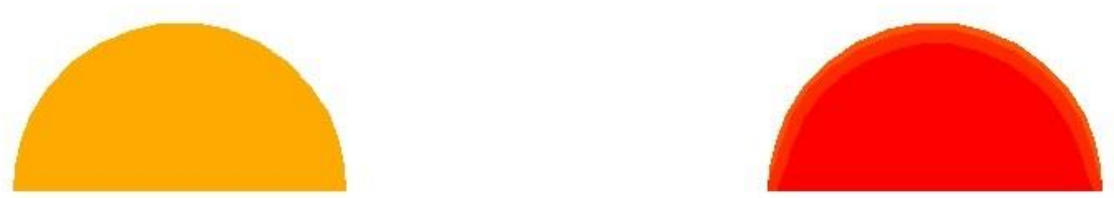

Figure 62: Inlet and Outlet Temperature Contour 

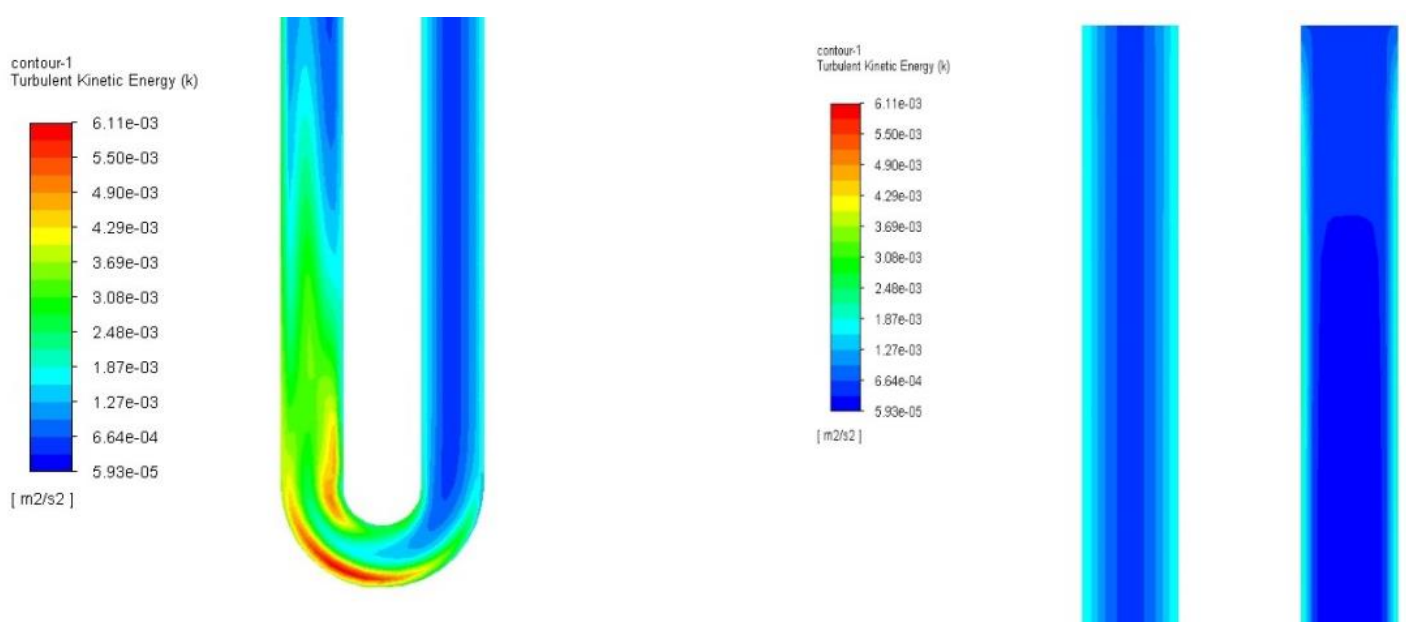

Figure 63 : Turbulent Kinetic Energy Contour at U-Bend and at Inlet and Outlet Sections
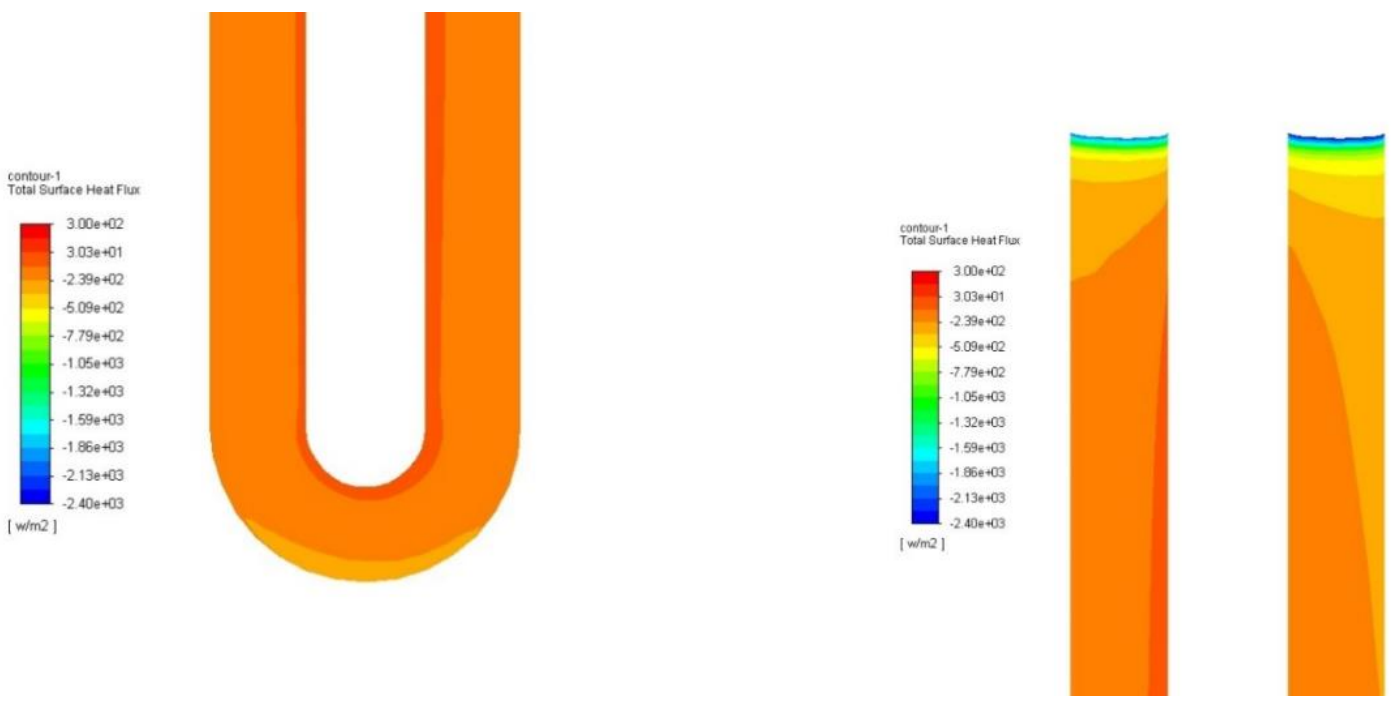

Figure 64: Heat Flux Contour at U-Bend and at Inlet and Outlet Sections in the fluidpipe-interface 

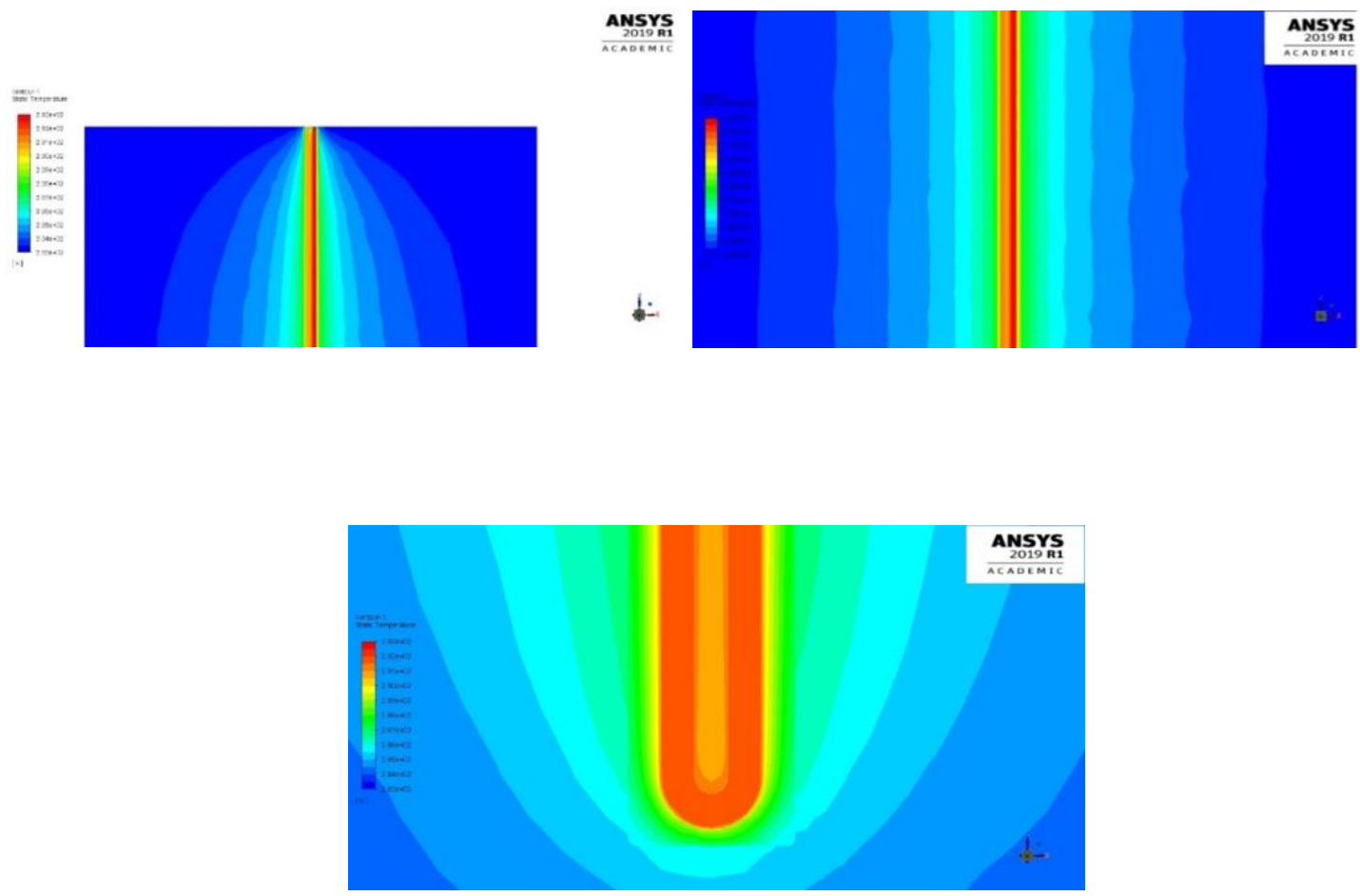

Figure 65 : Temperature Contours

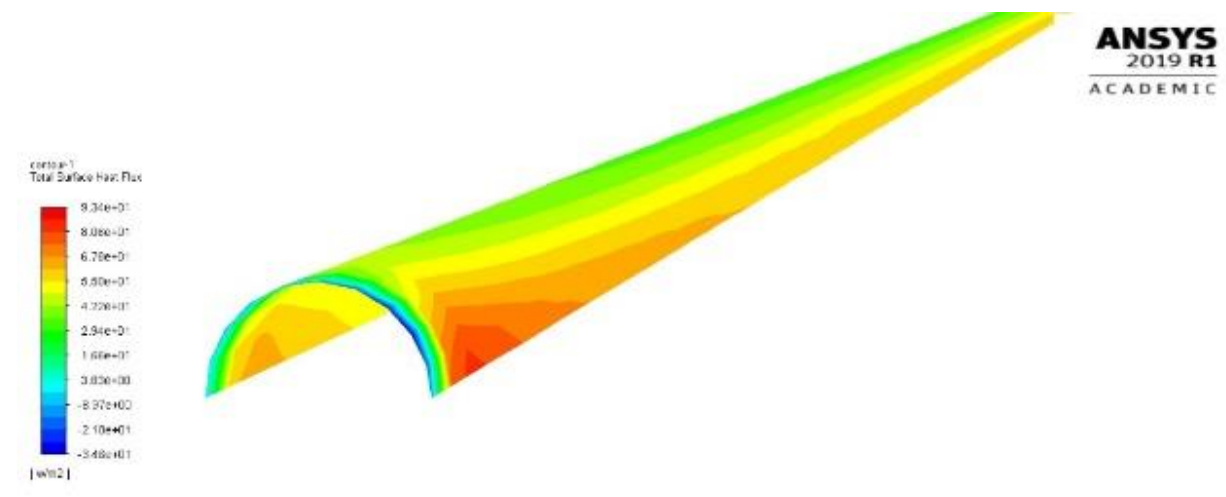

1.:-

Figure 66 : Heat Flux Contour at Grout-Domain Interface 


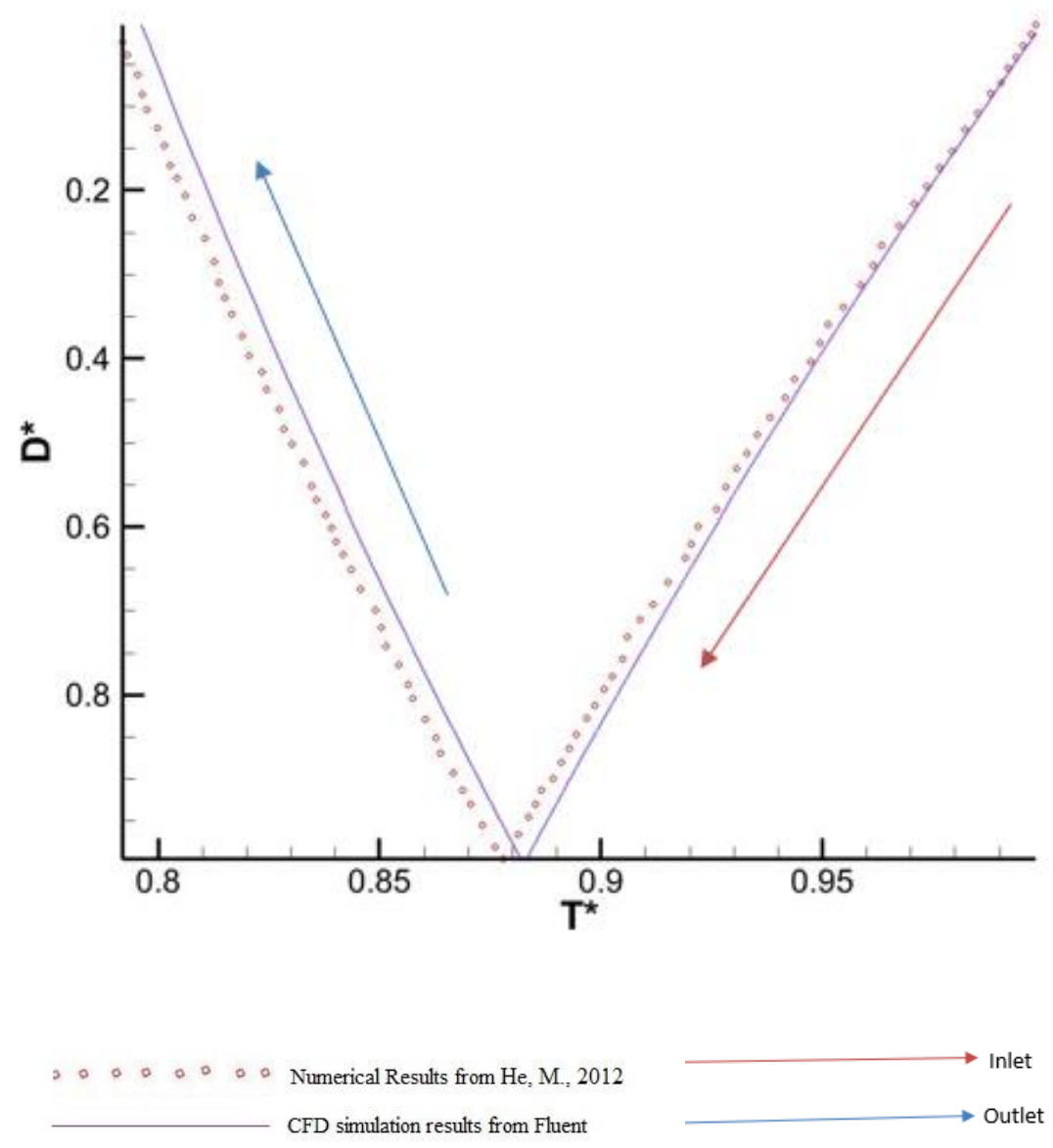

Figure 67 : Dotted Curve represents data from He, M., 2012 and Continuous line represents results obtained from CFD simulation in Fluent

Figure 62 shows the inlet and outlet temperature contours which shows that the outlet temperature achieved for this particular inlet fluid velocity was found to be 291.11 K.Figure 63 shows the turbulent kinetic energy contour at the straight section of the pipe and the ubend section. It is evident from the contour that at the inlet there is minor turbulence due to the pressure driven flow and at the u-bend section which leads to the generation of minor eddies which induces mixing of cold and hot fluid. Also, the surface heat flux contours at the fluid-pipe interface depicted in Figure 64 shows the heat transfer rate is higher wherever there is turbulence. Figure 65 shows the temperature distribution contour plotted at the 
symmetrical plane and Figure 66 shows the heat flux contour at the grout-domain interface. Finally, Figure 67 shows the curve between non-dimensional depth( $\left.\mathrm{D}^{*}\right)$ and nondimensional temperature ( $\left.T^{*}\right)$, where the dotted line represents the data from, He, M., 2012 and the continuous line represents the numerical simulation results from ANSYS Fluent 2019R1. It is seen from this figure that both the results are in agreement at the inlet sections due to the inlet boundary conditions being the same for both the simulation results whereas they deviate from as the flow proceeds towards the outlet via the u-bend section.

\subsection{Results of $0.6 \mathrm{~m} / \mathrm{s}$ Inlet velocity and Standard Wall Treatment and Standard k- $\varepsilon$ Model}

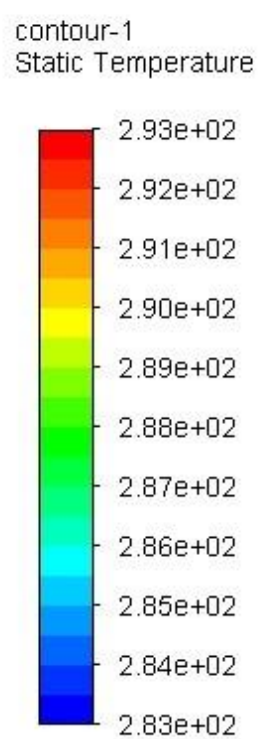

[k]
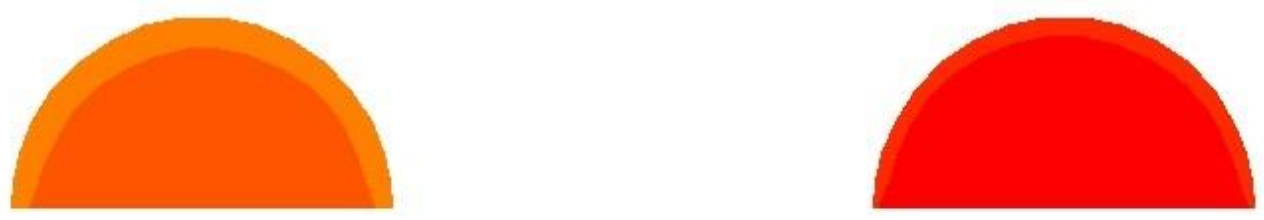

Figure 68: Inlet and Outlet Temperature Contour 

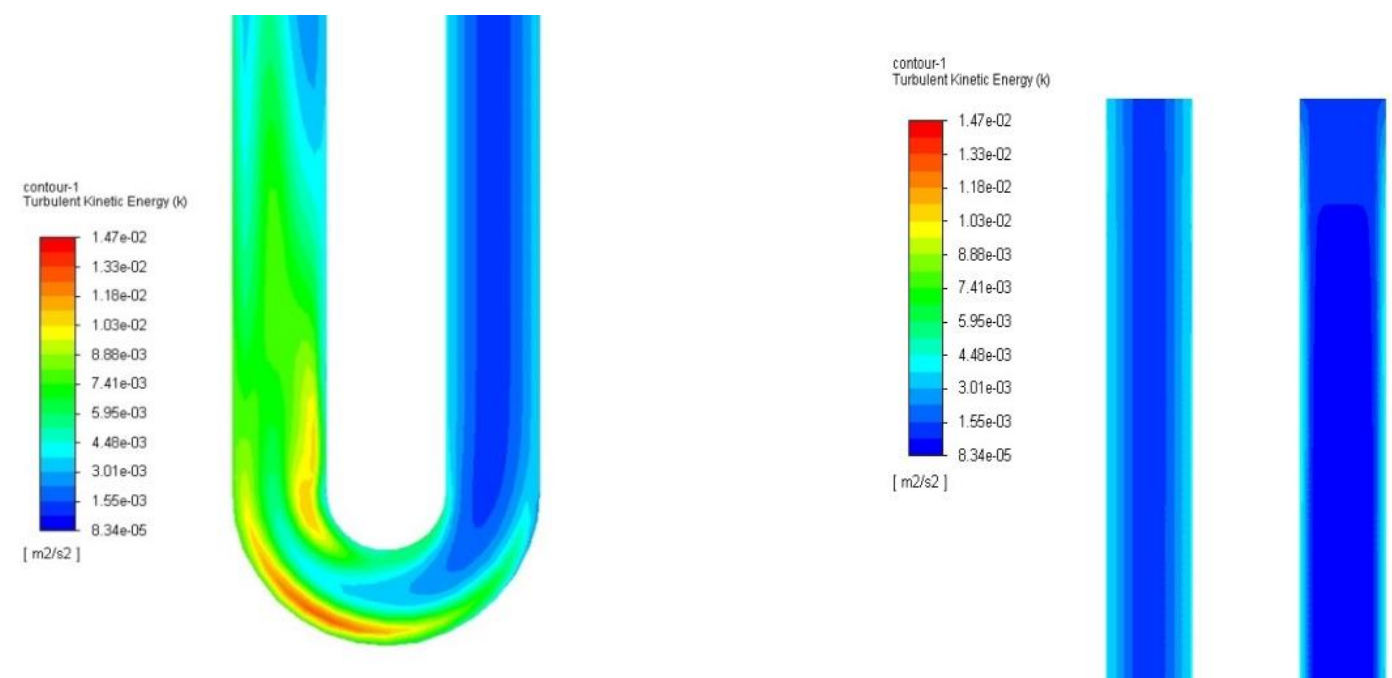

Figure 69 : Turbulent Kinetic Energy Contour at U-Bend and at Inlet and Outlet Sections
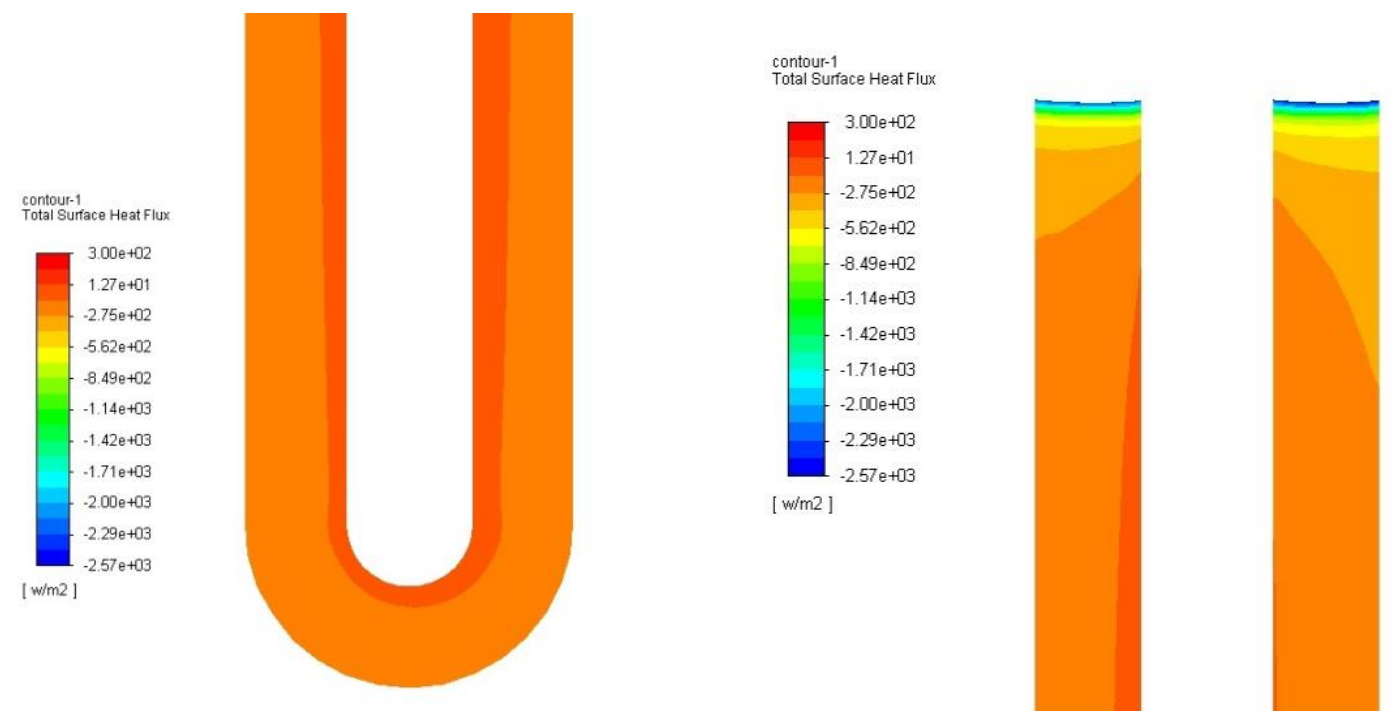

Figure 70 : Heat Flux Contour at U-Bend and at Inlet and Outlet Sections at Fluid-PipeInterface 

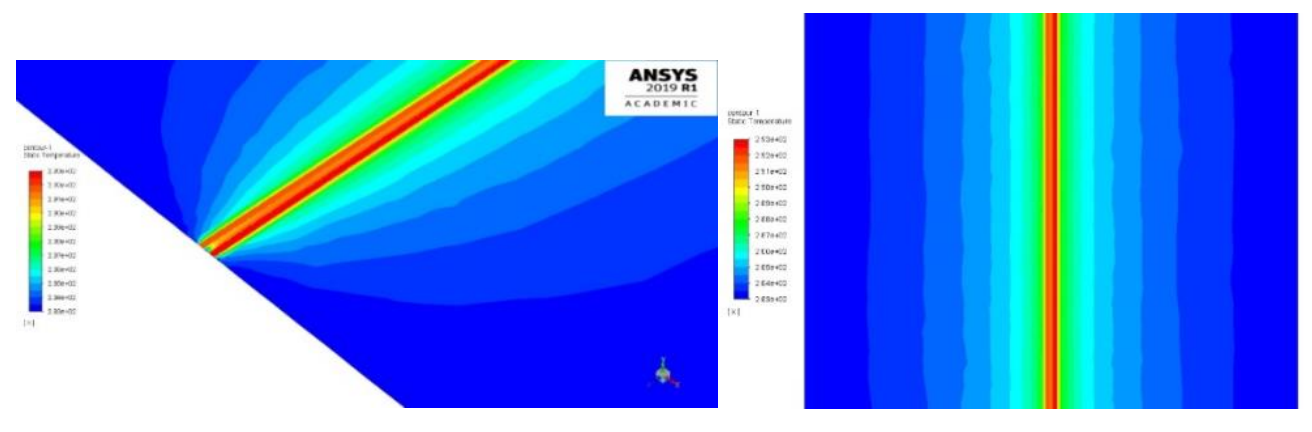

$\underset{2019}{\text { ANS }}$

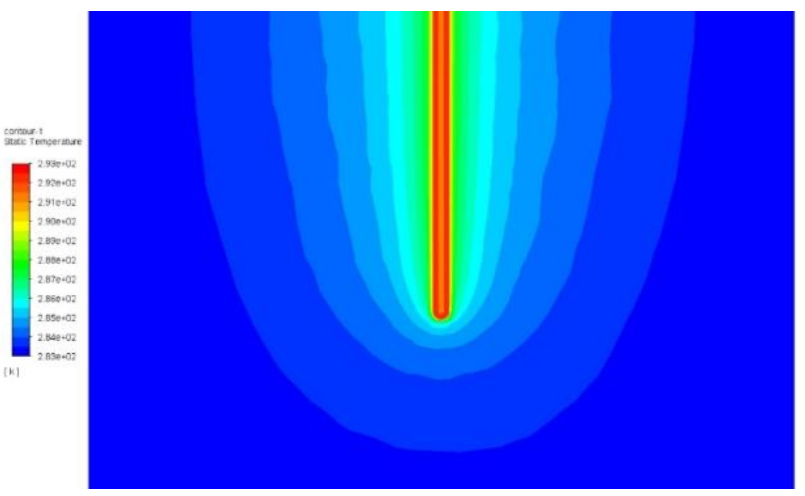

ANSYS

$\frac{\text { ACADEMIC }}{\text { A }}$

1.

Figure 71: Temperature Contours

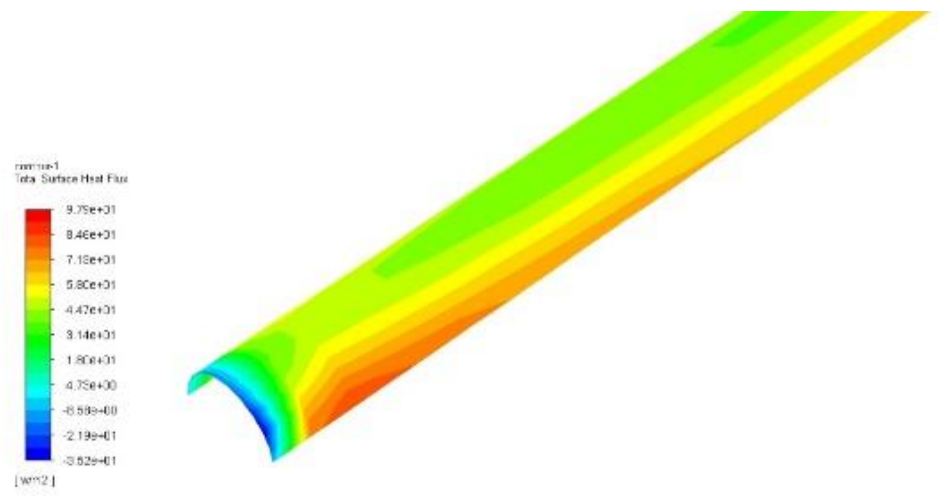

\section{ANSYS}

2019 R1

Figure 72 : Heat Flux Contour at Grout-Domain Interface

美. 


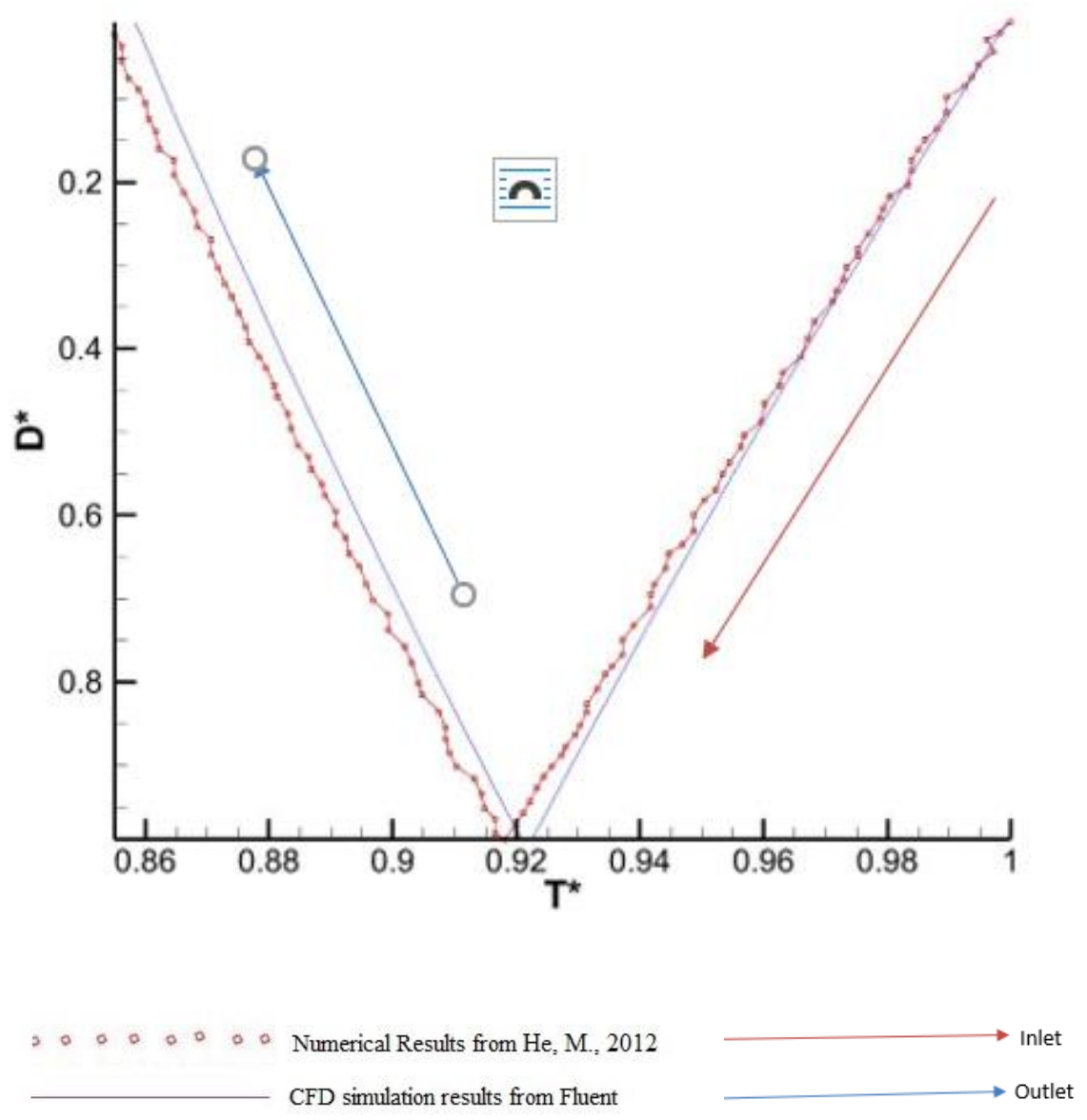

Figure 73: Dotted Curve represents data from He, M., 2012 and Continuous line represents results obtained from CFD simulation in Fluent

Figure 68 shows the inlet and outlet temperature contours which shows that the outlet temperature achieved for this particular inlet fluid velocity was found to be 291.72K.Figure 69 shows the turbulent kinetic energy contour at the straight section of the pipe and the ubend section. It is observed from the turbulent kinetic energy contour that at the inlet there is generation of minor turbulence due to the pressure driven flow and at the u-bend which leads to the generation of minor eddies which induces mixing of cold and hot fluid as mentioned earlier. Also, the surface heat flux contours at the fluid-pipe interface depicted in Figure 70 shows the heat transfer rate is higher wherever there is turbulence. Figure 71 
shows the temperature distribution contour plotted at the symmetrical plane and Figure 72 shows the heat flux contour at the grout-domain interface. Finally, Figure 73 shows the curve between non-dimensional depth( $\left.\mathrm{D}^{*}\right)$ and non-dimensional temperature $\left(\mathrm{T}^{*}\right)$, where the dotted line represents the data from, He, M., 2012 and the continuous line represents the numerical simulation results from ANSYS Fluent 2019R1. It is again observed from this figure that both the results are in agreement at the inlet sections due to the inlet boundary conditions being the same for both the simulation results whereas they deviate from as the flow proceeds towards the outlet via the u-bend section.

\subsection{Results of $0.8 \mathrm{~m} / \mathrm{s}$ Inlet Velocity Standard Wall Treatment and Standard k- $\varepsilon$ Model}
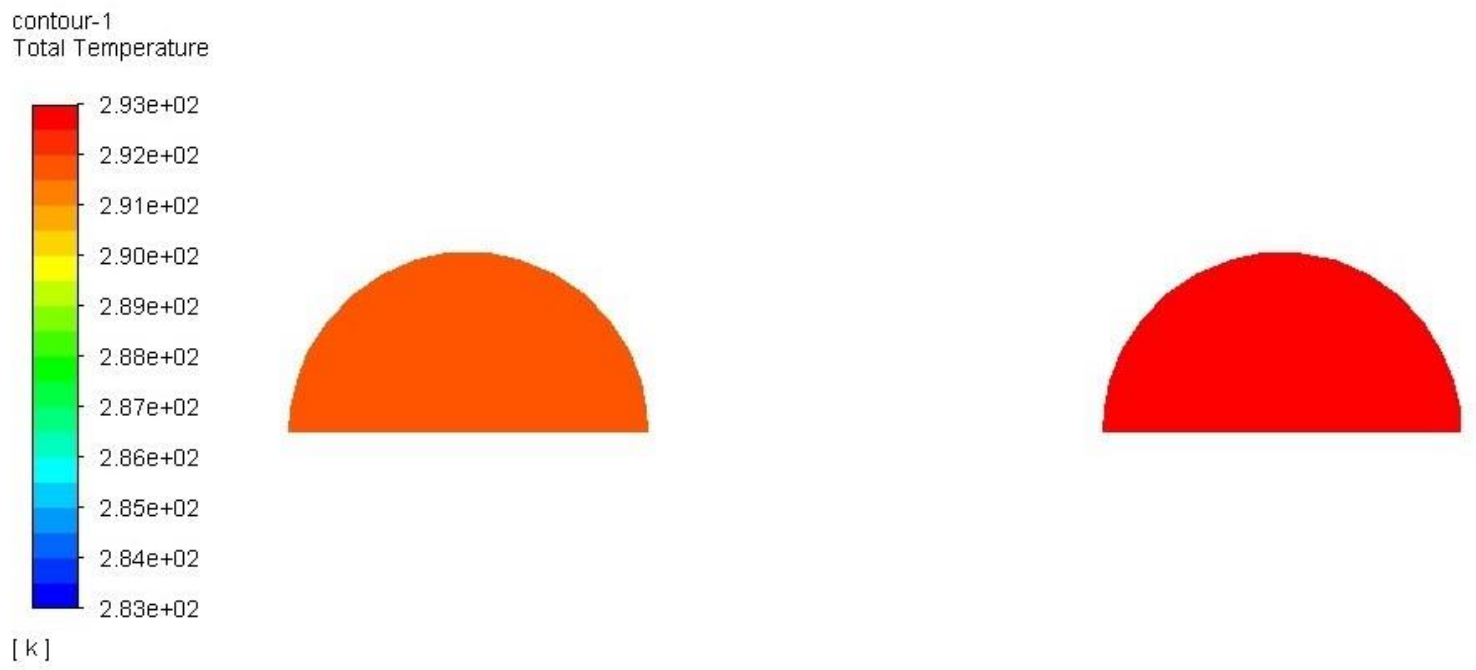

Figure 74 : Inlet and Outlet Temperature Contour 

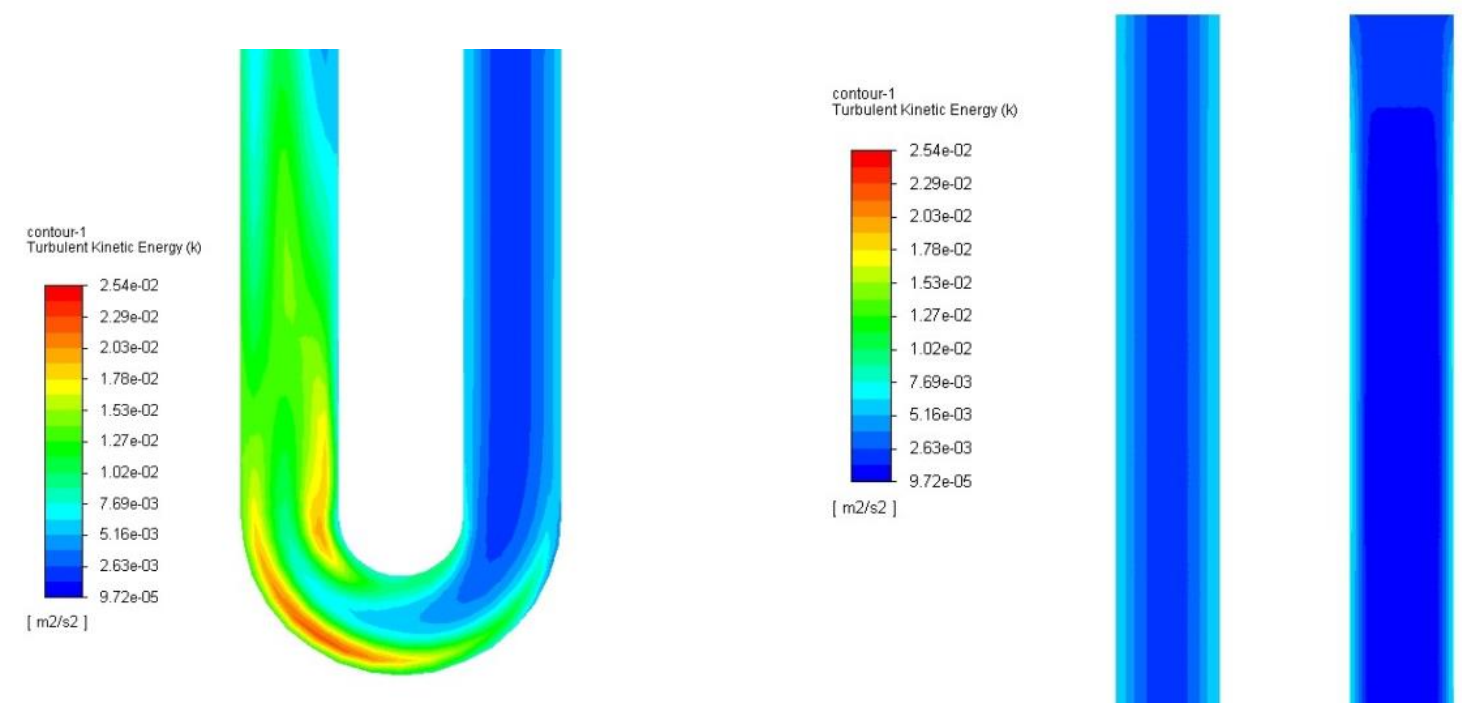

Figure 75 : Turbulent Kinetic Energy Contour at U-Bend and at Inlet and Outlet Sections
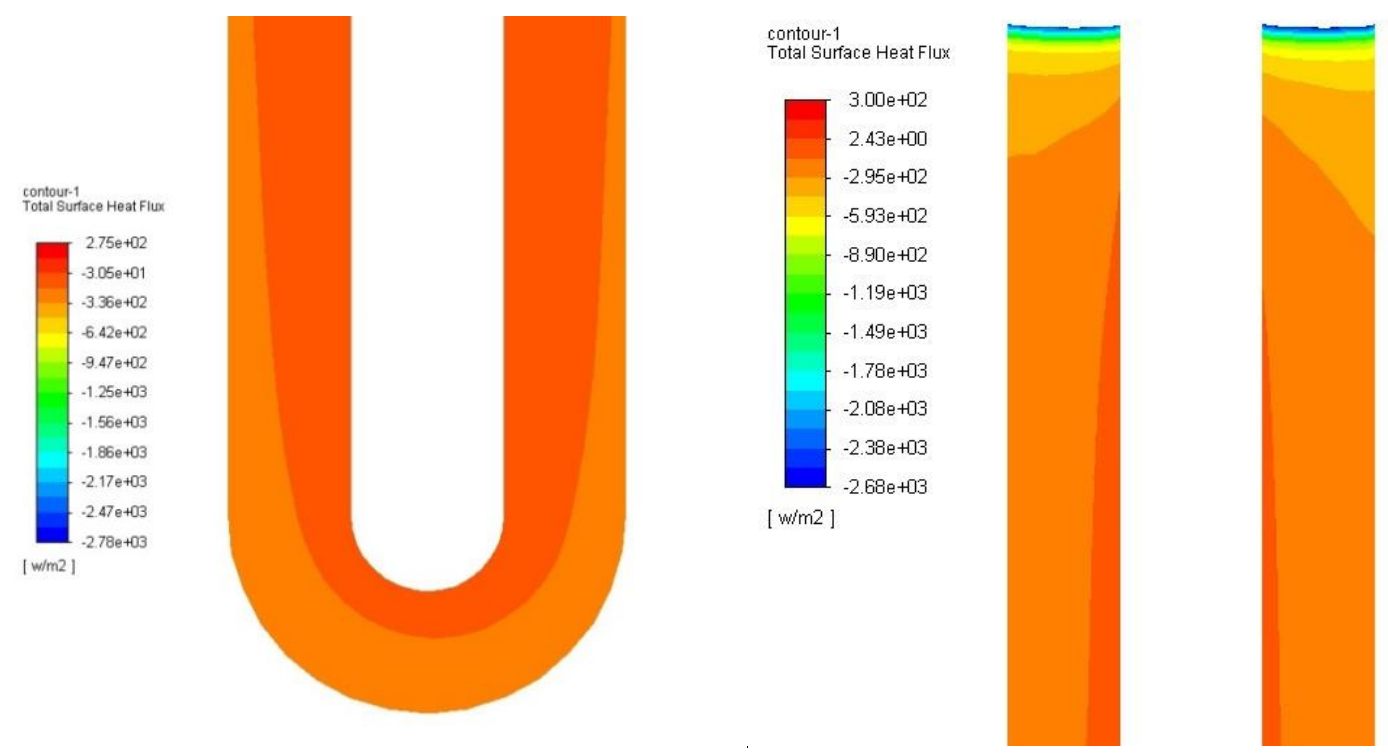

Figure 76: Heat Flux Contour at U-Bend and at Inlet and Outlet Sections at Fluid-PipeInterface 

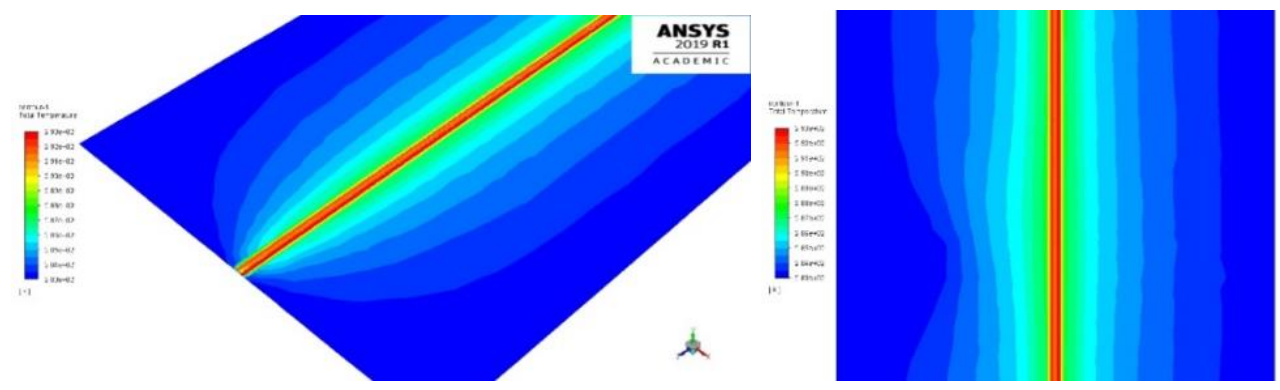

ANSYS

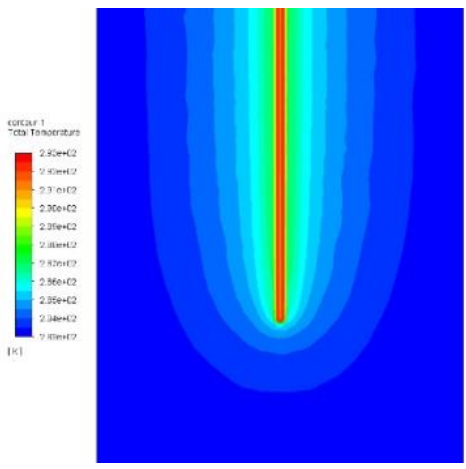

ANSYS

1.

Figure 77 : Temperature Contour

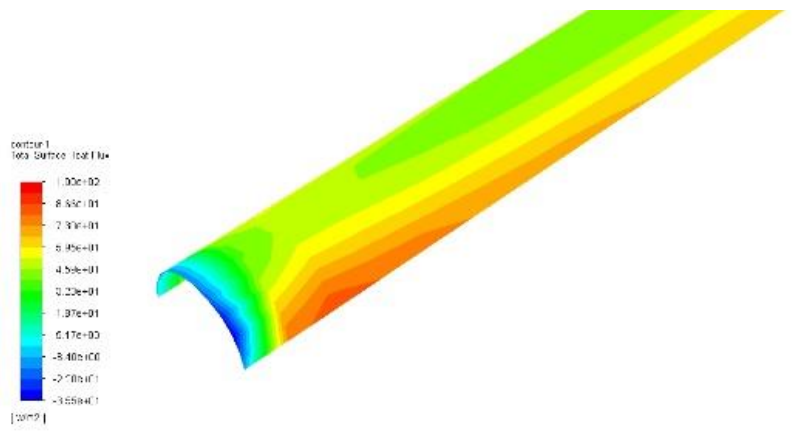

ANSYS

$\frac{2019 \text { R1 }}{\text { ACADEMIC }}$

오.

Figure 78 : Heat Flux Contour at Grout-Domain Interface 


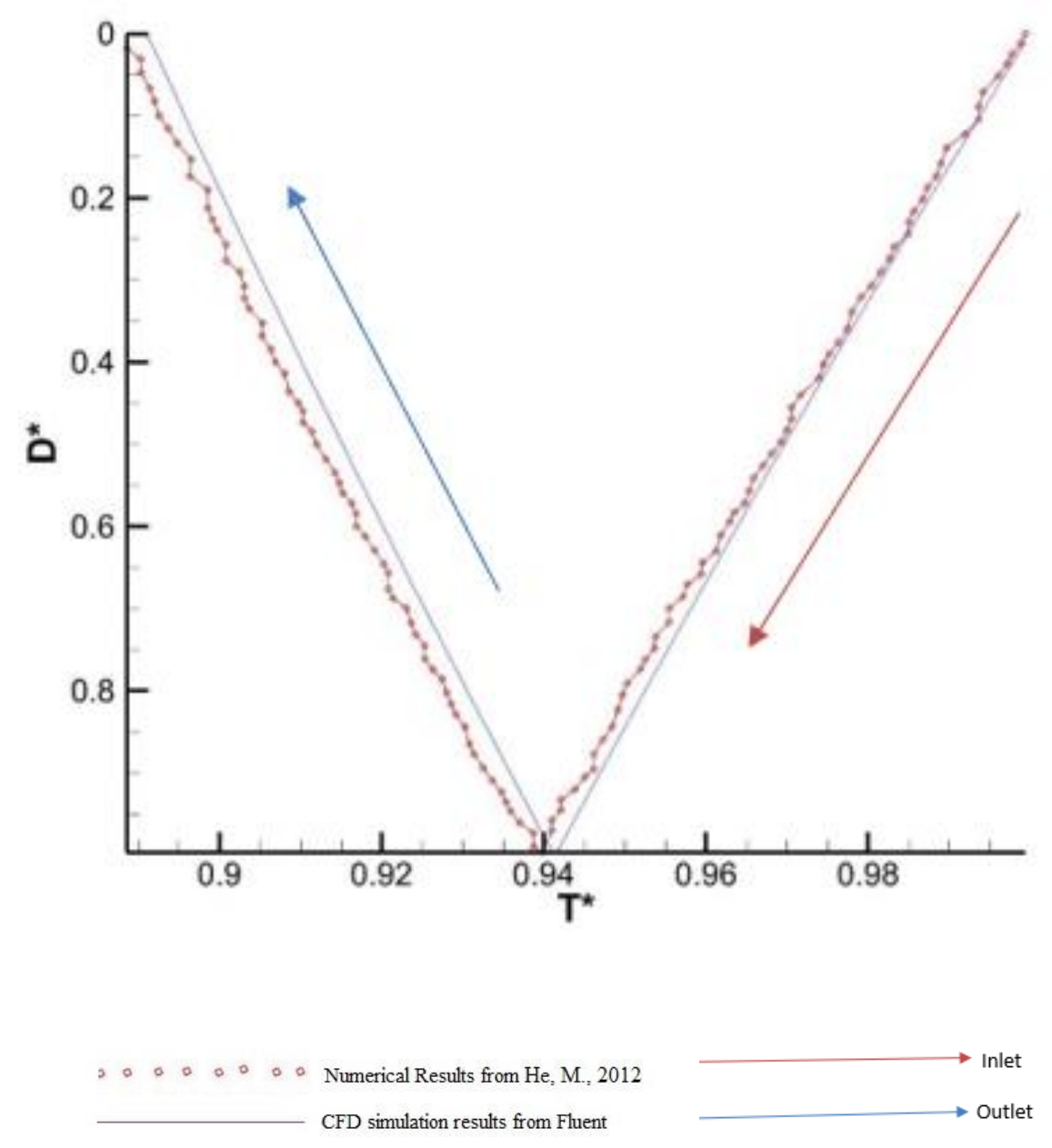

Figure 79 :Dotted Curve represents data from He, M., 2012 and Continuous line represents results obtained from CFD simulation in Fluent

Figure 74 shows the inlet and outlet temperature contours which shows that the outlet temperature achieved for this particular inlet fluid velocity was found to be 291.79 K.Figure 75 shows the turbulent kinetic energy contour at the straight section of the pipe and the ubend section. It is again observed from the turbulent kinetic energy contour that at the inlet there is generation of minor turbulence due to the pressure driven flow creating small eddies at the inlet and at the u-bend which induces mixing of cold and hot fluid as mentioned earlier. Also, the surface heat flux contours at the fluid-pipe interface depicted 
in Figure 76 shows the heat transfer rate is higher wherever there is turbulence. Figure 77 shows the temperature distribution contour plotted at the symmetrical plane and Figure 78 shows the heat flux contour at the grout-domain interface. Finally, Figure 79 shows the curve between non-dimensional depth( $\left(\mathrm{D}^{*}\right)$ and non-dimensional temperature $\left(\mathrm{T}^{*}\right)$, where the dotted line represents the data from, He, M., 2012 and the continuous line represents the numerical simulation results from ANSYS Fluent 2019R1. It is again observed from this figure that both the results are in agreement at the inlet sections due to the inlet boundary conditions being the same for both the simulation results whereas they deviate from as the flow proceeds towards the outlet via the u-bend section as seen in the earlier test cases.

\subsection{Results of $1 \mathrm{~m} / \mathrm{s}$ Inlet velocity with Standard Wall Treatment and Standard k- $\varepsilon$ Model}

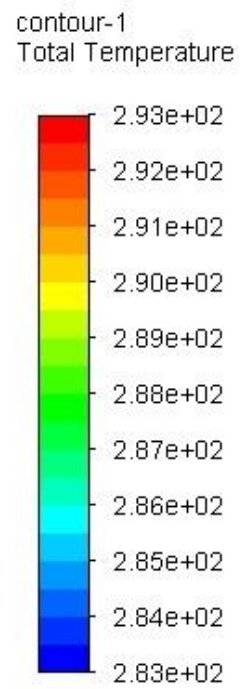

Figure 80 : Inlet and Outlet Temperature Contour 

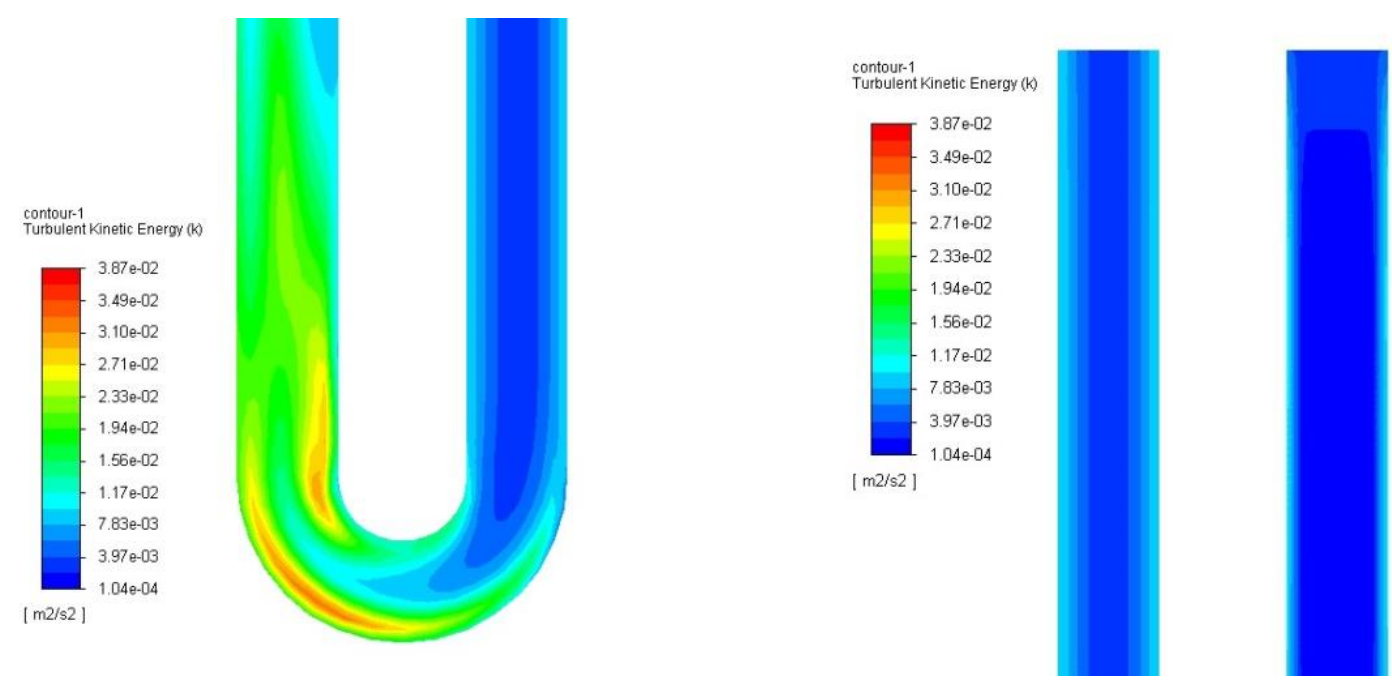

Figure 81 : Turbulent Kinetic Energy Contour at U-Bend and at Inlet and Outlet Sections
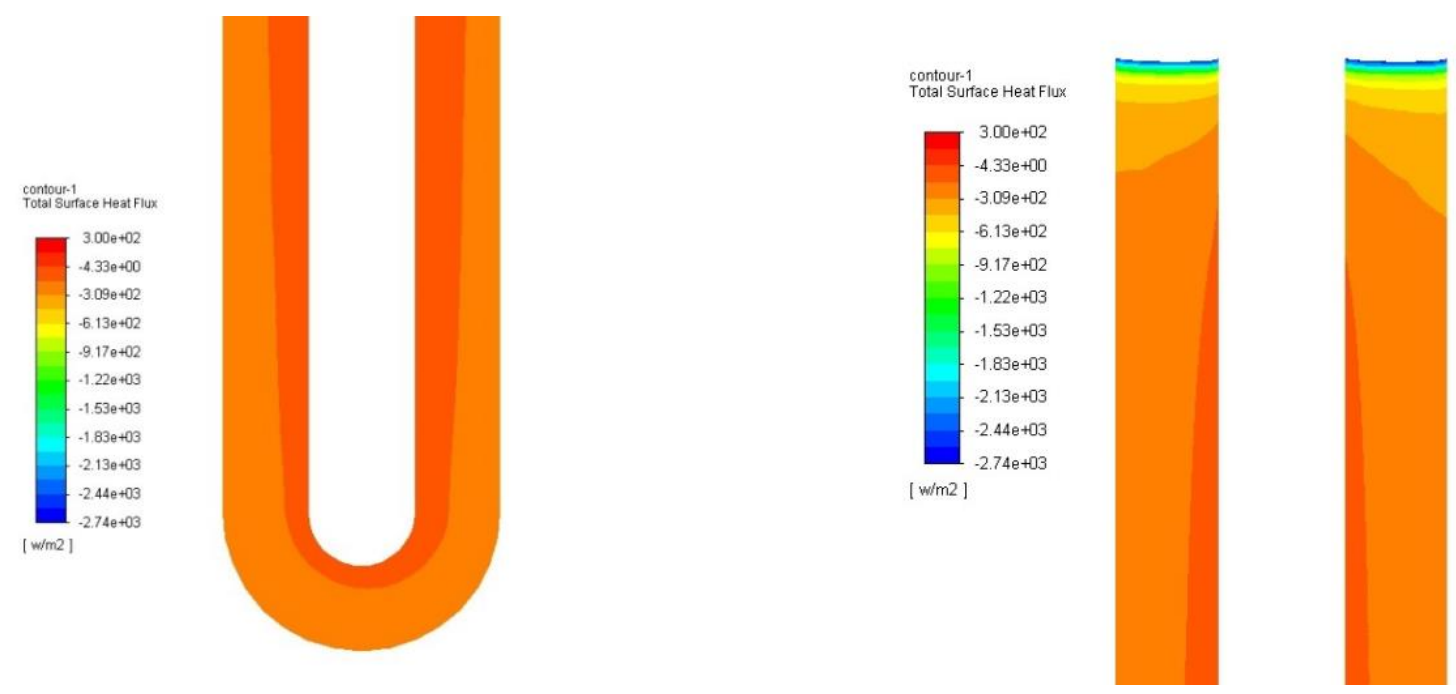

Figure 82: Heat Flux Contour at U-Bend and at Inlet and Outlet Sections at Fluid-PipeInterface 

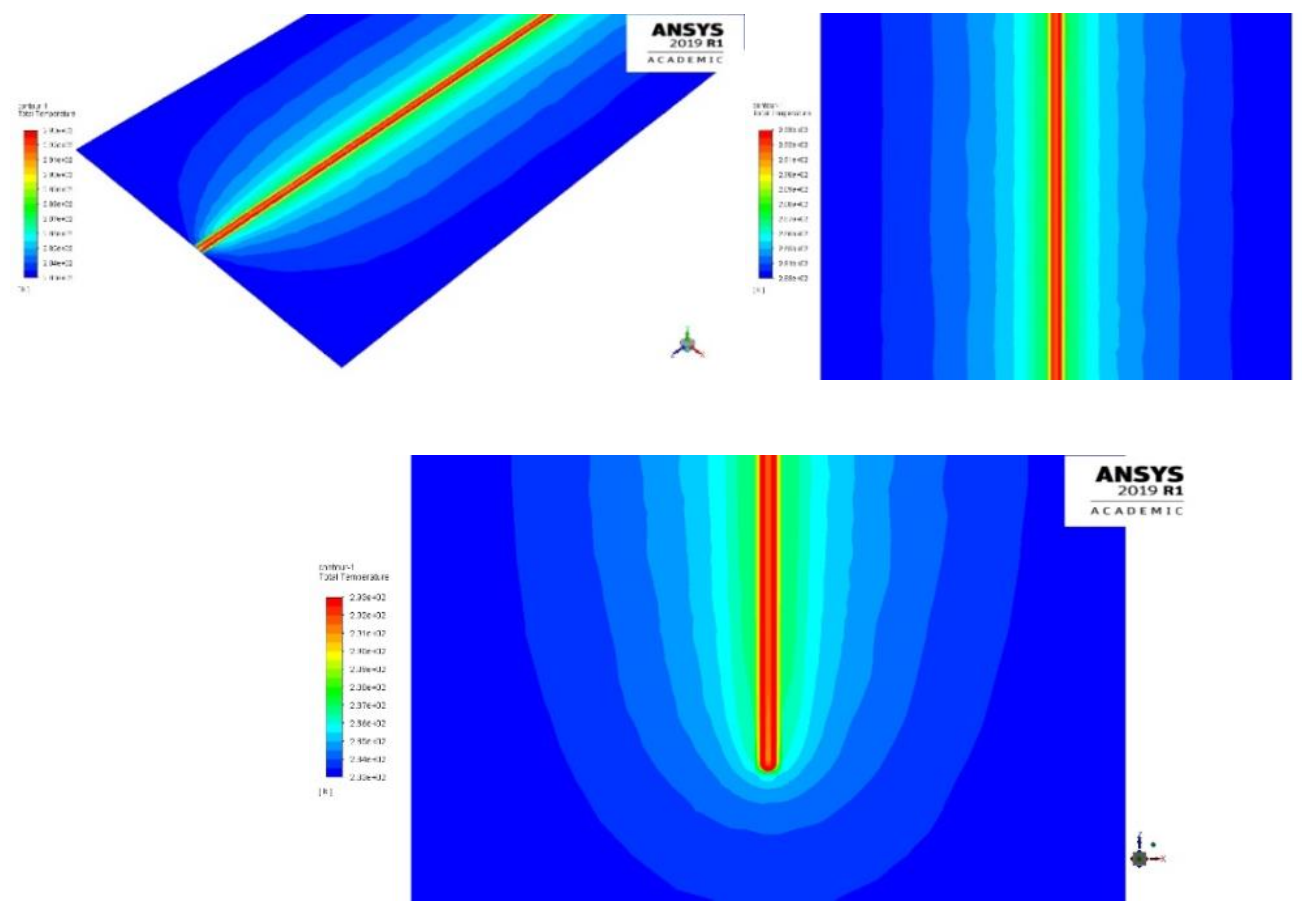

Figure 83 : Temperature Contours
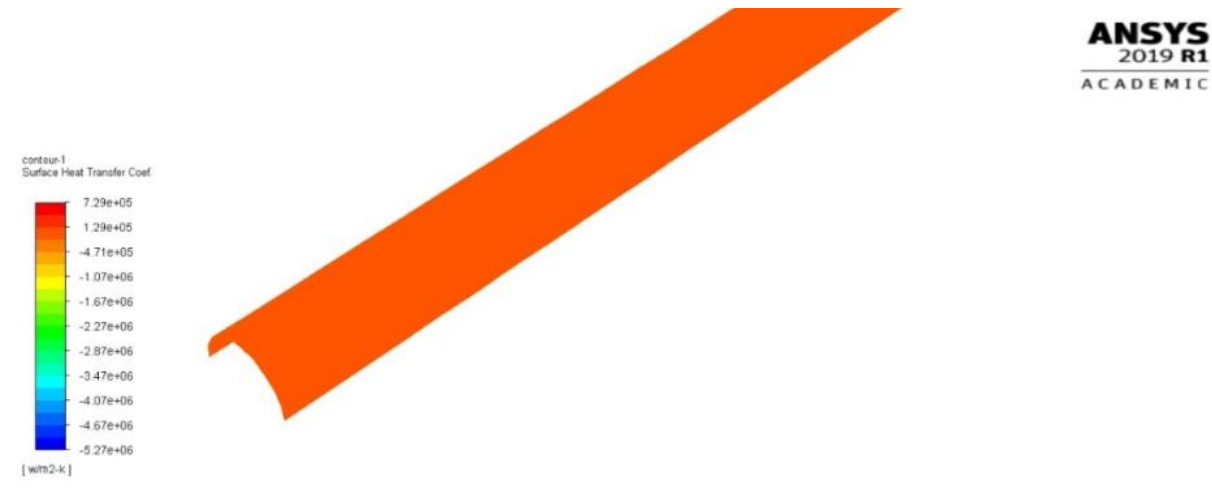

$\frac{2019 \text { R1 }}{\text { ACADEMIC }}$

妾

Figure 84: Heat Flux Contour at Grout-Domain Interface 


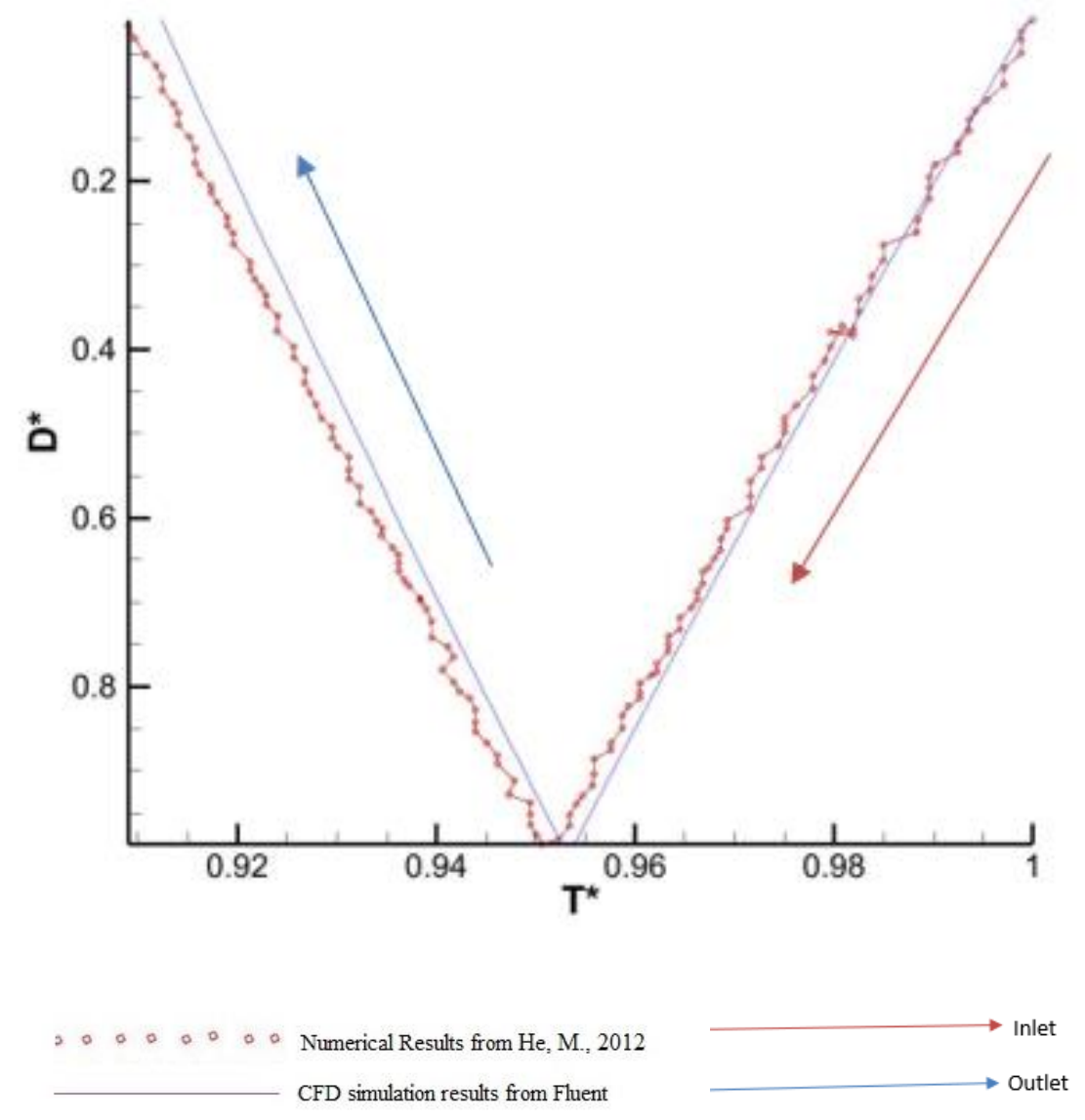

Figure 85 : Dotted Curve represents data from He, M., 2012. and Continuous line represents results obtained from CFD simulation in Fluent

Figure 80 shows the inlet and outlet temperature contours which shows that the outlet temperature achieved for this particular inlet fluid velocity was found to be $292.26 \mathrm{~K}$. Figure 81 shows the turbulent kinetic energy contour at the straight section of the pipe and the ubend section. It is seen from the turbulent kinetic energy contour that at the inlet there is generation of minor turbulence due to the pressure driven flow creating small eddies at the inlet and at the u-bend ,inducing mixing of cold and hot fluid as mentioned earlier. Also, the surface heat flux contours at the fluid-pipe interface depicted in Figure 82 shows that there is enhanced heat transfer rate wherever there is turbulence. Figure 83 shows the 
temperature distribution contour plotted at the symmetrical plane and Figure 84 shows the heat flux contour at the grout-domain interface. Finally, Figure 85 shows the curve between non-dimensional depth( $\left.\mathrm{D}^{*}\right)$ and non-dimensional temperature $\left(\mathrm{T}^{*}\right)$, where the dotted line represents the data from, He, M., 2012 and the continuous line represents the numerical simulation results from ANSYS Fluent 2019R1. It is again observed from this figure that both the results are in agreement at the inlet sections due to the inlet boundary conditions being the same for both the simulation results whereas they deviate from as the flow proceeds towards the outlet via the u-bend section as seen in the earlier test cases.

\subsection{Discussion}

The test case with three different polyhedral mesh sizes showed that the size of the grid had negligible effect upon the simulation results and was within the investigated parameters, as such it was seen that the accuracy of the solution increased as the size of the grid was refined to maximum possibility. However, using a very refined mesh was computationally expensive and extensive. It was also noted that the generation of prism layer also had no effect on the solution of the simulation.

Therefore, to save the computational time and effort required for the simulation ins ANSYS Fluent 2019R1, hexahedral mesh with size 4.0 million cells was used for verification of numerical simulation results from He, M., 2012. The reasons for variation in the results from ANSYS Fluent and He, M., 2012 has been discussed in section 3.8 of this chapter.

A detailed summary of the results obtained from the numerical simulation has been tabulated in Table 13, and Figure 86 shows the variation of Average Surface Heat Transfer Co-efficient and Heat Flux with Reynolds Number. 
Table 13:Summary of results obtained from numerical simulation in ANSYS Fluent

\begin{tabular}{|c|c|c|c|c|c|c|c|c|}
\hline $\begin{array}{c}\text { Inlet } \\
\text { Velocity }\end{array}$ & $\begin{array}{c}\text { Reynolds } \\
\text { Number }\end{array}$ & $\begin{array}{c}\text { Outlet } \\
\text { Temper } \\
\text { ature } \\
\text { Obtaine } \\
\text { d }\end{array}$ & $\begin{array}{c}\text { Outlet } \\
\text { Velocit } \\
\mathbf{y}\end{array}$ & $\begin{array}{l}\mathbf{T}_{\text {inlet- }} \\
\mathbf{T}_{\text {outlet }}\end{array}$ & $\begin{array}{l}\text { Effective } \\
\text { ness }\end{array}$ & $\begin{array}{c}\text { Surfac } \\
\text { e Heat } \\
\text { Transf } \\
\text { er } \\
\text { Coeffic } \\
\text { ient (h) } \\
\text { W/m² } \\
\text { K }\end{array}$ & $\begin{array}{c}\text { Heat } \\
\text { Flux in } \\
W / \mathbf{m}^{2}\end{array}$ & $\begin{array}{c}\text { Heat } \\
\text { Flux } \\
\text { per } \\
\text { unit } \\
\text { length } \\
\text { in } \\
\mathbf{W} / \mathbf{m}^{3}\end{array}$ \\
\hline $1.0 \mathrm{~m} / \mathrm{s}$ & 25400 & $292.26 \mathrm{~K}$ & $\begin{array}{c}1.38 \mathrm{~m} / \\
\mathrm{s}\end{array}$ & $0.88 \mathrm{~K}$ & 0.95 & 27.93 & 125.71 & 1.2571 \\
\hline $0.8 \mathrm{~m} / \mathrm{s}$ & 20320 & $291.05 \mathrm{~K}$ & $\begin{array}{c}0.95 \mathrm{~m} / \\
\mathrm{s}\end{array}$ & $1.10 \mathrm{~K}$ & 0.93 & 28.41 & 124.48 & 1.2448 \\
\hline $0.6 \mathrm{~m} / \mathrm{s}$ & 15240 & $291.72 \mathrm{~K}$ & $\begin{array}{c}0.72 \mathrm{~m} / \\
\mathrm{s}\end{array}$ & $1.42 \mathrm{~K}$ & 0.91 & 29.08 & 121.75 & 1.2175 \\
\hline $0.4 \mathrm{~m} / \mathrm{s}$ & 10160 & $291.11 \mathrm{~K}$ & $\begin{array}{c}0.48 \mathrm{~m} / \\
\mathrm{s}\end{array}$ & $2.03 \mathrm{~K}$ & 0.88 & 30.58 & 116.47 & 1.1647 \\
\hline $0.2 \mathrm{~m} / \mathrm{s}$ & 5080 & $289.56 \mathrm{~K}$ & $\begin{array}{c}0.24 \mathrm{~m} / \\
\mathrm{s}\end{array}$ & $3.58 \mathrm{~K}$ & 0.77 & 37.90 & 102.48 & 1.0248 \\
\hline
\end{tabular}

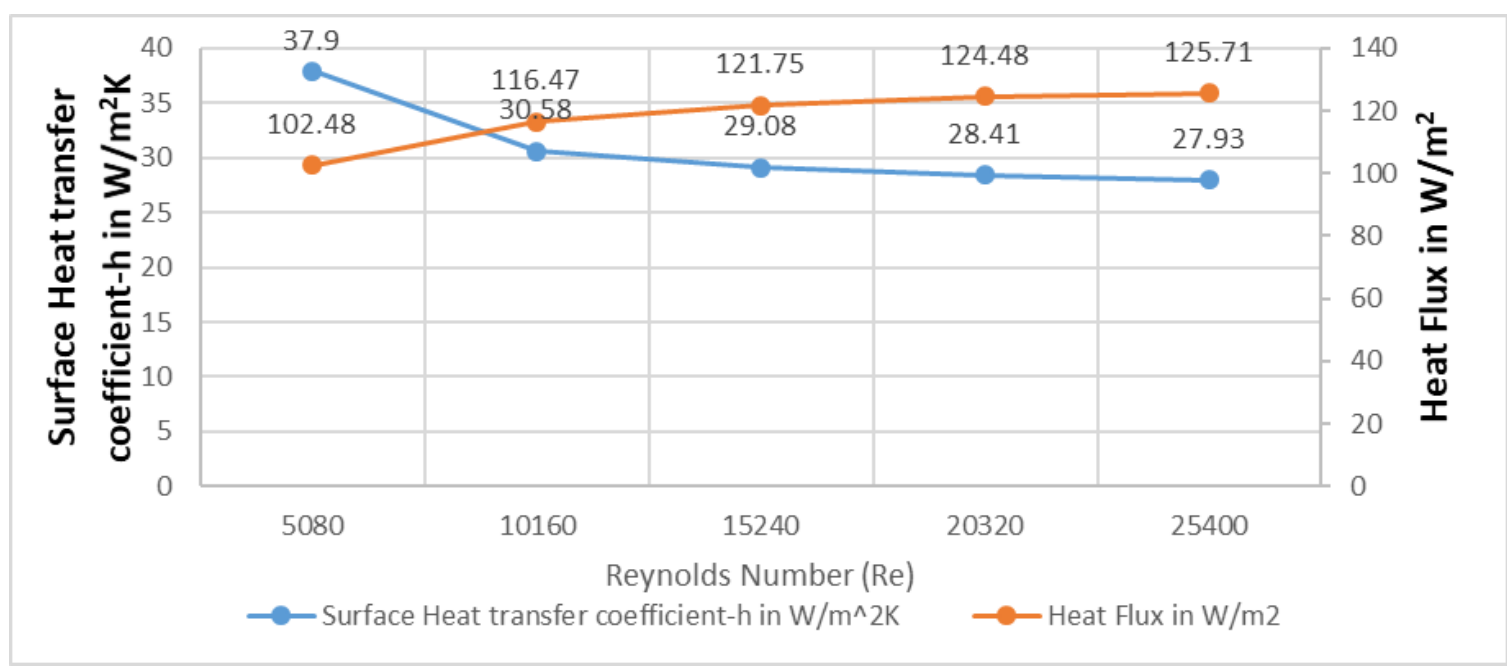

Figure 86: Correlation between Average Surface Heat Transfer Co-efficient and Heat Flux with Reynolds Number

\subsubsection{Validation with Experimental Data}

The test cases set-up in ANSYS Workbench with coarse hexahedral mesh was used to validate the experimental results from Pu.et al ,2014. The geometry and the mesh sizes was 
kept as same as mentioned earlier in the chapter. The dimensions of the geometry were not altered because the experimental set-up had similar dimensions.

The viscous model selected was Standard k- $\varepsilon$ Model with Standard Wall Treatment. However, the thermal properties of the materials of the various components was changed as per the experimental set-up, which have been elucidated in the table 9: -

The steady state simulation with two test cases were run to validate the experimental results; the boundary conditions for each case have been mentioned below: -

- Inlet Temperature- $308.47 \mathrm{~K}$ and $278.21 \mathrm{~K}$

- Undisturbed Ground Temperature- 292.25K

- Inlet volume flow rates- $1.173 \mathrm{~kg} / \mathrm{h}$ or $0.552 \mathrm{~m} / \mathrm{s}$ for $308.47 \mathrm{~K}$ and $1.144 \mathrm{~kg} / \mathrm{h}$ or $0.53861 \mathrm{~m} / \mathrm{s}$ for $278.21 \mathrm{~K}$.

Table 14:Comparison between experimental result and CFD result for $308.47 \mathrm{~K}$ inlet temperature

\begin{tabular}{|c|c|c|c|c|c|}
\hline & $\begin{array}{c}\Delta \mathbf{T} \\
\text { Outlet } \\
\text { Temperature }\end{array}$ & $\begin{array}{c}\Delta \text { Surface Heat } \\
\text { (Tinlet- } \\
\mathbf{T}_{\text {outlet }}\end{array}$ & Effectiveness & $\begin{array}{c}\text { Heat } \\
\text { Transfer } \\
\text { Coefficient(h) } \\
\text { in W/m2 } \mathbf{~}\end{array}$ & $\begin{array}{c}\text { Heax } \\
\text { Flux in } \\
\mathbf{W} / \mathbf{m}^{2}\end{array}$ \\
\hline $\begin{array}{c}\text { Experimental } \\
\text { Results }\end{array}$ & $304.63 \mathrm{~K}$ & $3.84 \mathrm{~K}$ & 0.89 & - & 324.70 \\
\hline $\begin{array}{c}\text { Simulation } \\
\text { Results }\end{array}$ & $305.01 \mathrm{~K}$ & $3.45 \mathrm{~K}$ & 0.82 & 11.95 & 224.17 \\
\hline $\begin{array}{c}\text { Percentage } \\
\text { Error }\end{array}$ & $0.12 \%$ & $11.30 \%$ & $8.53 \%$ & - & $44.84 \%$ \\
\hline
\end{tabular}

Table 15:Comparison between experimental result and CFD result for 278.21K inlet temperature 


\begin{tabular}{|c|c|c|c|c|c|}
\hline & $\begin{array}{c}\text { Outlet } \\
\text { Temperature }\end{array}$ & $\begin{array}{c}\Delta \mathbf{T} \\
\left(\mathbf{T}_{\text {inlet- }}\right. \\
\mathbf{T}_{\text {outlet})}\end{array}$ & Effectiveness & $\begin{array}{c}\text { Surface Heat } \\
\text { Transfer } \\
\text { Coefficient(h) } \\
\text { in W/m } \mathbf{2} \text { K }\end{array}$ & $\begin{array}{c}\text { Heat } \\
\text { Flux in } \\
\mathbf{W} / \mathbf{m}^{2}\end{array}$ \\
\hline $\begin{array}{c}\text { Experimental } \\
\text { Results }\end{array}$ & $281.16 \mathrm{~K}$ & $2.95 \mathrm{~K}$ & 0.11 & - & 243.14 \\
\hline $\begin{array}{c}\text { Simulation } \\
\text { Results }\end{array}$ & $280.73 \mathrm{~K}$ & $2.52 \mathrm{~K}$ & 0.17 & 22.64 & 193.42 \\
\hline $\begin{array}{c}\text { Percentage } \\
\text { Error }\end{array}$ & $0.15 \%$ & $17.06 \%$ & $35.29 \%$ & - & $25.70 \%$ \\
\hline
\end{tabular}

Table 14 shows the comparison and validation between the experimental results and the numerical simulation results for cooling mode, whereas Table 15 shows the comparison and validation between the experimental and numerical simulation results for heating mode. On observing the results from the results from the above two mentioned tables, we see that there is slight variation between the experimental and simulation results for both the cases. We see the change in temperature, i.e., $\Delta \mathrm{T}$ ( $\mathrm{T}_{\text {inlet- }} \mathrm{T}_{\text {outlet}}$ ) for both the cases is similar. The percentage error for $\Delta \mathrm{T}$ for both cooling and heating mode is less than $20 \%$. Also, the variation between the numerical results and experimental results for effectiveness and the heat flux can be because of various factors. The possible reasons for the difference in the experimental results and simulation results have been discussed in section 3.8 of the chapter.

3.7. Comparison between the Thermal Resistance of the Borehole using the Steady State Model Equation and the Thermal Resistance of the Borehole from the Numerical Simulation

The borehole thermal resistance includes the convective resistance of the fluid, the conductive resistance of the pipes, and the conductive resistance of the grout. The relationship of the borehole thermal resistance and the thermal resistance of fluid, pipe and grout can be defined as: 


$$
R_{b}=\frac{R_{f}+R_{p}}{2}+R_{g}
$$

where, $R_{f}$ is the convective resistance of the fluid

$R_{p}$ is the conductive resistance of pipe,

$R_{g}$ is the conductive resistance of the grout

The convective resistance of the fluid $\quad R_{f}=\frac{1}{2 \pi r_{1} h} \quad$ was found to be $9.417 \times 10^{-5} \quad \mathrm{~K} / \mathrm{W}$.

where, $r_{1}$ inner pipe diameter and $r_{2}$ is outer pipe

The conductive resistance of pipe can be calculated by

$$
R_{p}=\frac{\ln \left(\frac{r_{2}}{r_{1}}\right)}{2 \pi k_{p}}
$$

which was found to be $0.08 \mathrm{~K} / \mathrm{W}$.

Now, $R_{g}$ is calculated using Equivalent diameter model where

$$
D_{e q}=\sqrt{2 D_{p} \cdot L_{s}} \quad D_{p} \leq L_{s} \leq r_{\text {borehole }} \quad \text { and } \quad R_{g}=\frac{\ln \left(\frac{D_{b}}{D_{e q}}\right)}{2 \pi k_{g}}
$$

Therefore, $D_{e q}$ was found to be $0.06431 \mathrm{~m}$ and subsequently $R_{g}$ was found to be 0.18306 $\mathrm{K} / \mathrm{W}$.

Substituting all the values in the relation for $R_{b}$, we found $R_{b}$ to be $0.20810 \mathrm{~K} / \mathrm{W}$.

Now using the relation $R_{b}=\frac{T_{f}-T_{b}}{Q} \quad$ it was found that for all velocities starting from $0.2 \mathrm{~m} / \mathrm{s}$ to $1.0 \mathrm{~m} / \mathrm{s}$, the borehole thermal resistance was found to be approximately $0.2 \mathrm{~K} / \mathrm{W}$. 
Therefore, the value of borehole thermal resistance $R_{b}$ using the steady-state analytical approach was found to be $0.20810 \mathrm{~K} / \mathrm{W}$ and the value of $R_{b}$ from the numerical simulations for all inlet velocities was found to be nearly equal to $0.2 \mathrm{~K} / \mathrm{W}$. As such we can conclude that the process developed, verified and validated earlier in the chapter holds good with respect to analytical solution as well.

\subsection{Conclusion}

The numerical simulation performed can be summarized below: -

- The 3D geometry was discretized in two different mesh types with 4 different mesh sizes, as shown in table 16:-

Table 16: Table summarizing the different mesh types and mesh sizes used for Grid Independence and Mesh Independence Study

\begin{tabular}{|c|c|c|c|c|c|c|}
\hline Mesh Type & $\begin{array}{l}\text { Component } \\
\text { Name }\end{array}$ & $\begin{array}{l}\text { Number } \\
\text { of Cells } \\
\text { (in } \\
\text { millions) }\end{array}$ & $\begin{array}{l}\text { Cells } \\
\text { across } \\
\text { gap }\end{array}$ & $\begin{array}{l}\text { Prism } \\
\text { cells in } \\
\text { millions }\end{array}$ & $\begin{array}{l}\text { Number } \\
\text { of Prism } \\
\text { layers }\end{array}$ & $\begin{array}{l}\text { Outlet } \\
\text { Temperature } \\
\text { in K }\end{array}$ \\
\hline \multirow{4}{*}{$\begin{array}{l}\text { Hexahedral- } \\
4.0 \text { million } \\
\text { cells }\end{array}$} & Domain & 0.22 & 3 & - & - & \multirow[t]{4}{*}{$291.05 \mathrm{~K}$} \\
\hline & Grout & 1.01 & 4 & - & - & \\
\hline & Pipe & 1.31 & 5 & - & - & \\
\hline & Fluid & 1.49 & 10 & - & - & \\
\hline \multirow{4}{*}{$\begin{array}{l}\text { Polyhedral- } \\
3.92 \text { million } \\
\text { cells }\end{array}$} & Domain & 0.485 & 3 & - & - & \multirow[t]{4}{*}{$291.56 \mathrm{~K}$} \\
\hline & Grout & 1.57 & 10 & - & - & \\
\hline & Pipe & 0.95 & 3 & - & - & \\
\hline & Fluid & 0.92 & 3 & - & - & \\
\hline \multirow{4}{*}{$\begin{array}{l}\text { Polyhedral- } \\
5.9 \text { million } \\
\text { cells }\end{array}$} & Domain & 0.485 & 3 & - & - & \multirow[t]{4}{*}{$291.843 \mathrm{~K}$} \\
\hline & Grout & 1.57 & 10 & - & - & \\
\hline & Pipe & 0.95 & 3 & - & - & \\
\hline & Fluid & 2.92 & 10 & 1.16 & 3 & \\
\hline \multirow{4}{*}{$\begin{array}{l}\text { Polyhedral- } \\
14.5 \text { million } \\
\text { cells }\end{array}$} & Domain & 0.485 & 3 & - & - & \multirow[t]{4}{*}{$291.840 \mathrm{~K}$} \\
\hline & Grout & 1.57 & 10 & - & - & \\
\hline & Pipe & 4.58 & 12 & - & - & \\
\hline & Fluid & 8.16 & 15 & 4.89 & 4 & \\
\hline
\end{tabular}


- The inlet velocity for the grid independence study was $0.8 \mathrm{~m} / \mathrm{s}$ using three different polyhedral mesh sizes and have been performed by the comparison of results in sections 3.6.1.1., 3.6.1.2. and 3.6.1.3.

- The inlet velocity for the mesh independence study was $0.8 \mathrm{~m} / \mathrm{s}$ using the hexahedral mesh with size 4.0 million cells and polyhedral mesh with size 3.92 million cells and have been performed by the comparison of results in sections 3.6.1.1. and 3.6.1.4.

- The hex mesh was numerical simulated with $0.8 \mathrm{~m} / \mathrm{s}$ inlet velocity using Standard Wall Function k-epsilon model and Enhanced Wall Treatment function k-epsilon model and compared from the results in sections 3.6.1.4. and 3.6.1.5.

- The effect of gravity was studied using the hex mesh with $0.8 \mathrm{~m} / \mathrm{s}$ inlet velocity and Standard Wall Treatment function k-epsilon model by comparing results from sections 3.6.1.4. and 3.6.1.6.

- Using the hex mesh, two different validations were performed, the first one was verification of numerical simulation results from He, M., 2012 and second validation with experimental data from Pu.et al ,2014

The following conclusions and key findings were drawn from the results of the simulation of the 3D BHE: -

- From Table 16 and Figures 35, 39 and 43 it has been observed that the results of the numerical simulation were independent of the size of the grid, as such the grid independence of the solution has been confirmed. 
- Again, from Table 16 and Figures 35 and 47 is was also observed that the results of the simulation were independent of the type of mesh used, as such the mesh independence of the solution has also been confirmed.

- Figures 47 and 51 show that the type of turbulence model used had no effect on the outcome of the numerical simulation.

- Figures 47 and 55 show that gravity had no effect upon the result of the simulation.

- It was observed that the residence time of the fluid inside the pipe had a major role to play in the amount of heat transferred from the fluid to the surroundings. This is clearly evident from the outlet temperatures being obtained from the various flow velocities, where it was seen that for $0.2 \mathrm{~m} / \mathrm{s}$ inlet fluid velocity the outlet velocity obtained was $289.5627 \mathrm{~K}$ while for $1.0 \mathrm{~m} / \mathrm{s}$ inlet fluid velocity the outlet fluid velocity obtained was $292.2697 \mathrm{~K}$. A such it can be said that higher the residence time of the fluid, higher is the amount of heat transferred to/from the fluid.

- From the heat flux profiles, it was observed that the maximum heat transfer was observed from the outer sections of the pipe rather than the inner sections (sections of the pipe in between the legs), this was due to the fact that the outer section was more exposed nearer to the boundary conditions.

- From the turbulence kinetic energy contours it was observed that at the inlet of the fluid in the pipe, turbulent the kinetic energy was higher as compared to the rest of the section of the straight pipe due to the flow being pressure driven at the inlet, which in turn resulted in the generation of minor eddies. The generation of eddies acts as a catalyst for mixing of the flow, i.e. the mixing of the colder and the warmer sections of the fluid flow, which in turn aids in the transfer of heat. As such it is 
seen from the heat flux profiles that there is more heat transfer near the inlet of the fluid flow.

Also, from the turbulent kinetic energy contours, it is seen that at the u-bend of the pipe the turbulent kinetic energy of the flow increases, aiding in the generation of eddies of higher intensity. As such the mixing in the flow increases, subsequently the transfer of heat from the fluid towards the system, increases, which is evident from the heat flux profiles.

- On validation with He, M., 2012 in section 3.6.2.1. it was seen that the numerical solution from the given thesis and the numerical simulation performed in this thesis paper had good agreement. At the inlet section of the flow it was seen that the results had no variation, but it was noted that as the flow proceeded towards the outlet via the u-section, there were minor deviation. The reasons for those deviations are the following: -

- The 3D model developed by He, M., 2012 was built upon a finite volume solver known as GEMS3D (General Elliptical Multi-block Solver in 3 Dimensions), which is an in-house code that has been implemented in Fortran 90.

○ This solver applies the finite volume method to solve the partial differential advection-diffusion equation for heat transfer on 3D boundary fitted grids.

o Three-dimensional multi-block boundary fitted structured meshes for BHEs are generated using an in-house developed program.

- There was a difference between the mesh size and type of mesh used in both the cases. 
○ First order backward implicit scheme was used by He, M., 2012., while second order scheme was used in this thesis.

- Also, the ANSYS Fluent Solver is used in Double Precision mode which gives more accurate results.

- The experimental data from Pu.et al ,2014 has been successfully validated in section 3.6.2.2., which concludes that the 3D numerical simulation results had good identity with the experimental test results. However, it was also seen that there were errors between the experimental results and the simulation results, which can be because of the following reasons: -

○ The experimental set-up might not have well calibrated and accurate sensors.

- The flow inside the pipe may not have been fully developed.

- There may be a difference in the size of the experimental domain which can give varying results.

- Finally, on the comparison between the analytical borehole resistance and the numerically calculated borehole resistance as shown in section 3.7 of this chapter had a good identity with each other as such the process developed in this thesis holds true to its hypothesis. 
DESIGN MODIFICATION TO THE BHE TO IMPROVE HEAT TRANSFER

Chapter 2 presented a brief overview of the various models that have been developed to study the heat transfer and thermal characteristics of the BHE. This ranges from the analytical models, which can only be implemented to study the in-situ ground test data, as it ignores the geometry of the solution, as such it cannot be implemented to study the dynamic temperature response of the model to geometrical changes. The steady state models have been developed to calculate the thermal resistance of the borehole, which assumes that the heat transfer inside the borehole takes place in steady state. The other methods discussed in the chapter combined the usage of both analytical and numerical methods of improving the existing models, however, these models the heat transfer and thermal characteristics of the BHE. The solution depended upon the thermal resistance data obtained by analytical means.

Even though the analytical models and analytical-numerical models, require less computational efforts and computing time, they are not suitable for studying the heat transfer and thermal characteristics of the system in varying time, involving the fluid transport and its interaction with the surrounding components. The $2 \mathrm{D}$ discretized models that have been developed, consider the geometry of the pipes and the grout along with their thermal properties, however, the change in the temperature of the fluid along the depth of the borehole cannot be modeled or ascertained. The 3D models as discussed earlier that have been developed have the following advantages: -

- The change in the temperature of the fluid along the depth and as well as the surrounding areas can be modeled and numerically simulated. 
- The transport of the fluid can be modeled explicitly.

- Heat transfer and Thermal characteristics of each component of the borehole can be fully determined.

There have been various attempts to improve the efficiency, Zhao et al., 2016 and the heat transfer characteristics of the BHE. Some methods that have been attempted have been discussed below: -

- There has been attempts made to enhance the heat transfer surface area of the heat exchanger through variation in design of the heat exchange, such as implementation of multiple u-tube heat exchangers Aydin et al., 2015 or helical type of heat exchangers, Park et al., 2013. Even though these methods improved the heat transfer of the BHE, however, the major drawback was mainly due to the manufacturing and installation constraints.

- The dimensions used in this thesis and all other available literature on the BHE are based on experimental thermal response test data that have been performed to optimize the design of the heat exchanger. As such any variation in dimensions will not yield optimized results from the heat exchanger.

- There has been considerable research being conducted by various researchers to vary the materials used in the components of the BHE, Wang et al.,2014 studied a phase change material( $\mathrm{PCM}$ ) grout made from enhanced n-decanoic acid and lauric acid, however, they have so far yielded inconclusive results and as such cannot be implemented due to cost and manufacturing constraints. 
In this chapter, the methods of improving the transfer of heat to and from the fluid inside the 3D borehole heat exchanger model with the help of simple enhancement structures has been discussed. This has been achieved by the proposing a change in the design of the heat exchanger, where the addition of extended surfaces or fins in the geometry has been used for achieving the improvement of the heat transfer.

As we know that, flow of heat depends upon three factors, viz., area of surface, temperature difference and convective heat transfer coefficient. The rate of transfer of heat can be improved by varying any of these factors. However, amongst all these factors, the basic surface area exposed for transfer of heat is limited. Secondly the temperature difference is limited according to the requirement and the boundary conditions, where either reducing the ambient temperature or the boundary temperatures is impractical. On the other hand, the convection coefficient can be increased by increasing the fluid velocity and/or the fluid temperature could be varied. However, increasing the convective heat transfer coefficient even to its maximum possible value is often insufficient to obtain the desired heat transfer rate.

However, fins can be employed where the surface area is insufficient to transfer heat as per the requirement, to compensate for low heat transfer coefficient and low temperature gradients. Fins have been employed for various purposes, for example in the cylinder heads of air-cooled engines and compressors. In radiators and air-conditioning equipment, tubes having circumferential fins are normally utilized to increase heat flow. Electronic components cannot function without having fins to dissipate heat from their surface.

There are various types of fins that are used in varied shapes depending upon the types of applications which has been shown in Figure 87. 
- Plate type fins with constant area of cross-section(a)

- Plate fins with variable area of cross-section (c \&d).

- Annular type circumferential fins with constant thickness(b).

- Annular fins with variable thickness.

- Pin type fins with constant area of cross-section (g).

- Pin type fins with variable area of cross-section (h \&j).

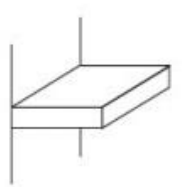

(a)

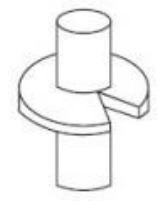

(e)

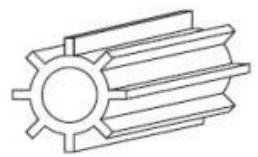

(b)

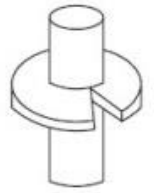

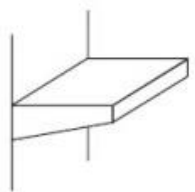

(c)

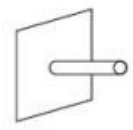

(g)

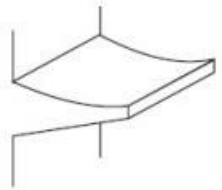

(d)

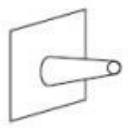

(h)

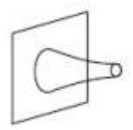

(i)

Figure 87: Different types of fin design used in cooling of various heated components

\subsection{Development of 3D Model and Geometry}

Due to dimensional complexities of the BHE, any design modification that can be implemented needs to consider the following factors: -

- Manufacturing costs associated with the change in design.

- The installation costs associated with the Borehole Heat Exchanger being very high, any change in design should not significantly affect the installation cost.

- Feasibility of installation is of primary importance as the process of installation of a BHE is highly complex as it involves the use of machines that need to bore around 
$100 \mathrm{~m}$ in depth, and $150 \mathrm{~mm}$ in diameter. The modification should not increase the boring effort required.

Keeping all these factors in mind, a simple rectangular plate profile fins with variable crosssectional area being fit onto a thin tube has been proposed for increasing surface area of heat transfer and improve the efficiency of the heat exchanger.

The modified design of the heat exchanger has been created using ANSYS SpaceClaim Design Modeler 2019R1. Again, due to the symmetrical nature of the geometry, only half of the BHE is modeled, which has bene done to significantly reduce the computational power required for the numerical simulation.

Table 17 shows the dimensions of the various components of the modified heat exchanger and the schematic diagram of the heat exchanger has been shown in Figure 88. Figure 89 shows the modified dimension of the simulation domain, while Figure 90 shows the geometry of the fin structure, Figure 91 shows the geometry of the grout, Figure 92 depicts the geometry of the pipe while Figure 93 shows the fluid geometry.

The modified design of the heat exchanger has been depicted the figure below: -

Table 17: BHE component dimension table with fins

\begin{tabular}{|l|c|c|}
\hline \multicolumn{1}{|c|}{ Part } & Dimension & Unit \\
\hline Diameter of Fluid Section & 27.4 & $\mathrm{~mm}$ \\
\hline $\begin{array}{l}\text { Length of Fluid Straight } \\
\text { Section }\end{array}$ & 99.938 & $\mathrm{~m}$ \\
\hline Pipe Inner Diameter & 27.4 & $\mathrm{~mm}$ \\
\hline Pipe Outer Diameter & 33.4 & $\mathrm{~mm}$ \\
\hline Shank Spacing & 34.53 & $\mathrm{~mm}$ \\
\hline Diameter of Grout & 152.4 & $\mathrm{~mm}$ \\
\hline Inner Diameter of Fin Plate & 152.4 & $\mathrm{~mm}$ \\
\hline Outer Diameter of Fin Plate & 175 & $\mathrm{~mm}$ \\
\hline Length of Fin & 22.99 & $\mathrm{~mm}$ \\
\hline
\end{tabular}




\begin{tabular}{|l|c|c|}
\hline Thickness of Fin at root & 16.895 & $\mathrm{~mm}$ \\
\hline Thickness of Fin at Tip & 10 & $\mathrm{~mm}$ \\
\hline Length of Borehole & 100 & $\mathrm{~m}$ \\
\hline $\begin{array}{l}\text { Length of Simulation } \\
\text { Domain }\end{array}$ & 120 & $\mathrm{~m}$ \\
\hline $\begin{array}{l}\text { Cross-sectional Dimension } \\
\text { of Domain }\end{array}$ & $2 \times 4$ & \\
\hline
\end{tabular}
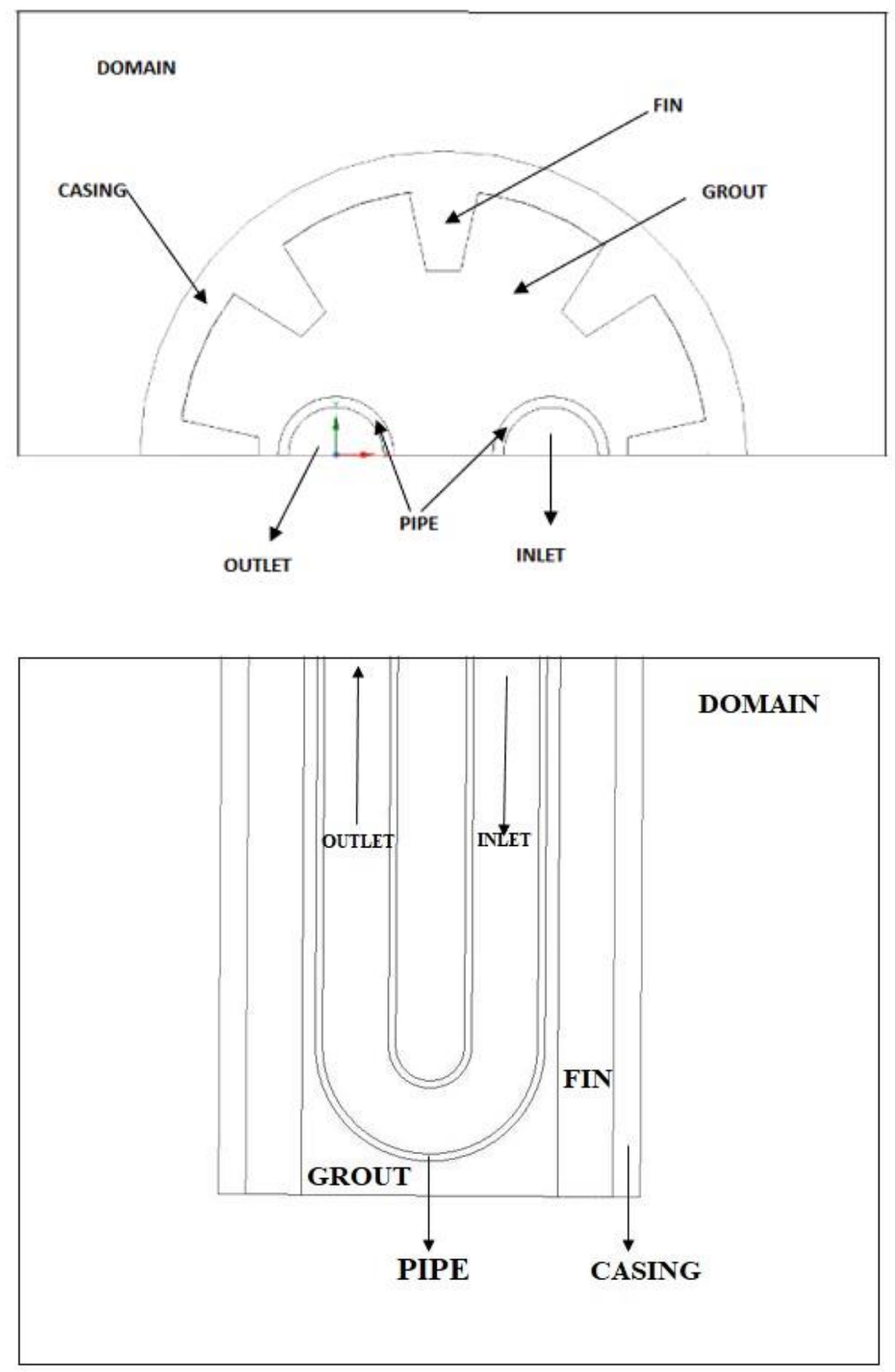

Figure 88: Schematic Diagram of Modified Heat Exchanger 


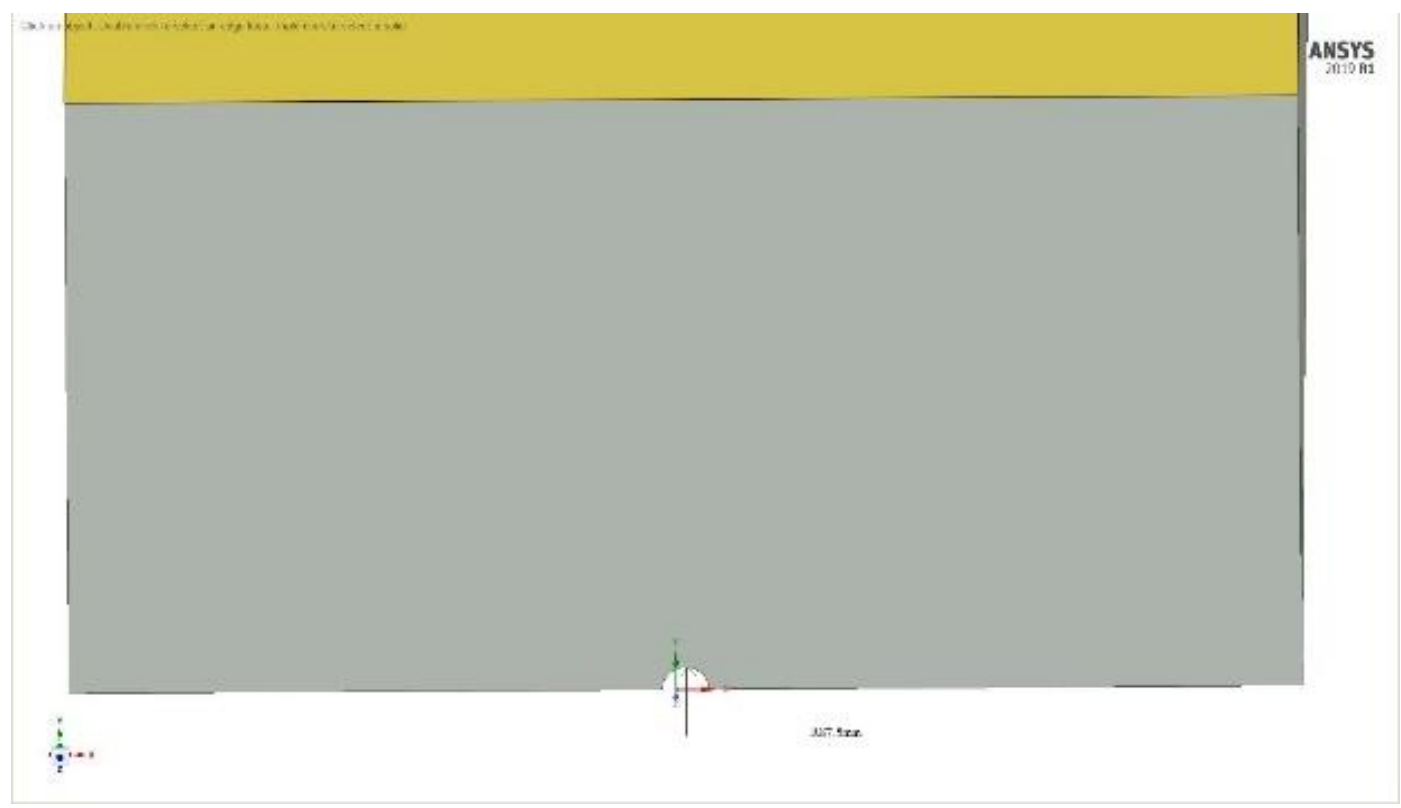

Figure 89: Geometry of Modified Domain

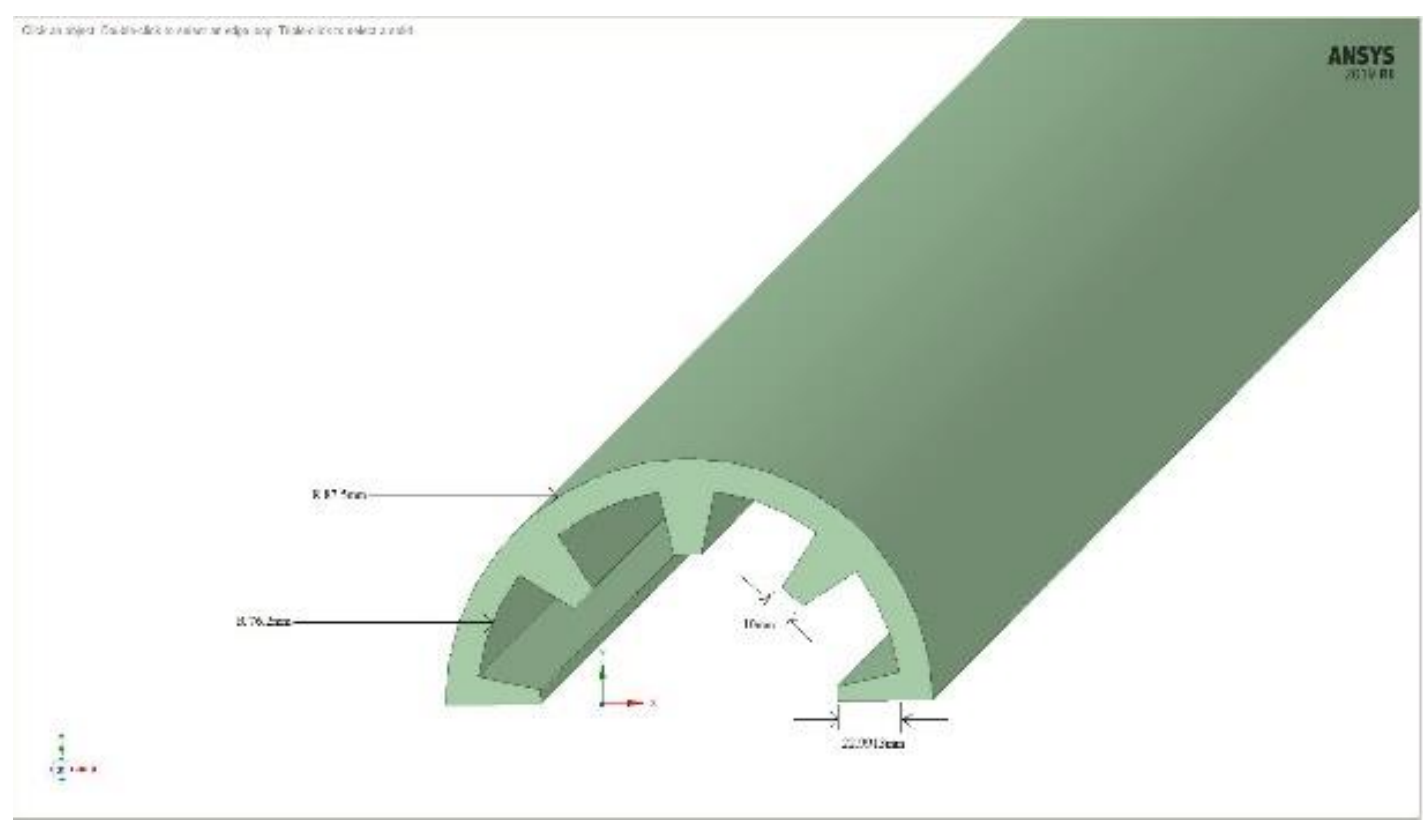

Figure 90: Geometry of fin 


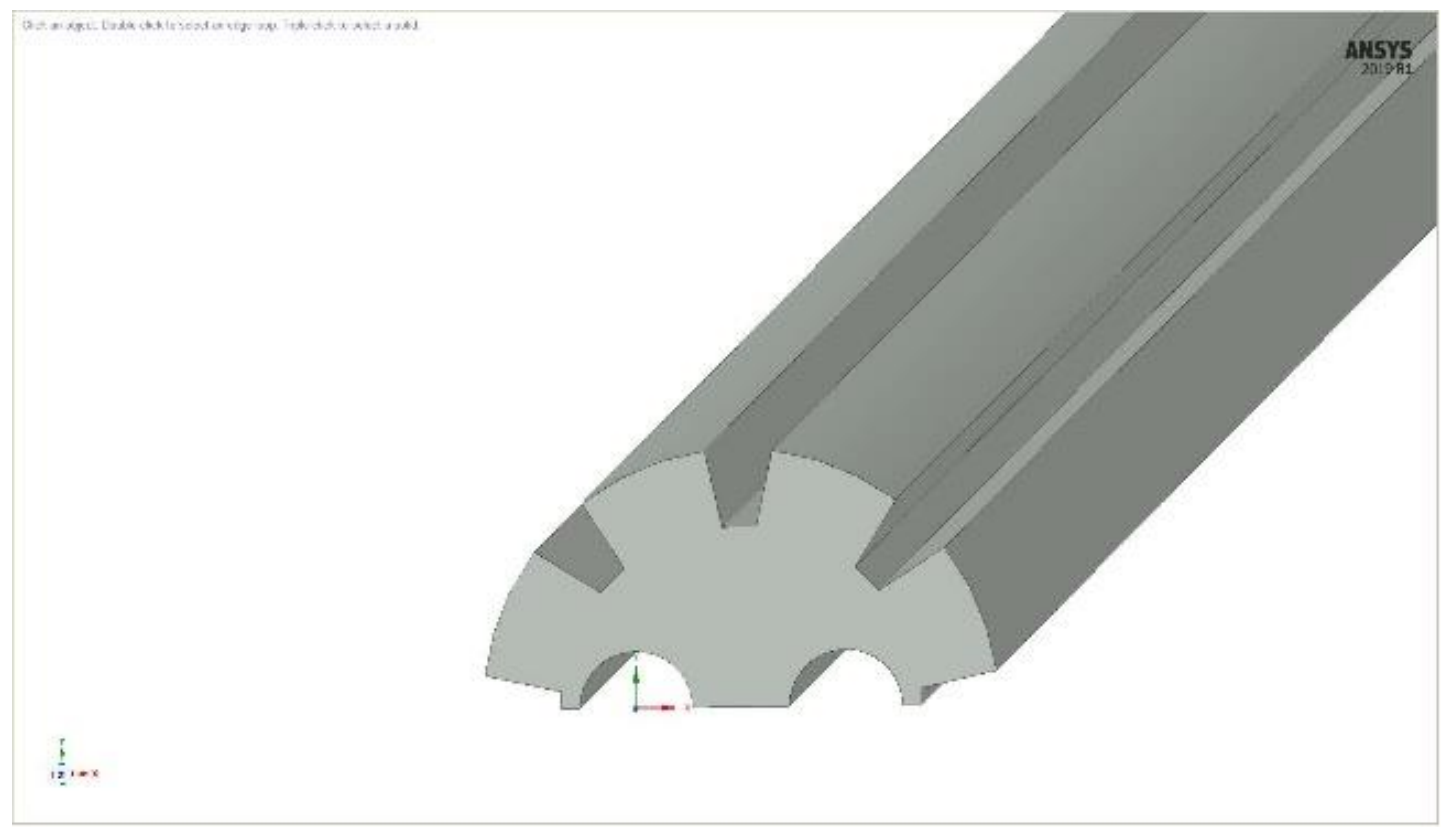

Figure 91:Geometry of Modified Grout

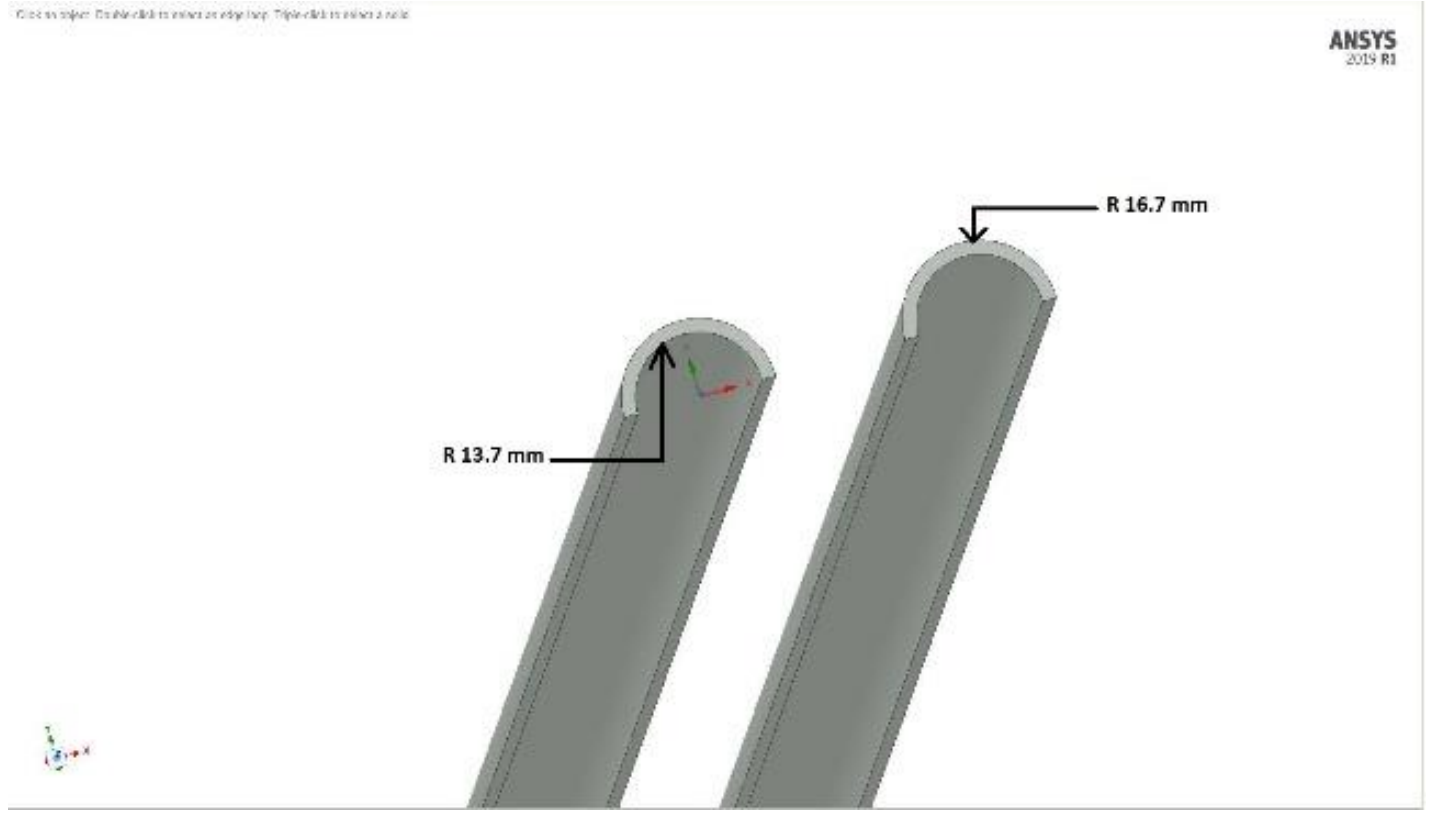

Figure 92: Geometry of Pipe 


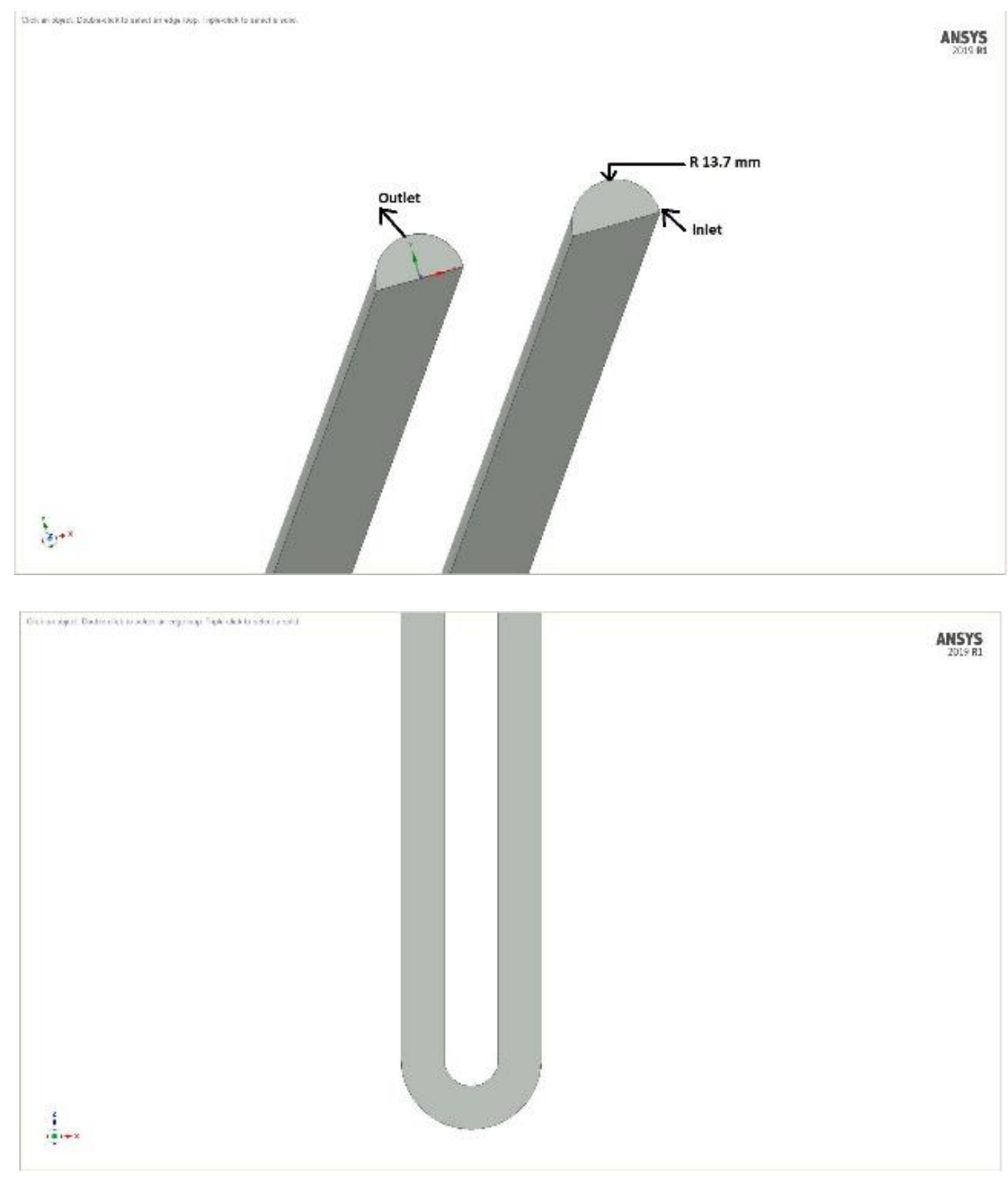

Figure 93:Geometry of Fluid

\subsection{Discretizing of 3D Geometry}

The 3D modified geometry created for the numerical simulation was discretized in ANSYS Fluent 2019R1 Mesher. The type of mesh used for discretizing the geometry is polyhedral mesh with medium refinement. The ideology and method used for creating the volume mesh of the geometry was same as that used in meshing the geometry as mentioned in chapter three. The mesh sizing controls for the domain, grout, pipe and the fluid were same as that used in the medium refined polyhedral mesh before. For the generation of the mesh 
of the fins, the size controls were kept as same as that of the pipe. This was done due to geometrical similarities between the geometry of the pipe and the fins. Figure 94 shows the top view of the entire discretized geometry. Figure 95 shows the discretized modified domain, Figure 96 shows the meshed fin structure, Figure 97 shows the discretized pipe, and Figure 98 shows the meshed modified grout, and Figure 99 shows the meshed fluid geometry with 3 prism layers.

The mesh sizes for various components have been tabulated in Table 18 below: -

\begin{tabular}{|l|l|}
\hline Name of Component & Number of Cells \\
\hline Domain & 485007 \\
\hline Fins & 802054 \\
\hline Grout & 1406448 \\
\hline Pipe & 950690 \\
\hline Fluid & 2925086 with 1164700 prism cells \\
\hline
\end{tabular}

Table 18: Table for mesh sizes of different components

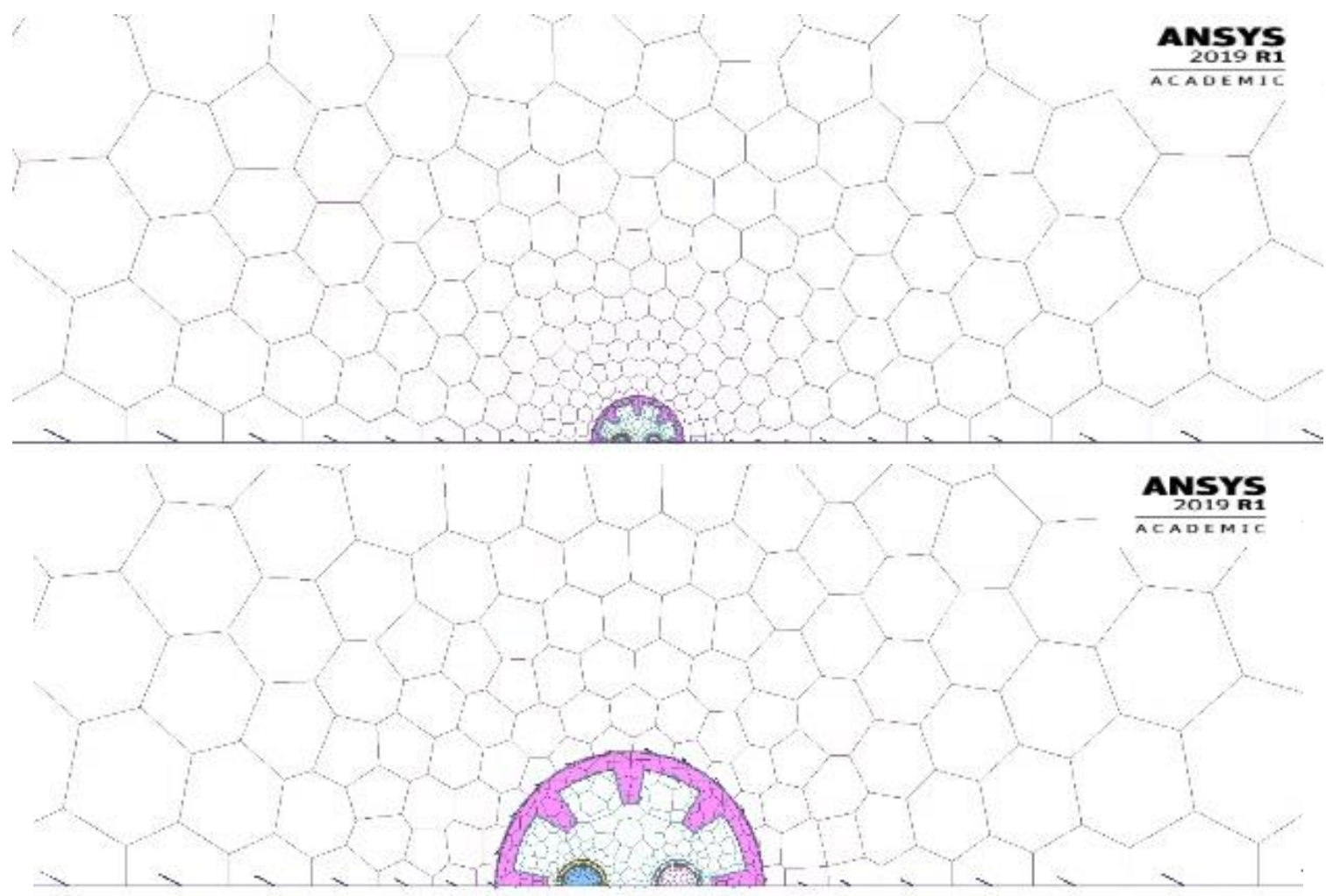

Figure 94:Discretized Geometry 


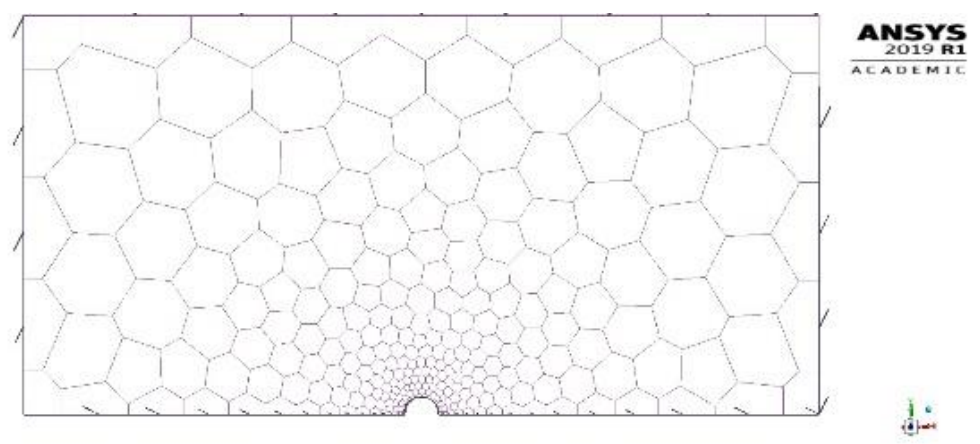

Figure 95:Discretized Modified Domain

$\frac{\text { ANSYS }}{2010 \text { R1 }}$

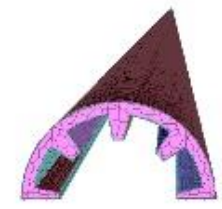

Figure 96: Discretized Fin
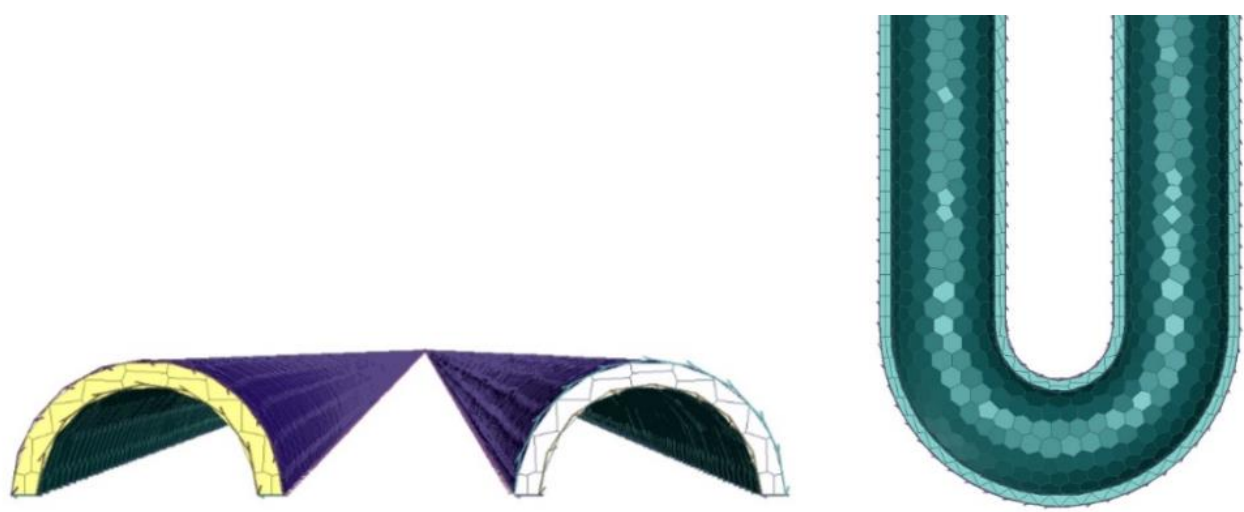

Figure 97: Discretized Pipe 


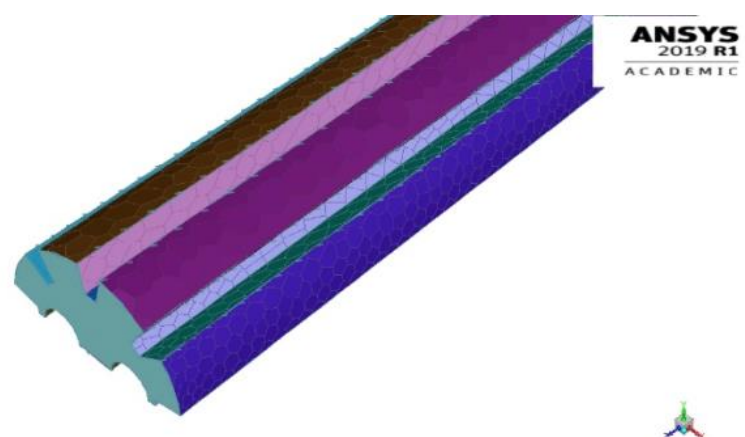

Figure 98: Discretized Grout
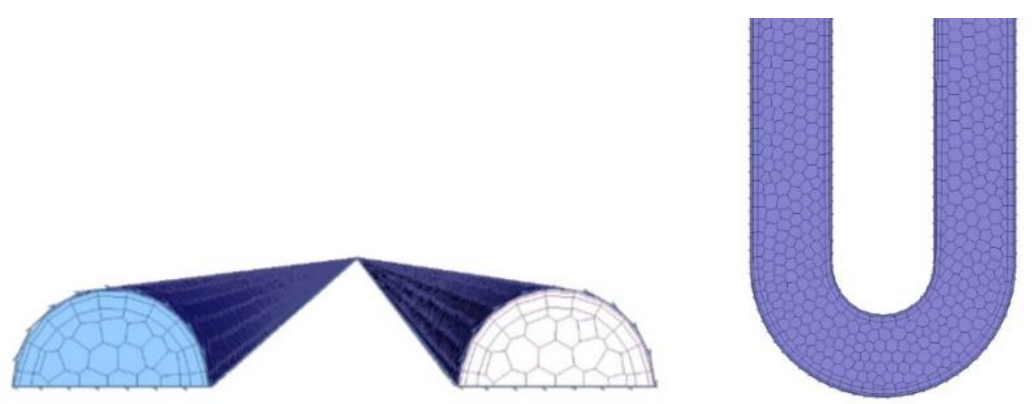

Figure 99: Discretized Fluid Domain

\subsection{Assumptions and Boundary Conditions for the simulation of 3D model}

The assumptions and boundary conditions that have been made to perform the numerical simulation are as follows: -

- The temperature of the ground is assumed to be constant, i.e. the undisturbed ground temperature and fixed to $283.15 \mathrm{~K}$.

- The material properties of various components of the BHE are homogenous and independent of temperature variation.

- Steady state simulations have bene performed to test the new design.

- The inlet temperature of the fluid is taken to be $293.15 \mathrm{~K}$. 
- The inlet velocities tested is $1.0 \mathrm{~m} / \mathrm{s}, 08 . \mathrm{m} / \mathrm{s}, 0.6 \mathrm{~m} / \mathrm{s}, 0.4 \mathrm{~m} / \mathrm{s}$ and $0.2 \mathrm{~m} / \mathrm{s}$.

4.3. Material and Thermal Properties of various components of the modified BHE design

\begin{tabular}{|c|c|c|c|c|}
\hline $\begin{array}{l}\text { Component } \\
\text { Name }\end{array}$ & Material & $\begin{array}{l}\text { Density in } \\
\mathrm{kg} / \mathrm{m}^{3}\end{array}$ & $\begin{array}{l}\text { Specific Heat } \\
\text { Capacity in } \\
\text { J/kgK }\end{array}$ & $\begin{array}{l}\text { Thermal } \\
\text { Conductivity in } \\
\text { W/K.m }\end{array}$ \\
\hline Domain & $\begin{array}{l}\text { Saturated } \\
\text { Sand }\end{array}$ & 1613 & 1549.9 & 2.5 \\
\hline Fins & Aluminum & 2719 & 871 & 202.4 \\
\hline Grout & $\begin{array}{l}30 \% \\
\text { Bentonite } \\
\text { and Sand }\end{array}$ & 1158 & 3443 & 0.75 \\
\hline Pipe & $\begin{array}{l}\text { High Density } \\
\text { Polyethylene }\end{array}$ & 944 & 1900 & 0.39 \\
\hline Fluid & Water & 998.2 & 4182 & 0.6 \\
\hline
\end{tabular}

Table 19:Table for material properties

The selection of Aluminum as fin material was because of the following reasons: -

- The material should have high thermal conductivity like Copper or Aluminum. Although Copper has high thermal conductivity, Aluminum based alloys are more common because they are of low cost and density.

- Increasing the ratio of the perimeter to the cross-sectional area of the fin. The use of thin, but closely spaced, fins is preferred to that of thick fins.

\subsection{Case Set-up in ANSYS Fluent 2019R1 and Initialization}

The case was set-up in the same way as that in chapter 3.5.1 for the test cases mentioned.

The viscous model tested was Standard K-epsilon model with Standard Wall Treatment Function.

The interfaces between the components have been coupled to enable data transfer from the BHE with suitable materials properties assigned to each part. 
The pressure-velocity coupling was achieved using the SIMPLE scheme, and the solution was initialized from the inlet of the fluid flow. Static temperature monitors were set-up at the outlet of the pipe to check the convergence of the simulation.

\subsection{Results Obtained}

After performing the numerical solution of the modified BHE design, the following results were obtained as shown in Table 20: -

Table 20:Comparison of results with and without fins

\begin{tabular}{|c|c|c|c|c|c|c|c|c|c|c|}
\hline $\begin{array}{l}\text { Inlet } \\
\text { Veloc } \\
\text { ity }\end{array}$ & $\begin{array}{l}\text { Reynol } \\
\text { ds } \\
\text { Numbe } \\
\text { r }\end{array}$ & $\begin{array}{l}\text { Outlet } \\
\text { temperatu } \\
\text { re without } \\
\text { fins }\end{array}$ & $\begin{array}{l}\text { Outlet } \\
\text { temperatu } \\
\text { re with } \\
\text { fins }\end{array}$ & $\begin{array}{l}\Delta \mathbf{T}_{\mathrm{w} / \mathrm{o}} \\
\text { fins }\left(\mathbf{T}_{\text {inl }}\right. \\
\text { et}^{-} \\
\left.\mathbf{T}_{\text {outlet }}\right)\end{array}$ & $\begin{array}{l}\Delta \mathbf{T}_{\mathbf{w}} \\
\text { fins }\left(\mathbf{T}_{\mathrm{inl}}\right. \\
\text { et }^{-} \\
\left.\mathbf{T}_{\text {outlet }}\right)\end{array}$ & $\begin{array}{l}\text { Effectiven } \\
\text { ess without } \\
\text { fins }\end{array}$ & $\begin{array}{l}\text { Effectiven } \\
\text { ess with } \\
\text { fins }\end{array}$ & $\begin{array}{l}\text { Surface } \\
\text { Heat } \\
\text { Transfer } \\
\text { Coefficie } \\
\text { nt(h) in } \\
\text { W/m²K } \\
\text { with fins }\end{array}$ & $\begin{array}{l}\text { Heat } \\
\text { Flux in } \\
\text { W/m² } \\
\text { With } \\
\text { fins }\end{array}$ & $\begin{array}{l}\text { Heat } \\
\text { Flux } \\
\text { per } \\
\text { unit } \\
\text { lengt } \\
h \text { in } \\
W / m \\
3\end{array}$ \\
\hline $\begin{array}{l}1.0 \mathrm{~m} / \\
\mathrm{s}\end{array}$ & 25400 & $292.26 \mathrm{~K}$ & $291.82 \mathrm{~K}$ & $0.88 \mathrm{~K}$ & $1.33 \mathrm{~K}$ & 0.95 & 0.93 & 35.08 & 153.50 & $\begin{array}{l}1.53 \\
50\end{array}$ \\
\hline $\begin{array}{l}0.8 \mathrm{~m} / \\
\mathrm{s}\end{array}$ & 20320 & $292.05 \mathrm{~K}$ & $291.71 \mathrm{~K}$ & $1.10 \mathrm{~K}$ & $1.44 \mathrm{~K}$ & 0.93 & 0.92 & 35.92 & 151.07 & $\begin{array}{l}1.51 \\
07\end{array}$ \\
\hline $\begin{array}{l}0.6 \mathrm{~m} / \\
\mathrm{s}\end{array}$ & 15240 & $291.72 \mathrm{~K}$ & $291.19 \mathrm{~K}$ & $1.42 \mathrm{~K}$ & $1.96 \mathrm{~K}$ & 0.91 & 0.89 & 36.78 & 147.10 & $\begin{array}{l}1.47 \\
10\end{array}$ \\
\hline $\begin{array}{l}0.4 \mathrm{~m} / \\
\mathrm{s}\end{array}$ & 10160 & $291.11 \mathrm{~K}$ & $290.42 \mathrm{~K}$ & $2.03 \mathrm{~K}$ & $2.73 \mathrm{~K}$ & 0.88 & 0.85 & 39.37 & 139.52 & $\begin{array}{l}1.39 \\
52\end{array}$ \\
\hline $\begin{array}{l}0.2 \mathrm{~m} / \\
\mathrm{s}\end{array}$ & 5080 & $289.56 \mathrm{~K}$ & $288.69 \mathrm{~K}$ & $3.58 \mathrm{~K}$ & $4.46 \mathrm{~K}$ & 0.77 & 0.72 & 54.90 & 118.7 & $\begin{array}{l}1.18 \\
70\end{array}$ \\
\hline
\end{tabular}

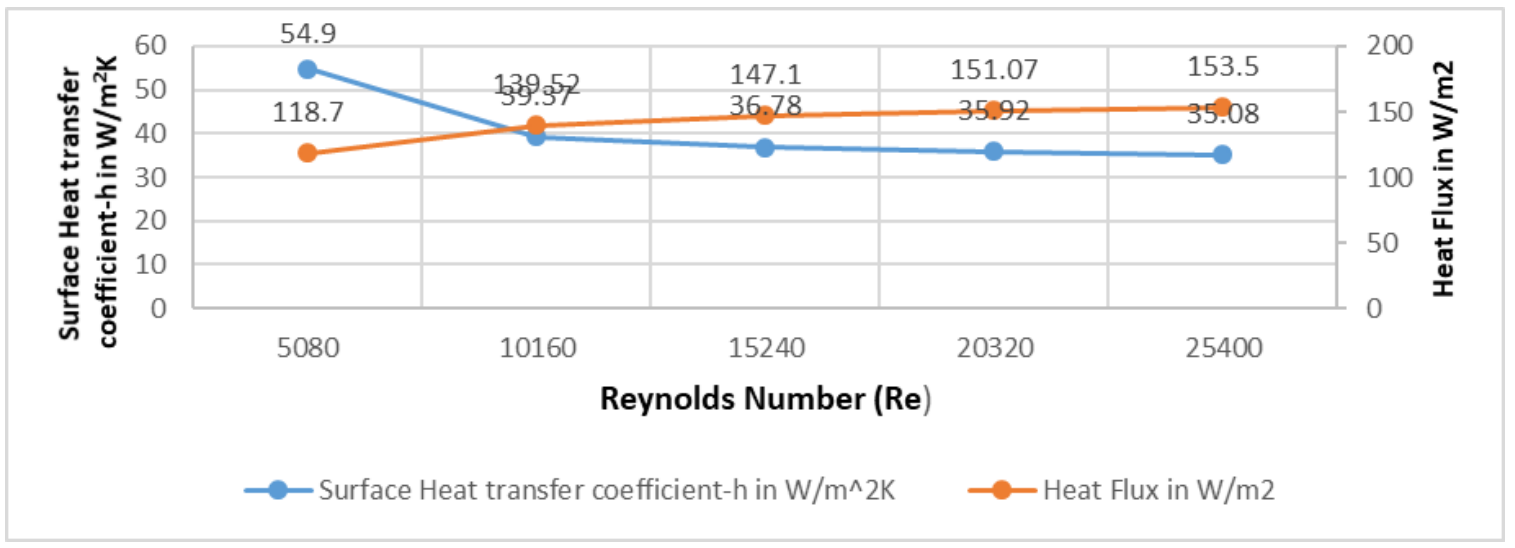

Figure 100: Correlation between Average Surface Heat Transfer Co-efficient and Heat Flux with Reynolds Number 
Table 20 shows a comparative analysis of the inlet and outlet temperature difference between the of the heat exchanger with fins and without fins, it also compares the effectiveness of the heat exchanger when used in conjunction with fins and without it. We see that the performance of the fins has been increased marginally. This increase was only marginal because the design of the fins has not been optimized by a parametric study of the fin structure. An optimized design of the fin followed by a thermal response test verifying the design would improve the performance of the heat exchanger with fins.

Figure 100 shows the variation of Average Surface Heat Transfer Co-efficient and Heat Flux with Reynolds Number for different inlet velocities.

\subsection{Cost Analysis}

The cost of installation of the BHE used as Ground Source Heat Pump accounts for majority of the total cost of the entire GSHP systems. For the installation of the vertical type BHE, first a borehole is drilled and then the U-tubes are installed into the borehole and the gap is then backfilled with grouting materials, where as we know the grouting material is used for sealing the borehole and for enhancing the heat transfer performance.

The total cost of the entire Borehole Heat Exchanger System depends upon the following factors:

- Thermal properties of the ground as it is used to calculate the size of the BHE that can needs to be installed.

- The cooling/heating load that is required and the coefficient of performance that needs to be targeted.

- Materials that needs to be used for the components of the BHE. 
- Cost of manufacturing the components.

- Cost of transportation of the manufactured parts to the location.

- Cost of transporting and repositioning the drill jig onto the position for drilling the bore.

- Cost of installing including the cost of labor.

Liu, et.al ,2018 have provided a detailed study on the cost analysis of the BHE. According to the study done by Liu, et. al the wages the labor costs are as follows: -

\section{Direct costs}

- Driller- $\$ 25 / \mathrm{h}$

- Helper- $\$ 20 / \mathrm{h}$

\section{Major Indirect costs}

- Workmen's Compensation-18\%

- Medical Insurance- $\$ 250 /$ month/person

- Medicare- $1.45 \%$

Drilling Costs range from $-\$ 4.75$ to $\$ 14$ per feet depending upon the type of drilling required in the ground

\section{Material Costs}

Table 21: Price of Material used in Installation of BHE

\begin{tabular}{|l|l|l|}
\hline Material & Typical Price & Unit \\
\hline Bentonite & 0.41 & Per pound \\
\hline Water & 0.0003 & Per gallon \\
\hline HDPE Pipe & 0.52 & Per foot of bore length \\
\hline Grout (Bentonite mix) & 0.33 & Per gallon \\
\hline
\end{tabular}




\begin{tabular}{|l|l|l|}
\hline Header & 8.40 & Per bore \\
\hline Drill bit & 350 & Each \\
\hline $\begin{array}{l}\text { Heat transfer fluid(anti- } \\
\text { freeze ethanol) }\end{array}$ & 2.30 & Per gallon \\
\hline
\end{tabular}

\section{Equipment Costs}

Costs of equipment is based upon hourly rate for using the equipment which includes, drill jig, air compressor and other auxiliary components. The price of equipment, interest rate of the loan, depreciation period, and effective working time of the equipment are used to calculate a portion of the hourly rate needed to pay back the loan. The other portion of the hourly rate is to recover the maintenance cost.

Conclusively Liu, et.al stated that the total cost of implementing an individual single utube vertical BHE is $\$ 949.86$ ignoring the sizing of the BHE, however from the cost analysis it can be seen that the maximum cost is contributed by the drilling process, where it accounts for around $46 \%$ of the total cost.

The addition of aluminum fins would give an additional cost of $\$ 0.15$ per pound of Al used.

\section{Cost of New Design}

Now it is imperative to see if the cost of the new design is feasible in terms of the efficiency achieved for extra investment. From Table 13 and Table 20 we have seen the heat flux per unit length for each velocity, without the fins (Table 13) and with the fins (Table 20). Now assuming that the average required heat flux is $127.48 \mathrm{~W} / \mathrm{m}^{2}$ and the average inlet velocity is $0.5 \mathrm{~m} / \mathrm{s}$ for the fluid. Therefore, we see from Table 20 that the for $0.4 \mathrm{~m} / \mathrm{s}$ inlet velocity, heat flux per unit length is $1.3952 \mathrm{~W} / \mathrm{m}^{3}$. 
So, from the relation, $\mathrm{q} / \mathrm{L}=$ heat flux per unit length, we find the length of the modified heat exchanger.

where, $\mathrm{q}=$ heat flux in $\mathrm{W} / \mathrm{m}^{2}$. And $\mathrm{L}=$ length of the borehole

On assuming $\mathrm{q}=127.48 \mathrm{~W} / \mathrm{m}^{2}$ and heat flux per unit length to be $1.3952 \mathrm{~W} / \mathrm{m}^{3}$ and subsequently substituting in the above said relation, we find that the length of the borehole reduces to approximately $90 \mathrm{~m}$.

This reduced length approximately reduces the drilling cost by around $1500 \$$ for geothermal boring. Now, the question arises that if the addition of fins would be feasible in terms of cost. Now it is seen that general cost of installing a 100m deep casing is $2000 \$$ for a $100 \mathrm{~m}$ deep borehole made of aluminum. The cost of adding fins to the casing would result in additional costs.

On analysis the cost comparison of the heat exchange with the fins and without the fins, it comes across that the heat exchange without the fins would be more cost beneficial, however, it can be said that the cost of adding fins can be optimized if a parametric study of the fins is performed and the design of the fin is optimized as per the heat transfer requirement and the manufacturing costs associated with it. Also, the addition of fins giving higher efficiency as compared to the heat exchanger with fins without the fins, would result in lesser operating costs in the long run after installation. As such it can be said that the extra investment on the addition of fins would beneficial in the long run.

\subsection{Conclusion}

The simulation results from of the modified heat exchanger can be summarized below: - 
- The design of the BHE was modified to incorporate aluminum trapezoidal fins between the grout and domain.

- The modified heat exchanger was numerically simulated with 5 different inlet velocities for the flow of fluid inside the pipe.

- The outlet temperature achieved by the addition of fins inside the heat exchanger was observed and also the heat flux achieved for every inlet velocity.

The following conclusions can be drawn from the above simulation results: -

- The addition of fins resulted in enhanced heat transfer from the fluid towards the ground. This is evident from Table 20 where, the inlet and outlet temperature difference achieved by the heat exchanger with fins and the heat exchanger without the fins was $0.5 \mathrm{~K}$ for higher velocities and around $1 \mathrm{~K}$ for lower inlet fluid velocities.

- It was also seen from table 20 that the addition of fins increased the heat flux from the fluid towards the ground in the range of $15-30 \mathrm{~W} / \mathrm{m}^{2}$.

- It can also be said that the surface heat transfer coefficient increased in the range of $8-15 \mathrm{~W} / \mathrm{m}^{2} \mathrm{~K}$ from higher inlet velocities to lower inlet velocities.

- The major conclusion and benefit of using this design for the heat exchanger is that the length of the heat exchanger can be reduced as per the required heat transfer and outlet temperature needed.

- As such the $\mathrm{q} / \mathrm{L}$ ratio can be used for designing heat exchangers for a reduced length which would subsequently reduce the costs involved in installing the system. 


\section{CHAPTER 5 CONCLUSION AND FUTURE SCOPE OF WORK}

The primary aim of this work was to develop a new design of the single u-tube vertical borehole heat exchanger(BHE) in order to improve the working efficiency of the BHE, so that the size of the conventional design of the BHE can be reduced without compromising on the output.

In this chapter a summary of the main findings is presented along with a discussion justifying the findings. The limitations of the research being conducted in this study and the future scope of work has been briefly discussed.

\subsection{Main Findings}

- The size of the grid being used to discretize the geometry in this problem has negligible effect upon the solution of the numerical simulation, which has been observed from the Figures 35,39 and 43 depicting the variation of non-dimensional temperature with respect to non-dimensional depth of the borehole. This is also evident from Table 16.

- Further refinement of the grid size will yield more accurate results but will come at a cost of more computational power being used for the discretization and modeling.

- The presence of prism layers had no effect upon the results of the simulation.

- From Figure 35 and Figure 47 it was also seen that the type of mesh used for numerical simulation, hexahedral or polyhedral had minor effect upon the result of the numerical simulation. The hexahedral mesh over-predicted the results while the polyhedral mesh under-predicted the results. 
- The polyhedral mesh gives more accurate results as compared to hexahedral mesh as in the cell center of each cell of the polyhedral mesh the data comes from more than 12 faces, whereas in the hexahedral mesh, in the cell center of each cell the data comes from 6 faces.

- The generation of unstructured polyhedral mesh reduces the cell count as compare to the hexahedral mesh, however, polyhedral mesh being unstructured, the number of cells used for discretizing the geometry cannot be varied as per the requirement of the simulation. On the other hand, the hexahedral mesh was used to give a more refined mesh in the radial direction while less refined in the longitudinal direction.

- The time required to generate the polyhedral mesh was very less as compared to the generation of hex mesh. A highly refined poly mesh for the fluid section with 4 prism layers took 3 hours to generate whereas, the hex mesh for the fluid took more than 6 hours to generate. Further refinement of the fluid section using hex mesh took more than a day's time to generate without the prism layers.

- The hex mesh simulation took more 200 more iterations than the poly mesh simulation to converge. However, the computational time required for the poly mesh simulation was more than hex mesh due to the fact that the poly mesh simulation required average of data at each cell center from more than 12 faces, as compared to the 6 faces of the hex mesh.

- As such it was seen that accuracy of the solution using refined poly mesh was compromised in comparison to the simulation results from the hex mesh in favor of computational time and effort. 
- From Figures 47 and 51 it was evident that the type of turbulence model used for simulation had no effect upon the result of the simulation. This was due to the fact that the flow was fully developed and in the transition zone of pipe flow.

- It was also seen from Figures 47 and 55 it was seen that in pressure driven flow gravity has no effect upon the numerical simulation results.

- One of the main conclusions from Table 13 is that the residence time of the fluid inside the pipe, is the most important factor in the rate and amount of heat transfer, as the residence time increases the heat transfer from the fluid increases, subsequently, more temperature drop is observed.

- The above condition can also be justified by observing from Figure 86, which shows that as the residence time of the fluid increases, the surface heat transfer coefficient increases.

- From the turbulent kinetic energy contours it was seen that at the inlet of the pipe, there was minor turbulence due to generation of eddies which aided mixing of the flow, and as the flow proceeded the eddies died out in the straight section, furthermore it was also observed that at the u-bend section of the pipe, there was generation of eddies which again aided mixing of the hot and cold sections of the fluid.

- The result from the turbulent mixing of the flow, was the enhancement of heat transfer in sections where this phenomenon was observed. It was evident from the heat flux profiles that at the straight sections the rate of heat transfer was less as compared to the rate of heat transfer where there was turbulent mixing of the flow. 
- From the heat flux contours of the fluid-pipe-interface it was also observed that the outer sections of the pipe had more heat transfer rate as compared to the inner sections, as the outer sections was more exposed to the boundary conditions as compared to inner sections.

- From the validation with the numerical simulation from He, M., 2012, it was seen that the scheme and the solver used for the numerical simulation had minor effects on the result obtained.

- On observing the outlet temperatures of the modified system of the heat exchanger it is seen that the heat transfer from the fluid towards the domain has increased. This is because the fins or the extended surfaces added to the system between the grout and domain increased the contact surface area for heat transfer. As such the hypothesis of using fins as a medium for enhancing the rate of heat transfer has been successfully proved correct.

- It has also been observed that the heat flux and surface heat transfer coefficient has also increased considerably for the modified heat exchanger from Table 20.

- The major conclusion and benefit of using this design for the heat exchanger is that the length of the heat exchanger can be reduced as per the required heat transfer and outlet temperature needed.

- The modified heat exchanger design also given heat flux per unit length of the heat exchanger for various inlet temperature of the fluid. As such the $q / L$ ratio can be used for designing heat exchangers for a reduced length which would subsequently reduce the operating costs involved in the system as discussed in section 4.7. 
- However, the addition of fins increases the computational time and effort required to perform the numerical simulation. This study was however, performed to demonstrate a possible method through which the efficiency of the system can be increased.

- The initial cost of installation of the finned BHE would be higher as compared to conventional ones, however, the operational cost of using a reduced length BHE with fins would be lower as compared to the conventional BHE.

\subsection{Future Scope of Work}

- To use a different type of mesh for discretization where, the core of the body to be discretized would be made up of hexahedral mesh and the polyhedral mesh would be used to generate the outer sections of the body.

- There are many other possibilities for enhancing efficiency of the BHE keeping in mind the costs, but this study explores one only of the possibilities of achieving the goal.

- The most important future scope of work for a finned BHE, would be to perform a parametric study of the fins, where the design and dimensions of the fin and the casing can be optimized to give better results and reduce the overall manufacturing costs involved.

- The major limitation of utilizing fins as a component to the heat exchanger is the feasibility of installation and manufacturing of the finned tube. Once the parametric study is performed, the idea of using a thin hollow cylinder cut in sections with fins and then installed into the bore of the heat exchanger, with then the grout being subsequently backfilled to fill the gaps can be explored. 
- From the simulation results used to verify the numerical solution of He, M., 2012, it can be seen as the swirling or the eddy generation within the flow and the transit time of the flow increases, the rate of heat transfer also increases. This is due to the fact that the generation of eddies in the flow enhances the mixing of the cold and hot fluid within the flow. This observation can be used to enhance the heat transfer rate within the borehole, which can subsequently be achieved by providing external swirling capabilities to the flow.

- By adding water swirlers in the pipe the mixing of the cold and hot fluid can be aided and as such the heat transfer in the zones of mixing can be enhanced subsequently it would increase the transit time of the flow. However, as the mixing would die out after a certain length, swirlers will need to be fixed at certain distances to start the mixing in the flow once again. 


\section{LIST OF REFERENCES}

AL-KHOURY, R. \& BONNIER, P. G. 2006. Efficient finite element formulation for geothermal heating systems Part II: Transient. International Journal for Numerical Methods in Engineering, 67, 725-745.

AL-KHOURY, R., BONNIER, P. G. \& BRINKGREVE, R. B. J. 2005. Efficient finite element formulation for geothermal heating systems Part I: Steady state. International Journal for Numerical Methods in Engineering, 63, 988-1013.

Al-Chalabi, R., 2013. Thermal resistance of U-tube borehole heat exchanger system: numerical study (Doctoral dissertation, The University of Manchester (United Kingdom)).

Aydin, M. and Sisman, A., 2015. Experimental and computational investigation of multi U-tube boreholes. Applied energy, 145, pp.163-171.

BENNET, J., CLAESSON, J. \& HELLSTROM, G. 1987. Multipole Method to Compute the Conductive Heat Flows To and Between Pipes In a Composite Cylinder. University of Lund, Sweden.

CARSLAW, H. S. \& JAEGER, J. C. 1947. Conduction of Heat in Solid, Oxford, Claremore Press.

Carslaw, H.S., J.C. Jaeger. 1947. Conduction of Heat in Solids. Oxford, UK: Oxford University Press, pp. 510.

Çengel Y.A. and Boles M.A. ,1994.Thermodynamics: An Engineering Approach. McGraw-Hill, Inc., New York.

DE CARLI, M., TONON, M., ZARRELA, A. \& ZECCHIN, R. 2010. A computational capacity resistance model $(\mathrm{CaRM})$ for vertical ground-coupled heat exchangers. Renewable Energy, 35, 1537-1550. 
DIERSCH, H.-J. G., BAUER, D., HEIDEMANN, W., RUHAAK, W. \& SCHATZL, P. 2011a. Finite element modeling of borehole heat exchanger systems Part 1. Fundamentals. Computers \& Geosciences, 37, 1122-1135.

DIERSCH, H.-J. G., BAUER, D., HEIDEMANN, W., RUHAAK, W. \& SCHATZL, P. 2011b. Finite element modeling of borehole heat exchanger systems Part 2. Numerical simulation. Computers \& Geosciences, 37, 1136-1147.

ESKILSON, P. 1987. Thermal Analysis of Heat Extraction Boreholes. PhD, University of Lund.

GU, Y. \& O'NEAL, D. 1998. Development of an equivalent diameter expression for vertical u-tubes used in ground-coupled heat pumps. ASHRAE Transactions, 104, 347355.

HE, M., REES, S. J. \& SHAO, L. 2009. RE: Applications of a Dynamic Three-Dimensional Numerical Model for Borehole Heat Exchangers.

He, M., 2012. Numerical modelling of geothermal borehole heat exchanger systems.

HELLSTROM, G. 1991. Ground Heat Storage: Thermal Analysis of Duct Storage Systems: Part I Theory. PhD, University of Lund.

HERN, S. A. 2004. Design of an experimental facility for hybrid ground source heat pump systems. MSc, Oklahoma State University.

INCROPERA, F. P., DEWITT, D. P., BERGMAN, T. L. \& LAVINE, A. S. 2007. Fundamentals of Heat and Mass Transfer, Wiley.

INGERSOLL, L. R., ZOBEL, O. J. \& INGERSOLL, A. C. 1954. Heat Conduction with Engineering, Geological, and Other Applications, New York, McGraw-Hill.

Jeon, J.S., Lee, S.R. and Kim, M.J., 2018. A modified mathematical model for spiral coiltype horizontal ground heat exchangers. Energy, 152, pp.732-743. 
KAVANAUGH, S. P. 1985. Simulation and experimental verification of vertical groundcoupled heat pump systems. $\mathrm{PhD}$, Oklahoma State University.

KAVANAUGH, S. P. 1992. Field test of a vertical ground coupled heat pump in alabama. ASHRAE Transactions.

KELVIN, S. W. T. 1882. Mathematical and Physical Papers, II. 41, cited by Ingersoll, et al. (1954).

Launder, B.E. and Spalding, D.B., 1983. The numerical computation of turbulent flows. In Numerical prediction of flow, heat transfer, turbulence and combustion (pp. 96-116). Pergamon.

Liu, X., Polsky, Y., Qian, D. and Mcdonald, J., 2018. Analysis of cost reduction potential of vertical bore ground heat exchanger. ORNL/TM-2018/756. Oak Ridge, Tennessee: Oak Ridge National Laboratory.

Lund, J.W.; Sanner, B.; Rybach, L.; Curtis, R. \& Hellström G. ,2007. Geothermal Energy Uses. Geo-Heat Centre Quarterly Bulletin. Klamath Falls, Oregon. Oregon Institute of Technology, Vol. 28.

Park, H., Lee, S.R., Yoon, S. and Choi, J.C., 2013. Evaluation of thermal response and performance of PHC energy pile: Field experiments and numerical simulation. Applied Energy, 103, pp.12-24.

PAUL, N. D. 1996. The effect of grout thermal conductivity on vertical geothermal heat exchanger design and performance. Master of Science, South Dakota State University.

Pu, L., Qi, D., Li, K., Tan, H. and Li, Y., 2015. Simulation study on the thermal performance of vertical U-tube heat exchangers for ground source heat pump system. Applied Thermal Engineering, 79, pp.202-213.

Pielke Jr, R.A., 2009. The British Climate Change Act: a critical evaluation and proposed alternative approach. Environmental research letters, 4(2), p.024010. 
REES, S. J., SPITLER, J. D., DENG, Z., ORIO, C. D. \& JOHNSON, C. N. 2004. A study of geothermal heat pump and standing column well performance. ASHRAE Transactions, 109, 3-13.

REES, S. J., SPITLER, J. D. \& XIAO, X. 2002. Transient analysis of snow-melting system performance. ASHRAE Transactions, 108, 406-423.

Robin C. ,1999. Integrated building design BSRIA, Interactive CD.

Ruqun Wu 2009. Energy Efficiency Technologies-Air Source Heat pump vs. Ground Source Heat Pump. Journal of Sustainable Development. Australia.

SPITLER, J. D. 2000. GLHEPRO - A Design Tool For Commercial Building Ground Loop Heat Exchangers. the Fourth International Heat Pumps in Cold Climates Conference. Aylmer, Quebec.

SPITLER, J. D., CULLINE, J., BERNIER, M., KUMMERT, M., CUI, P., LIU, X., LEE, E. \& FISHER, D. E. 2009. Preliminary intermodel comparison of ground heat exchanger simulation models. 11th International Conference on Thermal Energy Storage; Effstock 2009. Stockholm, Sweden.

Steve Kavanaugh, 2010. Borehole ResistCalc xls: A program to Calculate Borehole Thermal Resistance from Formation Thermal Property Test Data.

WETTER, M. \& HUBER, A. 1997. TRNSYS Type 451: Vertical Borehole Heat Exchanger EWS Model, Version 3.1 - Model Description and Implementing into TRNSYS. Transsolar GmbH, Stuttgart, Germany.

YAVUZTURK, C. 1999. Modeling of Vertical Ground Loop Heat Exchangers for Ground Source Heat Pump Systems. PhD, Oklahoma State University.

YAVUZTURK, C. \& SPITLER, J. D. 1999. A Short Time Step Response Factor Model for Vertical Ground Loop Heat Exchangers. ASHRAE Transactions, 105, 475-485. 
YAVUZTURK, C., SPITLER, J. D. \& REES, S. J. 1999. A Transient Two-Dimensional Finite Volume Model for the Simulation of Vertical U-Tube Ground Heat Exchangers. ASHRAE Transactions, 105, 465-474.

YOUNG, T. R. 2004. Development, Verification, and Design Analysis of the Borehole Fluid Thermal Mass Model for Approximating Short Term Borehole Thermal Responser. Master of Science, Oklahoma State University.

Zhao, J., Li, Y. and Wang, J., 2016. A review on heat transfer enhancement of borehole heat exchanger. Energy Procedia, 104, pp.413-418.

Zarrella, A., De Carli, M. and Galgaro, A., 2013. Thermal performance of two types of energy foundation pile: helical pipe and triple U-tube. Applied Thermal Engineering, 61(2), pp.301-310.

Zhang, W., Yang, H., Lu, L., Cui, P. and Fang, Z., 2014. The research on ring-coil heat transfer models of pile foundation ground heat exchangers in the case of groundwater seepage. Energy and buildings, 71, pp.115-128.

Zhao, J., Wang, H., Li, X. and Dai, C., 2008. Experimental investigation and theoretical model of heat transfer of saturated soil around coaxial ground coupled heat exchanger. Applied Thermal Engineering, 28(2-3), pp.116-125.

Wang, J.L., Zhao, J.D. and Liu, N., 2014. Numerical simulation of borehole heat transfer with phase change material as grout. In Applied Mechanics and Materials (Vol. 577, pp. 44-47). Trans Tech Publications Ltd. 